Florida International University

FIU Digital Commons

FIU Electronic Theses and Dissertations

University Graduate School

$10-11-2010$

\title{
Assessing the Effectiveness of the Internationalization Process in Higher Education Institutions: A Case Study of Florida International University
}

Flavia Eleonora Iuspa

Florida International University, fiusp001@fiu.edu

DOI: $10.25148 /$ etd.FI10120304

Follow this and additional works at: https://digitalcommons.fiu.edu/etd

Part of the Curriculum and Instruction Commons

\section{Recommended Citation}

Iuspa, Flavia Eleonora, "Assessing the Effectiveness of the Internationalization Process in Higher Education Institutions: A Case Study of Florida International University" (2010). FIU Electronic Theses and Dissertations. 316.

https://digitalcommons.fiu.edu/etd/316

This work is brought to you for free and open access by the University Graduate School at FIU Digital Commons. It has been accepted for inclusion in FIU Electronic Theses and Dissertations by an authorized administrator of FIU Digital Commons. For more information, please contact dcc@fiu.edu. 


\title{
FLORIDA INTERNATIONAL UNIVERSITY \\ Miami, Florida
}

\section{ASSESSING THE EFFECTIVENESS OF THE INTERNATIONALIZATION PROCESS IN HIGHER EDUCATION INSTITUTIONS: \\ A CASE STUDY OF FLORIDA INTERNATIONAL UNIVERSITY}

\author{
A dissertation submitted in partial fulfillment of the \\ requirements for the degree of \\ DOCTOR OF EDUCATION \\ in \\ CURRICULUM AND INSTRUCTION \\ by
}

Flavia Eleonora Iuspa

2010 
To: Interim Dean Delia C. Garcia

College of Education

This dissertation, written by Flavia Eleonora Iuspa, and entitled Assessing the Effectiveness of the Internationalization Process in Higher Education Institutions: A Case Study of Florida International University, having been approved in respect to style and intellectual content, is referred to you for judgment.

We have read this dissertation and recommend that it be approved.

$\begin{array}{r}\hline \text { Roger Gonzalez } \\ \hline \text { Hilary Landorf } \\ \hline \text { Angela Salmon } \\ \hline \text { Mohammed K. Farouk, Major Professor }\end{array}$

Date of Defense: October 11, 2010

The dissertation of Flavia Eleonora Iuspa is approved.

\begin{tabular}{r}
$\begin{array}{r}\text { Interim Dean Delia C. Garcia } \\
\text { College of Education }\end{array}$ \\
\hline Interim Dean Kevin O'Shea \\
University Graduate School
\end{tabular}

Florida International University, 2010 
C Copyright 2010 by Flavia Eleonora Iuspa

All rights reserved. 


\section{DEDICATION}

I dedicate my dissertation to my dear husband, Francisco, for his constant encouragement and support. Last but not least, to my parents and all breast cancer survivors. 


\section{ACKNOWLEDGMENTS}

I would like to thank Dr. Mohammed K. Farouk, my major professor, for working with me through this arduous process. He always encouraged me, guided me, and listened to me when finishing my dissertation seemed an impossible dream.

I also greatly appreciate all my committee members; Dr. Roger Gonzalez, Dr. Hilary Landlord, and Dr. Angela Salmon, thanks for your valuable feedback. I am also grateful to Dr. Linda Bliss and Dr. Isadore Newman, from the College of Education Office of Graduate Studies (OGS), thanks for your time and effort on my dissertation.

I am indebted to Dr. Dan Paracka, from Kennesaw State University (KSU) for granting me permission to use KSU's Student and Faculty Survey on Internationalization in my dissertation. I am also indebted to all Florida International University (FIU) faculty and students that responded to my surveys. Your participation made my study a reality. Finally, I am eternally grateful to FIU's provost, deans, and directors who gave me their time to interview them despite their busy schedule. 


\section{ABSTRACT OF THE DISSERTATION \\ ASSESSING THE EFFECTIVENESS OF THE INTERNATIONALIZATION \\ PROCESS IN HIGHER EDUCATION INSTITUTIONS: \\ A CASE STUDY OF FLORIDA INTERNATIONAL UNIVERSITY \\ by}

Flavia Eleonora Iuspa

Florida International University, 2010

Miami, Florida

Professor Mohammed K. Farouk, Major Professor

The purpose of this study was to examine a Higher Education Institution's (HEI) process of internationalization. The theoretical model developed by Van Dijk and Miejer (1997) was used to review Florida International University (FIU)'s policy, support, and implementation dimensions and determine its position on the Internationalization Cube, and assess how FIU's international activities fit into its different organizational processes. In addition, the study sought to shed light on student and faculty attitudes toward internationalization.

Qualitative and quantitative data were collected from examining organizational documents, interviews, descriptive data on FIU's international activities using the International Dimension Index, and the Student and Faculty Survey on

Internationalization. FIU's international activities results were analyzed in relation to a panel of experts' item relevancy index. The Likert-type survey scales' frequencies and percentages were calculated as well as Spearman Rho correlations between the survey's three scales and demographic and experiences variables. 
The study found that FIU is located on position six of a possible eight positions on the Van Dijk and Meijer Internationalization Cube with the following characteristics: Priority Policy, One-Sided Support, and Structured Implementation toward internationalization. The analysis of FIU's results on international activities showed that FIU exhibits all the activities considered to be strong indicators of internationalization but for position seven placement special attention is needed in the areas of foreign language study, international students, study abroad, faculty movement and involvement in international projects. The survey indicated students and faculty rated the Benefits of Internationalization highly but didn't perceive strong institutional Support for Internationalization. Faculty age and offshore programs participation; student gender, race/ethnicity and class status; and for both, study abroad and knowledge of students travel grant had significant positive correlations with student and faculty attitudes.

The study concluded that an association exists between FIU's position on the Internationalization Cube and its international activities. Recommendations for policy, implementation, and future studies were made. It was concluded that advancing FIU's position on the Cube will require adjustments in FIU's policy, support and implementation dimensions. Differences in student and faculty views toward internationalization should be taken into account when planning internationalization efforts. 


\section{TABLE OF CONTENTS}

CHAPTER

PAGE

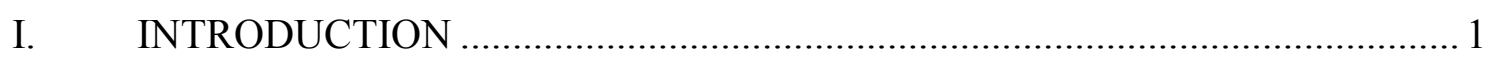

Statement of the Problem................................................................................. 3

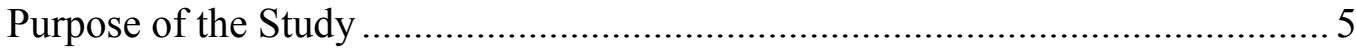

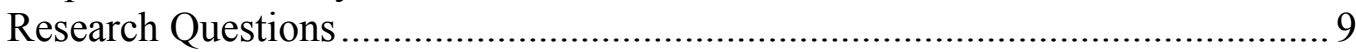

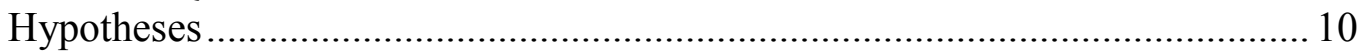

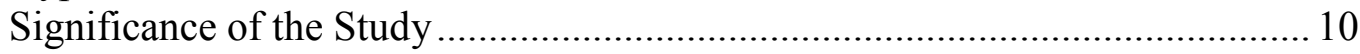

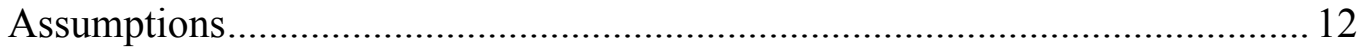

Delimitations of the Study ........................................................................... 13

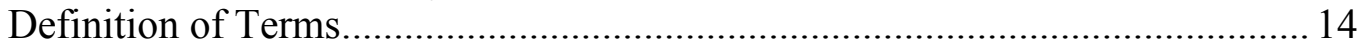

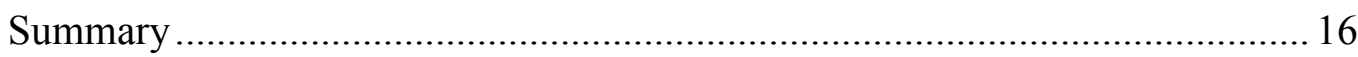

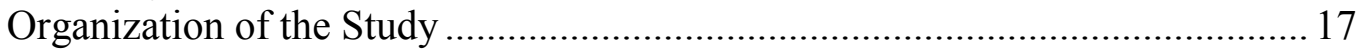

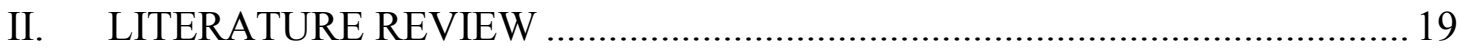

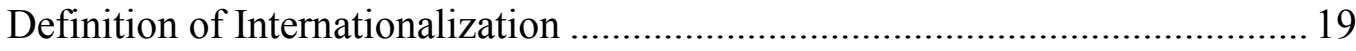

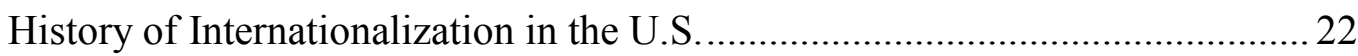

The First World War and Internationalization............................................22

The Second World War and Internationalization ....................................... 24

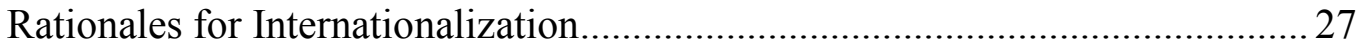

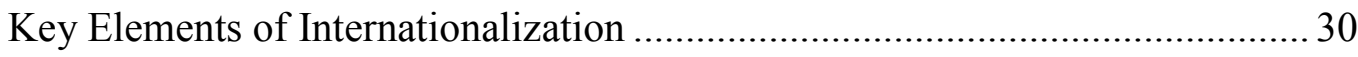

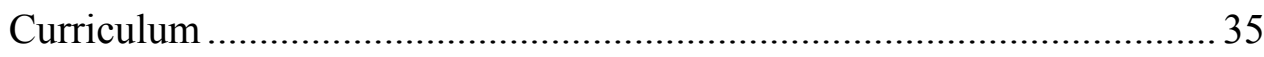

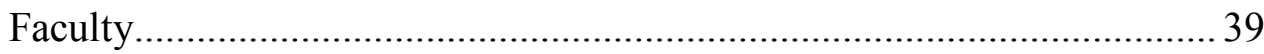

Faculty and Student Attitudes Toward Internationalization ....................... 40

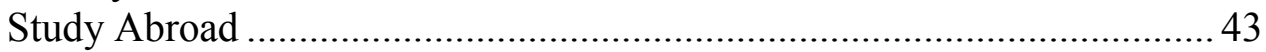

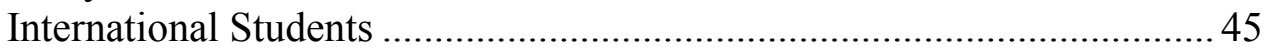

Challenges in Internationalization ................................................................... 47

Models of Internationalization ......................................................................... 51

System Theory and Organization Change ………………………………......... 59

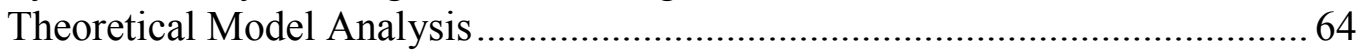

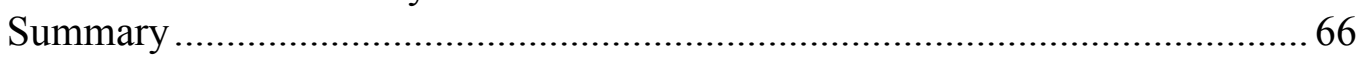

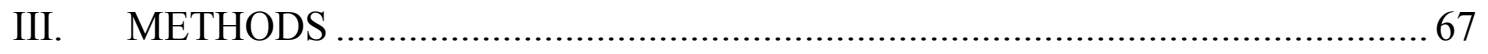

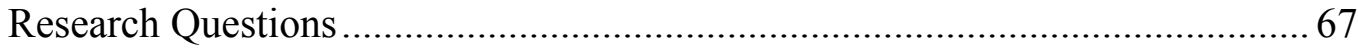

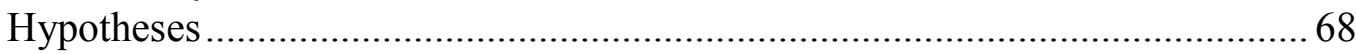

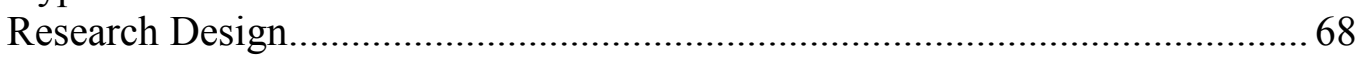

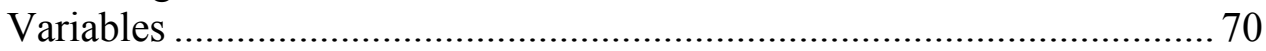

Case Study: Florida International University ........................................... 71

Case Study Validity and Reliability.............................................................. 74

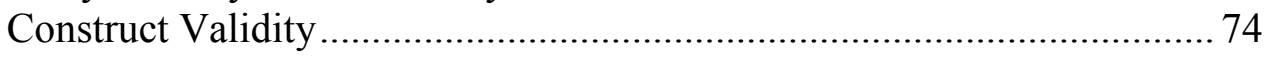

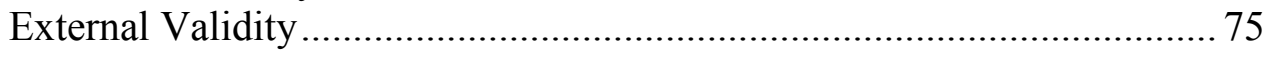

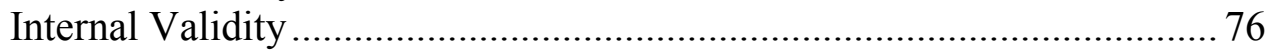

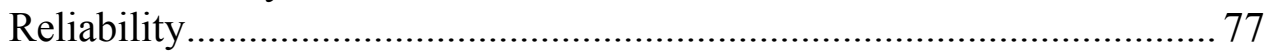




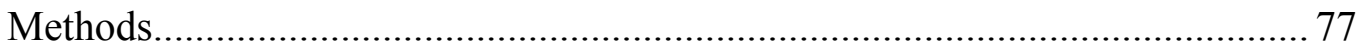

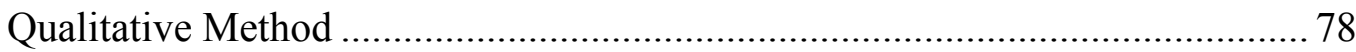

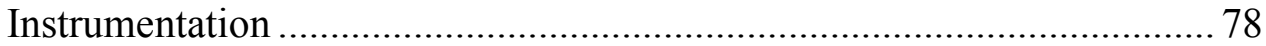

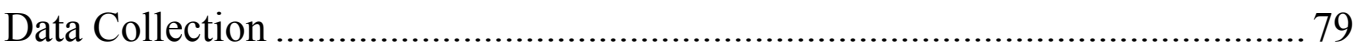

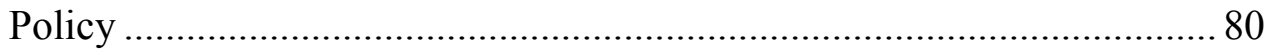

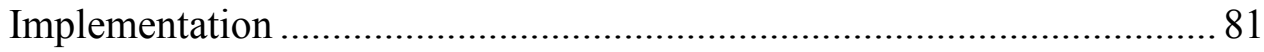

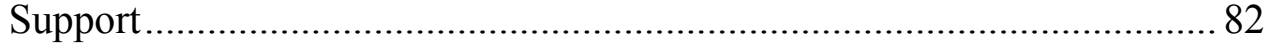

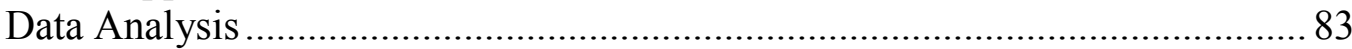

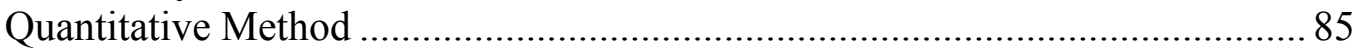

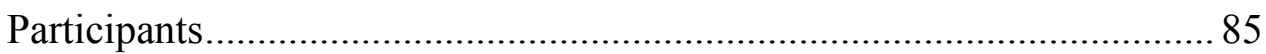

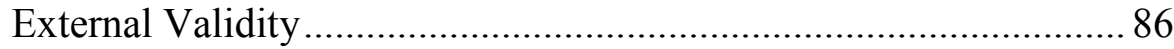

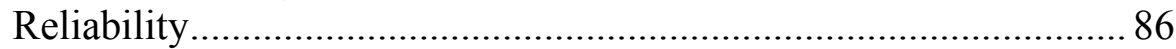

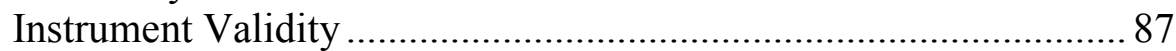

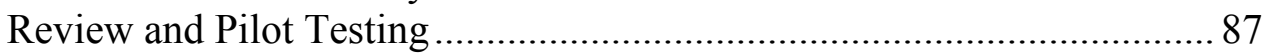

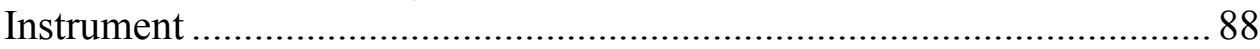

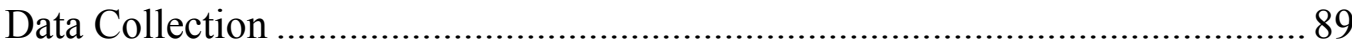

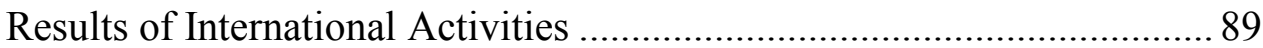

Student and Faculty Attitudes on Internationalization................................ 92

Administration of the Instrument............................................................ 94

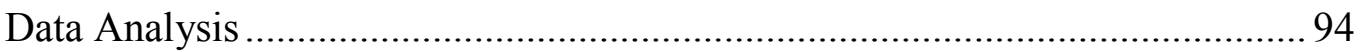

Results of Internationalization ............................................................. 94

Student and Faculty Attitudes on Internationalization................................ 97

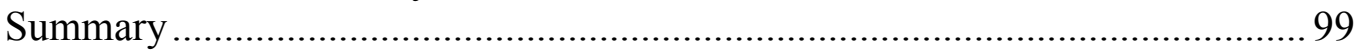

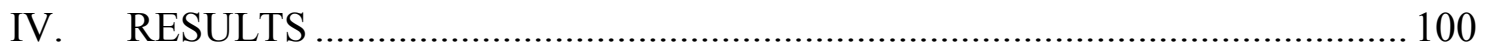

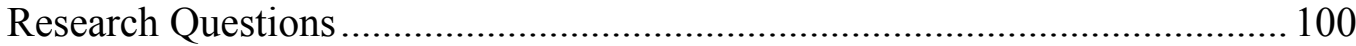

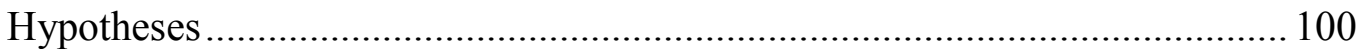

Florida International University's (FIU) Background ............................................. 101

FIU's Position on the Van Dijk and Meijer Internationalization Cube ............ 103

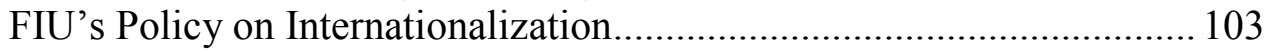

FIU's Implementation of Internationalization .......................................... 110

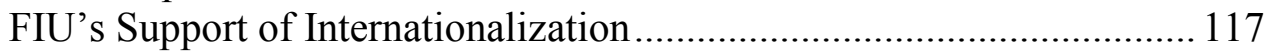

FIU's Challenges to and Opportunities for Internationalization......................... 122

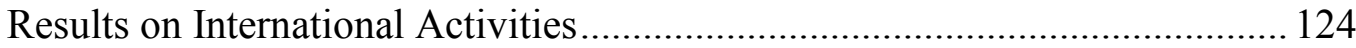

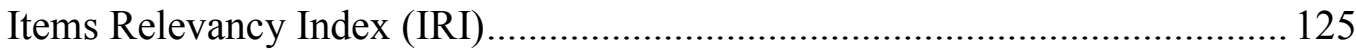

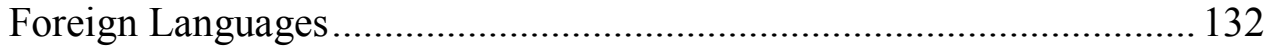

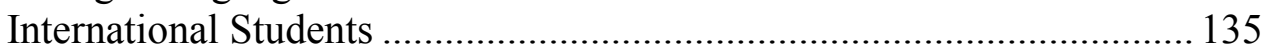

International Movement of Faculty ...................................................... 138

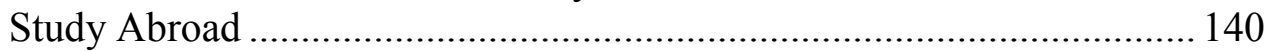

International Development Projects....................................................... 143

Student and Faculty Attitudes Survey on Internationalization ........................... 145

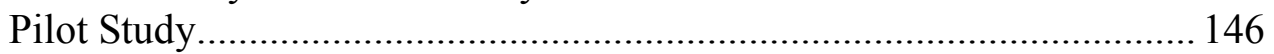

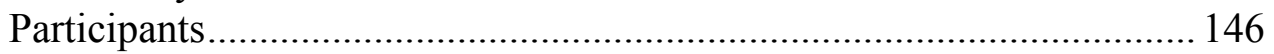

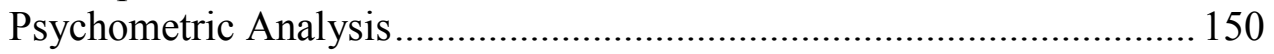


Student Attitudes Survey on Internationalization ........................ 150

Faculty Attitudes Survey on Internationalization ......................... 153

Student and Faculty Survey Responses Toward

Internationalization

Student and Faculty General Attitudes Toward

Internationalization Factor

Student and Faculty Perceived Support Toward

Internationalization Factor

Student and Faculty Perceived Benefits of

Internationalization Factor

Students' Correlations With Demographic Variables...................................... 166

Students' Correlations With Experience Variables ......................................... 168

Faculty Correlations With Demographic Variables....................................... 178

Faculty Correlations With Experience Variables ........................................... 180

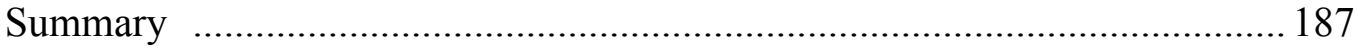

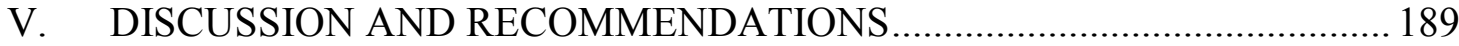

Summary of Findings................................................................................. 190

FIU's Position on the Van Dijk and Meijer Internationalization Cube ... 190

FIU's Results on International Activities ........................................... 192

Student and Faculty Survey on Internationalization............................ 194

General Attitudes toward Internationalization............................... 195

Perceived Support for Internationalization ................................... 196

Perceived Benefits of Internationalization.................................... 197

Demographic Variables and Past Experiences on Students

and Faculty views ............................................................................. 198

Implications of the Study ......................................................................... 199

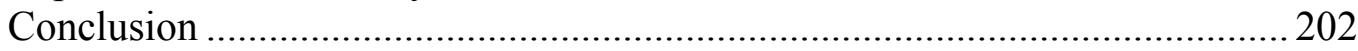

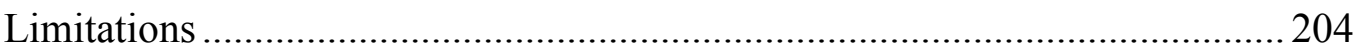

Recommendations for Future Research ................................................ 205

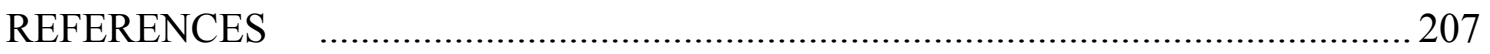

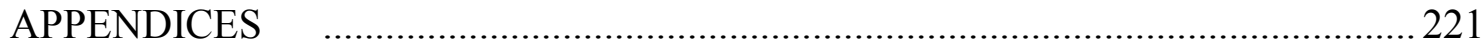

VITA 


\section{LIST OF TABLES}

TABLE

PAGE

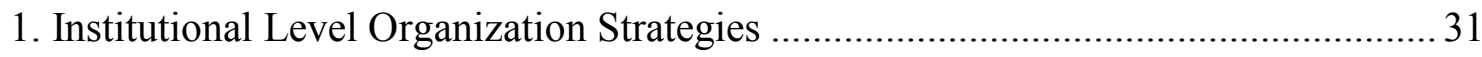

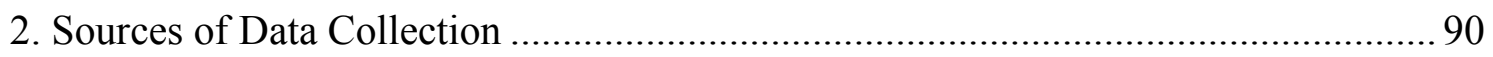

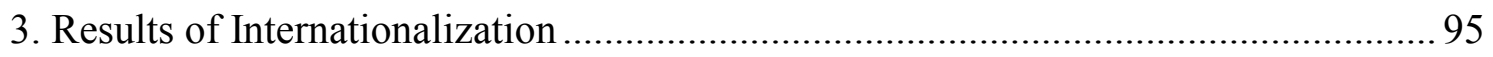

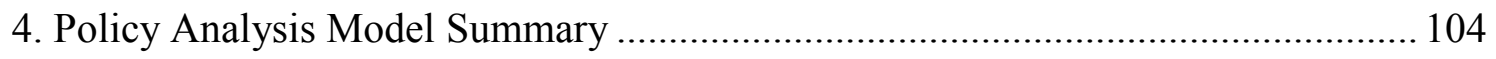

5. Implementation Analysis Model......................................................................... 113

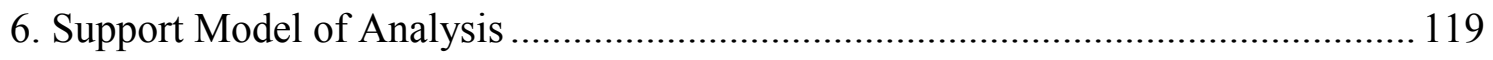

7. Challenges and Opportunities to Internationalization............................................. 123

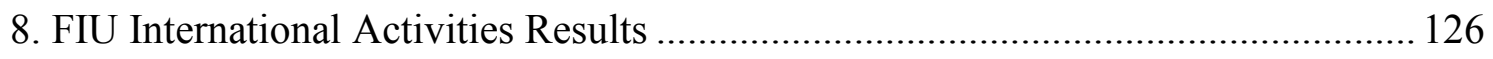

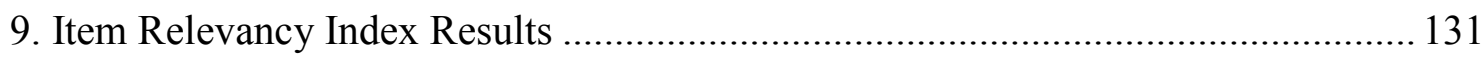

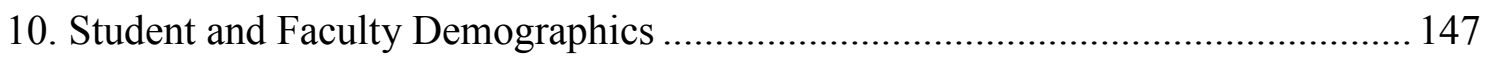

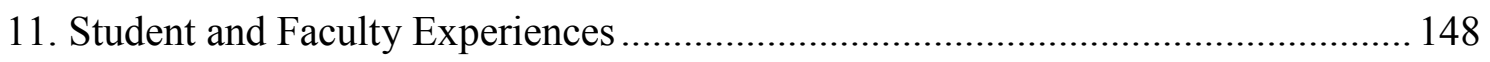

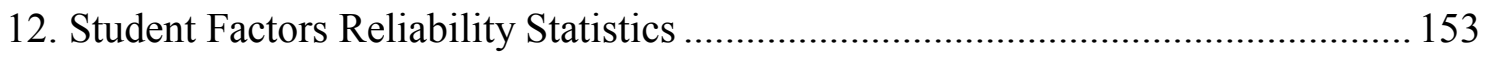

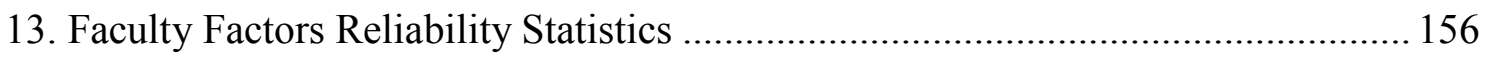

14. Student and Faculty General Attitudes Toward Internationalization

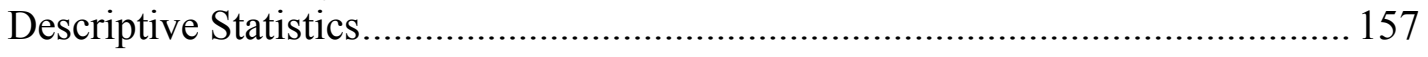

15. Student and Faculty Support for Internationalization

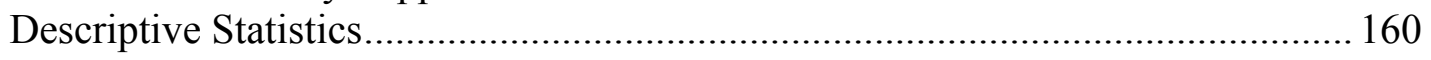

16. Student and Faculty Benefits of Internationalization

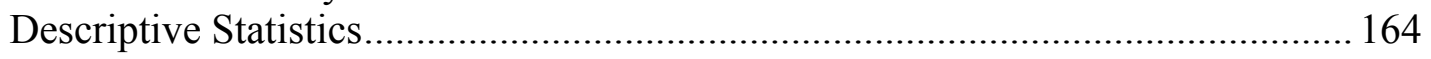

17. Student Factors Correlations with Demographics ................................................. 166

18. Student Factors Correlations with Experiences ………………………................. 169

19. Student General Attitudes Factor Items Correlations

Results 
20. Student Perceived Benefits Factor Items Correlation Results ............................. 173

21. Student Perceived Support Factor Items Correlation Results.............................. 176

22. Faculty Factors Correlations with Demographics............................................ 178

23. Faculty Factors Correlations with Experiences ................................................ 180

24. Faculty Perceived Support Factor Items Correlation Results .............................. 182

25. Faculty Perceived Benefits Factor Items Correlation Results ............................. 185 


\section{LIST OF FIGURES}

FIGURE

PAGE

1. Panel of Experts' Percentage Agreement on Minimum Number of Undergraduate Enrollment in Foreign Language

2. Panel of Experts' Percentage Agreement on Minimum Number of

Graduate Enrollment in Foreign Language.

3. Panel of Experts' Percentage Agreement on Minimum Percentage of International Students ....

4. Panel of Experts' Percentage Agreement on Minimum Number of Fulbright Faculty Awards

5. Panel of Experts' Percentage Agreement on Minimum Number of Fulbright Faculty Awardees Hosted at University X...

6. Panel of Experts' Percentage Agreement on Minimum Number of Students Participating in Study Abroad.

7. Panel of Experts' Percentage Agreement on Minimum Number of Faculty Involvement in International Development Projects

8. Student Factors Scree Plot 151

9. Faculty Factors Scree Plot 154 


\section{CHAPTER I}

\section{INTRODUCTION}

As Higher Education Institutions (HEIs) engage in international activities such as study abroad programs, dual degrees, faculty exchanges, or offshore (transnational) programs, a general consensus exists among higher education administrators, faculty, students, parents, and employers that international activities promote students' preparation for world citizenship (Harari, 1981). Being a global citizen requires global competency and an informed understanding of the world. As Harari (1981) explains "international understanding has come to represent a very practical and urgent need, and clearly higher education has the major responsibility in this area in the long term" (p. 1).

Johnston and Edelstein (1993) reinforce Harari's remarks by stating, "Globalization is here to stay, and its pace in the foreseeable future will only accelerate. Increasingly, the expansion of the international dimension of higher education is not so much an option as a responsibility” (p. 3). Green (2002) ties HEIs' responsibilities to undergraduate education by saying, "an undergraduate education ... must produce graduates who will be productive contributors to civic life both locally and globally and understand that the fates of nations, individuals, and the planet are inextricably linked" (p. 7).

The general public also concurs with academia on the need for an international dimension in higher education. In 2002, the American Council on Education (ACE) published a public opinion poll on attitudes about international education after September 11, 2001. The poll showed that students, parents, and employers expect HEIs to provide them with the knowledge and skills needed (such as language proficiency, cultural 
sensitivity, or awareness and understanding of global issues, among others) in today's globalized world. According to the ACE's (Green, Siaya, \& Porcelli, 2002) research:

1. More than $90 \%$ of respondents [in both surveys] agreed that knowledge about international issues would be important to the careers of younger generations ( $p$. $3)$.

2. Nearly three out of four respondents, regardless of race, age, income, or education, agreed that higher education has a responsibility to educate the public about international education (p. 3).

3. $77 \%$ of the public still supported international education courses.

4. $60 \%$ of undergraduate students agree that all students should have a studyabroad experience during their college or university careers (p. 6).

For HEIs, the responsibility of promoting international education requires a university wide collaboration. International education transcends "any particular discipline or school. It belongs to the entire curriculum and to the values to be imparted to the students to enable them to function effectively and humanely in a conglomerate of nations, races, cultures, economies, and military-industrial complexes" (Harari, 1981, p. $1)$.

In addition, the Association of International Educators (known as NAFSA) in their 2003 report entitled Securing America's Future: Global Education for Global Age emphasizes that national security depends on international understanding. The report asserts that

The challenge of the new millennium is unquestionably global in nature. This reality imposes a new and urgent demand on Americans, one this country has been all too quick to ignore: international knowledge and skills are imperative for the future security and competitiveness of the United States. (p. iv) 
HEIs are therefore compelled to transform these imperatives into actions. To do that, HEIs must act proactively and foster a holistic international dimension — not only palpable in research and academic offerings but also in the area of articulated university goals, mission, support, and so forth. HEIs should fit into place an organizational framework that will embed their international activities within their internationalization ethos. For this investment to be successful, HEIs need to understand the dynamics of the internationalization process and its relationship to organizational factors such as "commitment and support from senior leaders, adequate international funding, and policy statements among others" (Knight, 1994, p. 7), if internationalization is to become a central element of the institution's strategic planning.

\section{Statement of the Problem}

Despite the growing emphasis on international activities, little emphasis has been given to how international activities fit into the current HEIs' structures and processes (Burriss, 2006). This has led to a limited understanding of the efforts of HEIs to make their internationalization process sustainable. Internationalization is an intricate process, as it encompasses many components, such as policies, students, and curriculum.

Therefore, to fully understand HEIs' efforts to sustain their internationalization process, all of its components must be examined.

Cummings (2001) elaborates on this challenge by stating, "because international education is not a primary concern of most scholars in the field, research has been somewhat sporadic, non-cumulative, and tends to be carried out by national organizations as part of advocacy projects" (p. 3). Taylor (2004) expands on this concern by stating "although this outburst of [international] activity is clearly visible in many universities 
throughout the world, it is much less clear to what extent conventional planning theory and methodologies have been applied to the process of internationalization" (p. 150). According to Green (2002), "the little assessment on internationalization that does occur is accomplished through a series of approximate and easily counted measures, such as number of international students on campus, students studying abroad, or foreign language enrollments" (p. 16). However, she continues to say,

While this supply-side approach of internationalization provides a starting point, institutions that are serious about its effect on students should be taking a close look at learning goals, course content, pedagogy, enrollments patterns, and institutional policies and practices to get a more complete picture of their success. (p. 16)

Furthermore, as Ellingboe (2003) points out, "this ongoing process involves many stakeholders working to change the internal dynamics of an institution to respond and adapt appropriately to an increasingly diverse, globally focused, ever-changing external environment" (p. 22). Consequently, given the complex nature of the internationalization process, HEIs should be questioning how their institutional management - through their policy, support and implementation dimensions- respond to the different stakeholders' (such as students, administrators, faculty, and the community) needs and promote their international activities.

According to Engberg and Green (2002), HEIs are used to making marginal changes when it comes to their international activities, such as adding a new language course, infusing an international dimension in the curriculum, or promoting study abroad.

Instead, each of these should be considered a piece of the larger whole. Comprehensive internationalization is a change that is both broad-affecting departments, schools, and activities across the institution - and deep, expressed in institutional culture, values, and policies and practices. (Green, 2002, p. 10) 
Internationalization, therefore, brings with it an institutional transformation affecting not only students but also faculty and administrators. This institutional transformation requires strategic planning encompassing all the different university stakeholders. Unfortunately,

Many universities have traditionally focused planning efforts on the gathering of data for supporting the routine decision process rather than providing a context for long-term considerations. As a result, all too often universities tend to react - or even resist- external pressures rather than take strong, decisive actions to determine and pursue their own goals. (Hirsch \& Weber, 2001, p. 26)

Using the Internationalization Dimension Index (IDI) developed by Afonso (1990) and Krane (1994), the results of faculty and students' attitudes survey toward internationalization, and the application of the Van Dijk and Meijer (1997) model, the present study sought to address the problem of assessing internationalization on the basis of separate elements, such as curriculum, faculty, students, policies, practices among others. The study provides a comprehensive organizational analysis of how Florida International University (FIU) is implementing its process of internationalization by presenting a holistic organizational framework instead of a fragmented international activities organizational analysis.

\section{Purpose of the Study}

The purpose of the study was to examine Higher Education Institutions (HEIs) in the process of internationalization by applying the internationalization cube theoretical model developed by Van Dijk and Meijer (1997) to assess Florida International University's (FIU) internationalization process. The Van Dijk and Miejer (1997) model was used to first determine FIU position on the internationalization cube, and then to assess how FIU's international activities fit into its different organizational processes- 
teaching, learning, research, and service functions (Knight, 2003a). In addition, the study used the International Dimension Index (IDI) and the results of faculty and student attitudinal surveys toward internationalization as separate frameworks for analyzing FIU's internationalization process. The study was modeled after Burriss' (2006) dissertation study, Institutional Effectiveness in Internationalization: A Case Study of Internationalization at Three Higher Education Institutions.

The current study added an attitudinal student and faculty survey on internationalization to Burriss' study. Even though Burriss (2006) presented a welldefined and thoughtful analytical framework to assess HEIs' internationalization process, it does not look at faculty and student perceptions on internationalization.

Internationalization, as a systemic process, is strongly dependent on faculty and student perceptions toward internationalization. The different stakeholders' rationales or views on why and how the institution should internationalize may have an impact on the university's overall policy, support and implementation dimensions. According to Gross and Godwin (2005), “well structured consideration of expanded interests [of stakeholders] leads to a better planning, new and creative initiatives and improved resourced allocation — all which promote organizational success and curb failure" (para. 9).

The internationalization cube is a three-dimensional (policy, support, and implementation), eight-cell cube analysis model for internationalization. Through the application of the cube, HEIs can assess how their international activities are institutionalized in terms of internal processes of decision-making (policy), support, and implementation (Van Dijk \& Meijer, 1997). Though other organizational models for 
internationalization exist, for example, Neave (1992), Rudzki's (1998), van de Wende (1996), Knight (1994), Van Dijk and Meijer's (1997) internationalization cube was selected due to its analytical emphasis on the three-dimensional organizational dimensions, and its capability to "distinguish different processes of development within an institution" (De Wit, 2002, p. 132).

The results of international activities are described using the IDI. Developed by Afonso (1990) and Krane (1994), the IDI consists of 14 quantitative variables closely correlated to an international dimension within HEIs. These variables can be grouped under seven broad categories (Afonso, 1990): foreign language study, international curriculum, study abroad opportunities, number of foreign students, international movement of faculty, international development assistance (funds), and advanced training and research.

Student and faculty perceptions of internationalization were measured using an attitudinal survey developed at Kennesaw State University (Carley, Cheurprakobkit, \& Paracka, 2006). The survey focused on four categories: (a) general attitudes about internationalization, (b) support for internationalization, (c) benefits of internationalization, and (d) participation in international activities—study abroad, offshore programs, and co-curriculum. The results of the student and faculty survey were used to: (a) assess whether student and faculty attitudes toward internationalization are similar or different (provide a diagnostic value for policy or communication changes if needed); (b) provide psychometric estimates of the construct being measured; and (c) provide a more enhanced picture of FIU's position on the Van Dijk and Meijer (1997) internationalization cube. 
The study focused on Florida International University (FIU). FIU, a large, high research activity, state-supported urban, multicultural, and multicampus university, serves as a rich case analysis for the application of the internationalization model due to the following reasons:

1. Its name carries the word "international" reinforcing its mission statement as a university serving not only the local but also the international community.

2. One of FIU's Institutional Goals is to prepare students to "understand their culture and cultures of others and appreciate the complexities and diversity of our global society" (FIU, n.d., p. 16), as well as attain national and international recognition through research promoting life-long learning.

3. FIU's location and campus diversity is worth of recognition. As an urban and fast-growing university located in Miami, Florida, FIU is not only the largest Hispanic serving university in the U.S., but also attracts foreign students from all over the world, hosting in the 2007-2008 academic year a foreign students population of 3,271 (FIU, n.d.). This enhances FIU's campus internationalization.

4. Greater international understanding is one of the three founding goals of FIU. It's in the statute that established the university as a legal entity, displayed on a plaque outside Primera Casa, and has been a goal in every strategic planning document.

Given FIU's consistent commitment to internationalization and the fact that the decision to internationalize is not only pedagogical but also administrative, this study 
sought to shed light on the dynamics of the internationalization process within and across FIU by:

1. Applying the Van Dijk and Meijer model (1997) as an organizational model of analysis to identify the strengths and weaknesses of FIU policy, support, and implementation dimensions guiding the institution's internationalization process and its international activities,

2. Introducing a model of organizational self-assessment relevant to FIU's quality assurance exercise and institutional planning,

3. Establishing a relationship between FIU's position on the internationalization cube and the results of internationalization, and

4. Presenting FIU's student and faculty attitudes toward internationalization.

\section{Research Questions}

The following research questions comprised the core of the study:

1. What is Florida International University's (FIU's) position on the Van Dijk and Meijer's Internationalization Cube (1997)?

2. To what extent is FIU's position on the Van Dijk and Meijer's Internationalization Cube (1997) aligned to the International Dimension Index (IDI) results on internationalization?

3. How do FIU student and faculty attitudes toward internationalization compare on the General Attitudes, Support, and Benefits survey scales? 


\section{Hypotheses}

The following hypotheses were tested in this study:

1. Given FIU's historical and environmental context, FIU is positioned in quadrant 7 of the Van Dijk and Meijer Internationalization Cube (1997).

2. FIU's position on the internationalization cube is aligned to the IDI results of internationalization.

3. There is a relationship between student and faculty attitudes toward internationalization on the General Attitudes, Support, and Benefits survey scales at FIU.

\section{Significance of the Study}

The significance of the study includes both the macro and micro (institutional) levels. At the macro level, by applying the internationalization cube, the study adds to the theoretical body of literature on the internationalization process of HEIs. Due to the varied types of HEIs - research universities, public/private, liberal/comprehensive, and so forth, only by investigating all HEI types can a more accurate theoretical model on internationalization be developed (Krane, 1994). In addition, the application of the internationalization model to FIU responds to an explicit need within the international education field to apply and assess theoretical models for the process of internationalization. Literature in the field shows that emphasis has been given on quantifiable outcomes measuring international activities, but less emphasis has been put on developing theoretical frameworks guiding institutional strategies toward the internationalization process within HEIs. Therefore, this study focuses on the application of a theoretical model for internationalization. 
At the micro or institutional level, the relevance of the study lies in presenting a model to assess the effectiveness of accomplishing FIU's institutional purpose toward international education. The study's importance rests on assessing FIU's international activities as well as student and faculty attitudes toward internationalization vis-à-vis its policy, support and implementation strategies. By using this model, the study may provide to FIU decision makers information about the internationalization process to guide FIU's strategic planning. FIU decision makers would be able to determine its position on the cube, identify any gaps between the university's goals on internationalization and its practices, and develop strategies to act upon the appropriate policy, support and/or implementation dimensions. Engaging in an internationalization review would permit FIU's decision makers to move to the next level of the cube or generate a plan to sustain its current internationalization process.

Also, the notion of self-assessment is closely related to an institution's efforts in maintaining its quality assurance. Assessing the contribution of internationalization at the universitywide level is not only a concern for HEIs but also for accrediting bodies. De Wit (2002) elaborates on this by stating,

[But] the analysis of an institution's performance and achievements according to their articulated aims and objectives for internationalization is critical to assess and eventually ensure the quality of the international dimension and the contribution internationalization makes to the primary functions of the institution. The process must indicate directions for improvement and change of the internationalization strategy of the institution... (p. 161) 
Furthermore, FIU's self-assessment on its internationalization efforts will serve as a preliminary report responding to the Southern Association of Colleges and Schools' (SACS) requirement of providing a Quality Enhancement Plan (QEP) as part of FIU's reaffirmation of accreditation process.

Above all, the Van Dijk and Meijer (1997) model for internationalization contributes to promoting a strategic management analysis to foster the understanding of the internationalization process. This analysis permits higher education institutions to assess the alignment of their policy, support, and implementation dimension within and across the organization in relation to the results of internationalization and students and faculty attitudes.

\section{Assumptions}

The basic assumptions of this study were:

1. Florida International University's rationales for internationalization are political, cultural, economic, and educational in nature.

2. Florida International University's approaches to internationalization are characterized by, but not limited to, activities and students' competencies.

3. Florida International University has in place some type of internationalization process.

4. Internationalization can be understood through the analysis of organizational policy, support, and implementation processes (Burriss, 2006).

5. The IDI serves as the strongest indicator of HEIs' efforts on internationalization (Burriss, 2006). 
6. The need exists to further the analysis of the institutionalization of the internationalization process within HEIs.

7. The subjects' responses to the interview and survey questions reflect their honest perceptions.

\section{Delimitations of the Study}

This study presented the following delimitations. First, the study was limited to the analysis of the internationalization process at Florida International University (FIU). This limits the possibility of making generalizable conclusions. Second, though an attempt is made in acknowledging external factors influencing the internationalization process, the main focus was on the three organizational dimensions that are easier to internally control and change, which are policy, support, and implementation. Third, it is important to mention FIU's selection of the term, Global Learning Initiatives, versus the term Internationalization used in the study. The term global learning focuses on a studentlearning as presented in the FIU's Quality Enhancement Plan (QEP), particularly through the curriculum and co-curriculum, while the former includes the different range of elements — such as curriculum, faculty, students, polices, practices, activities, and others - embodying internationalization. Finally, the time-period (spring term 2010) during which the student and faculty survey was carried out is worth mentioning. This period coincided with the first planning years of FIU's QEP efforts. This time factor may have delimited the students and faculty survey responses at that particular time as the QEP efforts evolved. 


\section{Definition of Terms}

For the purpose of this study, the following terms are defined as follows:

Internationalization. "The process of integrating an international, intercultural and/or global dimension into the goals, functions (teaching/learning, research, service) and delivery of higher education" (Knight, 2003a, p. 11).

International Education. International education is an all-inclusive term encompassing three major strands: (a) international content in the curricula, (b) international movement of scholars and students concerned with training and research, and (c) arrangements engaging U.S. education abroad in technical assistance and education programs. (Harari, 1972, p. 3)

Globalization. "The flow of technology, economy, knowledge, people, values, [and] ideas ... across borders. Globalization affects each country in a different way due to a nation's individual history, traditions, culture, and priorities" (Knight \& de Wit, 1997, p. 6).

Global Citizenship. The willingness of individuals to apply their knowledge of interrelated issues, trends, and systems and multi-perspective analytical skills to local, global, international and intercultural problem solving (FIU, 2010, p. 57)

Global Competency: "Having an open mind while actively seeking to understand cultural norms and expectations of others, leveraging this gained knowledge to interact, communicate and work effectively outside one's environment" (Hunter et al., 2006, p. 270).

Internationalization Cube. A three-dimensional (policy, support, and implementation), eight-cell cube organizational analysis model for internationalization. Institutions 
located in Cell 1 are characterized by few international activities (low level of internationalization), while those located in cell 8 are highly internationalized.

Policy. As defined by Van Dijk and Meijer, policy relates to the importance attached to internationalization aims. Policy is characterized as priority (high importance attached to the internationalization aims within the institution shown by explicit mention and/or attention or commitment to global, international, multicultural mission/goals in university documents, magazines, webpage, etc.) or marginal (low attention or importance given to the internationalization aims within the institution shown by no indication and/or attention or explicit commitment to global, international or multicultural commitment in university documents, magazines, webpage, etc.). Policy analysis was based upon institutional documents review and interviews with administrators (such as President, Provost, Vice Provost, Deans, etc.) whose leadership influences the university's policymaking process.

Support. Type of assistance provided to the international activities (either through funding or staffing among others) characterized as interactive (two way process of interaction among central, faculty, and departmental levels) or unilateral/onesided (mainly central level of the institution or peripheral). The support dimension was determined through institutional documents analysis, interview questions compiled and adapted from Afonso (1990), Francis (1993), and Burriss (2006), and survey responses.

Implementation. The manner in which HEIs manage or introduce their international activities. Implementation can be structural/systematic (the management and/or 
introduction of international activities in a systematic manner; following explicit and precise procedures) or ad-hoc (the management and/or introduction of international activities as they occur without reference to established procedures). The implementation dimension was determined through institutional documents analysis and interview questions compiled and adapted from Davies (1992), Francis (1993), Burriss (2006).

Index. "A composite measure of the combined values of selected indicators" (Krane, 1994, p. 12).

Internationalization Dimension Index (IDI). "A standard institutional value that represents the sum of the products of the most highly correlated variables used to rate the results of institutional internationalization as identified by researchers Afonso (1990) and Krane (1994)" (Burriss, 2006, p. 17).

Item Relevancy Index (IRI). The proportion of experts who rates each item on the IDI as Relevant on a 2-point scale (Relevant and Not Relevant).

Results of Internationalization. In this study, results of internationalization refer to the descriptive data collected on internationalization using the IDI indicators. The IDI indicators of internationalization developed by Afonso (1990) and Krane (1994) demonstrate the level of international activities within HEIs (Burriss, 2006).

International Faculty. Non U.S. born faculty engaged in teaching, learning, research, and services within the institution.

\section{Summary}

This chapter introduced the present need facing HEIs to educate students to be global citizens. The growing importance of educating students with the necessary skills 
(such as language proficiency and cultural sensitivity) to function in a globalized world is pushing HEIs to adapt and invest in a university wide internationalization process. Due to the complex nature of the process and the different stakeholders involved in it, HEIs need to be aware of how their institutional management — through policies, support and implementation dimensions - sustain and manage their internationalization process.

The study focused on Florida International University's internationalization process by using the internationalization cube developed by Van Dijk and Meijer (1997) in relation to the IDI, and how these components fit into its different organizational processes - teaching, learning, research, and service functions (Knight, 2003a). In addition, the study sought to shed light on FIU student and faculty attitudes toward internationalization. The mid-section of the chapter put forward a description of the model, IDI, and the faculty and students attitudes used to do the evaluation. The final section discussed the assumptions delimitations, and limitations of the study, as well as definitions of terms.

\section{Organization of the Study}

In this section, the organization of the study is explained. Chapter 1 presented an introduction to the internationalization process at HEI, the research problem, research questions, hypothesis, assumptions, significance of the study, limitations of the study, and definition of terms. Chapter 2 consists of the literature review of the theoretical framework and relevant information on the internationalization process in HEIs. Chapter 3 describes the design of the study. The chapter begins with a definition of a case study, a description of the sampling technique used, collection of data, and the analysis of data. 
Chapter 4 presents data and results from the data analysis. Chapter 5 summarizes the research with a discussion, conclusions, and recommendations for further research. 


\section{CHAPTER II}

\section{LITERATURE REVIEW}

The review of literature in this chapter was intended to cover relevant information to the present study. The chapter began with the definition of internationalization, its history in the U.S., as well as its rationales, and key elements of effective internationalization. The literature also discussed the models for internationalization existent to date and barriers to an effective internationalization process. Finally, the chapter presented a description of the theoretical framework and the theoretical model analysis for this study.

\section{Definition of Internationalization}

Defining internationalization is a complex task, as multiple definitions of internationalization exist. Depending on the interpretation HEIs adopt, it influences their approach to internationalization.

Early definitions describe internationalization in regards to the international activities universities engage in, and do not necessarily call for a university wide internationalization plan. For Harari (1977) and Arun and van de Water (1992) internationalization refers to "the multiple activities, programs and services that fall within international studies, international education exchanges and technical cooperation" (as cited in Knight, 1994, p, 3). This definition focuses on three elements: (a) international content of the curriculum, (b) international movement of scholars and students concerned with training and research, and (c) international assistance and cooperation. 
The European Association for International Education moved away from an activity-oriented definition by stating: "internationalization being the whole range of processes by which higher education becomes less national and more international oriented" (de Wit, 2002, p.133). This definition highlights the growing interest on internationalization as a process within HEIs and the emphasis on international cooperation rather than as a set of individual activities.

Van der Wende (1997) revised his previous definition on internationalization based on international activities and presented a new one following an outcomes-oriented approach. For him internationalization is "any systematic effort aimed at making higher education (more) responsive to the requirements and challenges related to the globalization of societies, economy, and labour" (p. 19). According to van der Wende, this definition describes the internationalization of HEIs as a response to the global interaction of cultural, political and economic processes that transcend national borders (van der Wende, 1997). However, as Knight (2004) argues, this definition neglects to acknowledge the education sector's context where HEIs function.

Rudzki (1998) defines internationalization as a "process of organizational change, curriculum innovation, staff development and student mobility for the purpose of attaining excellence in teaching, research, and the other activities which universities undertake as part of their function" (p. 16). Soderqvist also presents a definition of internationalization focusing on institutional change. According to Soderqvist (2002), internationalization is defined as

A change process from a national higher education institution to an international higher education institution leading to the inclusion of an international dimension 
in all aspects of its holistic management in order to enhance the quality of teaching and learning and to achieve the desired competencies. (p. 29)

Mestenhauser (2002) explains internationalization as, "the internationalization of education is a program of change aiming to make international education a super-ordinate field of knowledge, inquiry and application, which is interdisciplinary, multi-dimensional and multi-cultural" (p. 170).

Knight (2004) proposes a process approach definition of internationalization as follows: "the process of integrating an international and intercultural dimension into the teaching (learning), research and service functions of the institution" (p. 9). Schoorman (1999) takes Knight's definition a step further by saying internationalization is an

Ongoing, counter hegemonic educational process that occurs in an international context of knowledge and practice where societies are viewed as subsystems of a larger, inclusive world. The process of internationalization at an educational institution entails a comprehensive, multifaceted program of action that is integrated into all aspects of education. (p. 21)

Both definitions frame internationalization as "a process that integrates an international dimension or perspective into the major functions of the institution" (de Wit, 2002, p. 118).

At the same time, it is relevant to distinguish between the terms internationalization and international education. Though both terms tend to be used interchangeably, for the purpose of this study, international education and internationalization stand for different things. International education as defined in Chapter 1 refers to an institution's international activities such as students and faculty exchange programs, foreign languages studies, and so on. The problem with such description according to Green and Olson (2003) is that 
The term international education suggests that it is separate from the rest of education and that it exists as a parallel or different undertaking. The result of this parallel concept is that international learning and experiences are not only disconnected from other aspects of education processes, but also marginalized and poorly integrated into the institution's mission strategic plan, structure, funding priorities. Framing international education as a separate part of the educational experience, occurring through a series of discrete activities, invites a fragmented approach. (p. 1)

Internationalization, on the other hand, indicates an integrative process of international efforts (Green \& Olson, 2003) throughout the institution (seen at the policy, implementation and, support levels) rather than just fragmented activities.

The review of literature above shows the difficulty of defining internationalization. This complexity manifests in the variety of approaches to internationalization. Knight's definition is used in this study as it allows for the analysis of internationalization as interdependent processes that cross over and affect the teaching (learning), research and service functions of the institution.

\section{History of Internationalization in the U.S.}

The internationalization of higher education in the last decades has been strongly associated with external and internal political events, which not only influenced the drafting of strategies and policies but also contributed to its inconsistent significance in the U.S. education agenda. Despite its shifting nature, it can be argued that the constant rationales for the internationalization of American HEIs have been peace, mutual understanding, national security and foreign policy (de Wit, 2002). These rationales can be argued were motivated on promoting the American way of life into other nations, safeguarding ethnocentric feelings rather than enhancing a deeper understanding of other nations' cultures, ideas, and perspectives. 
According to Merkx (2003), the internationalization of HEIs in the U.S. came about in two waves; the first wave emerging out of World War I and World War II and the second one out of the rapid globalization of the world.

\section{The First World War and Internationalization}

The end of World War I brought forth the need for the U.S. to promote and invest in international cooperation. One of the first results of internationalization was the creation of the Institute of International Education (IIE) in 1919 whose function was to promote educational exchange and cultural understanding among nations. According to the IIE website, IIE was created "as a catalyst for educational exchange. It met a real need for a central point of contact and source of information both for U.S. higher education and for foreign nations interested in establishing educational relations with the United States" (IIE, n.d.). In 1946, the IIE had its greatest moment with the creation of the Fulbright program by the U.S. government. The IIE was given the responsibility for what was to become its largest program, the administration of the graduate student component of the Fulbright Program.

Today the IIE as the earliest international education organization serves higher education institutions through a variety of programs and funds to promote understanding among nations. According to Vestal (1994), "under the Fulbright program, the State Department Bureau of Educational and Cultural Affairs (ECA) was, by 1966, sending 2,500 Americans abroad to study and bringing 6,000 foreign scholars and teachers to the United States" (p. 22). According to the 2005/2006 Annual Fulbright report, in 2005 1,210 American students went abroad, 2,444 foreign students were awarded or renewed 
grants to study in the U.S., and 715 foreign scholars came to the U.S. (U.S. Department of State, p. 40).

\section{The Second World War and Internationalization}

The end of WWII reinvigorated the idea that for international cooperation and peace to be sustained, internationalization of HEIs must become a top item on the U.S. education agenda. According to Pickert (1992), "World War II radically increased demand for international studies specialists, both in the short term for wartime service and in the long term for peacetime national security and reconstruction" (p. 27). As a result, the number of Ph.D.s produced in the areas of international studies increased from 100 in 1948 to 223 in 1951 (Merkx, 2003).

During this period, the internationalization of HEIs developed around specific areas such as foreign aid, foreign study abroad programs, student enrollment, foreign languages and foreign areas of study (Merkx, 2003). As a result, Merkx (2003) argues, "no single type of internationalization or organizational strategy emerged as dominant in American higher education" (p. 9).

The political events of 1960s, 70s and 80s, such as decolonialization of the developing world, the Cold War, and the expansion of higher education systems in other countries, led to an active "involvement of the federal government in encouraging internationalization through such programs as the National Defense Education Act (Title VI) and the Agency for International Development (foreign affairs agencies)" (Petronis, 2000, p. 26).

The United States Agency for International Development (USAID) agency was in charge of financing overseas technical assistance programs in Third World Countries 
through U.S. land grants and universities (Vestal, 1994). The USAID Foreign Assistance Act of 1961 gave priority to: (a) "Educational activities, including training of teachers and local agricultural extension agents, establishing agricultural universities, and assisting in the construction of new schools" (Vestal, 1994, p. 22), and (b) to the indirectly promotion of U.S. Foreign Policy in countries in need.

In the area of foreign languages studies, in 1958 the National Defense Education Act (NDEA) was enacted. This act came as a result of the Russian launching of Sputnik and the fear of Russian superiority. The NDEA was directed to providing federal subsidiaries to research higher education institutions interested in participating in teaching and research on foreign areas of study.

Overall, HEIs responded to the first wave of internationalization establishing "functional units with one of more specific missions, ... organizationally fragmented, insomuch as the usual response was to house the different functional units in different parts of the college of university" (Merkx, 2003, p. 9). The lack of organizational strategy in internationalization within higher education institutions has been inherited from those early approaches.

The end of the Cold War, the worldwide spread of the Internet, and the influence of globalization (Merkx, 2003) marked the beginning of the new wave of internationalization from the 1990s to date. The rationale of internationalization of HEIs started shifting from the previous political rationale to one of economic competitiveness (Callan 2000; de Wit 1995; Harari 1992) and global awareness rationale. The 2000 Memorandum on International Education Policy from President Clinton set the tone for that shift stating, 
To continue to compete successfully in the global economy and to maintain our role as a world leader, the United States needs to ensure that its citizens develop a broad understanding of the world, proficiency in other languages, and knowledge of other cultures. (Clinton, 2000)

Friedman (2005) discusses the evolutionary process of globalization, from Globalization 1.0 to Globalization 3.0 in his book, The Lexus and the Olive Tree. According to Friedman, globalization 3.0 is characterized by the interconnectiveness of human beings leading to an undeniable awareness and recognition of global cultures. Events such as the fall of the Berlin Wall and the emergence of the U.S. as the world's sole military power, the creation of regional structures (such as the European Union), the move toward a more knowledge-based society, and the tragedy of September 11, all reinforce the notion that the understanding of global issues and intercultural knowledge and communication skills is imperative. These global issues also confirm that parochialism, a viewpoint that has defined the American higher education system in the past century, is no longer an option (de Wit, 2002).

HEIs are responding to the current wave of internationalization by promulgating a more university-wide approach to internationalization. According to de Wit (2002), the need for an organized response by higher education to these external developments "resulted in an internationalization strategy that was based more on explicit choices (rationales) and a more integrated strategy (process approach)" (p. 17).

Analyzing the historical events and policies that have shaped the internationalization process of HEIs serves as a basis to understand why internationalization has been in and out of the American education agenda. 


\section{Rationales for Internationalization}

Just as several definitions and approaches to internationalization can be described, several rationales or motivations for the internationalization of higher education exist. According to de Wit (2000), rationales serve as means to an end toward internationalization providing the "why" HEIs engage in internationalization efforts. When analyzing rationales, it is important to acknowledge that several stakeholders (from the government sector, private sector, or education sector) influencing HEIs have an impact on the HEI's selection of rationales.

Furthermore, within the educational sector should also be "distinguished among three subgroups: the institutional level, the academic and their departments, and the students" (de Wit, 2000, p. 12). At the same time, these subgroups have their own rationales for internationalization. As these subgroups interact, their rationales may overlap leading to a combination or change of rationales guiding the internationalization process. Knight (2004) further explains that the rationales HEIs decide to follow are associated with "factors that range from mission, student population, faculty profile, geographic location, funding sourcing, level of resources, orientation to local, national, and international interests" (p. 25).

The following literature review shows the driving rationales in HEIs over the past decades:

Aigner et al. (1992) suggest three main rationales for internationalization that are interrelated and not mutually exclusive in nature: (a) interest for national security, (b) maintenance of economic competitiveness, and (c) fostering of human understanding of across nations. 
Scott (1992) articulates seven rationales for global education imperative. According to Scott, they are: (a) economic competitiveness, (b) environmental interdependence, (c) increasing ethnic and religious diversity of local communities, (d) the reality that many citizens work for foreign-owned firms, (e) the influence of international trade on small business, (f) the fact that college graduates will supervise or be supervised by people of different racial and ethnic groups than their own, and (g) national security and peaceful relations between nations (p. 2).

Warner (1992) identifies three different models as imperatives for internationalization. In the market model, HEIs are forced to compete for "'markets, ideas, and influence...” (p. 21). HEIs, hence, become competitive by introducing a relevant international dimension into the curriculum, preparing students to be able to work in the global market place that requires intercultural skills and knowledge of the interconnectedness of the world.

Warner's second model (1992), the liberal model shifts from global competition to global cooperation (p. 21). The goal for this model is for HEIs to prepare students to become world citizens. "The liberal model stresses activities such as the broadening of the cultural framework in the curriculum, international exchanges and collaboration with a broad range of countries, programs, and events to enhance global conspicuousness"(p. 21).

The social transformation model, Warner's last model (1992), builds upon the liberal model adding the "dimension of critical social analysis" (p. 21). The social 
transformation model calls upon a curriculum that will give students a deep awareness in international and intercultural issues dealing with equality and justice, and provide the necessary skills to promote social change.

Knight and de Wit (1997) recognize two groups of rationales for internationalization: economic and political, and cultural and educational. In a later study, Knight (2004) divides the two groups into four separate rationales:

Economic -based on economic growth and competitiveness, the labor market, and financial incentives for institutions and governments-, Political -foreign policy, national security, technical assistance, peace and mutual understanding, national identity, and regional identity-, Socio-cultural -national cultural identity, intercultural understanding, citizenship development, social and community development-, and Academic -international dimension to research and teaching, extension of academic horizon, institution building, profile and status, enhancement of quality, and international academic standards. (p. 23)

In 2003, the International Association of Universities (IAU) surveyed its members on the practices and priorities of HEIs toward internationalization. The survey reports 12 top rationales for internationalization (Knight, 2003b). These are: Mobility and exchanges for students and teachers, teaching and research collaboration, academic standards and quality, research projects, co-operation and development assistance, curriculum development, international and intercultural understanding, promotion and profile of institution, diversify source of faculty and students, regional issues and integration, international student recruitment, and diversify income generation.

In 2005, the IAU surveyed its members again and the universities' responses demonstrate a shift toward a cultural competences rationale. While in 2003 the top rationales were mobility and exchange of students and teachers and teaching and research collaboration (Knight, 2003b), in 2005 they were "to increase student and faculty 
international knowledge and intercultural understanding, and to strengthen research and knowledge capacity production" (Mooney, 2006, p. 21).

In review, rationales serve as the founding pillars of the internationalization process. Since these rationales are not mutually exclusive, HEIs must have a clear understating of "Why" internationalization is significant for the institution. Which rationales HEIs decide to follow, as Knight (1994) comments, will depend on the institution's history, resources, and the stakeholders' influences.

\section{Key Elements of Internationalization}

The complex definition of internationalization suggests many elements are present in the internationalization process that can either hinder or promote internationalization. According to Knight (1994), "these elements may be called key ingredients, mechanisms, facilitators, barriers, factors, steps" (p. 5). In addition, these elements can be divided into two groups: organizational factors (such as the mission statement, annual planning, or assessment review) and academic programs and services (Knight, 1994).

Several researchers have written on the most significant elements on internationalization though they do not necessarily distinguish them between Knight's two groups. In the academic programs and services groups, researchers such as Aigner et al. (1992), American Association of State Colleges and Universities, 1985, Audas, 1991, Francis, 1993, Harari, 1989, Knight, 1994, Mestenhauser, 2002, Paige, 2005, Scott, 1992 list as the most significant elements: an internationalized curriculum, foreign languages, study aboard programs, international students and scholars, international linkages, and cooperation with other universities. 
The same researchers list as most significant organizational factors: leadership from the organization (including mission statements, strategic plans, institutional commitment and ethos, and policies, among others), faculty and staff development and involvement, and support (from budget and resource allocation to structures to sustain internationalization).

Knight (1999) emphasizes the importance of organizational factors stating

The focus on organizational strategies is what distinguishes the process approach from the other approaches. By stressing the importance of integrating the international dimension into the institution's mission statement, planning and review systems, policies and procedures, hiring and promotion systems one is working toward ensuring that the international dimension is institutionalized. (p. 25)

Knight's (2004) institutional levels of organization strategies are shown in Table

1.

Table 1

Institutional Level Organization Strategies

\begin{tabular}{ll}
\hline Institutional Level & Organization Strategies \\
\hline Governance & $\begin{array}{l}\text { Expressed commitment by senior leaders } \\
\text { Active involvement of faculty and staff } \\
\text { Articulated rationale and goals for internationalization } \\
\text { Recognition of an international dimension in institutional } \\
\text { mission statements, planning, and policy documents }\end{array}$ \\
& \\
& $\begin{array}{l}\text { Integrated into institution-wide and department/college- } \\
\text { level planning, budgeting and quality review systems } \\
\text { Appropriate organizational structures } \\
\text { Systems (formal and informal) for communication, liaison, } \\
\text { and coordination } \\
\text { Balance between centralized and decentralized promotion } \\
\text { and management of internationalization }\end{array}$
\end{tabular}

(table continues) 
Table 1 (continued)

Institutional Level Organization Strategies

Adequate financial support and resource allocation systems

Services Support from institution-wide service units, i.e. student housing, registrariat, fund-raising, alumni, information technology

Involvement of academic support units, i.e. library, teaching and learning, curriculum development, faculty and staff training Student support services for incoming and outgoing students, i.e. orientation programs, counseling, crosscultural training, visa advice

Human Resources

Recruitment and selection procedures that recognize international expertise

Reward and promotion policies to reinforce faculty and staff contributions

Faculty and staff professional development activities

Support for international assignments and sabbaticals

Note. From "Internationalization Remodeled: Definition, Approaches, and Rationales," by J. Knight, 2004, Journal of Studies in International Education, 8(1), 14-15.

To date, the studies described in the following text have reinforced the importance of these elements combined or individually on internationalization.

Afonso (1990) studied the internationalization dimension of 104 American

Research I or Research II universities as categorized by the Carnegie Foundation. In her study, Afonso (1990) developed an international dimension index (IDI) to measure and rank universities on their internationalization practices on seven specific dimensions: foreign language curriculum, international curriculum, foreign students, international movement of faculty, international development assistance, and advance training and research. According to Afonso (1990), "the primary purpose of [her] study was to 
examine the nature of international education and to provide a single multivariate measure of the international dimension within individual institutions" (p. 9).

Following Afonso's steps, Krane's (1994) quantitative study presented an IDI for liberal arts colleges to "describe variation in degree of internationalization among those institutions, and identify institutional characteristics that contribute to the variation in degree of internationalization" (p. 7). The significance of both studies lies in demonstrating the multi-faceted nature of internationalization, and the correlation between the curriculum, faculty, students, administrators and staff. "These indicators were simple measures of the results of internationalization including international and area studies, study abroad, and foreign languages" (Burriss, 2006, p. 53).

Ellingboe's (1998) two major qualitative research studies on U.S. universities resulted on the identification of six dimensions of internationalization. The significance of Ellingboe's study focuses on the fact that "five of these dimensions-faculty involvements in international activities, an internationalized curriculum, study abroad, international students and scholars, and college leadership — appear in almost all of the internationalization documents and as such represent key components cross- nationally" (Paige, 2005, p. 104).

Petronis (2000) studied the internationalization of business schools by focusing on 10 of the most frequent elements on internationalization: foreign language offered, foreign students enrollment, business language requirement, business faculty language fluent, international courses offered, international instructional methods use, student exchange opportunities, faculty exchange experiences, international faculty development options, institutional students enrollment, and business component student enrollment. 
Based on those 10 elements, Petronis developed an internationalization of business component index (ICBI) measuring "the level on internationalization of institutional business components" (Petronis, 2000, p. 16).

According to the NAFSA (Association of International Education Administration, 2003), the following organizational factors are responsible for building commitment within the institutions toward internationalization: (a) a shared vision and common understanding of why internationalization is important for the institution, (b) a shared ownership, where each stakeholder is engaged in working toward internationalization, hence, contributing to a long-term sustainability of change, (c) planning and evaluation, establishing clear long term goals and intended (expected) outcomes toward internationalization, (d) information and communication among the different stakeholders, vital for the assessment process, (e) staff development, investment in human capital to promote knowledge and understanding of capabilities needed to effectively implement changes, and (f) consideration of internal and external factors. These six elements embody the union of the organizational factors and academic programs and services.

In 2002, the American Council on Education (ACE) selected eight HEIs to be part of an internationalization collaboration project. From the internationalization project, ACE later published a campus case studies report on internationalization of the eight HEIs. The report called Promising Practices: Spotlighting Excellence in Comprehensive Internationalization (Engberg \& Green, 2002) measured the universities' efforts and challenges on seven specific elements: an intentional, integrative, and comprehensive approach; strong leadership from the top from presidents and other senior leaders as the 
chief international educator administrator; committed leadership throughout the institution; widespread faculty engagement, a commitment to meeting students needs; an ethos of internationalization; and finally supportive structures and resources. This report reinforces the concept that internationalization efforts are shaped by more than one element, and a holistic/comprehensive approach should be considered for internationalization to be fully embedded into the institution.

\section{Curriculum}

In an era where global understanding, knowledge, and skills are imperative, an internationalized curriculum becomes the central element of the internationalization process. According to Kirkwood (2001), today's students:

[Their] daily contacts will include individuals from diverse ethnic, gender, linguistic, racial, and socioeconomic backgrounds. They will experience some of history's most serious health problems, inequities among less-developed and more-developed nations, environmental deterioration, overpopulation transnational migrations, ethnic nationalism, and the decline of the nation-state. (Kirkwood, 2001, p. 2)

Therefore, a relevant internationalized curriculum must strive to "enable students to fully experience how other cultures and belief systems work.... calling for an integrated and learner-center system that fosters intercultural, interdisciplinary, comparative, and global learning" (Green \& Olson, 2003, p. 57). Ideally, such curriculum will include "all or most of the following disciplinary approaches: general education, area studies, international relations, foreign languages and cultures, and comparative and international approaches to individual subject areas" (Chandler, 1999, p.10).

Harari (1989) reinforces the importance of an internationalized curriculum by stating: 
At the heart of internationalization of an institution is and will always remain its curriculum, precisely because the acquisition of knowledge, plus analytical and other skills, as well as the conduct of research, is what a university is primarily about. (p. 3)

The review of literature that follows demonstrates several approaches to internationalizing the curriculum:

Knight (1994), lists the following elements as requirements to internationalized the curriculum: the infusion of disciplines with international content; comparative approaches; issue-oriented approaches and interdisciplinary studies; area studies and civilizational approaches; international studies and intercultural studies, international development studies (theory and practice).

Bremer and van der Wende (1995) consider an international curriculum "a curriculum with an international orientation in content, aimed at preparing students for performing (professionally/socially) in an international and multicultural context, and designed for domestic students and/or foreign students" (as cited in Green \& Olson, 2003, p. 59)

Bremer and van der Wende (1995) add to Knight's elements a specific professional capability, calling for a

Curriculum which prepares students for defined international professions; curricula in foreign languages or linguistics that explicitly address cross communication issues and provide training in intercultural skills; curriculum leading to internationally recognized professional qualifications, and a curricula in which the contest is especially designed for foreign students. (Green \& Olson, 2003, p. 59)

Mestenhauser (1998) refers to the internationalization of the curriculum in terms of learning outcomes: to achieve conceptual flexibility and alteration, to broaden 
knowledge of at least one other country or culture, to achieve breadth and understanding, and to connect the international dimension of the discipline to its application to careers and professions.

Paige and Mestenhauser (1999), emphasize that an internationalized curriculum provides learning opportunities that are, among other things, intercultural, interdisciplinary, comparative, global, and integrative in character. For Paige and Mestenhauser (1999),

These all combine to form what we refer to as an international mindset. In an internationalized field of study, these perspectives find expression in the education that graduate students receive, the research being conducted by scholars, and the policies developed and implemented by educational planners and administrators. (p. 505)

The American Council on Education (ACE) (2003), in its report Internationalizing Strategies, warns that

The internationalization of the curriculum requires thinking about curriculum differently, it does not occur silently in a few courses or majors and does not serve as simply an additive to existing programs. It calls for an interdisciplinary and multifaceted process that will affect all faculty and students. (p. 80)

As a result, ACE recommends: internationalizing general education; infusing majors in a variety of disciplines with international content and methods; creating majors or minors, or certificates with international focus; internationalizing professional school curriculum; integrating study or internships abroad into the curriculum; developing foreign languages requirements across the curriculum; creating joint curriculum (between domestic and foreign institutions); and developing policies and programs that encourage faculty to internationalize the curriculum. 
All the approaches discussed above challenge the traditional discipline oriented perspective in place. According to Brustein (2005),

Most of our institutions address the need for global competence by adding a diversity or international course(s) requirement - hardly sufficient to instill global competence in our students - or by offering degrees, minors or certificates in area or international studies. However, there are major shortcomings in the way both area and international studies are generally carried out. Area studies programs tend to be highly descriptive and too often display an apparent abhorrence towards theorizing. The curriculum frequently resembles a cafeteria-style menu: one selection or course from this shelf followed by selections from various other shelves. Somehow students are expected miraculously to pull together the disparate pieces into some coherent whole. (p. 1)

Brustein's concern can be seen in the 2006 Modern Language Association (MLA) report on undergraduate students' enrollments. According to the report, though the number of enrollments in language classes between 2002 and 2006 expanded by $12.9 \%$, retaining students to upper-level courses remains low (MLA, 2007). This means that students graduating with lower class language courses have less proficiency and knowledge of other cultures "despite the current consensus that globally fluent graduates are essential to American competitiveness" (Pappano, 2007). In addition, when comparing the modern language course enrollments per 100 enrollments from 1960 to date, a significant decrease is seen from 16.1 to 8.6 (MLA, 2007).

An internationalized curriculum, calls for "new pedagogical and curricular practices that introduce multivaried modes of thinking and learning" (ACE, 1998). An internationalized curriculum, consequently, should introduce change into the current pedagogical system by going beyond teaching facts to students but rather enhancing the understating of how cultural variables influence how and what we know (Odgers \& Giroux, 2006). 


\section{Faculty}

If an internationalized curriculum constitutes the heart of internationalized HEIs, the faculty is the heart of an internationalized curriculum. Preparing students to understand other cultures and to be able to interact with them, "is directly correlated to the development and teaching of curricula that broadens the global perspective of students" (Carter, 1992, p. 42).

Morris (1996) elaborates on the importance of the faculty on curriculum development stating that

It is a hopeless task to add international content to the university curriculum without major increases in faculty involvement in international work...Internationalization of the faculty is the key to changes in the curriculum and, ultimately, the types of students who graduate from the university. (p. 1)

Harari (1981), also, in his book called Internationalizing the curriculum and the campus: Guidelines for the American Association of State Colleges and Universities (AASCU) concludes that, "the degree of internationalization of a campus is not a function of size, location, or overall budget. In the last analysis it is a function of faculty competence and commitment and of institutional leadership" (p. 29).

However, despite the close relationship between faculty internationalization and the internationalization of HEIs, the American professoriate remains mainly inward looking. In 1992, the Carnegie Foundation carried out a survey on 14 nations regarding the status of the academic professoriate. Among the nations surveyed were the U.S., England, Sweden, the Netherlands, Germany, Japan, and Taiwan, among others. Results from the survey show that:

American faculty is the least committed to internationalism among scholars from fourteen countries. While more than 90 percent of the faculty in thirteen countries 
believe that a scholar must read books and journals from abroad to keep up with scholarly developments, only 62 percent of Americans believe this. Upwards of 80 percent of the faculty in thirteen countries value connections with scholars in other countries. A little over half the American professoriate are in agreement. (Altbach, 2005, p. 148)

Pertaining to the internationalization of the curriculum and foreign trips, data from the report illustrates that:

American faculty are similarly indifferent about further internationalizing the curriculum, with only 45 percent agreeing that this should be done, and 65 percent of American academics reporting no foreign trips for study or research in the last three years. Americans scored last among the 14 countries in overseas travel and research. American rank last among the 14 countries included in the survey. (Altbach, 2005, p. 149)

Finally, the report states that American faculty demonstrates mixed feelings toward internationalization. Though American professors show enthusiasm in dealing and teaching international students and participating in conferences abroad, they seem less likely to pay attention to and incorporate foreign academic work into their classrooms (Altbach, 2005).

\section{Faculty and Student Attitudes Toward Internationalization}

While it is unquestionable that faculty plays a pivotal role on the level of internationalization of the teaching, research, and service within an institution, students also expect an undergraduate education that will prepare then to be competitive in a more globalized world.

Following those premises, ACE in 2008 published a final report on the status of internationalization within U.S. campuses called Mapping Internationalization on U.S. Campuses (Green, Luu, \& Burris, 2008). The final report, intended to examine current efforts in U.S. colleges and universities toward internationalization, was the result of three national surveys looking at topics such as faculty and students attitudes toward 
internationalization, institutional policies and practices, and differences on internationalization efforts among Community Colleges, Liberal Arts Colleges, Comprehensive Universities, and research Universities. Among the many significant conclusions of the report, the one that resonates for the purpose of this study is the still present contradiction between students and faculty attitudes toward internationalization and their actions and/or behaviors.

The report highlights that students are pro internationalization showing that " 68 percent of the students thought foreign language proficiency would be important. More than 80 percent thought that understanding other cultures and knowledge of international issues were important for job success" (Siaya \& Hayward, 2003, p. 8). Most importantly, $58 \%$ of the students state that it is the faculty's responsibility to

Help students become aware of other countries, cultures, or global issues. Students clearly looked to their institutions to provide opportunities to acquire these skills, as well as to the faculty to provide students with the international skills and knowledge they believed would be necessary for their careers. (Siaya \& Hayward, 2003, p. 9)

Unfortunately, the report also concludes that despite the students' favorable predisposition toward internationalization, international education is still seen as a value added commodity by many rather than an integral part of their undergraduate education (Siaya \& Hayward, 2003). Not surprisingly, this paradox is reflected on a mere $20 \%$ of students participating in on-campus extracurricular activities and a low participation on study abroad despite a $12 \%$ increase overall (Siaya \& Hayward, 2003).

Regarding faculty attitudes toward internationalization, the report pointed that $67 \%$ of the respondents agree with the statement that it is all faculty responsibility to provide students an international education (Siaya \& Hayward, 2003). However, it is 
worth noting that a low $36 \%$ of the faculty agree with the statement "the more time spent teaching students about other countries, cultures, and global issues, the less time is available for teaching the basics" (Siaya \& Hayward, 2003, p. 10), while $25 \%$ agree that "international education is useful but not a necessary component of undergraduate education" (Siaya \& Hayward, 2003, p. 10). Yet, $82 \%$ of the faculty favors requiring students to take courses covering international topics, and a $62 \%$ favors the idea of all students participating in study abroad (Siaya \& Hayward, 2003).

It serves of great value to higher education administrators to acknowledge the mixed attitudes faculty and students have toward internationalization. Attitude is defined as "a tendency or disposition to evaluate an object or symbol of that object in a certain way" (Katz \& Stotland, 1959, p. 428). The significance of this definition lies in the notion that attitudes are the result of constant evaluations of objects influenced by a given environment.

Attitudes serve to explain the consistency of individual behavior to an object or event (Oudhof \& Keuzenkamp, 2002). Comprehending the manner faculty and students perceive and respond to internationalization is key if internationalization is to be not only discussed but also lived in an institution. As faculty play several roles within the institution shaping the teaching, service, and research, HEIs concerned with internationalization of their institutions should pay close attention to their institution's current policies affecting hiring, promotion, tenure as well as curriculum (Johnston \& Edelstein, 1993) that unconsciously condition (for better or for worse) faculty's and students' attitudes and behaviors. 


\section{Study Abroad}

According to the latest Open Door report, the number of American students participating in study abroad is 223,534 , showing an increase of $8.5 \%$ from the previous year (IIE, 2009). This increase demonstrates that having an experience abroad is becoming to "students, parents, employers, the government and many others to prepare students to have jobs in a global market, become internationally informed citizens, and contribute to the (our) national security" (Hoffa, 2007, p. B16).

Similar to language proficiency and an internationalized curriculum, study abroad according to Koehn and Rosenau (2002), helps students to foster transnational competences by acquiring the following four competences:

Analytical competence- defined as the ability to link counterpart-country conditions to one's own circumstances and vice versa, emotional competence or the motivation and ability to open oneself up continuously to divergent cultural influences and experiences, creative/imaginative competence or the ability to envision viable mutually acceptable alternatives, and behavioral competence, described as communicative proficiency in and use of counterparts' language and functional adroitness (project/tasks) to develop and maintain positive interpersonal relationships. (p. 110)

Harari (1992), as well, elaborates on the significance of students' exchanges by saying: "exchanges serve to broader objectives of internationalizing the teaching learning-process, content and environment, and when properly orchestrated on the home campus or abroad, they become an integral component of the internationalization of the institution" (p. 69).

The Lincoln Commission in the U.S. Congress also acknowledges the relevancy of study abroad on the younger generations. The still pending approval bill from the Senate - the Paul Simon Study Abroad bill—notes "how critical it is to America's 
competitiveness and national security to provide more students with international students, and lays out the ambitious goal of sending 1 million students abroad each year" (Obst, Bhandari, \& Witherell, 2007, p. 5).

However, despite the growing interest and benefits of study abroad, HEIs face several challenges on this regard. First, there is a significant and consistent gender and ethnic difference in the percentage of students participating in study abroad. According to the 2007 Open Doors report, women constitute $65.5 \%$ of the student body compared to a $34.5 \%$ of men (IIE, 2009).

Also, when analyzing the ethnicity of students, Caucasians lead the list with an overwhelming $85 \%$ in contrast to an $8.8 \%$ for Asian/Pacific Islanders, a 5.4\% for Hispanic-Americans, and an even lower 3.5\% for African-Americans. These statistics demonstrate that despite the importance of study abroad, not all students are getting the benefit, and more diversity should be striven for in study abroad.

According to the IIE (2009) report, other significant factors to analyze when assessing the effectiveness of HEIs' internationalization efforts are the academic level, fields of study, and locations of study abroad. Study abroad occurs at the junior level, with $34.2 \%$ of students, against $19.8 \%$ at the senior level, and even lower at a master's $(4.8 \%)$ and doctoral level (0.4\%).

In regards to the fields of study, social sciences capture $21.7 \%$ of the U.S. student population; followed by business \& management with $17.7 \%$ and humanities with $14.2 \%$. Unfortunately, foreign languages reports only $7.8 \%$ of U.S. students (which correlates to 
students not taking advanced foreign languages courses), fine or applied arts with $7.5 \%$, physical or life sciences with $6.9 \%$, education with $4.1 \%$, and health sciences with $3.8 \%$ (IIE, 2009).

Finally, the location of U.S. students abroad continues overall to be Europe with 58.3\%, followed by Latin America with 15.2\%, Asia with 9.3\%, Africa with 3.8\%, and the Middle East with 1.2\% (IIE, 2009).

The significance of these statistics when analyzing them all together shows a dim picture of the internationalization of HEIs. Despite the explicit need to prepare students to understand other cultures, foreign languages, and non-Western countries, studies on those disciplines remain very low. In addition, argues Altbach (2004), “American-study abroad experience has become shorter on average — often a summer or even less — and many critics point to a decline in academic rigor in such programs" (p. 6-7).

\section{International Students}

According to the 2007 Open Doors Report, the number of international students in U.S. HEIs has "increased by 3.9 percent to a total of 63,749 in the $2006 / 07$ academic year from a 61,342 in the 2005/06 academic year" (IIE, 2009). This increase certainly brings good news, as international students are another significant element of internationalization.

International students bring several benefits to HEIs. First, a diverse international student body helps to promote cultural understanding between the foreign and local students. Christensen and Thielen (1983) state, “students' contributions can be organized to provide an intercultural component in the educational activities of the institution, both in its formal academic programs and in its outreach to the surrounding community" (p. 
210). This statement acknowledges that international students are valuable sources for not only bringing different perspectives into the classrooms, but also for promoting interaction within the community that fosters cultural sensitivity and tolerance.

Secondly, in a period where HEIs are facing deep budget cuts, international students provide another source of income. According to the 2007 Open Doors Report, students contribute approximately $\$ 14.5$ billion dollars to the U.S. economy, through their expenditure on tuition and living expenses (IIE, 2009). Given its economic contributions, HEIs must provide international students with an invaluable experiencenot only academically but also emotionally.

At the academic level, $17.8 \%$ of international students pursue business and management studies followed by a $15.3 \%$ in engineering (IIE, 2009), showing an important disparity among other disciplines such as humanities (including foreign languages and philosophy, among others) with a $2.8 \%$, mathematics and computer sciences with a $7.8 \%$, and social sciences, $8.4 \%$.

Consequently, HEIs receiving international students must ensure that their curriculum incorporates a multicultural pedagogical approach. Based on Hosftede' work, Otten (2000) reflects upon four situations of possible cultural conflicts for faculty to be aware when teaching: the different meaning of the relative social positions of lecturers and students in various cultures; the relevance of curriculum content; the profiles of cognitive abilities; and the expected patterns of student-lecturer and student-student interaction. "Sensitivity to cultural diversity at home requires reflection upon the implicit cultural patterns of the entire context of educational and social interaction" (p. 18). 
At the emotional level, HEIs should strive to decrease the students' cultural shock by providing social support for integration in the following levels:

1. Fundamentals daily needs (financial means, adequate accommodations and food, transportation),

2. Students learning to cope with institutional problems (climate at the institution and in classes...),

3. Demands specific to the content and curriculum of the study program (Otten, 2000, p. 17).

\section{Challenges in Internationalization}

Providing successful policies, support and implementation strategies toward internationalization require a deep understanding of the challenges or barriers that HEIs face.

At the context level, the forces of globalization cannot be ignored. As markets get smaller, interconnectivity intensifies, and job mobility increases, HEIs are under constant pressure to be more competitive. According to Ghosh (2004), "globalization [therefore] demands that education facilitate innovation in an economic web, which is a concept that implies interconnectedness and multi-level, multi-directional relationships. New business strategies and changing communications technology make global teams imperative for survival in global competition" (p. 94).

The continuous drive of HEIs to remain competitive and attract students enhances the tendency to engage in a short-term vision and quick fixes of internationalization rather than developing a systemic approach (Mestenhauser, 2002). As HEIs strive to keep 
up with globalization, the lack of a long-term institutional view of internationalization indirectly maintains the gap between the rhetoric and reality of internationalization.

Secondly, the "distorted view about the converging "effect" of globalization [that] gives many the idea that cultural differences no longer matter" (Mestenhauser, 2000, p, 205). According to Ghosh (2004), the expansion of capitalism, and the movement of products and services across national borders facilitate the development of an "ideology of consumerism across the globe, which has resulted in the globalization of culture" ( $p$. 88). Ghosh (2004) goes on saying that this global culture has been possible through the use of the technological advancements in information systems and global marketing efforts favoring the "transmission of a homogenous consumer culture" (p. 88).

However, Ghosh (2004) explains that while consumer homogenization is possible, the fusion of cultures at the consumer level does not translate to a cultural homogenization as "it emphasizes identity because individuals see the world from their own perspectives and have multiple identities, some of which may be contradictory" ( $p$. $95)$.

Mestenhauser (2002) also warns HEIs against reinforcing the perception that the emergence of a consumer homogeneous culture will lead to a global culture diminishing the importance of national identities, and the need to understand others' languages, values, and beliefs. This barrier, as Mestenhauser (2002) expands represent a "lack of sophistication and conceptualization about making comparative judgments regarding what is similar, what is different, and what is "mixed" (p. 206).

Green (n.d.), talks about institutional and individual barriers to internationalization within HEIs. Institutional barriers are present in the form of "scarce 
resources, disciplinary paradigms, structures, or the absence of incentives" (p. 1). At the individual level, Green (n.d) lists as barriers "lack of faculty interest, negative attitudes, or the unwillingness or inability of faculty to integrate international learning into their disciplinary perspectives" (p. 1).

Mestenhauser (2002) expands on Green's barriers particularly focusing on disciplinary paradigms. In his work, he states that the fragmentation of knowledge by different disciplines continues the disconnection of knowledge rather than promoting an integrative and interdisciplinary thinking and knowledge.

Ellingboe (1996) discusses as two major barriers to internationalization academic ethnocentrism and conservatism. Ethnocentrism has been defined as the "cultural blinder that limits what we see and how we interpret it" (as cited in Mestenhauser, 2002, p. 172). For Ellingboe academic ethnocentrism is manifested in the curriculum by the lack of inclusion of foreign academic works and perceptions on how other nations see the U.S. (Mestenhauser, 2002).

Ellingboe's second barrier, conservative mindset, focuses on the area of change. Conservative mindsets, as Ellingboe's describes them, are reluctant to change and support the status quo "on the grounds that the present is an extension of the past, that things are satisfactory the way they are, that problems are self-correcting ad that changes are not needed" (Mestenhauser, 2002, p. 173). Both ethnocentrism and a conservative mindset not only has a direct impact on the way students think and see the world, but also negates the richness of other culture perpetuating the Us versus Them dialogue.

HEI s' autonomous and fragmented structures also fail to promote a systemic view of the internationalization process. The disconnection between the different 
university's units (such as departments, schools and activities across the institution) reinforces the current position of isolated parts working for their goals rather than the whole. Green elaborates by saying: "different reporting structures and different goals may isolate the different activities so that there is no little synergy among them" (p. 16). An effective internationalization process is as van de Wende (1999) explains one that facilitates the "integration, acceptance, and application of the international dimension throughout the institution in its different units and functions" (p. 9).

Internationalization as a systemic process of transformation requires that not only a deeper understanding of the components of internationalization, but also a change in the university's stakeholders' assumptions, values, and practices from a myopic, ethnocentric focus to an international perspective (Ellingboe, 1999, Knight, 1994, Shoorman, 1997).

Unfortunately, HEIs are deficient in understanding how to bring about change and reform within and across the different stakeholders. Mestenhauser (1998) notes, "the perspective about education reform that appear to be most lacking are knowledge about change, knowledge about identification of problems that need to be addressed, knowledge about strategies to affect the desired change without too much cost and bureaucracy, and knowledge about the future consequences of decisions" (p. 22).

Understanding the role the different stakeholders (such as president, administration, faculty, etc) play, as well as the current policy, support, and implementation efforts is key in not only removing some of the barriers of the internationalization process, but also managing the university wide internationalization process effectively. 


\section{Models of Internationalization}

Acknowledging the systematic nature of internationalization, the following six different organizational models present a descriptive and prescriptive methodological and analytical tool to assess and promote the institutionalization of internationalization.

The first model by Neave's (1992) is a paradigmatic model for servicing and administering international cooperation. Neave's model was based on the analysis of global cases written for the UNESCO. Two paradigmatic models, one "leadership driven" and the second one "base unit driven" describe Neave's model. Neave's model main feature is the "lack of formal connection below the level of the central administration, while the second model sees such central administrative units mainly as service oriented to activities coming from below" (de wit, 2002, p. 126). It is inherent in Neave's model, therefore, that a difference exists between the centralized and decentralized models of internationalization.

In addition, Neave classifies them as managerial rational versus the academic consensual models. For Neave (1992), these two models are "as opposite ends of a species of continuum, where structures administering international co-operation which mould around one paradigm may in certain specific conditions, move toward the opposite end of the continuum" (p. 166). He continues saying, "the administrative structures of international co-operation (should be) continually provisional"'(p.168). To facilitate the analysis, Neave combines the leadership and base unit model for administration in a matrix with definitional and elaborative scopes of institutional strategy (Neave, 1992).

Rudzki criticized Neave's model due to its lack of practical application and selfevidence. As a result, Rudzki presented his own model for internationalization. Rudzki's 
model (1998) looks at internationalization through four main components: mobility, staff dimension, curriculum innovation, and organizational change. In addition, Rudzki proposes that internationalization can take place in a continuum that ranges from a proactive to a reactive model to internationalization (Rudzki, 2000).

The reactive model presents five stages:

Stage 1. Contact: Academic staff engages in contacts with colleagues in other countries; curriculum development; limited mobility; links lack clear formulation of purpose and duration.

Stage 2. Formalization: Some links are formalized with institutional agreements. Resources may or may not be available.

Stage 3. Central control: Growth in activity and response by management who seek to gain control.

Stage 4. Conflict: Organizational conflict between staff and management leads to withdrawing of good will by staff. Possible decline in activity and disenchantment.

Stage 5. Maturity or decline: Possible move to a more coherent, that is, proactive approach.

The proactive model presents the following stages:

Stage 1. Analysis: Awareness of what internationalization is and what entails. Strategic analysis of short-, mid-, and long-term organizational objectives, answering the question "Should we internationalize?" and "Why bother", staff training and discussionsunderstanding of options- what types of international activities are available, International audit of existing activities and staff audit, SWOT analysis. Cost-benefit analysis. 
Stage 2. Choice: Strategic plan and policy drawn up in conjunction with staff and explicit use made of mutual interest of staff and organization. Performance measures defined. Resources allocated. Networking with internal and external organizations.

Stage 3. Implementation: Measure performance.

Stage 4. Review: Assessment of performance against policy and plan.

Stage 5. Redefinition of Objectives-Plan-Policy: Process of continual improvement and the issues of quality this entails. Return to stage 1 in cycle of growth and development.

Rudzki (1995b) applied these two models to analyze the internationalization of business schools in the United Kingdom. From his study, Rudzki (1995b) concludes, "that the spectrum of activity ranges from those business schools who have positioned themselves on the global stage and are committed to internationalization, to one institution which has taken a strategic decision not to engage in international activity"( $p$. 25).

Rudzki (1998) revised his model later into what he called the fractal process model of internationalization. In the revised version, Rudzki adds a hierarchical assessment of the "Context" (referring to the external environment), the "Approach" (referring to the culture and history of the institution), and the "Rationale" (De wit, 2002), followed later by the analysis of the four actions /dimensions international activities, monitoring and periodic review, and finally adjust and reconceptualisation. According to Rudzki (2000),”this six stage process model allows individuals as well as institutions to undertake an analysis of the actions and issues that must be addressed, and to perform that analysis in the correct sequence" (p. 81). 
Rudzki's model presents some shortcomings. First, the distinction made between context and approach. The internal organizational characteristics that define the approach level could be included in the context, having then an internal and external context (de Witt, 2002). Secondly, the hierarchical order used implies that the approach (organizational culture and history) is less important than the external environment when making strategic decisions.

Finally, according to de Wit (2002), the selection of the four dimension of internationalization can be questioned. First, the model uses the generic variable such as organizational change together with three more concrete activities, and finally, "because of his subjective choice of the three activities, curriculum development, staff development, and student mobility, excludes other program strategies or place them under organizational change" (de Wit, 2002, p. 128).

The next organizational model, Davies (1992), centers his model "on the need for universities to develop a framework for their internal activities in response to changes in the external environment" (de Wit, 2002, p. 129). Davies designs his model based on G. Keller's (1983) work Academic Strategy. Keller's well known work presents a strategic planning chart for HEIs (see Appendix A) listing two factors and six elements for the development of strategies - three related to the external factor and three to the internal aspect of the institutions (Keller, 1983).

Davies' model (1992), prescriptive in nature states: “A university espousing internationalism should have clear statements of where it stands in this respect, as its mission should influence planning processes and agendas and resource-allocation criteria, 
serve as a rallying standard internally and indicate to external constituencies a basic and stable set of beliefs and values" (p.178).

As a result, Davies conceptual framework facilitates the analyses of the internationalization process through two dimensions: organizational policies (defined as the importance attached to internationalization aims) and organizational design (defined as explicit procedures and systematic manner international activities are managed). According to Davies (1992), organizational design can be assessed within a spectrum of Ad -hoc (sporadic, irregular, no procedures in place) or systematic (intensive involvement in international activities with structures in place), while policy can be considered marginal or integral to the university's policies, creating another spectrum from marginality to centrality.

These two dimensions can be "combined in a matrix and universities may place themselves in one or other of the four quadrants" (Davies, 1992, p. 188). These quadrants are (see Appendix B): (a) Quadrant A - Ad-hoc- Marginal: International efforts within the university are very small, sporadic and marginal to the university policies. (b) Quadrant B - Systematic-Marginal - International efforts are still small but institutions show some organizational structures. Some relative level of strategic planning took place. Staff training is available but limited. (c) Quadrant C - Ad-hoc Central - The amount of international efforts are seen across a number of different categories and a wide range of market segments and client groups. Acceptance of projects is based on "knee-jerked basis and support services are often not geared toward international effort, and ground rules change rapidly" (Davies, 1992, p. 188). (d) Quadrant D - Central- Systematic Universities present a large volume of international activities, which reinforce each other 
and have intellectual coherent. The "international mission is explicit and followed through with specific policies and supporting procedures" (Davies, 1992, p. 188).

The fourth model by van Dijk and Meijer (1993) came out as a result of a study on internationalization carried out in the Netherlands. The study intended to further the understanding of the internationalization process in higher education institutions. Following their analysis, van Dijk and Meijer decided to expand Davies' model by adding a support dimension (referring to type of support available for international activities). As a result, van Dijk and Meijer (1997) Internationalization Cube presents the following three dimensions and specific level associated with each dimension: Policy can be either Priority or Marginal, Support - either Interactive (support provided with interaction between central, faculty, and departmental levels) or Unilateral/One-sided (support provided at the central or peripheral level), and Implementation - either Structural/Systematic or Ad hoc.

This model has eight cells (see Appendix C) and institutions can be positioned "in one of the cells of the cube produced by this three dimensional model... The model is not intended to be normative. It seeks to help in explaining the development of internationalization where there is an active international strategy" (van Dijk and Meijer, 1997, p. 159).

According to the van Dijk and Meijer's model, three different routes are identified for HEIs to achieve internationalization (de Wit, 2002, p. 133):

Route 1-2-6-8, indicating a thoughtful approach and a well-structured organizational culture, defined by them as "slow starters." 
Route 1-5-6-8, indicating strong international commitment and an organized institutional culture, defined as "organized leaders."

Route 1-5-7-8, indicating a quick response to external developments, a great variety of activities at different levels, and much commitment, which is only at a later stage organized in a more systematic way, defined as "entrepreneurial institutions."

The remaining two models of internationalization, van der Wende (1996) and Knight (1994) differ from the previous models as they adopt a process approach (rather than organizational) to strategizing and assessing the output internationalization.

Van der Wende's (1996) model recognizes three important factors for internationalization. The first factor is the goals and strategies toward internationalization (as defined by the university itself and other (inter) national policies). The second factor corresponds to the Implementation of the goals and strategies in three particular areas: student mobility, staff mobility, and curriculum development (van der Wende, 1996). The last factor to consider is the effects of the implementation phase. Within this phase, the model analyses the short term effects on student mobility, staff mobility, and curriculum development, and the long term effects on the quality of education, output, and the position of the institution (van der Wende, 1996).

According to van der Wende herself, her model presents two limitations. First, van der Wende's model focuses only on three specific international educational activities leaving out other significant indicators of internationalization. Secondly, van der Wende recognizes that her description of motives is too narrow as it only uses formal policy documents (de Wit, 2002). 
The final process model designed by Knight describes internationalization as a cyclical -continuous cycle rather than linear. Knight's (1994) Internationalization Cycle presents internationalization as the results of six sequence- two-way-flow steps encircled by a supportive culture that integrates internationalization. According to Knight (1994), "the proposed cycle has six phases which colleges and universities would move through at its own pace" (p. 12).

The six phases are (Knight, 1994): (a) Awareness (of the need, purpose, and benefit of internationalization for staff, students, faculty, and society), (b) Commitment (by senior administration, Board of Governors, faculty, staff, and students), (c) Planning (identify needs and resources; purpose and objectives; priorities; strategies), (d) Operationalize (academics activities and services; organizational factors; use guiding principles), (e) Review (assess and enhance quality and impact of initiatives and process of strategy), (f) Reinforcement (develop incentives, recognition and rewards for faculty, staff and students participation).

Knight's Internationalization Circle can be questioned on several aspects. First, due to its lack of explicit attention to the external environment, the model fails to acknowledge that the external environment influences HEIs, shaping its responses and forcing HEIs to adapt and change. Secondly, the emphasis on the six steps mentioned above, overlooks the existent link and power among the different departments and schools in an institution.

Due to their models deficiencies, Knight and van der Wende develop a modified model version unifying both models. The new nine steps model includes van der Wende's three steps - analysis of the environment as first step, an implementation 
analysis, and an integration effect-, and Knight's six steps. The new model, though, still focuses on a process view of internationalization, incorporates an analysis "in all the phases of the institution, both the institutional and the specific departmental aspects..., as well as the link between them" (de Wit, 2002, p, 137).

\section{System Theory and Organization Change}

Derived from Bertalanffy's General System Theory (GST), systems theory (Katz \& Kahn, 1978) describes higher education institutions as an organizational system, entailing "a flagrantly open system in that the input of energies and the conversion of output into further energic input consist of transactions between the organization and its environment” (Katz \& Kahn, 1978, p.16). Serge (1990) provides another definition of system theory as:

System thinking is a discipline for seeing wholes. It is a framework for seeing interrelationships rather than things, for seeing patterns of change rather that static 'snapshots.' It is a set of principles ...It is a set of specific tools and techniques... that have been applied to understand a wide range of ...systems.... (pp. 68-69)

HEIs, as an open system, present the following characteristics:

1) being nested within a larger system; 2) importing, transforming, and exporting energy (inputs, transformation, and outputs) with their environments to avoid decay (negative entropy); 3) given to reach a certain state (homeostasis) by a number of paths equifinality); 4) having complex feedback and regulatory mechanisms that permit adaptive responses to changes in their environment; and 5) social activities are viewed as patterned cycles of events rather than the behaviors of individuals actors. (Zammuto, 1982, p. 34)

Applying system theory to the internationalization of HEIs has several benefits.

First, system theory takes into account the different subparts of the system. Secondly, system theory sees HEIs as adaptive systems, in which growth occurs as a result of the interaction between the external environment and the system's subparts parts, or among 
the subparts themselves. Third, since internationalization of HEIs requires an integration of an international intercultural dimension into the teaching (learning), research and service functions of the institution, change needs to occur at the three levels for it to be effective. Finally, systems theory's emphasis on understanding how the sub-parts relate recognizes four ways how interrelationships occurs (Mestenhauser 2002):

1. Correlational - when changes in one element causes change in another, e.g. new laws, dynamics of local politics,

2. Parts are related by changes caused by a third element (e.g. emergence of competitiveness),

3. Chain relationships (parts of elements are parts of other systems, e.g., uneasy relationship between international and multicultural education),

4. Networks of chains of complex relationships (e.g., emergence of technology in instruction, terrorism), Failing to establish relationship by these criteria.

Based on previous research on system theory and international education from Easton 1965; Gardner 1983; Littlejohn 1996; and Senge 1990, Mestenhauser (2002) develop a comprehensive conceptualization framework for understanding the systemic nature of international education. According to Mestenhauser (2002), the system approach presents five interrelated variables and seven domains. The five variables are:

1. Stakeholders and constituents; individuals (e.g. students, teachers), or institutions (e.g. employers, governments, or foundations).

2. Scope of international education, e.g. single county, cross-national research, region of the world, global perspective, inclusion of one own's country; what 
do we add to make it international education- perspective about knowledge, learning and teaching.

3. Education - learning and teaching.

4. Context in which international education functions, and

5. Meta-knowledge about knowledge of international education; the character of the field and its culture (p. 174).

The seven domains that interact with the variables are: (a) international studies/relations; (b) area studies; (c) foreign languages, (d) international dimensions of academic disciplines; (e) educational exchanges of students and scholars; (f) development contracts and inter-university agreements; (g) organization, administration, policy, governance, and financing (Mestenhauser, 2002, p. 174).

The system approach underlines the notion that any change in the five variables will produce change in any of the seven learning domains as "any international project in the seven domains has connections to each of the five perspectives. Even if we do not see them, they may exist; we may just not be familiar with the multiple concepts on which practices are based. Our ignorance is a symptom of the knowledge gap" (Mestenhauser, 2002, p. 175).

HEIs, as open-systems, are adaptive in nature. They adapt their behavior according to changes in their environment or in parts of the system itself. These changes occur in cyclical manner in which changes in some parts of the system will eventually lead to a change of the whole. Due to the interdisciplinary and interrelated nature of the internationalization process, change within HEIs is inevitable. 
According to Redwood, Goldwasser, and Street (1995), change is defined as "any consciously directed project or initiative that seeks to improve business (institutional performance)" (p. 5). Hanson (1979) expands stating "change is reflected only when a pattern of events is repeated systematically" (p. 151); otherwise, no change will happen and the patterns of events will return to its original manner.

Walker, Armenakis, and Bernerth (2007) carried out a study on organizational change by looking at the integrative nature of four common factors of change: content (referring to the manner change is introduced either fundamental or episodic), context (referring to the external and internal environment), process (dealing with the actions taken during the introduction or implementation period), and individual differences.

Their study shows that for change to be successful, management should plan change with the four factors in mind (Walker, Armenakis, and Bernerth, 2007). Specifically, the study demonstrates that "individuals' tolerance for ambiguity will be negatively related to cynicism, cynicisms will be negatively related to change beliefs, and change beliefs will be positively related to affective commitment" (Walker, Armenakis, and Bernerth, 2007, p. 769).

Kimberly and Neilsen (1975) in their study on organizational development and change in organizational performance suggest three different orders of organizational change within larger systems such as HEIs. The first-order change concerns changes within a particular individual subpart that do not influence the whole system. The secondorder change involves a category or process in particular sets of subsystems. The change at this level is associated with procedural changes. 
The final third-order of change affects some organizational processes affected by multiple organizational factors (Burke, 2002, p. 106). The change at this level is characterized by a chain of changes (from one unit to another) that ultimate leads to systemic change guided by an organizational goal. Furthermore, a systemic change of third-order will affect the organization's ethos (norms and values).

Hence, for a systemic change on internationalization to come about within HEIs, a third order change needs to take place within the organizations' subsystems, such as the university's mission and strategies, departments, administrators, faculty, programs, classrooms, or students (Hanson, 1979). Chafee and Tierney (1998) forewarn in this regard that how people perceive the organization and its environment deserves far more attention that often receives"(p. 182). It is difficult that a systemic change will occur without some modification on the institution's image and culture (Burriss 2006).

The ACE report On Change V Riding the Waves of Change: Insights from Transforming Institutions (Eckel, P., Green, M., and Hill, B, 2001) refers to a third-order change as a transformation with significant university-wide changes. The ACE report defines transformation as: (a) alters the culture of the institution by underlying assumptions and overt institutional behaviors, processes, and structures; (b) is deep and pervasive, affecting the whole institution; (c) is intentional, and (d) occurs over time (p. $5)$.

For the internationalization process to be learn, lived, and assimilated by all university's stakeholders, attention to the internationalization process and aims must be raised, communication and dissemination must be done at all level in a consistent 
manner throughout the institution, and lastly but not least information should be clear and easy to comprehend highlighting the benefits of internationalization.

\section{Theoretical Model Analysis}

The present study uses Van Dijk and Meijer's Internationalization Cube as the model for internationalization of HEIs to assess their organizational efforts (through their policy, support, and implementation dimensions) on internationalization. Van Dijk and Meijer's three dimensional internationalization cube was selected for several reasons: First, the study is based on Burriss' (2006) work that used it on her study of three HEIs members of a university consortium. By applying the theoretical model, the study seeks to enhance the link between theory and practice.

Secondly, the organizational frameworks of Neave, Rudzki, Davies, and van Dijk and Meijer described above "complement one another in their prescriptive and descriptive aspects. They offer a means of measuring the formal, paper commitment of institutions against the proactive to be found in concrete operating structures"(de Wit, 2002, p. 133). These models convey an organizational approach to the internationalization process of HEIs relevant to the purpose of the study. However, van Dijk and Meijer's model (together with Davies) gives a more in depth picture of the internationalization efforts within and across the institution by focusing on its policy, support, and implementation dimensions.

The model's three dimensions embodies the organizational framework of analysis (such as the governance, operations, services, and human resources) not only described 
by advocates such as Knight (2004), De Wit (2002), and Mestenhauser (2002), but also reinforces the complexity and interrelations of processes that constitute the universitywide internationalization efforts.

In addition, it is important to acknowledge that van Dijk and Meijer's model comes from two sound theoretical foundations on academic strategy. First, as already noted, one of van Dijk and Meijer's model pillars comes from Davies' (1995) model for internationalization. According to Davies (1992), "the considerable expansion of international activities in universities over the last decade is a phenomenon closely linked with financial reductions, the rise of academic entrepreneurialism, and a genuine philosophical commitment to close cultural perspectives in the advancement and dissemination of knowledge" (p. 177).

Finally, Keller's (1983) work Academic Strategy: The Management Revolution in American Higher Education significantly influenced Davies' model. Keller's work introduces the concept of applying strategic management thinking to academics. For Keller, an academic strategy is the result of the analysis and interaction of internal and external factors. Keller (1983) describes internal factors as a university's values and traditions, its strengths and weakness, and the leadership capabilities, whereas the external factors as the environmental trends, market directions, and the institutions' opportunities and threats.

Van Dijk and Meijer's (1997) internationalization cube with its three dimensions of analysis (policy, support, and implementation) takes into account Keller's internal and external factors, though less emphasis is put on the external forces influencing the university. 
However, this lesser emphasizes on external factors can be considered a deficiency, as it assumes that such factors are already manifested in the universities' current policies, support, and implementation dimensions. A second shortcoming of the model can be described as the lack of attention to faculty and students attitudes toward internationalization. As significant stakeholders, an intertwine relationship exists among faculty, students and the degree of internationalization. By adding students and faculty attitudes, the exploratory characteristics of the model are advanced while providing a more substantive and representative appraisal of an institution's internationalization process.

In summary, Van Dijk and Meijer's internationalization cube serve as a preliminary assessment model to guide the understanding of where on the internationalization cube HEIs find themselves, and allows for the development or enhancement of an academic strategy toward internationalization.

\section{Summary}

This chapter presented a selected and relevant literature on internationalization. The chapter began with the different definitions of internationalization and its rationales. A brief history of internationalization set the context for its on and off nature in the American education agenda.

This chapter also introduced the key elements for internationalization within HEIs, looking in particular to an internationalized curriculum and faculty body, foreign students and study abroad, as well as the existent organizational models of internationalization. Finally, it demonstrated the relevancy of describing the internationalization efforts within a system theory and change theory framework. 


\section{CHAPTER III}

\section{METHODS}

The purpose of this research was to provide an analysis of Florida International University's (FIU) internationalization process. Specifically, the evaluation was done through the application of the internationalization cube allowing FIU to determine its position on the internationalization cube, and how its international activities and students and faculty attitudes fit into its different teaching, learning, research, and service functions (Knight, 2003). The International Dimension Index (IDI) and the results of faculty and student attitudinal surveys toward internationalization served as separate frameworks for analyzing FIU's internationalization process.

This chapter describes the methods intended to answer the research questions. The chapter includes research questions, sampling procedures, variables, research design, instrumentation, procedures, limitations, delimitations, and statistical analysis.

\section{Research Questions}

The following research questions comprised the core of the study:

1. What is Florida International University's (FIU's) position on the Van Dijk and Meijer's Internationalization Cube (1997)?

2. To what extent is FIU's position on the Van Dijk and Meijer's Internationalization Cube (1997) aligned to the International Dimension Index (IDI) results on internationalization?

3. How do FIU student and faculty attitudes toward internationalization compare on the General Attitudes, Support, and Benefits survey scales? 


\section{Hypotheses}

The following represents the alternative hypotheses tested in this study:

1. Given FIU's historical and environmental context, FIU is positioned in quadrant 7 of the Van Dijk and Meijer Internationalization Cube (1997).

2. FIU's position on the internationalization cube is aligned to the IDI results of internationalization.

3. There is a relationship between student and faculty attitudes (or vice versa) toward internationalization on the General Attitudes, Support, and Benefits survey scales at FIU.

\section{Research Design}

Johnson and Christensen (2004) define research design as the outline, plan or strategy guiding the answering of a research question. In other words, the research design presents the framework for gathering and analyzing data linking it to the research question. For Conrad and Serlin (2006) design "is concerned with the assumptions underlying the manner in which the study is constructed to pursue inquiry about the phenomenon....and determines whether the research question can be answered adequately through the manner in which the data was collected" (p. 377).

The current study drew on a case study methodology. As defined by Merriam (1988), "a case study is an intensive, holistic description and analysis of a single entity, phenomenon or social unit” (p. 16). MacDonald and Walker (1977) define a case study as "an examination of an instance in action" (p. 181). Becker (1968) defines the purpose of a case study as "to arrive at a comprehensive understanding of the groups under study" and "to develop general theoretical statements about regularities in social structure and 
process" (p. 233). All these definitions illustrate the main qualities of a case study which are the exploration and description of a particular group or entity at given time.

Merrian (1998) elaborates by stating that "a case study design is employed to gain an in-depth understanding of the situation and meaning for those involved. The interest is in the process rather than in the outcome, in context rather than a specific variable, in discovery rather than confirmation" (p. 19). Maxwell (1996) expands by saying that "the strength of a qualitative research method is in understanding the process by which phenomena take place" (p. 59).

Briggs and Coleman (2007) go a step further and provide a definition for an educational case study. For Briggs and Coleman (2007), an educational case study is "a critical inquiry aimed at informing educational judgments and decisions in order to improve educational action" (p. 142). Therefore, as an empirical inquiry, the educational research presents the following characteristics: (a) it is conducted within a localized space and time, (b) looks into an interesting aspect of an educational activity, program, institution or organization, and (c) it is analyzed within its natural context and within an ethic of respect for persons (Briggs \& Coleman, 2007, p. 143).

Given the holistic description of the study, a mixed methods case study design was used. Mixed methods can be defined as the combination of qualitative and quantitative research techniques, methods, or approaches in a study (Johnson \& Onwuengbuzie, 2004). The benefits of using such an approach lies in "its logic of inquiry (that) includes the use of induction (or discovery of patterns), deduction (testing of theories and hypotheses), and abduction (uncovering and relying on the best of a set of explanations for understanding one's results" (Johnson \& Onwuengbuzie, 2004, p. 17). 
Caracelli and Greene (1993) list five purposes of mixed methods designs, one being a complementarity purpose. Mixed methods with a complementarity purpose use quantitative and qualitative methods to measure "overlapping, but distinct facets of the phenomenon under investigation. Results from one method type are intended to enhance, illustrate, or clarify results from the other" (p. 196).

By using this method, the study sought to provide a deeper understanding and a snapshot of FIU's international activities as well as faculty and student attitudes toward internationalization within its particular organizational context and interactions (policy, support, and implementation dimension). As a result, FIU's internationalization process served as the main unit of analysis. This case study design allowed assessing and describing the unit of analysis in depth. Yin (1994) elaborates on this by stating that "each unit of analysis would call for a slightly different research design and data collection strategy" (p. 23). Van Dijk \& Meijer's (1997) internationalization cube's three dimensions - policy, support, implementation dimensions-, FIU's results on international activities, and the student and faculty attitudes and perceptions served as the units of observation (units on which data was collected and analyzed).

\section{Variables}

The qualitative aspect of the study looked at the internationalization process through the categorical variables of the internationalization cube: (a) policy, (b) support, and (c) implementation dimensions. As defined by Johnson and Christensen (2004), a categorical variable is a "variable that is made up of different types or categories of a phenomenon" (p. 36). In this study, each categorical variable presented the following 
dichotomous characteristics: policy - priority or marginal; support - interactive or onesided; implementation - structured or ad-hoc.

The quantitative aspect of the study looked at: (a) the International Dimension Index (IDI) items, and (b) the student and faculty attitudes toward internationalization as the dependent variable.

The faculty and student perceptions dependent variables were divided into four categories: (a) general attitudes about internationalization, (b) support for internationalization, (c) perceived benefits of internationalization, and (d) participation in international activities, such as study abroad, offshore programs, and co-curriculum. The independent variables were the faculty and students' demographic characteristics.

\section{Case Study: Florida International University}

The study was conducted at Florida International University (FIU). Due to the nature of the case study, a purposeful sampling strategy was used to select FIU. According to Patton (2002), a "purposeful sampling focuses on selecting information rich-cases whose study will illuminate the questions under study" (p. 230).

Bogdan and Biklen (1982) elaborate on purposeful sampling stating that "you choose particular subjects to include because they are believed to facilitate the expansion of the developing theory. This is not random sampling; that is, sampling to insure that the characteristics of the subjects in your study appear in the same proportion they appear in the total population" (p. 67). Miles and Huberman (1994) add that sampling in qualitative research is guided by the conceptual question of the study and not the need for "representativeness". 
Florida International University was established in 1965 welcoming the first 5,667 students in 1972 , and though a young university, it already ranks as a Research University in the High Research Activity category of the Carnegie Foundation classification system. FIU is a large, state supported urban, multicultural, and multicampus university.

With an operating budget of $\$ 643.3$ million for the 2008-2009 academic year, the university serves more than 40,000 students, 1,000 full-time faculty, and over 124,000 alumni. In addition, FIU offers nearly 200 bachelor's, master's, and doctoral programs in 21 colleges and schools (FIU, 2009), and a recently opened much desired medical school. FIU constitutes a rich-case to study for the following reasons:

First, FIU's three founding purposes are: provide a valuable education to students, provide service to the local community, and promote international understanding as described by the Florida Statute establishing the "business of FIU" (Florida Department of State, 1976). As a result, its name carries the international word reinforcing not only FIU's mission statement, as a university serving not only the local but also the international community, but also its purpose of providing a "Greater International Understanding - to become a major international education center with a primary emphasis on creating greater mutual understanding among the Americas and throughout the world" (Florida Department of State, 1976).

Second, it is part of FIU's Institutional Goals to prepare students to "understand their culture and cultures of others and appreciate the complexities and diversity of our global society" (FIU, n.d., p. 16), as well as attain national and international recognition through research promoting life-long learning. 
Third, within its Millennium Strategic Plan FIU identifies an International Theme with the goal to respond to its mission by "promoting international understanding by appointing faculty who have professional expertise in fields that are international in content and application and who have professional experience abroad as well as by encouraging our students to pursue a bilingual/biliterate competency and study abroad experience" (FIU, n.d., p. 12).

Fourth, as part of FIU's reaccreditation process, the university selected Global Learning for Global Citizenship as its Quality Enhancement Plan (QEP). The Global Learning for Global Citizenship QEP goal is to educate all FIU undergraduate students for global citizenship through the curriculum and co-curriculum. The selection of the this theme reinforces not only FIU's purpose of promoting international learning but also its commitment to serving its community by providing a relevant education to all students focused on developing international/global citizens.

Fifth, FIU displays an active approach on internationalization at home and abroad. FIU's variety of offerings of programs abroad and exchanges, areas of study centers, and programs with international focus exemplify FIU's internationalization efforts at home. Examples of FIU's internationalization abroad undertakings include its engagement in several offshore (transnational) programs, the opening of FIU's Center for Education, Research and Development in Madrid, Spain, as well as its offshore campus in China.

Finally, for FIU's, geography is destiny. As an urban and fast growing university located in Miami, Florida, FIU is the largest Hispanic serving university in the U.S., and attracts foreign students from all over the world, hosting in the 2007-2008 academic year 
2,882 foreign students enhancing FIU's campus internationalization. Other considerations in the purposeful selection of FIU are the researcher's knowledge of FIU and access to FIU data.

\section{Case Study Validity and Reliability}

According to Merriam (1998), "assessing the validity and reliability of a qualitative study involves examining its component parts, as you might in other types of research" (p. 199). Guba and Lincoln (1981) state that assessing validity and reliability for a qualitative study is not that different from a quantitative one. According to Guba and Lincoln (1981),

In experimental study you can talk about the validity and reliability of the instrumentation, the appropriateness of the data analysis techniques, the degree upon which they presumably rest, and so on... in a qualitative study were the interviews reliably and validly constructed, was the content of the documents properly analyzed; do the conclusions of the case study rest upon data? (p. 378)

Merriam (1998) explains that validity and reliability of any type of research "can be approached through careful attention to a study's conceptualization and the way in which the data were collected, analyzed and interpreted" (p. 200). Yin (1994) elaborates stating that special consideration to construct validity, internal validity, external validity, and reliability serves to achieve reliability and validity in qualitative studies. A description of each of them for the study follows:

\section{Construct Validity}

According to Gall, Gall, and Borg (2003), construct validity "is the extent to which a measure used in a case study correctly operationalizes the concepts being studied" (p. 460). In the present study, the concept being measured was the phenomenon of internationalization of a higher education institution (Burriss, 2006), particularly the 
case of Florida International University. The phenomenon of internationalization has been operationalized in three ways:

1. Through the description and quantifying results of FIU's international activities presented in the format of the international dimension index.

2. Though the application of the Internationalization Cube developed by Van Dijk and Meijer (1997). This organizational model utilized in the study permits to operationalize and measure the internationalization process through its policy, support, and implementation dimensions.

3. Through the analysis of FIU's students and faculty attitudes survey results toward internationalization.

\section{External Validity}

Merriam (1998) defines external validity as the "extent to which the findings of the study can be applied to other situations" (207). Erickson (1986) notes that creating generalizable knowledge is an "inappropriate goal for interpretative research... The search is not for abstract universals arrived at by statistical generalizations from a sample to a population, but for concrete universals arrived at by studying a specific case study in great details and then comparing it with other cases studied in equally great detail” ( $\mathrm{p}$. 130).

Merriam (1998) explains that the reason for engaging in a qualitative case study is "because the researcher wishes to understand the particular in depth, not to find out what is generally true of many" (p. 208). Qualitative researchers such as Wilson (1979), Lincoln and Guba (1985), and Merriam $(1988,1998)$ emphasize that generalizability should be left to the reader and what he or she is trying to learn from it. 
The following strategy was used in the current study to enhance the external validity as recommended by Merriam $(1988,1998)$ : Provide a rich and thick description of the internationalization process, research design, analysis process, and findings with conclusions so other readers interested in making a judgment or transferring the findings have complete information, establishing FIU as an interesting case to study so comparisons can take place.

\section{Internal Validity}

Merriam (1998) refers to internal validity as the extent to which the research findings match the reality of the phenomenon being studied. Since the researcher is the "primary instrument of data collection and analysis in qualitative studies" (Merriam, 1998, p. 203), the utilization of multiple sources of data collection and analysis will facilitate enhancing internal validity of the case conclusions through the confirmation of emerging data. The current research study was designed to include multiple sources of data collection such as document analysis, interviews, institutional reporting, and surveys. Furthermore, as recommended by Maxwell (2005), the following strategies to safeguard the internal validity were applied: verbatim transcripts from interviews as well as respondent validation. These strategies assisted the researcher to capture the interviewee's responses accurately.

In addition, Merriam (1998) also recommends that the researcher acknowledge their biases and assumptions "at the outset of the study" (p. 205). The researcher's assumptions for the case study have been stated in Chapter 1. Finally, the researcher's biases lie in the pre-determined knowledge of and beliefs in the internationalization 
process at FIU. To counter balance the researcher's biases the strategies described above were followed.

\section{Reliability}

Reliability refers to the extent to which one's study can be replicated (Merriam, $1988)$ arriving at a similar response. Merriam $(1988,1998)$ goes on to state that reliability is usually judged by the assumptions that the realities of a phenomenon are constant. The qualitative researcher, however, is interested in "describing and explaining the world as those in the world experience it" (Merriam, 1998, p. 205). Given that experiences are changeable, highly contextual and multifaceted, replication results will not yield the same results (Merriam, 1998). Guba and Lincoln (1981) add in this regard by stating that "since it is impossible to have internal validity without reliability, a demonstration of internal validity amounts to a simultaneous demonstration of reliability” (p. 120).

There were some strategies to safeguard reliability. Among the most noted were: (a) the researcher provided careful attention to how data was collected and recorded under the study's units of observation; (b) Documents and interview transcripts were gathered and kept as inventory by the researcher.

\section{Methods}

The current study blended a combination of qualitative and quantitative techniques. A case study design served as the methodological framework using qualitative and quantitative research techniques such as documents analysis, interviews, survey and the International Dimension Index (IDI) results. 


\section{Qualitative Method}

In addressing Question One of the study, What is Florida International University's (FIU's) position on the Van Dijk and Meijer's Internationalization Cube (1997)?, the study looked at FIU's policies, support and implementation dimension toward Internationalization.

\section{Instrumentation}

The current study used the following sources of data collection: documents analysis and interviews.

Documents as described by Patton (1998) "refers to a wide range of written, visual and physical material relevant to the study in hand" (p. 112) such as memorandum, institution's newsletters, and administrative or organizational documents . Documents have the advantages of presenting to the researcher a historical context of the phenomenon being studied and also documentary stability. Patton (1998) elaborates stating, "Documentary data are objective sources of data compared to other forms" (p. 126) since the documents have been written and reported for other reasons than the research. At the same time, Patton (1998) recommends verifying the authenticity and accuracy of documents prior to engaging in any document analysis. Patton (1998) states, “it is the investigator's responsibility to determine as much as possible about the document, its origins and reasons for being written, its author and the context in which it was written" (p. 121).

Interviews are a rich tool to gather thick details on the study in question. According to Rubin and Rubin (1995), qualitative interviewing is a "way of finding out what others feel and think about their worlds" (p. 1). The interview guide (protocol) for 
the each dimension was listed in Appendix D. The interview guide was further arranged into questions relevant to the position of the administrative personnel to be interviewed as shown in Appendix E. According to Yin (1994), "key informants are often critical to the success of the case study. Such persons not only provide the case study investigator with insights into a matter but also can suggest sources of corroboratory evidence — and initiate the access to such sources"(p. 84).

Interview questions were compiled and adapted from Afonso (1990), Francis (1993), NASULGC International Student Survey (2007), and Burriss (2006) guiding specific aspects of the policy, support and implementation dimensions. Through these questions, the researcher sought to explore individual differences and document variations (Sewell, n.d.) of senior administrative leaders whose decision making directly influences FIU's policy, support, and implementation dimension toward its internationalization process.

Interviewees were contacted via email to request interviews. Follow up visits to their offices were planned to make sure an interview was granted and scheduled. In addition, interviewees were asked to sign the Consent to Participate in a Research Study form at the beginning of the interview. For consent to participate in research study- email presentation and consent to participate in a research study refer to Appendix F \& G. The complete list of interviewees is shown in Appendix H.

\section{Data Collection}

Data collection on the three dimensions included qualitative elements. The qualitative elements consisted of document analysis, interviews and questionnaires. The 
cut-off timeframe for data collection was the end of Fall semester 2009. Following is a description of each element of data collection.

\section{Policy}

The policy dimension of the internationalization cube as defined by Van Dijk and Miejer (1997) refers to the importance attached to the internationalization aims within an institution visible (explicitly mentioned) in several of its documents. These documents should serve not only as internal guiding points to administrators, faculty, and students, but also to affirm the university's values to the external stakeholders (Burriss, 2006). The policy dimension can be priority (high importance attached to the internationalization aims within the institution shown by explicit mention and/or attention or commitment to Global, international, multicultural mission/goals in university documents, magazines, webpage, etc), or marginal (low attention or importance given to the internationalization aims within the institution shown by no indication and/or attention or explicit commitment to global, international or multicultural commitment in university documents, magazines, webpage, etc.).

The primary source of data collection for this dimension consisted of review of institutional documents, such as the institution's mission statement, millennium strategic planning documents, the institution's international policy papers, admissions packages, website analysis, campus publications, and the faculty Tenure and Promotion manual. For this dimension, documents analysis were studied, recorded, and tabulated according to their prominence, frequency, level of distribution and significance on internationalization (Burriss, 2006). 
The secondary source of data collection consisted of structured interviews with the university executive vice president \& provost/ chief operating officer, director of the Office of Global Learning Initiatives, director of Graduate Admissions, and deans of schools and colleges that offer some type of international activities whose leadership influences the university's policy. The complete list of Deans who were interviewed and questions are shown on Appendix I and J.

The final source of data collection came from questions 1, 2, 3, and 12 from the students and faculty survey toward internationalization.

\section{Implementation}

Van Dijk and Meijer (1997) refer to the implementation dimension as "a way or manner on which international activities are managed" (p. 159) within a HEI. Internationalization, as Van Dijk and Meijer (1997) explains, can be established in a topdown (centralized) or bottom-up (decentralized) manner. However, at some level of activities interaction is required between the central, faculty, and department level (Van Dijk and Meijer, 1995). Thus, the implementation dimension can be systematic (the management and/or introduction of international activities in a systematic manner; following explicit and precise procedures) or ad hoc (the management and/or introduction of international activities as they occur without reference to established procedures). According to Paige (2005), "if the university has a governance structure for internationalization, the possibilities are greater that the process will succeed" (p. 108).

The primary source for data collection for this dimension consisted of review of institutional documents describing organizational charts, policies, and established procedures toward internationalization. The collection of data format utilized in this 
section was developed using the Chief International Administrator (CIEA) survey (Burriss, 2006). According to the CIEA survey, the chief international administrator serves as the individual responsible for the operation of a unit within HEIs in charge of internationalizing the institution.

The secondary source of data collection consisted of structured interviews with the executive vice president $\&$ provost/ chief operating officer, director of the Office of Global Learning Initiatives, Director of Graduate Admissions. In addition, deans of the schools and colleges that offer some type of international activities and are direct agents of implementation of policies were also contacted for interviews. The complete list of Deans interviewed and questions are shown on Appendix I and J.

\section{Support}

The support dimension refers to the type of support, assistance, or management practices provided to international activities within HEIs characterized as interactive (support provided with interaction between central, faculty, and departmental levels) or unilateral (support provided at the central or peripheral level).

The primary source of data collection for the support dimension involved structured interviews with the Executive Vice President \& Provost/ Chief Operating Officer, Director of the Office of Global Learning Initiatives, Director of Graduate Admissions. In addition, Deans of the schools and colleges that offer some type of international activities and have some level of responsibility in providing support were also interviewed. The complete list of Deans interviewed and questions are shown in Appendix I and J. 
The secondary source of data collection comprised a review of institutional data such as funding sources (institutional funds, students fees, and grants/contracts), library resources, and faculty and staff development support, among others. Finally, questions 13 through 18 from the students and faculty surveys on internationalization provided additional sources of data collection for the support dimension.

\section{Data Analysis}

According to Merrian (1988), "data analysis is the process of making sense out of one's data" (p. 127), or as Taylor and Bogdan (1984) elaborate data analysis is the process "to come up with reasonable conclusions and generalizations based on the preponderance of the data" (p. 139).

The content analysis process was as follows:

First, to understand FIU's position in the cube, the data collected from institutional documents were coded and divided into the three internationalization cube dimensions (unit of analysis): Policy, Support, and Implementation.

Data collected from the interviews were first transcribed into word documents and together with the Deans' responses then coded into the three internationalization cube dimensions: Policy, Support, and Implementation. This process allowed for patterns to be identified and facilitated comparison between what the different stakeholders said and how concepts were understood.

Second, the results for each dimension were sorted out according to each

dimension subcategory: Policy - Priority or Marginal, Support - Interactive or Unilateral, Implementation - Structural or Ad hoc. 
The rubric used for content analysis to determine the policy dimension follows: (a) Priority $=$ wide distribution, prominence of statements, and/or frequency of occurrence mentioning global, international, or multicultural mission/goals, commitment to diversity, strong emphasis on global/international experience, strong international component in the curriculum; (b) Marginal= no or little indication of global, international or multicultural commitment, no mention of global/international dimension and little or no global content in courses.

The categorization of the implementation dimension as either structured or ad hoc were determined by the analysis of institutional documents demonstrating explicit policies or processes in place guiding FIU's internationalization and frequency counts of interviews and questionnaires responses (patterns) on this dimension. The rubric used for content analysis to determine the implementation dimension follows: (a)

Structured/Systematic $=$ Clear indication or presence of organizational structure/guidelines/procedures toward internationalization; (b) Ad hoc= No clear indication or presence of organizational structure/guidelines/procedures toward internationalization.

The categorization of the support dimension as either unilateral or interactive was determined by the existence of institutional documents demonstrating support and frequency counts of interviews and questionnaires responses (patterns) on this dimension. The rubric for content analysis to determine the support dimension follows: (a) Interactive $=$ Clear indication of support among central, faculty, and departmental level; (b) Unilateral/One-sided= Support provided at the central or peripheral level. 
The data analysis for the policy, support and implementation dimensions were guided but not limited to their respective analysis models developed by Burriss (2006) and adapted from Mapping Internationalization on U.S. Campuses (Green, Luu, and Burris, 2008) shown in Appendix K, and the interviews responses context analysis summary matrix shown in Appendix L. Miles and Huberman (1984) recommend using matrices, among other techniques, as a way to organize and analyze data, as well as counting the frequency of different events, variances, and cross tabulations to examine the relationships between variables. After careful consideration of the all information gathered, the overall analysis for each dimension helped determine FIU's position in the internationalization cube.

\section{Quantitative Method}

In addressing Question Two of the study, To what extent is FIU's position on the Van Dijk and Meijer's Internationalization Cube aligned to the IDI results?, the study presented FIU's numerical descriptive results of internationalization through the International Dimension Index (IDI) and the five-member panel's responses descriptive statistics’ Item Relevancy Index (IRI) to determine the level of alignment.

In addressing Question Three of the study, How do students and faculty attitudes toward internationalization compare on the General Attitudes, Support, and Benefits scales at FIU?, the study used correlation and factor analysis to examine the student and faculty's attitudes toward internationalization.

\section{Participants}

The sample population for Question Three consisted of FIU faculty and students. The attitudinal survey on internationalization was distributed to FIU students (N) 
population $=59,985($ Spring 2009 data) and $(\mathrm{N})$ faculty $=1,000$. The study recognized the voluntary nature of the respondents as a limitation.

External Validity. Merriam (1988) maintains, "within a single case, for example, one can randomly sample from a subunit ... and then treat the data quantitatively" (p. 174). The current study was designed to allow for some generalization as the FIU faculty and students' subunits were randomly sampled and their responses subjected to statistical analysis. It should be noted that one of the limitations that KSU survey had was its lack of generalizability due to the low number of faculty responses' received.

Reliability. The psychometric properties of the student and faculty attitude surveys were assessed through an item-level and scale-level analysis. The item -level scale examined the psychometric properties of each individual item included in the scale, while the scale-level analyses evaluated the scale as a whole.

According to Bann and Berkman, et al. (2003), "the reliability of internal consistency measures the degree to which items on a scale are related to each other and therefore appear to be measuring the same construct" (p. 114). The internal consistency reliability was measured using the Cronbach' alpha coefficient (Cronbach, 1951) set at the minimum required alpha coefficient of .70 or above (Bann \& Berkman, et al., 2003; Guilford, 1956; Nunnally, 1978). For the scale-level reliability internal consistency a covariance matrix was analyzed. A preliminary pilot study was done to test the internal consistency reliability on the students and faculty survey.

To safeguard reliability special consideration was given to the confidentiality of survey responses. The current study presented faculty and students participating in the survey written confirmation that their response remained confidential. 
Instrument Validity. The validity of the instrument comes from Kennesaw State University (KSU) careful development process of the student and faculty survey based on their Global Leaning Outcomes designed to promote and advance KSU's QEP goals focusing on Global Learning for Engaged Citizenship (Kennesaw State University, 2007). The instrument was the result of a studious analysis of literature on the topic and reviews of similar instruments developed by participating institutions on the Global Learning For All Project under the auspices of the American Council on Education (ACE). The final survey used by KSU, and also published by ACE in A Handbookfor Advancing Comprehensive Internationalization: What Institutions Can Do and What Students Should Learn, is the result of several reviews and revisions from the faculty steering committee (approximately 15 faculty members from 12 disciplines) in charge of establishing KSU's Global leaning outcomes, as well as international education experts (Carley, Cheurprakobkit, \& Paracka, 2006). For this study, permission to use the survey was granted by KSU.

Additional questions to the survey were incorporated from Davies' (1995) conceptual framework for internationalization assessment described in University Strategies for Internationalization in Different Institutional and Cultural Settings, and FIU's Quality Enhancement Plan's Survey on faculty internationalization.

\section{Review and Pilot Testing}

To enhance the validity of the instrument, content and construct validity in particular was looked at. For content validity, the following strategies were followed: a professional peer review (DeVon et. al, 2007) of the instrument by the FIU QEP Development Team that is familiar with internationalization and a pre-test pilot analysis 
of the instrument by five faculty and students. Revisions emergent from the pilot testing were analyzed and incorporated into the surveys. For construct validity, an explanatory factor analysis (EFA) was performed as described under the Student and Faculty attitudes on internationalization data analysis section.

\section{Instrument}

Gall, Gall and Borg (2003) defines surveys as "the use of questionnaires or interviews to collect data about the characteristics, experiences, knowledge, or opinions of a sample or a population" (p. 638). Brigg and Coleman (2007) add that a survey permit collecting data "at a single point on time", and "is the appropriate approach to use when systematically collected and comparable data are needed which can be obtained from a (relatively) large number of individuals" (p. 128).

For the collection of data to be accurate, Gall, Gall, and Borg (2003) recommend spending time in the following three steps from the total of seven they list: (a) Defining the research objective, (b) Selecting a sample, and (c) Designing the questionnaire format (p. 224).

The research objective of the survey in the current research study was to solicit FIU's student and faculty attitudes on international education; as significant stakeholders, the student and faculty attitudes toward internationalization play a significant role influencing policy development, support, and implementation that ultimately fosters the university ethos toward internationalization. The selected sample, therefore, was FIU full time faculty and students. 


\section{Data Collection}

\section{Results of International Activities}

Data collection for the results of internationalization was collected in two concurrent but not mutually exclusive steps: (a) collection of descriptive data of FIU's results of internationalization, and (b) collection of the 12-member panel of experts' Item Relevancy Index (IRI) based on Lynn's (1986) Content Validity Index.

First, the descriptive results of internationalization at FIU were gathered using the International Dimension Index (IDI). The IDI (Afonso, 1990, Krane, 1994, Burriss, 2006) serves as quantitative institutional indicators that strongly correlate to internationalization. The IDI consists of seven categories under which international activities within a HEI can be organized. According to Afonso (1990), "the activities falling within these categories are universally recognized as principal contributors to the international dimension of the institution" (p. 35).

The seven categories as described in Chapter 1 were: foreign language study, international curriculum, study abroad opportunities, number of foreign students, international movement of faculty, international development assistance (funds), and advanced training and research. For the purpose of this study, the last two categories were combined into the International Development Projects category. In addition, two categories were added: the number of offshore (transnational) programs and cocurriculum. The number of offshore programs was added to the IDI developed by Afonso (1990) and Krane (1994), as an indicator relevant to FIU. The co-curriculum category was added as an important indicator of the extracurricular international learning enhancing internationalization (Green, Luu, \& Burris, 2008). The study collected data on 
FIU descriptive results of internationalization for the following academic years: 20072008 and 2008-2009.

Sources of data collection for each indicator follow in Table 2:

Table 2

Sources of Data Collection

\begin{tabular}{|c|c|}
\hline Indicator Name & Source \\
\hline Foreign Language & \\
\hline FL Entrance Requirement & FIU Catalog \\
\hline FL Graduation Requirement & FIU Catalog \\
\hline \# of Majors/Minors & $\begin{array}{l}\text { Office of Planning \& Institutional } \\
\text { Effectiveness }\end{array}$ \\
\hline$\#$ of undergraduate degree in FL conferred & $\begin{array}{l}\text { Office of Planning \& Institutional } \\
\text { Effectiveness }\end{array}$ \\
\hline $\begin{array}{l}\text { Total \# of undergraduate and graduate } \\
\text { enrollment }\end{array}$ & $\begin{array}{l}\text { Office of Planning \& Institutional } \\
\text { Effectiveness }\end{array}$ \\
\hline \multicolumn{2}{|l|}{$\begin{array}{l}\text { International Studies } \\
\text { (International Curriculum) }\end{array}$} \\
\hline $\begin{array}{l}\text { \# of undergraduate degree in areas of } \\
\text { studies conferred }\end{array}$ & $\begin{array}{l}\text { Office of Planning \& Institutional } \\
\text { Effectiveness }\end{array}$ \\
\hline $\begin{array}{l}\text { Total \# of undergraduate and } \\
\text { graduate enrollment }\end{array}$ & $\begin{array}{l}\text { Office of Planning \& Institutional } \\
\text { Effectiveness }\end{array}$ \\
\hline Geographic & $\begin{array}{l}\text { Office of Planning \& Institutional } \\
\text { Effectiveness }\end{array}$ \\
\hline \multicolumn{2}{|l|}{ International Students } \\
\hline Percent International & $\begin{array}{l}\text { Office of Planning \& Institutional } \\
\text { Effectiveness }\end{array}$ \\
\hline $\begin{array}{l}\text { Total \# of undergraduate and } \\
\text { graduate enrollment }\end{array}$ & $\begin{array}{l}\text { Office of Planning \& Institutional } \\
\text { Effectiveness }\end{array}$ \\
\hline Geographic & $\begin{array}{l}\text { Office of Planning \& Institutional } \\
\text { Effectiveness }\end{array}$ \\
\hline $\begin{array}{l}\text { Faculty Exchange } \\
\text { \# of FIU faculty with Fulbright } \\
\text { awards to work outside the U.S. }\end{array}$ & CIES database/FIU records \\
\hline $\begin{array}{l}\text { \# of faculty with Fulbright } \\
\text { awardees hosted by FIU }\end{array}$ & CIES database/FIU records \\
\hline
\end{tabular}


Table 2 (continued)

\begin{tabular}{|c|c|}
\hline Indicator Name & Source \\
\hline $\begin{array}{l}\text { Co-Curriculum (international events } \\
\text { outside the Classroom- campus life) }\end{array}$ & FIU records/Website \\
\hline $\begin{array}{l}\text { Study Abroad } \\
\text { International Programs } \\
\text { \# of students going abroad } \\
\text { \# of external exchange students }\end{array}$ & $\begin{array}{l}\text { FIU records/Office of Education Abroad } \\
\text { FIU records/Office of Education Abroad } \\
\text { FIU records/Office of Education Abroad }\end{array}$ \\
\hline $\begin{array}{l}\text { International Development Projects } \\
\text { \# of Int. Dev. Projects }\end{array}$ & $\begin{array}{l}\text { Association of Public and Land-grant } \\
\text { Universities (APLU) Website \& FIU's } \\
\text { Office of Sponsored Research } \\
\text { Administration (OSRA) }\end{array}$ \\
\hline $\begin{array}{l}\text { Geographic location } \\
\text { Project Area of activity } \\
\text { Funding Sources }\end{array}$ & $\begin{array}{l}\text { APLU Website \& FIU's OSRA } \\
\text { APLU Website \& FIU's OSRA } \\
\text { APLU Website \& FIU's OSRA }\end{array}$ \\
\hline $\begin{array}{l}\text { Offshore Programs } \\
\text { \# of Offshore programs }\end{array}$ & FIU Office of Accreditation \\
\hline
\end{tabular}

Second, the 22 items in the revised International Dimension Index (IDI) were put in a survey format and sent via email to a 12 -member panel of experts in international education. The survey was intended to establish an Item Relevancy Index (IRI) for each item on the IDI and the minimum item quantity output for an HEI placed on position seven of the Van Dijk and Meijer's Internationalization Cube (1997). The expert panel was formed using individuals who were faculty and administrators from FIU and partner institutions. The criteria for inclusion in the expert panel were: (a) have more than 5 years of experience in the international education field, and (b) be currently involved in the development and/or management of international activities within higher education institutions. For a complete view of Panel Instructions and Survey, refer to Appendix M. 


\section{Student and Faculty Attitudes on Internationalization}

Data on student and faculty perceptions on internationalization was collected using the student and faculty attitudinal surveys. The surveys were intended to enhance and measure an overlapping, but distinct facet of the internationalization process.

The survey instruments consisted of 36 Likert-type statements for full-time faculty and 26 Likert-type statements for students divided in four categories: (a) general attitudes about internationalization, (b) support for internationalization, (c) benefits on internationalization and (d) participation on international activities - mainly study abroad and offshore programs for faculty, and study abroad and co-curriculum for students.

The general attitudes section measured faculty and student attitudes on internationalization in general (Carley, Cheurprakobkit, \& Paracka, 2006). In this section, questions $1,2,3$, and 12 were added to the students and faculty survey relating directly to the policy dimension as recommended by Davies (1995) when analyzing the policy dimension. The support section measured the faculty perceived support in "internationalization from their campus, college/school, and department and whether their course with international content included sufficient relevant examples" (Carley, Cheurprakobkit, \& Paracka, 2006, p.11).

Within the support section, the researcher added questions to the student and faculty surveys. On the faculty survey, question 18 was included to measure the delivery of workshops/seminars to faculty on internationalizing the curriculum. Questions 19 through 22 were included to measure FIU's support on faculty international research and services. Questions 19 through 22 were taken from FIU's Quality Enhancement Plan 
(QEP) faculty survey. Questions 18, 19, 20, and 21 from the faculty survey were removed from the student survey as the measured items do not apply to students.

The benefits of internationalization section focused on student and faculty attitudes toward the perceived benefits internationalization brings to them overall.

The general attitudes, support, and benefits sections described above were measured using a 5-point Likert-type scale, with 1 representing "strongly disagree," and 5 representing "strongly agree".

The last section of the survey related to attitudes toward participation on international activities - mainly study abroad and offshore programs for faculty, and attitudes and knowledge toward participation on study abroad and co-curriculum for students. This section was measured in a dichotomous format (Yes/No responses).

Literature review on Internet surveys shows that response rates can range from 4 to $44 \%$ (Schonlau, Fricker, and Elliott, 2002). Given FIU's student and faculty population, a minimum $60 \%$ response rate for email survey was considered as very good as reported by the Division of Instructional Innovation and Assessment at the University of Texas at Austin (2007). Since there was less than $70-80 \%$ rate of return it was difficult to generalize and this was noted in the dissertation. However, the sample was analyzed by demographics reported on page 98 for the proportion of each in the returns. These proportions were compared to those in the school population. This analysis gave a better idea if one demographic was better or more poorly represented by the returned survey and what needs to be done. In addition, to achieve a minimum of $60 \%$ rate of correct factor structure, a minimum 10:1 ratio of subjects to items on EFA was applied (Osborne \& Costello, 2005). 


\section{Administration of the Instrument}

Permission to access the student listserve emails was obtained from the Vice President Students Affairs and Undergraduate Education. Once permission was granted, an invitation email to participate in the study was distributed to students via the University Technology Services (UTS). The email explained the purpose of the survey and included the link to access the same. Faculty emails were collected from the different Schools and Colleges websites. A master list of faculty emails was put together and divided in two groups to better manage the data. Randomly selected faculty from each group were sent an invitation email to participate in the study. For a complete view of faculty and students' cover email invitation and the student and faculty surveys refer to Appendix $\mathrm{N}$ and $\mathrm{O}$. In order to enhance the response rate, the following strategies were used: (a) leave the online survey open for 2 weeks, (b) send a reminder to complete the survey on the third day, and (c) send a final reminder of the survey the day before the survey closing (Hamilton, 2003; Sheehan, 2001).

\section{Data Analysis}

\section{Results of Internationalization}

To respond to the question To what extent is FIU's position on the Van Dijk and Meijer's Internationalization Cube aligned to the IDI results? the researcher used descriptive data on FIU's results of internationalization and the experts panel's Item Relevancy Index (IRI). The descriptive data on the results of internationalization, as demonstrated in previous studies by Afonso (1992), Krane (1994), and Burriss (2006), showed the current level of international activities present at FIU. The Item Relevancy 
Index (IRI) obtained from the experts show item relevancy to an HEI placed on position seven of the Van Dijk and Meijer's (1997) Internationalization Cube served as final criteria of analysis.

The level of alignment between FIU's placement on the cube and the results of internationalization was determined in two steps:

The first step consisted of tabulating the 12-member expert panel's responses to determine the Item Relevancy Index (IRI), and the minimum number requirement for the items on the IDI. The IRI for each item was calculated as the proportion of experts who rates the item as Relevant on a 2 - point scale (Relevant and Not Relevant). A minimum IRI of $80 \%$ (10 out of 12$)$ was desired among the panel members for an item to be considered as relevant. The minimum number requirement for an item was reported based on the panel's tabulated responses.

FIU's results on internationalization were presented following Burriss' (2006) model shown Table 3 .

Table 3

Results of Internationalization

\begin{tabular}{l}
\hline Indicator Name \\
\hline Foreign Language \\
FL Entrance Requirement \\
FL Graduation Requirement \\
\# of Majors/Minors \\
Total \# of undergraduate and graduate \\
enrollment \\
\# of undergraduate degree in FL conferred \\
$\quad$ International Studies \\
$\quad$ International Curriculum)
\end{tabular}


Table 3 (continued)

\begin{tabular}{l}
\hline Indicator Name \\
\# of undergraduate degree in areas of \\
studies conferred \\
Total \# of undergraduate and \\
graduate enrollment \\
Geographic \\
International Students \\
Percent International \\
Total \# of undergraduate and \\
graduate enrollment \\
Geographic \\
International Movement of faculty \\
\# of FIU faculty with Fulbright \\
awards to work outside the U.S. \\
\# of faculty with Fulbright \\
awardees hosted by FIU \\
Co-Curriculum (international events \\
outside the Classroom- campus life) \\
Study Abroad \\
International Programs \\
\# of students going abroad \\
\# of external exchange students \\
International Development Projects \\
\# of Int. Dev. Projects \\
Geographic location \\
Project Area of activity \\
Funding Sources \\
Offshore Programs \\
\# of Offshore programs
\end{tabular}

Finally, FIU's descriptive data on the results on internationalization was analyzed in relation to the panel's IRI. 


\section{Student and Faculty Attitudes on Internationalization}

Survey results from the survey database were downloaded into an Excel document and then imported to SPSS 16.0 for analysis. The quantitative data obtained from the students and faculty surveys were analyzed in the following manner:

First, a psychometrics analysis of the survey was done. The psychometrics analysis comprised of the calculation of the Cronbach' alpha coefficient (internal consistency reliability) for the overall scale (survey) comprised of 35 items, and the itemlevel correlations. The Cronbach'Alpha coefficient serves as an index of "reliability associated with the variation accounted for by the true score of the "underlying construct" (Santos, 1999). Cronbach's Alpha coefficient values goes from 0 to 1 , and the closer to 1 the score, the more reliable the scale would be (Santos, 1999). A minimum .70 Cronbach's Alpha coefficient is desired as cut-off value (Nunnally, 1978).

The item-level analysis reported the correlations between each item on the scale and the total score. By performing an item -total score correlation, the study sought to provide additional information of the contribution of the item to the reliability of the scale (Bann \& Berkman, et al. 2003). A minimum correlation of .30 was desired between the item an total score as cited by Kerlinger (1986),

Secondly, an exploratory factor analysis (EFA) was conducted on three sections of the student and faculty surveys: (a) General attitudes about Internationalization, (b) Support for Internationalization, and (c) Benefits of Internationalization. A factor analysis was done to explore if a correlation among items within each section existed and reduced the number of factors to find a common factor among them. According to Daniel (1988), factor analysis is "designed to examine the covariance structure of a set of variables and 
to provide an explanation of the relationships among those variables in terms of a smaller number of unobserved latent variables called factors" (p. 2).

The analytical process for the exploratory factor analysis consisted of first calculating a correlation (or variance-covariance) matrix representing the relationships among the set of variables in the study (how the variables cluster together). The KaiserMeyer-Olkin measure of sampling adequacy and the Bartlett's test of sphericity was calculated. For the Kaiser-Meyer-Olkin measure of sampling adequacy a minimum value of .6 is desired.

The extraction of factors was determined using the principal component analysis (PCA). PCA was calculated and reported following the Kaiser-Guttman rule of eigenvalues - components with eigenvalues less than 1.0 are dropped. In addition, the scree plot was also used to visualize and confirm the factors to be extracted. Once factor solutions were obtained, factors were subjected to a Varimax rotation to facilitate more interpretable results.

Finally, data from the students and faculty survey were analyzed by factors in the following manner:

1. The mean score for the obtained student and faculty factors was calculated.

2. Frequency and percentage of Student and Faculty Factors items reported.

3. Spearman Correlations of Student and Faculty Factors mean scores with various demographic and experiences variables. Spearman Rho correlations were run and reported when $\mathrm{p}<.05$.

4. Itemized factors' Spearman Rho correlations with significant demographic and experiences variables. 
The demographic variables for faculty were: age, gender, race, tenure status, and international faculty. The experiences variables were: have visited FIU's Education Abroad, have participated in study abroad, would like to participate in study abroad, and Do you know if there are international travel grants offered to FIU students? The two final variables "have participated in offshore programs" and "like to participate in offshore programs" were added as they are relevant to FIU.

The demographic variables for students were: age, gender, race, class status, student status, work status. The experiences variables were: have visited FIU's Education Abroad, have participated in study abroad, would like to participate in study abroad, and Do you know if there are international travel grants offered to FIU students?

\section{Summary}

The present chapter introduced and defined the mixed-methods case study approach used in the study. The qualitative approach of the study involved the analysis of institutional documents, and interviews. The quantitative approach of the study entailed collecting FIU's descriptive data on international activities, and student and faculty attitudes toward internationalization survey results.

This chapter described in details the data collection and data analysis processes

for both approaches, and listed the reasons why Florida International University served as a rich case study for internationalization. 


\section{CHAPTER IV}

\section{RESULTS}

This chapter presents the findings of the study. The results of the data analysis are presented. Florida International University's (FIU) position on the Van Dijk and Meijer (1997) Internationalization Cube, the Results of International Activities, and the Student and Faculty Attitude Surveys toward Internationalization are discussed.

\section{Research Questions}

The following research questions guided the study:

1. What is Florida International University's (FIU's) position on the Van Dijk and Meijer's Internationalization Cube?

2. To what extent is FIU's position on the Van Dijk and Meijer's Internationalization Cube aligned to the International Dimension Index (IDI) results on internationalization?

3. How do FIU student and faculty attitudes toward internationalization compare on the General Attitudes, Support, and Benefits survey scales?

\section{Hypotheses}

The following alternative hypotheses were tested in this study:

1. Given FIU's historical and environmental context, FIU is positioned in quadrant 7 of the Van Dijk and Meijer internationalization cube.

2. FIU's position on the internationalization cube is aligned to the IDI results of internationalization. 
3. There is a relationship between student and faculty attitudes (or vice versa) toward internationalization on the General Attitudes, Support, and Benefits survey scales at FIU.

\section{Florida International University's (FIU) Background}

Florida International University is an urban public university established in 1972. Though a young university, FIU has achieved the status of a high research university serving over 40,000 students, more than 100,000 alumni, and 1,000 faculty. FIU comprises two campuses-Modesto Maidique Campus located in the southwest Miami area and the Biscayne Campus in the northeastern Miami area. In addition, FIU has two off-site academic locations_-Broward Pines Center in Pembroke Pines and the Miami downtown site. FIU campuses present students with a vibrant place for interaction and to experience FIU's international flavor.

In terms of academic programs, FIU provides to the community nearly 200 bachelor's, master's, and doctoral degrees in 21 schools and colleges. Among the latest schools and colleges opened, FIU launched its Medical School in Fall 2009 and the School of Public and International Affairs (SIPA) in Spring 2008.

FIU's geographical location, Miami-Dade County in Florida, contributes to the university's diverse student population. According to FIU data, $60 \%$ of the students attending the university are Hispanic, followed by $17 \%$ Non-Hispanic, $12 \%$ Black, $4 \%$ Asian or Pacific Islander, and 7\% minority groups (FIU, 2009). In addition, 77\% of the students reside in Miami-Dade County.

FIU reports an operating budget for the 2008-2009 academic year of $\$ 643.4$ million. According to FIU's Office of Planning and Institutional Effectiveness 2008 Fact 
Book, the top three sources of funds are: $52 \%$ education and general (E\&G), $15 \%$ auxiliary enterprises, and $13 \%$ from sponsored research. The remaining $20 \%$ of the FIU budget comes from Activity and Service (2\%), Athletics (3\%), and Auxiliary Enterprises (15\%). FIU's budget has not escaped the economic crisis affecting the state of Florida. FIU's budget for the 2009-2010 academic year suffered a $15 \%$ reduction in recurring general revenue (support funds received from the State). According to former FIU President, Modesto Maidique (2009), FIU, like our sister universities, must accommodate a 15 percent reduction in recurring General Revenue. Units were already planning to reduce their 2009-10 budgets by $\$ 8.2$ million. However, an additional $\$ 11.4$ million cut in $2009-10$ is necessary to respond to the latest legislative cuts. (para. 3)

For FIU, the reduction of state funding leads to an arduous job of meeting the budget's needs and maintaining the health of the institution by closing 19 programs, freezing hiring for adjunct faculty and administrative positions while protecting FIU's academic integrity and programs.

In August 2009, FIU appointed a new president, Mark Rosenberg. President Rosenberg is not a new face for FIU. Former FIU Interim Provost and Executive VicePresident, Director of the Latin American and Caribbean Center (LACC), and a faculty member, Rosenberg returns to FIU after holding the position of chancellor of the Florida State University System. According to President Rosenberg, whose motto has been "Hit the Ground- Running," one of his priorities will be to make the university financially sustainable (Cochran, 2009). President Rosenberg stated: "We are in the budget fight of our lives." 


\section{FIU's Position on the Van Dijk and Meijer Internationalization Cube}

The following section analyzes FIU's policy, support, and implementation decisions toward internationalization, answering research question 1 - What is Florida International University's (FIU's) position on the Van Dijk and Meijer's Internationalization Cube?

\section{FIU's Policy on Internationalization}

Van Dijk and Meijer (1997) defined policy as the importance attached to the internationalization aims of an institution that could be either priority or marginal. To assess an organization's policy dimension, Davies (1992) recommends looking at organizational documents, such as mission statements, strategy plans, admissions documents, and so forth, as they should provide a clear insight on where the university stands in terms or internationalization.

FIU was established with three founding purposes: provide a valuable education to students, provide service to the local community, and promote international understanding. FIU's third purpose - to promote a greater international understanding, to become a major international education center with the primary emphasis on creating greater mutual understanding among the Americas and throughout the world (Florida Department of State, 1976) — has provided a founding pillar and ethos guiding the university's international activities since FIU opened its doors.

Yet, the international purpose has not always been a priority. Rather, the international part had a more implicit connotation of the diverse community FIU serves. Modesto Maidique (2008), former university president, stated the following in a 2008 speech, FIU. 3.0 A new Strategic Paradigm: "For too long, the "international" in our 
name has been defined by our diversity and location" (p. 4). This speech marked a significant awakening of FIU to truly live up to its purpose and name. Furthermore, it demonstrated a commitment and change in conversations from the upper university administration toward internationalization, setting the background and top-down approach for the Quality Enhancement Plan initiative.

A list of FIU's documents reviewed is presented in Table 4:

Table 4

Policy Analysis Model Summary

\begin{tabular}{|c|c|c|}
\hline Documents & $\begin{array}{l}\mathrm{P}=\text { Priority } \\
\mathrm{M}=\text { Marginal }\end{array}$ & Evidence \\
\hline FIU University Purpose & $\mathrm{P}$ & $\begin{array}{l}\text { Explicit mention of university } \\
\text { purpose to provide "Greater } \\
\text { International Education-become a } \\
\text { major international education center } \\
\text { with a primary emphasis on } \\
\text { creating greater mutual } \\
\text { understanding among the Americas } \\
\text { and throughout the world." }\end{array}$ \\
\hline Mission Statement & $\mathrm{M}$ & $\begin{array}{l}\text { No specific mention of international } \\
\text { education. "Our mission is to impart } \\
\text { knowledge through excellent } \\
\text { teaching, promote public service, } \\
\text { discover new knowledge, solve } \\
\text { problems through research, and } \\
\text { foster creativity" }\end{array}$ \\
\hline $\begin{array}{l}\text { Millennium } \\
\text { Strategic Plans }\end{array}$ & $\mathrm{P}$ & $\begin{array}{l}\text { International included as a Strategic } \\
\text { Theme. Inclusion of understanding } \\
\text { of other cultures and appreciation of } \\
\text { global diversity in institution's goals. }\end{array}$ \\
\hline $\begin{array}{l}\text { Quality Enhancement Plan } \\
\text { Documents }\end{array}$ & $\mathrm{P}$ & $\begin{array}{l}\text { Curriculum and co-curriculum } \\
\text { internationalization }\end{array}$ \\
\hline
\end{tabular}


Table 4 (continued)

\begin{tabular}{|c|c|c|}
\hline Documents & $\begin{array}{l}\mathrm{P}=\text { Priority } \\
\mathrm{M}=\text { Marginal }\end{array}$ & Evidence \\
\hline $\begin{array}{l}\text { Developed international or } \\
\text { Global Learning Outcomes }\end{array}$ & $\mathrm{P}$ & $\begin{array}{l}\text { Global Awareness: Knowledge of } \\
\text { the interrelatedness of local, global, } \\
\text { international, and intercultural } \\
\text { issues, trends and systems. } \\
\text { Global Perspective: Ability to } \\
\text { conduct a multi-perspective analysis } \\
\text { of local, global, international, and } \\
\text { intercultural problems. } \\
\text { Global Engagement: } \\
\text { Willingness to engage in local, } \\
\text { global, international, and } \\
\text { intercultural problem solving. }\end{array}$ \\
\hline FIU's Catalog & M & $\begin{array}{l}\text { No prominent mention of } \\
\text { internationalization and multicultural } \\
\text { diversity. }\end{array}$ \\
\hline $\begin{array}{l}\text { Large Viewbook } \\
\text { Admissions Viewbook } \\
\text { campus }\end{array}$ & M & $\begin{array}{l}\text { No prominent mention of } \\
\text { multicultural and international }\end{array}$ \\
\hline $\begin{array}{l}\text { International student } \\
\text { Admissions Viewbook }\end{array}$ & $\mathrm{P}$ & $\begin{array}{l}\text { Prominent mention of multicultural } \\
\text { and international campus, links } \\
\text { internationalization to FIU's mission. } \\
\text { Mentions the Office of International } \\
\text { Student \& Scholar Services. Mention } \\
\text { of international clubs organizations. }\end{array}$ \\
\hline FIU Magazine & $\mathrm{P}$ & $\begin{array}{l}\text { Gift Supports the development of } \\
\text { international Education (Spring } \\
2007 \text { ) } \\
\text { Hospitality to Open School in China } \\
\text { (Winter 2007) } \\
\text { 1st Place on the Model United } \\
\text { Nations competition (Fall 2006). }\end{array}$ \\
\hline
\end{tabular}

(table continues) 
Table 4 (continued)

\begin{tabular}{lcl}
\hline Documents & $\begin{array}{c}\mathrm{P}=\text { Priority } \\
\text { M= Marginal }\end{array}$ & Evidence \\
\hline FIU Magazine & P & Professor Michael McClain leads a \\
& USAID-funded project (Winter \\
& 2006). \\
& A conversation with Rabbi Adin \\
& Steinsaltz (Winter 2005). \\
& International Business Program \\
& Ranks in Top 10 (Fall 2004). \\
& Dalai Lama to Visit FIU This Fall \\
& (summer 2004). \\
& \\
& Explicit mention of "international \\
& and multicultural understanding". \\
& \\
English Language & P & \\
Institute's Mission & No links to International \\
Statement & Studies (Available through the \\
& Interim Provost and Executive Vice- \\
FIU's Website & President page), or SIPA \\
(Main Portal) & No links to Spanish and Portuguese \\
& Language versions (Available \\
& through the Undergraduate \\
& Education Page) \\
& No mention of the Go Global Link- \\
& QEP (message from FIU \\
& President) added February 2010 \\
& Various announcements of lectures \\
& related to Latin American and \\
& Caribbean area of Studies, and SIPA. \\
& \\
\hline &
\end{tabular}

Another significant document reviewed was FIU's mission statement. John Heyl (2007) writes in his book The Senior International Office (SIO) as Change Agent, that a mission statement "usually relates most closely to the original terms of its founding and both the historic and ongoing setting of the institution. The mission statement thus explains succinctly why the institution exists" (p. 23). A careful analysis of FIU's 
mission statement illustrates a lack of attention to internationalization. FIU's mission statement emphasizes generating knowledge, promoting creativity and solving problems through research, but it does not make relevant its international purpose or "include the importance of preparing students for 'global citizenry"' (Heyl, 2007, p. 23). On the other hand, research has been an explicit priority at FIU fulfilling its mission by achieving the Carnegie Foundation for the Advancement of Teaching classification of Doctoral/Research University-Extensive.

FIU's Millennium Strategic Plan developed in the spring of 2001 explicitly incorporates "international" as one of the university's strategic themes. In particular, FIU's Strategic Millennium Plan puts emphasis on faculty international research as well as students' bilingual competence and study abroad. This document was developed as a response to the changing forces of globalization affecting FIU. It should be noted that a New Strategic Plan 2010-2015, called Worlds Ahead, is in process of being developed to reflect the changing times affecting FIU. The new strategic plan is planned to go to the FIU Board of Trustees for approval on December 2010.

To further understand FIU's internationalization policy, it is relevant to point out that FIU is undergoing a rebirth of its internationalization ethos. As part of FIU's reaffirmation of accreditation process in 2010, the Commission on Colleges of the Southern Association of Colleges and Schools (SACS) required that FIU develop and present a Quality Enhancement Plan (QEP). According to SACS (2004), “The Quality Enhancement Plan (QEP) is a document developed by the institution that describes a course of action for institutional improvement crucial to enhancing educational quality that is directly related to student learning" (p. 5). For FIU, as the Director of the Global 
Learning Initiatives Office explains, "Our plan, our quality enhancement plan or our QEP, titled Global Learning Initiatives, focuses on educating students to be global citizens, meaning students should be able to function in the 21 st century by having relevant skills such as critical thinking and cultural awareness."

It is also significant to mention that in the Spring 2009, the School of International and Public Affairs (SIPA) was launched. SIPA, under the College of Arts and Sciences, centralizes all the internationally oriented disciplines and centers. According to former Executive Vice President and Provost Ronald Berkman, SIPA "reaffirms FIU's commitment to participating in a public affairs at the local, national, and international level and helps us fulfill our role as an institution of research, teaching and public service" (FIU to break ground, 2008, para. 7). The Dean of the College of Arts and Science elaborated on SIPA stating, "the establishment of SIPA underscores our commitment to FIU's international mission and to our faculty's research and teaching interests in these areas" (FIU to break ground, 2008, para. 9). A look at the SIPA website shows that SIPA's purpose aligns to FIU's purpose of promoting international understanding and FIU's QEP goal of educating global citizens.

The QEP is driving FIU's goal toward internationalization. According to former FIU President, Modesto Maidique, FIU's goal of international education is to “internationalize FIU's undergraduate curriculum," setting a carefully planned direction of international learning and teaching at FIU. The newly drafted student learning outcomes (SLOs) for developing global citizens are the heart of the six newly developed and approved global learning core curriculum courses and the more than 120 existing upper division courses in revision to be implemented with global learning designation in 
2011-12 and beyond. All 61 academic programs at the university that serve undergraduates are revising a minimum of two courses to become global learning designated courses by 2012 .

Knight (2003b) states that, "It is interesting to look at the way in which definitions can shape policy and how practice can influence definitions and policy" (p. 1). Interviews with FIU deans reflect this interaction. When asked how they would define internationalization, the three most frequent themes mentioned were Global learning/Global citizen, Internationalized Curriculum, and International Activities. International students and internationalization as a process influencing the organization as a whole were less mentioned.

For example, one dean defined internationalization as "incorporating international awareness, attitudes, cultures, social mores into the curriculum, exposing the students into cultures other than their own." The Dean of Arts and Sciences defined it "as ensuring the students that graduate from FIU understand what it means to be a world citizen," while another dean stated,

Internationalization can be defined in a lot of different dimensions ... in terms of programs we offer in offshore locations, ...the study abroad programs, the teaching of international programs, our dual degrees programs where we go and recruit students, ... internationalization of the research, research conducted in another country that looks at issues that are particular to a country, look at crosscountry.

Interviews with FIU's interim provost and executive vice-president and deans reveal a consistency on defining internationalization in relations to the Quality Enhancement Plan requirement, Global Learning for Global Citizenship. At the same time, a question was presented as to whether FIU's mission statement supports their 
definition of internationalization. The interim provost and executive vice- president and deans' responses show a low level of consistency on the former divided among three patterns: (a) international being part of FIU's middle name but not integrated into the curriculum and student's experiences, (b) reference is made to FIU's strategic theme and name, and (c) providing a global education (through the QEP) to all students. The interim provost and executive vice-president in particular, indicated that

We will probably be working, as we increase our QEP and everything and go through the strategic planning process, we will probably be looking at revising the mission statement. The president has talked about local and global engagement and some of those words will probably be incorporated into the mission statement.

In March 2009, FIU became a member of the American Council on Education (ACE). ACE's Center for International Initiatives provides programs and services to its institutional members to enhance internationalization within the institutions. FIU's membership in this organization shows a commitment to learn and improve FIU's internationalization practices across the university.

The assessment of FIU's documents and interviews with deans and university interim provost and executive vice president demonstrates that FIU's policy toward internationalization is a priority.

\section{FIU's Implementation of Internationalization}

Van Dijk and Meijer (1997) refer to the implementation dimension as "a way or manner in which international activities are managed" (p. 159) within a HEI. Internationalization, as Van Dijk and Meijer (1997) explain, can be established in a topdown (centralized) or bottom-up (decentralized) manner. However, at some level of activities interaction is required between the central, faculty, and department level (Van 
Dijk \& Meijer, 1995). Thus, the implementation dimension can be systematic (the management and/or introduction of international activities in a systematic manner; following explicit and precise procedures) or ad hoc (the management and/or introduction of international activities as they occur without reference to established procedures).

FIU's organizational structure for internationalization seems to be scattered among several offices. The most prominent offices to date are the Office of Global Learning Initiatives (OGLI), the newly created School of International Public Affairs (SIPA), the Study Abroad Office, International Student and Scholar Services (ISSS), and the Office of Academic Planning and Accountability. Each of these offices oversees different aspects of internationalization at FIU but with no official chief international educator administrator (CIEA) overseeing the university's comprehensive internationalization efforts.

It should be pointed out that the position of Vice Provost for International Studies and the Office of International Studies were eliminated in the Spring 2008 term. The former Office of International Studies comprised different centers and institutes (now under SIPA) and the Office of Study Abroad (now under Undergraduate Education). The Office of International Studies was eliminated due to budget cuts that the Office of the Provost suffered leading to the office's reorganization. The interim provost and executive vice president has currently taken on the responsibilities of the CIEA. The interim provost and executive vice president stated that "I have assumed the role when external delegations come to campus. They used to meet with the Vice Provost for International Studies. They tend to meet with me now, in some cases, or with the director of SIPA.” 
The Office of Global Learning Initiative (OGLI) reports to the interim provost and executive vice-president. This office is driving internationalization at FIU mainly through the internationalization of the curriculum and co-curriculum shaping students learning and experiences at FIU. In the words of the Director of the OGLI, "The office of the GLI is facilitating the development, design and implementation of our Quality Enhancement Plan, which is an essential component of the SACS reaccreditation." The GLI office will operate until 2015, and by then as the Provost indicated, it will go away as the main core of the QEP process. Internationalization of the curriculum will have been incorporated into the university undergraduate lower- and upper-division courses. Undergraduate education will be responsible for the lower-division courses while the different schools and colleges will focus on the upper-division courses tied to the students' majors.

The OGLI has implemented four program goals for its Global Learning for Global Citizenship efforts. These goals are based on the best practices in the implementation of global learning in HEIs (Green Luu, Burriss, 2008; Hovland, 2006; McCarthy, 2007). These four goals present a consistent standard format and wording of programs goals used in program assessments across FIU (FIU, 2010). According to the director of the OGLI,

those program goals deal with providing the resources, the faculty development, the expanding circles of participation, co-curricular activities, the physical and human and financial resources, all the things in the university that will then enable the students to be able to gain these student learning outcomes of global learning.

Table 5 shows the Implementation Analysis model data for FIU's Implementation dimension: 
Table 5

Implementation Analysis Model

\begin{tabular}{|c|c|}
\hline 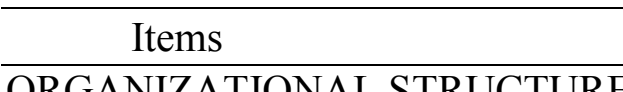 & Evidence \\
\hline \multicolumn{2}{|l|}{$\begin{array}{l}\text { ORGANIZATIONAL STRUCTURE } \\
\text { for internationalization }\end{array}$} \\
\hline CIEA TITLE & Interim Provost and Executive Vice President \\
\hline Level of Reporting line & President \\
\hline PRIMARY LEVEL OF & \multirow[t]{2}{*}{ Various } \\
\hline RESPONSIBILITY & \\
\hline \multirow{2}{*}{\multicolumn{2}{|c|}{$\begin{array}{l}\text { SECONDARY LEVEL OF } \\
\text { RESPONSIBILITY }\end{array}$}} \\
\hline & \\
\hline \multicolumn{2}{|l|}{$\begin{array}{l}\text { EXISTENCE OF CAMPUS-WIDE } \\
\text { INTERNATIONAL ADVISORY }\end{array}$} \\
\hline INTERNATIONAL ADVISORY & \\
\hline \multicolumn{2}{|l|}{ BOARD/COMMITTEE } \\
\hline Appointed & Appointed \\
\hline \multicolumn{2}{|l|}{ Elected } \\
\hline \multicolumn{2}{|l|}{ Number of Meetings/Year } \\
\hline Student Representation & Yes \\
\hline External/Internal/Combined & Internal \\
\hline \multicolumn{2}{|l|}{ PERSONNEL policies } \\
\hline International Faculty & No \\
\hline Inclusion of International & No \\
\hline \multicolumn{2}{|l|}{$\begin{array}{l}\text { efforts/expertise for tenure, } \\
\text { hiring, and rewarding decisions }\end{array}$} \\
\hline Explicit Procedures developed in an & \\
\hline $\begin{array}{l}\text { orderly or systematic fashion } \\
\text { International Students, Study Al }\end{array}$ & Yes \\
\hline \multicolumn{2}{|c|}{$\begin{array}{l}\text { International Students, Study Abroad, } \\
\text { Offshore Programs. Dual Degrees }\end{array}$} \\
\hline Curriculum Framework for Glob & al Learning \\
\hline
\end{tabular}

Note: Criteria: Clear Indication or Presence of organizational structure/guidelines/procedures toward Internationalization=Structured/Systematic; No clear Indication or Presence of organizational structure/ guidelines/procedures toward Internationalization $=\mathrm{Ad}$ hoc

A taskforce for internationalization is present at FIU but it is mainly related to the Quality Enhancement Plan (QEP). The taskforce or “development team” established in 
2008, composed of faculty representatives from FIU's colleges and schools, students, and administrators, was created to:

Participate in research and development of the QEP topic, devise the initial blueprint for developing strategic plan for QEP leadership, act as liaison between colleges, schools, and departments and the QEP leadership, serve as ambassadors for the QEP, provide feedback and recommendations for the Office of Global Learning Initiatives in the development of QEP design and activities, and provide feedback and recommendations for the Design Team. (Office of Accreditation, 2009)

In regards to explicit procedures toward internationalization, FIU has processes and guidelines in place for International Students (visa applications and Optional Practical Training, known as OPT), study abroad, offshore programs, and dual degrees. An approval policy on International Education Agreements is available, setting clear guidelines for units, Colleges and Schools initiating international activities. As one Dean stated,

Ten years ago, when the college started some international activities, I would say it was unstructured, but I believe that our initiatives forced structure on the process. So today we have a very structured process... We have contracts for how we do the dual degrees. We know what the rules and procedures are for offering programs offshore, and those are the two main areas where we need to have the procedures.

Yet, the initial development of any international activity rests mainly on faculty initiative and willingness to engage in international endeavors. Furthermore, the office of Academic Planning and Accountability is responsible for monitoring FIU's international agreements and accreditation compliance.

In terms of internationalizing the curriculum, a Global Learning for Global Citizenship Curricular Framework has been developed as a response to the QEP. The new curriculum strives to ensure that all students from FIU have the knowledge, skills, and 
attitudes to become global citizens even if they are not able to participate in study abroad or have any other international experience. As one Dean stated, "I think they [QEP] outline the goals for those particular classes for the students who aren't studying abroad or may not have another international type of experience...."

The Global Learning for Global Citizenship Curricular Framework will require students to take one lower-division course in global leaning foundations within their core curriculum and one upper-division global learning course as part of their major or field of study. The development of the new courses has taken place in a collaborative manner among the OGLI and faculty from the different schools and colleges. A pilot test for the new courses is scheduled for the spring term 2010.

The GLI office has three administrative personnel and provides specific guidelines for the development and revision of courses to incorporate the three global learning student learning outcomes, assessment of those outcomes, active learning strategies, and global learning content. The assessment process involves presenting a revised syllabus together with an assessment matrix showing clearly which SLOs are being addressed, what the student is expected to learn, and how the knowledge, skills and attitudes will be measured. In addition, three committees have been established to approve new or existing University Core Curriculum (UCC) courses: (a) Global Learning Curriculum Committee (GLCC), (b) an Ad-hoc Global Learning Curriculum Oversight Committee (AHGLCOC), and (c) University Core Curriculum Oversight Committee. The five member faculty senate-appointed AHGLCOC, in particular, has been established to review the new or revised UCC courses with a global dimension. The final approval of the new or revised course rests on the faculty senate and provost. The AHGLCOC also 
reviews and approves new or revised global learning Upper-division courses with final approval resting on the faculty senate.

Personnel policies toward internationalization, referring to hiring, annual evaluation, tenure and promotion, and/or facilitating research abroad seems to be less structured. A review of FIU's Tenure and Promotion Manual does not mention international work or activities as a requirement for tenure. Instead, its broad language leaves it up to the departments, colleges and schools, to determine if international work is relevant. Conversations with Deans show that a high level of consistency exists in the current practices affecting tenure and promotion. The most mentioned patterns were: (a) tenure and promotion depends on the area of study, and (b) including international activities or efforts as part of the tenure and promotion criteria for faculty is mainly determined by the units, schools and colleges.

According to the Interim Provost and Executive Vice-President, "The tenure and promotion guidelines are intentionally not all that prescriptive. They are sort of open because, for some faculty, it would be something that's very important. For other faculty, it wouldn't have any relevance at all." In addition, a dean stated,

I think they are consistent but seem to be more targeted to a particular area of study", and the director of the Global Learning Initiatives added: "with facilitating research abroad, I think we are doing a good job, now the challenge is to get the global learning and internationalization research and teaching activities and service into tenure and promotion and annual evaluations....

FIU's implementation dimension for internationalization can be categorized as structured. There are multiple offices as well as policies and guidelines for the management of FIU's internationalization efforts. 


\section{FIU's Support of Internationalization}

The support dimension refers to the type of support, assistance, or resources provided to promote international activities within HEIs. That support can be either interactive (support provided with interaction between central, faculty, and departmental levels) or unilateral (support provided at the central or peripheral level).

FIU's support for internationalization can be characterized as mainly one-sided, college/school/department-based, due to the peripheral nature of international activities and support, with specific areas of explicit interactive support for areas that cut across the university like the QEP, Study Abroad Office and the Office of International Student and Scholar Services (ISSS) that are officially sanctioned.

Conversations with deans show a high level of agreement on the limited funding support available at FIU for international activities except for the QEP efforts and the construction of new building for SIPA. According to the Dean of Arts and Sciences, "[financial support and policies] are probably not totally adequate. In terms of the level of support, I think that is across the board, we are an underfunded university". Deans within their schools and colleges are responsible for supporting their own international activities. For example, Offshore programs are offered as self-supporting programs, and during the 2008-2009 academic year the Director of the Study Abroad office explained that the study abroad programs were moved from FTE generating to self-supporting.

On the other hand, according to the director of the OGLI: the support comes from top down, and the support comes from bottom up, meaning there are dedicated resources to faculty development and to global learning, implementation of global learning 
curriculum, global learning faculty development, global learning co-curriculum. And from the bottom up, we have support from the Student Government Association. In terms of funding for the QEP, beginning in the Spring of 2008, FIU has committed half a million dollars annually for the next 5 years. Starting in 2016, Undergraduate Education and the Office of Assessment Planning and Accountability (APA) will receive the same half million dollars per year to support internationalization efforts across the university. Until 2015, these funds are dedicated to supporting the Global Learning Initiatives Office's personnel and activities. Among the many services the OGLI office provides are (a) faculty workshops for internationalization of the curriculum, (b) co-curriculum such as Tuesday Talks offered in collaboration with The New York Times and the Student Government Association (SGA), and (c) faculty stipends to develop the new and revised global learning lower and upper-division courses. In respect to the construction of the new building for SIPA, the five-story building is $50 \%$ funded from FIU's Education and General fund (E\&G) representing FIU's support to the School.

FIU provides a variety of international studies majors and minors in areas such as Latin American Studies, Asian Studies Civilization, African and African Diaspora Studies, Religious Studies, International and Intercultural Education, International Relations, International Business Management and Foreign Language Teacher Education. The support and development of these programs have been mainly college/department/unit based. However, some collaboration is taking place among schools and colleges in the form of dual degrees offered to students. Some examples of this collaboration are: the Master of Business Administration/Master of Arts in Latin 
American and Caribbean Studies Joint Degree Program, Master of Business

Administration/ Jurisprudence Doctor Joint Degree Program, and the Master of Arts in Asian Studies and the Ph.D. in International Relations Dual Degree Program among others.

Support for the internationalization of the curriculum has also come from several of FIU's professional schools' accrediting bodies. Two specific examples of this external support are seen in the Accreditation Board for Engineering and Technology (ABET) commission accrediting FIU's School of Engineering and the National League for Nursing Accrediting Commission (NLNAC) accrediting the School of Nursing. Both bodies have incorporated in their criteria for accrediting programs clear and specific program outcomes associated with global skills, knowledge and values. This support from external accrediting bodies reinforces FIU's commitment to educating global citizens through an internationalized curriculum and co-curriculum.

Table 6 shows an overview of the support model of analysis:

Table 6

Support Model of Analysis

\begin{tabular}{cl}
\hline Items & Evidence \\
\hline Foreign Languages & \\
FL Department & One-sided \\
FL Requirement & No \\
Entry Requirements & Yes- can be met with 2yrs of a FL in High \\
& School, College of Art \& Sciences \\
International Studies & One-sided \\
IS Majors/Minors & \\
\hline
\end{tabular}


Table 6 (continued)

\begin{tabular}{|c|c|}
\hline Items & Evidence \\
\hline $\begin{array}{l}\text { Internationalization of the } \\
\text { Curriculum- Faculty seminars/ } \\
\text { training/workshops }\end{array}$ & Interactive (QEP) \\
\hline $\begin{array}{l}\text { Study Abroad } \\
\text { Internal Programs } \\
\text { Non-academic Support }\end{array}$ & $\begin{array}{l}\text { Interactive } \\
\text { Yes } \\
\text { Yes (Office of Education Abroad) }\end{array}$ \\
\hline $\begin{array}{l}\text { International Students } \\
\text { Administrative and Staff } \\
\text { Services }\end{array}$ & Interactive \\
\hline $\begin{array}{l}\text { Faculty Expertise } \\
\text { External Grants } \\
\text { Institutional Support (research) }\end{array}$ & One-sided \\
\hline $\begin{array}{l}\text { Other Resources } \\
\text { Funding Sources (external } \\
\text { and internal sources) } \\
\text { Accrediting Agencies } \\
\text { Support on SLO }\end{array}$ & One-sided \\
\hline $\begin{array}{l}\text { Library Resources (international } \\
\text { newspapers, Foreign films, etc). }\end{array}$ & Interactive \\
\hline $\begin{array}{l}\text { Organization of International } \\
\text { Conferences }\end{array}$ & $\begin{array}{l}\text { One-sided } \\
- \text { i.e. First National K-12 Language for } \\
\text { Business Conference co-sponsored by } \\
\text { CIBER }\end{array}$ \\
\hline
\end{tabular}

Note: Criteria: Support provided with interaction among central, Faculty, and departmental level $=$ Interactive; Support provided at the central or peripheral level $=$ Unilateral/One-sided

In terms of the promotion of foreign languages, it mainly rests with the department of Foreign Languages. The department offers bachelor's degrees in Spanish, Portuguese, and French, and graduate programs in Spanish. Courses in Arabic, Chinese, German, Italian, and Japanese are also offered at the beginning and intermediate level. 
According to the Chair of the Department of Modern Languages, the promotion of foreign languages really comes from the department, and we [the department] have very little funding. The Department of Foreign Languages has established an advisory board to help with fundraising as well as promotion of programs and recruitment. The Chair did explain that some funding was allocated at the university level to the department of Foreign Languages to promote mainly the Ph.D. program in Spanish.

Despite the fact that FIU does have an entrance foreign language requirement, there has not been an overt emphasis on promoting language proficiency or fluency. According to the Chair of the Modern Languages department, "the university at large is not encouraging, or has not for all these years supported a higher degree of proficiency or competency for students across the board." The Chair also added that some support has been received from independent units such as the Latin American and Caribbean Center (LACC). LACC is revising its language requirement, as the chair explained, "to make it more relevant to the students in their degree programs, and encourage them to acquire better language skills in whatever area it may be: Portuguese, Haitian, Creole, Spanish.”

In terms of challenges, the Chair stated, "To offer more languages that are needed in certain areas, it's very difficult to start from nothing and meet the requirements in terms of enrollments." Particularly, the Chair elaborated that in a number of languages the department does not have full-time faculty to teach some of the foreign language courses but rather depends on adjuncts and instructors to do so. Not having tenure track faculty in foreign languages hinders the recruitment of students into foreign languages and the potential growth of the department on the long run. 
The provost and deans were asked how faculty members were rewarded for their international efforts. Their responses show a high level of agreement that rewards for international efforts depends primarily on the School or College the faculty belongs to. In terms of international grantsmanship, FIU pays significant attention to faculty research/grantsmanship but it does not differentiate or provide any emphasis/reward for international research or involvement in international projects. The Dean of Arts and Sciences stated, "I know within the college we try to highlight and recognize faculty particularly that are doing international projects but I think in the past it has not been necessarily a separate recognition for those faculty." Another Dean said, "I do not think we have any specific awards for international efforts. We give lots of awards, but it is for excellence in teaching and excellence in research, but we do not do any special for international." Finally, the OGLI director concluded,

That goes back to the annual evaluation and tenure, and tenure and promotion. This is a path we have to go on, and it is a culture that has to be created, and I think the more part of the culture the global learning curriculum and cocurriculum becomes within the university, the more it will be supported.

As per international service, such as being part of offshore programs, a dean expressed concern saying, "The University really rewards faculty for research and scholarship, not necessarily service, which in a way, this is a service [referring to offering offshore programs]."

\section{FIU's Challenges to and Opportunities for Internationalization}

FIU's challenges to and opportunities for internationalization were identified through the responses to the interview question: In your opinion, what are the challenges or opportunities to internationalization at FIU? 
Table 7 summarizes the main patterns that emerged from the interview data:

Table 7

Challenges and Opportunities to Internationalization

\begin{tabular}{lll}
\hline RANK* & Challenges & Opportunities \\
\hline 1 & Funding & New FIU President \\
2 & Faculty & International Community \\
& Overwhelmed Faculty & \\
& Resistance to internationalizing & \\
& Curriculum & \\
3 & Lack of alignment between resources & \\
& and allocation of funds & \\
\hline
\end{tabular}

Note. * Primary and most frequented cited (Burriss, 2006)

Not surprisingly, lack of or limited funding was the most frequently cited challenge FIU faces. When asked questions about challenges and opportunities, a dean stated, "We do so much already. One would be more funding [referring to a challenge]. I think sending our faculty on the faculty development workshops or trips... just having the money to support new types of international initiatives."

The second challenge to internationalization is faculty itself. Responses to the above question show that faculty feels overwhelmed. One Dean explained, "We are asking the professors to do so much, our faculty right now is at a low and we are building... but because of budget constraints they are teaching more students in the number of sections." Consequently, the dean continued that developing new undergraduate and graduate courses incorporating the internationalization aspects demand additional work on the delivery and reporting on an already strained faculty.

In terms of resistance to internationalize the curriculum, the director of the OGLI stated two challenges, "The first one is convincing faculty on what is stereotypically thought of as non-international course domains." The director continued, 
The other big challenge is that faculty own the curriculum, and faculty don't like to be told and can't be told what to do in their curriculum, so they have to be convinced that global learning will enhance their curriculum and their syllabi and their teaching rather than inhibit or take away from.

The third challenge goes to the heart of FIU's internationalization process. To align resources with the allocation of funds, internationalization needs to continue being a university wide priority and to expand its scope beyond the QEP.

It appears that FIU's number one opportunity is its new president. Conversations with the provost and deans point that high expectations are set on FIU's new president in making internationalization a priority. According to the provost, "The president is an international scholar now, and so he has a pretty clear interest in that and experience... and so I expect there will be continuing impetus from the top."

\section{Results on International Activities}

To answer research question two, To what extent is FIU's position on the Van Dijk and Meijer's Internationalization Cube aligned to the IDI results?, the study looks at FIU's numerical descriptive results of internationalization through the International Dimension Index (IDI) in relation to the 12-member panel's responses descriptive statistics to determine the level of alignment.

Data collection for the results of internationalization was done in two concurrent, but not mutually exclusive steps: (a) collection of descriptive data of FIU's results of internationalization for the 2007-2008 and 2008-2009 academic years, and (b) collection of the 14-member panel of experts' Item Relevancy Index (IRI).

FIU's results in international activities were collected using the International Dimension Index (IDI) developed by Afonso (1990) and Krane (1994). The IDI 
represents quantitative indicators of FIU's international activities that strongly correlate to internationalization as indicated by Afonso (1990) and Krane (1994). The IDI consists of seven categories under which international activates within a HEI can be organized. According to Afonso (1990), "The activities falling within these categories are universally recognized as principal contributors to the international dimension of the institution" (p. 35).

Table 8 shows FIU's international activities results.

\section{Items Relevancy Index (IRI)}

To determine the items relevancy index (IRI) and minimum number required for each international activity for an HEI placed on position 7 of the Internationalization Cube, the International Dimension Index (IDI) was put in a survey format and emailed to 15 experts in the international education field. Of the 15 panel experts, 12 completed the survey. The response rate to the IDI survey from the panel of experts was $80 \%$.

The experts were presented with a hypothetical university, University "X." University X, with approximately 30,000 students and 1,000 faculty members is assessing its internationalization process using the Van Dijk and Miejer' Internationalization Cube. After a careful analysis, University X determined that it is placed on position 7 of the Van Dijk and Miejer' Internationalization Cube (1997). According to University X's placement, University X presents the following characteristics toward internationalization: A Priority Policy, an Interactive Support, and an Ad hoc Implementation. 
Table 8

\section{FIU International Activities Results}

\begin{tabular}{|c|c|c|}
\hline Indicator Name & 2007-2008 Academic Year Results & 2008-2009 Academic Year Results \\
\hline \multicolumn{3}{|l|}{ Foreign Languages } \\
\hline Foreign Language Entrance Requirement & Yes & Yes \\
\hline Foreign Language Graduation Requirement & $\begin{array}{c}\text { Yes - College of Arts \& Sciences requires competency of } \\
\text { a foreign language or in American Sign Language at the } \\
\text { level of the second semester of a college language } \\
\text { sequence }\end{array}$ & $\begin{array}{c}\text { Yes - College of Arts \& Sciences requires } \\
\text { competency of a foreign language or in } \\
\text { American Sign Language at the level of the } \\
\text { second semester of a college language } \\
\text { sequence }\end{array}$ \\
\hline $\begin{array}{l}\text { Total \# of undergraduate and graduate } \\
\text { Enrollment }\end{array}$ & $\begin{array}{l}\text { Fall } 07 \text { - } 158 \text { (Undergrad: 113, Grad: 45), Spring 08- } \\
151 \text { (Undergrad: 106, Grad: 45) }\end{array}$ & $\begin{array}{c}\text { Fall } 08 \text { - } 155 \text { (Undergrad: 107, Grad: 48), } \\
\text { Spring } 09 \text { - } 147 \text { (Undergrad: 96, Grad: 50, } 1 \\
\text { Unclassified) }\end{array}$ \\
\hline \# of undergraduate degree in FL conferred & $\begin{array}{l}\text { French Language and Literature: } 6 \text { Bachelors, } \\
\text { Portuguese Language and Literature: } 2 \text { Bachelors, } \\
\text { Spanish Language and Literature: } 25 \text { Bachelors }\end{array}$ & $\begin{array}{c}\text { French Language and Literature: } 5 \\
\text { Bachelors, Spanish Language and Literature: } \\
12 \text { Bachelors }\end{array}$ \\
\hline \# of graduate degree in FL conferred. & Spanish Language and Literature: 6 Masters, 3 Doctoral & Spanish Language and Literature: 5 Masters \\
\hline
\end{tabular}

(table continues) 
Table 8 (continued)

\begin{tabular}{|c|c|c|}
\hline Indicator Name & 2007-2008 Academic Year Results & 2008-2009 Academic Year Results \\
\hline $\begin{array}{l}\text { International Studies (International } \\
\text { Curriculum) } \\
\text { \# of undergraduate degree in areas of studies } \\
\text { conferred. }\end{array}$ & $\begin{array}{l}\text { Asian Studies Civilization 13, Women's Studies 21, } \\
\text { Religion/Religious Studies 25, International Relations } \\
\text { and Affairs 174, International Business Mgmt. 379, } \\
\text { Foreign Language Teacher Ed. 2, Latin American } \\
\text { Studies } 22 \text { MA, Asian Studies Civilization } 6 \text { MA, } \\
\text { African-American/Black Studies } 2 \text { MA, Religious } \\
\text { Studies } 13 \text { MA, International and Comparative Ed. } 4 \\
\text { MA, International Relations and Affairs } 11 \text { MA \& } 3 \\
\text { PhD, International Business Mgmt. } 72 \text { MA, Foreign } \\
\text { Language Teacher Ed. } 7 \text { MA. }\end{array}$ & $\begin{array}{c}\text { Asian Studies Civilization 6, Women's Studies } \\
\text { 6, Religion/Religious Studies 14, International } \\
\text { Relations and Affairs 80, International Business } \\
\text { Mgmt. 245, Asian Studies } 2 \text { MA, Latin } \\
\text { American Studies } 8 \text { MA, African- } \\
\text { American/Black Studies } 2 \text { MA, International } \\
\text { and Comparative Ed. 6 MA, Religious Studies } \\
\text { 4 MA, International Relations 9 MA \& } 2 \text { PhD, } \\
\text { International Business Management 25, Foreign } \\
\text { Language Teacher Ed. 9 MA }\end{array}$ \\
\hline $\begin{array}{l}\text { Total \# of undergraduate and graduate } \\
\text { enrollment }\end{array}$ & $\begin{array}{l}\text { Fall 07- 2,092 (Undergraduate: } 1,836 \text { Grad: } 256 \text { ), } \\
\text { Spring } 08-2,130 \text { (Undergrad: } 1,878 \text {, Grad: } 252 \text { ) }\end{array}$ & $\begin{array}{l}\text { Fall 08- 2,366 (Undergraduate: 2,092; Grad: } \\
\text { 271, } 3 \text { Unclassified), Spring 09-2,303 } \\
\text { (Undergrad:2,016, Grad: } 286,1 \text { Unclassified) }\end{array}$ \\
\hline $\begin{array}{l}\text { International Students } \\
\text { Percent International }\end{array}$ & 6.25 & 6.38 \\
\hline Total International Students Headcount & 2,413 & 2,499 \\
\hline $\begin{array}{l}\text { International Headcount by Geographic } \\
\text { Areas }\end{array}$ & 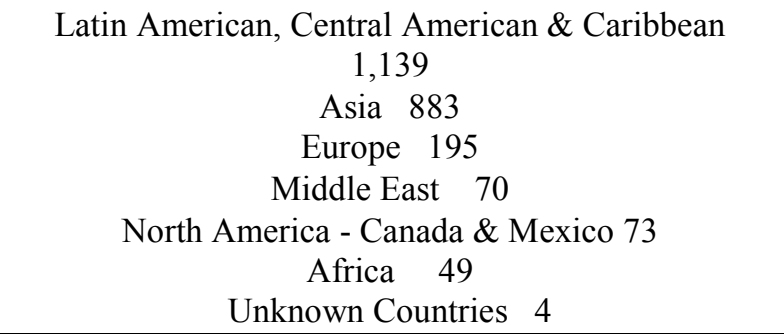 & 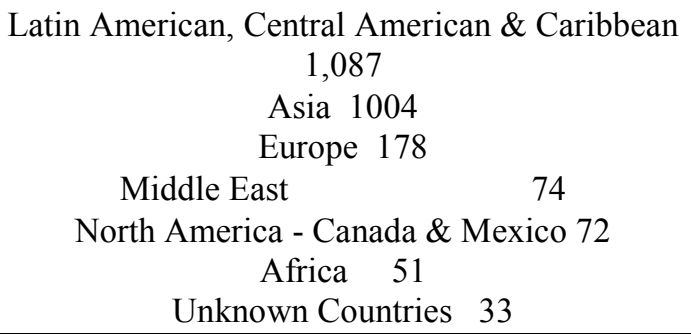 \\
\hline
\end{tabular}


Table 8 (continued)

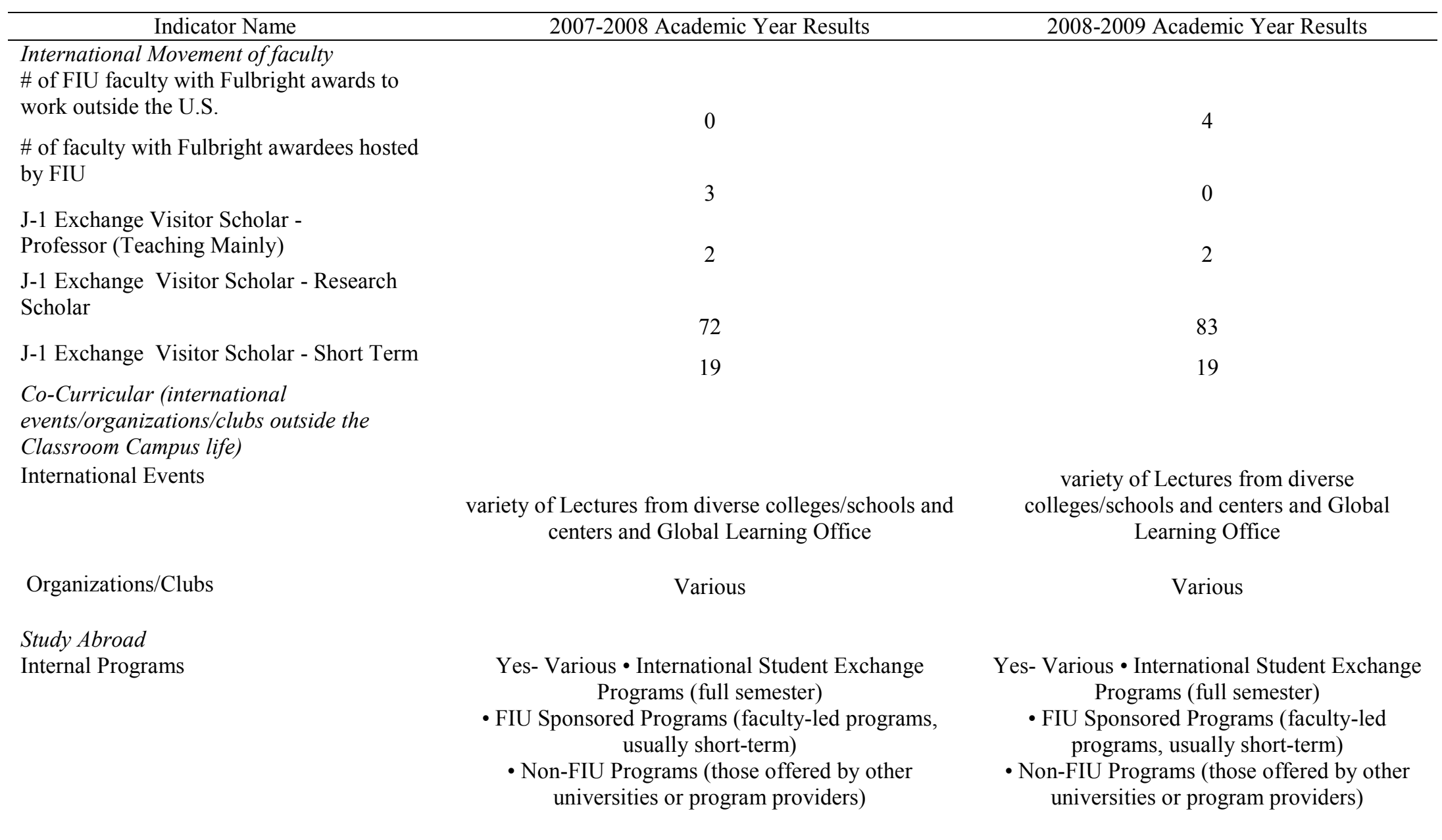

(tables continues) 
Table 8 (continued)

\begin{tabular}{|c|c|c|}
\hline Indicator Name & 2007-2008 Academic Year Results & 2008-2009 Academic Year Results \\
\hline Number of students going abroad & 550 & 617 \\
\hline Number of external exchange students & 25 & $\mathrm{n} / \mathrm{a}$ \\
\hline \multicolumn{3}{|l|}{ Offshore Programs } \\
\hline Number of offshore programs & 9 (active) & 8 (active) \\
\hline Geographic locations & China, Dominican Republic, Jamaica, Mexico & $\begin{array}{c}\text { China, Dominican Republic, Jamaica, } \\
\text { Mexico, and Panama }\end{array}$ \\
\hline \multicolumn{3}{|l|}{$\begin{array}{l}\text { International Development Assistance } \\
\text { (Projects) }\end{array}$} \\
\hline Number of Int. Dev. Projects & 69 & 72 \\
\hline Geographic location & $\begin{array}{l}\text { Australia, China, Colombia, Cuba, Dominican Republic, } \\
\text { Germany, Honduras, India, Israel, Italy, Jamaica, Japan, } \\
\text { Mexico, United Kingdom, Pakistan, United States, } \\
\text { Venezuela, Zambia, Central/South America, } \\
\text { Transcontinental (Spain, Morocco, Colombia, India), } \\
\text { Trans-regional (Central/South America, Indonesia, } \\
\text { Botswana, Sierra Leone \& Nigeria, Canada \& Mexico), } \\
\text { Trans-regional (Kenya, Tanzania, Ecuador, and India). }\end{array}$ & Same as previous academic year \\
\hline Primary Project Area Expertise & $\begin{array}{l}\text { Archeology, Community Construction Management, } \\
\text { Development, Education, Education/Social Sciences, } \\
\text { Freshwater and Coastal Resource, Geology, } \\
\text { Health/Medicine, Hospitality and Tourism Management, } \\
\text { Institutional capacity building, Law, Medicine, Natural } \\
\text { Resources \& Forestry, Policy Analysis, Rural } \\
\text { Development, Social Science, Telecommunication, } \\
\text { Women's Studies, Water Resources. }\end{array}$ & Same as previous academic year \\
\hline
\end{tabular}

(table continues) 
Table 8 (continued)

\begin{tabular}{lc}
\hline Indicator Name & 2007-2008 Academic Year Results \\
\hline Primary Funding Sources & Education and Cultural Affairs Bureau, Ford Foundation, \\
Governments of Sierra Leone and Nigeria, Hevel Eilot & Same as previous academic year \\
Regional Government, Miami-Dade County Government, \\
National Center for Minority Health and Health \\
Disparities, National Institute on Drug Abuse, National \\
Institutes of Health, National Science Foundation, \\
National Science Foundation through the Inter American \\
Institute for Global Change Research, Smithsonian \\
Tropical Research Institute, U.S. Agency for International \\
Development, U.S. State Department, European \\
Commission, University of Miami, Iowa State University.
\end{tabular}


Based on the information provided, the panel of experts was requested to: (a) determine if the international activities in the survey are relevant or not to the hypothetical university presented, and (b) if an international activity chosen was relevant, select the minimum number or percentage the hypothetical university should have of or offer that particular international activity.

The IRI for each item was calculated as the proportion of experts who rated the item as Relevant on a 2-point scale (Relevant and Not Relevant). A minimum IRI of $80 \%$ (10 out of 12) was desired among the panel members for an item to be considered as relevant. Table 9 shows the item relevancy index (IRI) results for each item.

Table 9

Items Relevancy Index Results

\begin{tabular}{|c|c|}
\hline IDI Item & Item Relevancy Index (IRI) \\
\hline Foreign Language & $83 \%(10 / 12)$ \\
\hline $\begin{array}{l}\text { Relevancy of foreign language entrance } \\
\text { requirement for all incoming undergraduate } \\
\text { students }\end{array}$ & $41 \%(5 / 12)$ \\
\hline $\begin{array}{l}\text { Relevancy of foreign language graduation } \\
\text { requirement for all undergraduate students }\end{array}$ & $75 \%(9 / 12)$ \\
\hline International Curriculum & $100 \%(12 / 12)$ \\
\hline International Students & $100 \%(12 / 12)$ \\
\hline Faculty Exchange & $100 \%(12 / 12)$ \\
\hline Co-curriculum & $100 \%(12 / 12)$ \\
\hline Study Abroad & $100 \%(12 / 12)$ \\
\hline Faculty International Development Projects & $100 \%(12 / 12)$ \\
\hline Offshore Programs & $92 \%(11 / 12)$ \\
\hline
\end{tabular}

According to the experts' responses, all items of the IDI are relevant for an HEI placed on position 7 of the Internationalization Cube as their IRIs are above the established minimum level of $80 \%$. For the Foreign Language item, however, the 
subcategory foreign language entrance requirement and foreign language graduation requirement were not considered as relevant as both presented an IRI below $80 \%(41 \%$ and $75 \%$ respectively).

The panel of experts was also requested to determine a minimum number or percentage for each relevant item on the IDI. A comparison of FIU's International Activities Results to the experts' numerical estimation showed the following about FIU's results on international activities.

\section{Foreign Languages}

The low support toward the promotion of and/or proficiency in foreign languages is reflected in FIU's undergraduate and graduate enrollment in foreign languages. Figures 1 and 2 show the panel of experts' responses in terms of the minimum number of undergraduate and graduate student enrollment a university positioned on cell 7 of the Van Dijk and Meijer Internationalization Cube should have. For undergraduate enrollment in Foreign Language programs, $40 \%$ of the experts express agreement that more than 1,501 students should be enrolled, while at the graduate level, $40 \%$ of the panel agreed that the minimum number of graduate enrollment should range from 500 to 1,000 .

According to the Modern Language Association (2006) survey, Enrollments in Languages Other Than English in United States Institutions of Higher Education, Fall 2006, FIU reported a total undergraduate enrollment of 1,784, an upper-division undergraduate enrollment of 720, and a graduate enrollment of 72 . Though a quick glance may show FIU at the undergraduate level is above the panel's response, there is a noteworthy difference between the lower and upper-division undergraduate enrollment. 
This may be due to the fact that lower-division undergraduate students are taking courses to meet the foreign language entrance requirement. At the graduate level, the enrollment is below the panel's response. In addition, enrollment in foreign languages degree programs is significantly lower. FIU reported 219 students for the 2007-2008 academic year and 203 students for the 2008-2009 academic year. FIU had 90 graduate students in 2007-2008 and 99 graduate students in 2008-2009.

The provost commented in this regard by stating that, "We have too long sort of rested on the fact that so many of our students are bilingual in the sense that they speak Spanish at home and go to class in English, and it does sort of meet the basic requirements." However, the provost also explained that some of FIU's Board of Trustees members indicated that that belief is inaccurate, and FIU students have a deficiency in Spanish at the professional level particularly when it comes to writing and translating.

In addition, the provost also explained that FIU has not dedicated funds in past years toward acquiring new technologies available for teaching foreign languages. The rationale for not doing so, according to the Provost, is: "We really haven't invested in that because so few, the vast majority of our students meet the requirement without having to do any of that" (that referring to having to take the foreign language requirement). At the same time, the Chair of the Department of Modern Languages further explained that "Some argue the students already have so many requirements, so they cannot ask for more" (referring to extending the foreign language requirement beyond the first year as it currently stands).

According to the National Security Language Initiative (U.S. Department of Education, 2007), Arabic, Chinese, Russian, Hindi, Farsi, and Japanese are languages 
classified as critical-need foreign languages for Americans to learn. FIU currently offers lower- and upper-division courses in Japanese, Russian, Chinese, and Arabic. However, no degree programs are offered in these languages. The chair of the Modern Languages Department expressed the possibility of proposing a bachelors' degree in Japanese.

The Chair expanded, "We have quite a few advanced level courses offered every semester, so we are getting to that point where we are going to be able to propose a major in Japanese."

Minimum number of undergraduate enrollment in Foreign Language University $X$ should have in an academic year.
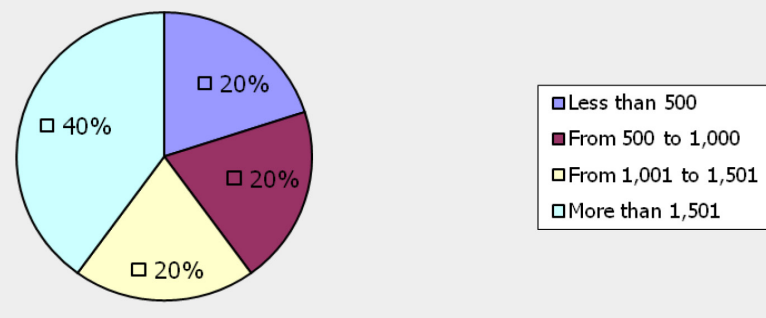

Figure 1. Panel of Experts' Percentage Agreement on Minimum Number of Undergraduate Enrollment in Foreign Language.

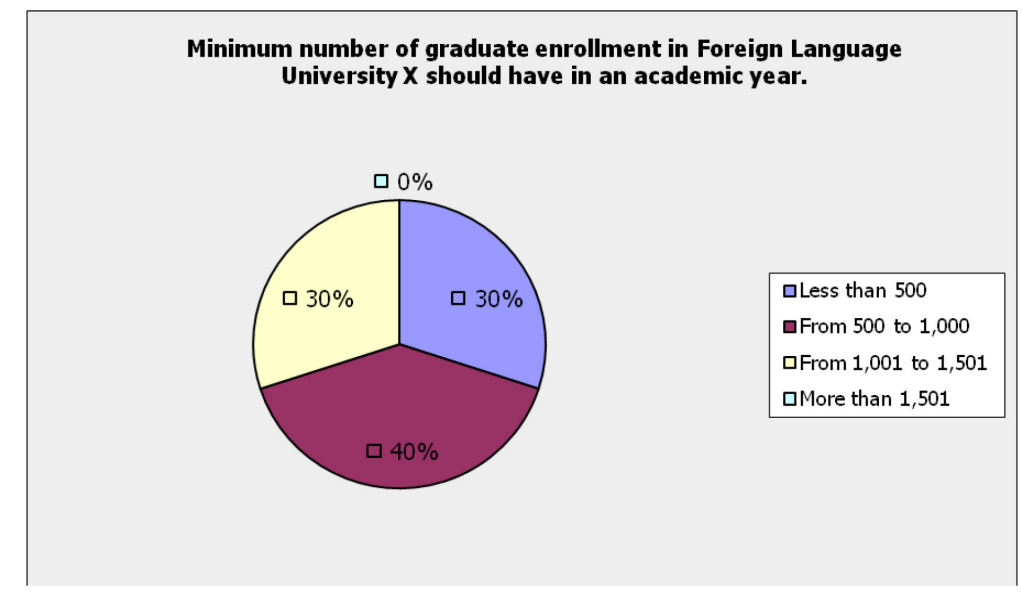

Figure 2. Panel of Experts' Percentage Agreement on Minimum Number of Graduate Enrollment in Foreign Language. 


\section{International Students}

International students on campus bring value not only to the academic setting the students are exposed to but also financial rewards to the institution. International students promote the internationalization of an HEI by "enriching classroom discussions with their different perspectives and expanding the horizons of U.S. students through friendships and out-of-classroom encounters" (Green et al., 2008, p. 19). A report from NAFSA (Association of International Educators [NAFSA], 2009) indicates that international students contribute to the state economy. For the state of Florida, the NAFSA report shows a net contribution of $\$ 806.6$ million by international students and their families (Association of International Educators [NAFSA], 2009, p. 2), and approximately $\$ 79,000$ for FIU and the Miami area. Therefore, the recruitment efforts of international students an HEI has in place serves as an "indicator of commitment toward internationalization" (Green et al., 2008, p. 19).

For the academic years 2007-2008 and 2008-2009, the percentage of international students enrolled at FIU was $6.25 \%$ and $6.38 \%$ respectively, representing far below the $10 \%$ to $25 \%$ the expert panel indicated as minimum enrollment of international students (see Figure 3). The slight increase in international students from one academic year to the next points to the lack of a strategic recruitment plan. According to the Provost, FIU does not have a concerted effort, mainly, as the Provost explained, "Because the whole Miami area is such a focus for immigrants, and whenever we have anybody that visits FIU from around the country, they walk across campus and say what an international campus you have." University-wide, therefore, the notion of FIU being already international limits the support available for the recruitment of international students. 
The recruitment of international students at FIU is more of a one-sided effort left to the schools and colleges than a university-wide endeavor. The Director of Graduate Admissions emphasized that the recruitment of international students "depends heavily on the units." According to the Director, the Graduate Admissions office sets admissions targets for the degree level (doctoral and master's) but not ethnicities. FIU is "overenrolled at the master's level, so the emphasis now is Ph.D.s," the director stated. Consequently, the University Graduate School (UGS) is trying to attract more international students particularly into FIU's Ph.D. programs. To do so, UGS has taken specific actions such as paying $75 \%$ of the international student health insurance and increasing the students' stipends to $\$ 30,000$.

In this regard, a Dean stated that, "The college is not recruiting international students per se, the international students come to us, but not because we put out any effort to recruit international students." Furthermore, the Dean explained that sometimes the university and government regulations after 9/11 make it harder for international students to come to FIU.

A closer look at the geographic areas from where FIU international students come points to three main regions: Central and South America and the Caribbean with over a 1,000 student headcount in 2007-2008 and 2008-2009 academic years, followed by Asia (with 1,000 students) and Europe with less than 200 students. Significantly, numbers of students from the Middle East, Canada and Mexico, and Africa do not reach the 100 headcount. It is not surprising to see FIU's largest group of international students coming from South and Central America and the Caribbean given FIU's location in South 
Florida. According to the Office of International Research, there are a total of 125 countries represented at FIU.

In terms of the academic level, approximately $48 \%$ of international students are undergraduates while $46 \%$ are graduates. At the graduate level, $70 \%$ are enrolled in master's programs which reinforce the effort of the Graduate School to enroll more international students at the Ph.D. level. According to the Office of International Student and Scholar Services website, the top three fields of study for international students are business, engineering, and the social sciences.

In terms of services available to international students at FIU, the Office of International Student and Scholar Services (ISSS) provides assistance on Immigration related issues, such as Visa information (F1 visa holders), Curricular Practical Training (CPT) or Optional Practical Training (OPT). A mandatory immigration orientation session is offered to all new international students arriving on campus at the beginning of the semester. Academic advising is provided in the respective Colleges and Schools.

As for social networks, FIU has an International Students Club. According to its website, the International Students Club was created to provide support and foster understanding of the American way of life. Finally, FIU also has an English Language Institute (ELI) dedicated to English language acquisition. The ELI provides a variety of programs for international students to learn or work on their English capabilities before applying to FIU as a degree-seeking student. Social events are organized within the ELI curriculum to promote cultural understanding. 


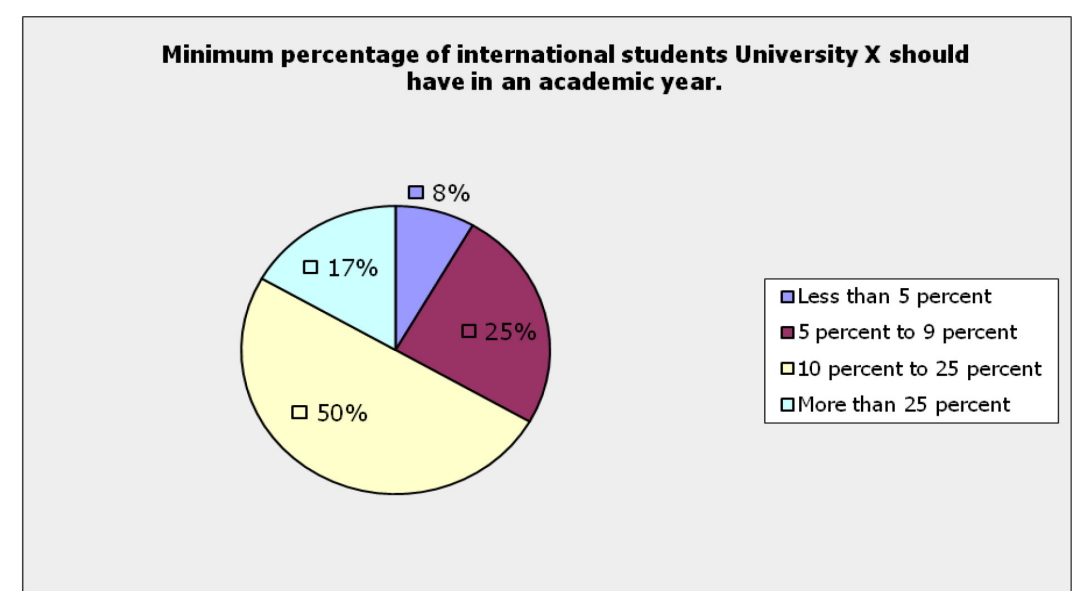

Figure 3. Panel of Experts' Percentage Agreement on Minimum Percentage of International Students.

\section{International Movement of Faculty}

The international movement of faculty refers to the exchange and collaboration of ideas, research and teaching among higher education institutions. According to Fung and Filippo (2002),

International experiences enable professors to have direct interaction with the people and culture of different countries, particularly within the host country's natural setting. Such activity enriches cross-cultural understanding or perspective of a country, and it may be a successful tool in the integration of [our] concepts and theories that govern [our] professional disciplines. (p. 58)

In particular, this section looks at Fulbright Scholars and J-1 Scholars.

Data collected from the Council for International Exchange of Scholars (CIES)

Scholar directory show that FIU had no Fulbright Awards for the Academic year 2007-

2008 but did host three Fulbright Awardees. For the 2008-2009 academic years FIU had four Fulbright Awards and hosted no Fulbright Awardees. According to the expert panel, $59 \%$ agreed that a university placed on position 7 of the Internationalization Cube should have a minimum of 50 to 100 faculty with Fulbright awards (refer to Figure 4). At the same time, $50 \%$ agree that it should host a minimum of 50 to 100 faculty Fulbright 
awardees (refer to Figure 5). A look at the FIU data demonstrates FIU is far below what the experts estimated.

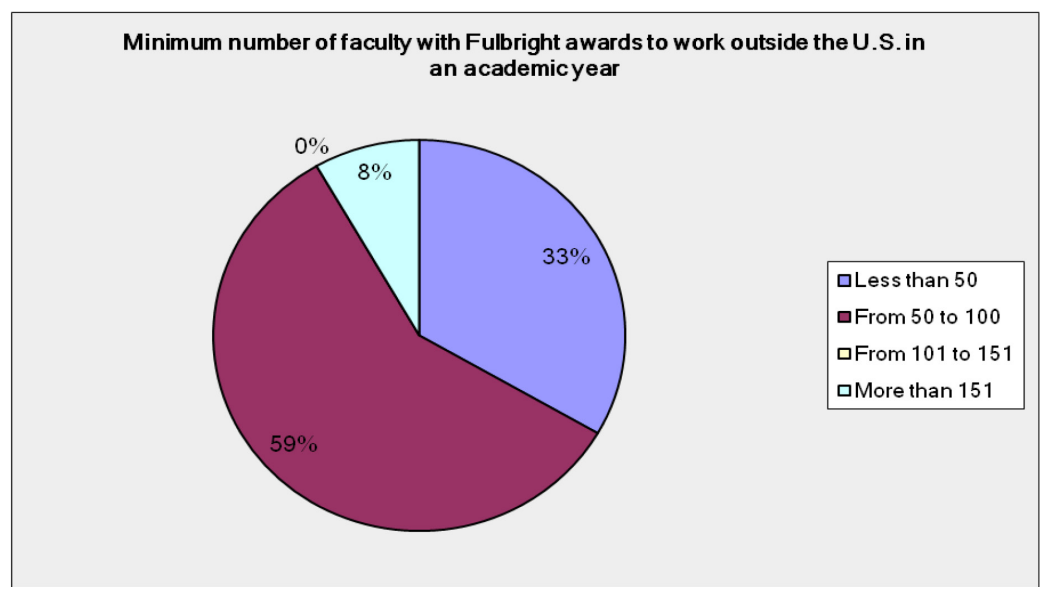

Figure 4. Panel of Experts' Percentage Agreement on Minimum Number of Fulbright Faculty Awards.

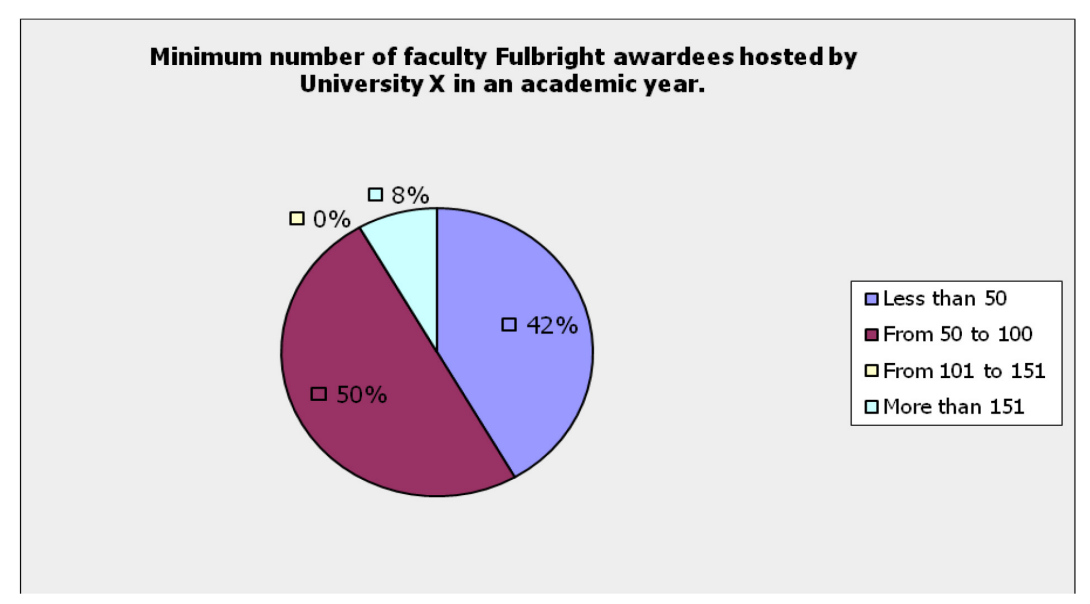

Figure 5. Panel of Experts' Percentage Agreement on Minimum Number of Fulbright Faculty Awardees Hosted at University X.

Though the panel was not asked about the J-1 Scholars the university should have, J-1 Scholars by definition serve a similar purpose as the Fulbright Scholar making it relevant to include the data in the analysis. According to the U.S. Department of State (n.d.), the J-1 Exchange Visitor Program (EVP) "promotes mutual understanding between the people of the United States and the people of other countries through 
educational and cultural exchanges" (Overview, para. 1). In 2007-2008 academic year, FIU reported hosting 72 J-1 Exchange Visitor Scholars and 83 in 2008-2009 who were mainly involved in research. On the other hand, for J-1 Scholars in the teaching only category, FIU reported only two for both academic years, 2007-2008 and 2008-2009. It is not surprising that the largest number of scholars falls under the research category given FIU's emphasis on research. In addition, for a university that has approximately 1,000 full-time faculty members, the total movement of international faculty in either J-1 visas as well as Fulbright scholars for both academic years represents only 10\% of FIU's faculty population.

\section{Study Abroad}

The Office of Education Abroad, under the Division of Undergraduate Education, offers a variety of International Student Exchange Programs (Semester long programs) and FIU Sponsored Programs (summer term faculty-led programs-weeks' long programs). The office's mission is to "promote education abroad programs and international educational exchange, and to help create a community that can respond to the increasing international needs and obligations of the University" (Office of Education Abroad, n.d).

Though the Study Abroad mission statement is aligned to FIU's efforts of promoting global knowledge, the number of students participating abroad is low. According to the panel of experts, $42 \%$ agree that the minimum number of students going abroad should range from $11 \%$ to $20 \%$ (refer to Figure 6). Currently, FIU has an average of 600 students going abroad, which translates to less than $5 \%$ of the student population, and an average of 25 exchange students coming to FIU. 
According to Yao and Hartnett (2009), financial resources available to an office of education abroad serve as a "predictor to estimate the number of study abroad students" (p. 5). FIU's Office of Education abroad counts on a budget of approximately $\$ 200,000$ from the university Education and General fund $(E \& G)$ and an operating budget that comes from the $\$ 175$ program fee charged to each student per program. The operating budget is determined by the total number of students going abroad; therefore, it fluctuates from one term to the next. When presented with the statement that the budget for the Office of Education Abroad was low, the Director of Study Abroad stated that, "Yes, it is. I think it has been kind of dwindling a little bit because of the cuts." The Director continued, "We need to be fundraising a little more, but because again, because of the office being so small, we are stretched very thin." The Director explained that the Director's salary as well as the Assistant Director's salary come from the University's E\&G funds while $50 \%$ of the Program Coordinator's salary comes from the University E\&G funds and $50 \%$ from program fees.

In terms of support, though the Office of Education Abroad is run by three administrative personnel, the office offers a variety of services to faculty and students. The office provides faculty with administrative support in putting programs details together, marketing the programs, managing budgets, as well as recruiting students through study aboard fairs and email. For students, the office presents a structured process for studying abroad, from advising, pre-departure orientation to transferring credits upon return. In addition, despite the limited budget, the study abroad Director explained that the office offers $\$ 300$ scholarships to study abroad. The Office of 
Education Abroad's website presents clear information and a good place for students to start if interested in studying abroad.

The Office of Education Abroad, however, faces several challenges. First, given the student population at FIU, the Office of Education Abroad is understaffed. Yao and Hartnett (2009) reported that though the number of staff members in an office of education abroad is not a direct indication of students going abroad, " a properly staffed OIP [Office of International Programs], especially study abroad directors, professional program coordinators and study abroad advisors, plays a critical role to encourage students and faculty [to go] abroad" (p. 4). The Director elaborated on this subject, "My hope is that we will eventually get another person so that person... if I can get one more line and we can give them more of the student base, then that frees me up to do more of the fundraising to bring in more scholarships."

Second, until recently, the Office of Education Abroad was not strategically placed to enhance its visibility. For many years, the office was located on the $4^{\text {th }}$ floor of the Deuxieme Maison (DM) Building. This location limited its accessibility to only those students going to the DM building or students looking for the study abroad office. In 2009, the Office was relocated to the Charles Perry Building (Primera Casa, PC) close to significant administrative offices for students such as Financial Aid Office, the Registrar's Office, Bursar's Office and the Admissions Office. The new location increases the office's visibility and moved it from a marginalized to a fore-front position.

Third, to further understand FIU's study abroad activities, it is relevant to examine FIU's student population. According to the FIU website, About FIU, "nearly 50 percent of all undergraduate students at FIU receive financial aid, and nearly 60 percent 
of those financial aid recipients come from families with annual household incomes under $\$ 30,000 "$ " (2009). For students who are already on financial aid, getting disposable funds to go abroad can be difficult. A look at the 19 summer short programs the Office of Education Abroad currently advertised for spring and summer 2010, shows that the cost of a study abroad program on average is close to US $\$ 3,500$, not including tuition, US\$175 program fee, airfare, and funds for additional personal expenses. It is important to mention that all short-term programs are self-supported. Therefore, faculty salary and administrative program expenses are covered by the program.

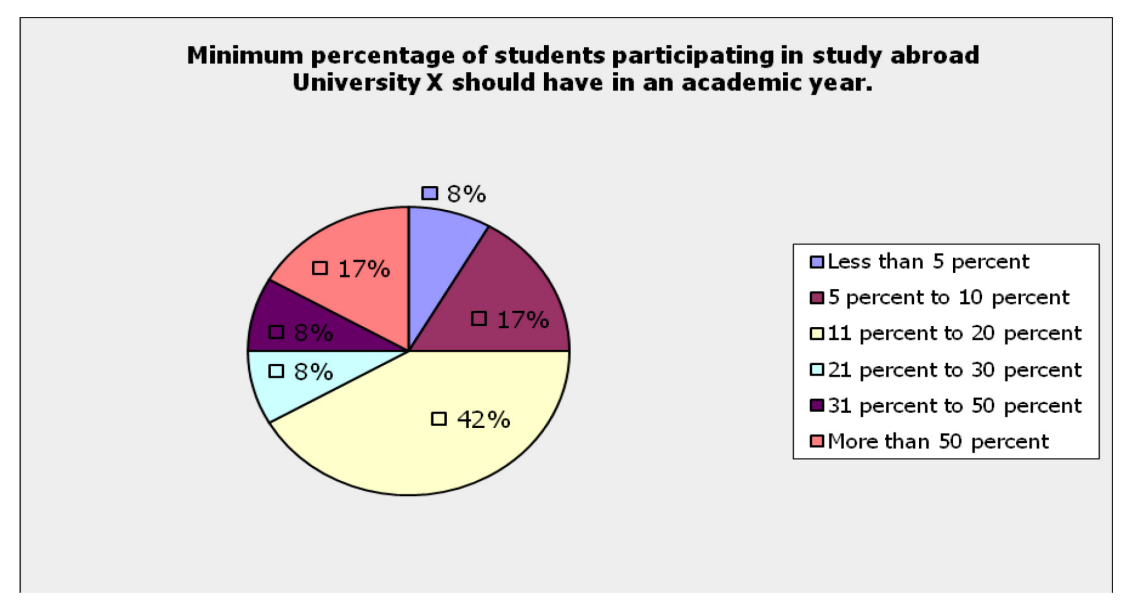

Figure 6. Panel of Experts' Percentage Agreement on Minimum Percentage of Students Participating in Study Abroad.

\section{International Development Projects}

Consistent with the studies of Afonso (1990) and Krane (1994), international development projects serve as other indicators of the level of internationalization within an HEI. Afonso (1990) defined this category as "activities involving technical assistance to developing nations" (p. 42). Furthermore, this category includes funds received "to advance international research and training" (Afonso, 1990, p. 42). 
The panel of experts rated this item as relevant for an HEI, and $67 \%$ estimated that a university placed on position 7 of the Internationalization Cube should have a minimum of 100 faculty involved in international development programs (see Figure 7).

The data collected from the Office of Sponsored Research Administration at FIU and the Association of Public and Land-Grant Universities (APLU)'s International Development Project Database accounted for 69 international grants in the 2007-2008 academic year and 72 for the 2008-2009 academic year, close to the numbers estimated by the expert panel. The grant funds received were oriented toward four types of activities: (a) Training, (b) Research, (c) Community Service, and (d) Fellowship. The total financial contribution for each academic year was \$12.9 million for the 2007-2008 academic year and \$16.2 million for the 2008-2009 academic year. In addition, research and training grants represent $50 \%$ and $40 \%$ respectively of the total funds received. It is significant to mention that FIU is part of the Center for International Business (CIBER) Program. Part of the U.S. Department of Education funds provided to CIBER Centers promotes "curriculum development, research, and training on issues of importance to U.S. trade and competitiveness" (U.S. Department of Education, n.d.). An example of the types of activities CIBER offers is the 14th Annual Mercosur Faculty Development in International Business (FDIB) Program. This program, designed for faculty development in business, is oriented toward enhancing knowledge on how Latin America (especially Brazil, Argentina, and Chile) are dealing with the "global economic crisis and how the 'change' in the U.S. will affect bilateral relations and the regional trading bloc" (CIBER, 2010). 
Engagement in international projects at FIU for 2007-2008 and 2008-2009 academic years shows a variety of areas of involvement from Archeology, Construction Management, Education/Social Sciences, Freshwater and Coastal Resource, Geology, Health/Medicine, Hospitality and Tourism, Management, Law, Social Science, Telecommunication, to Women's Studies to name a few. In terms of the geographic areas, diversity is also seen in the distribution of countries from Australia, China, Colombia, Cuba, Germany, Honduras, India, Israel, Japan, Mexico, to the United Kingdom among others.

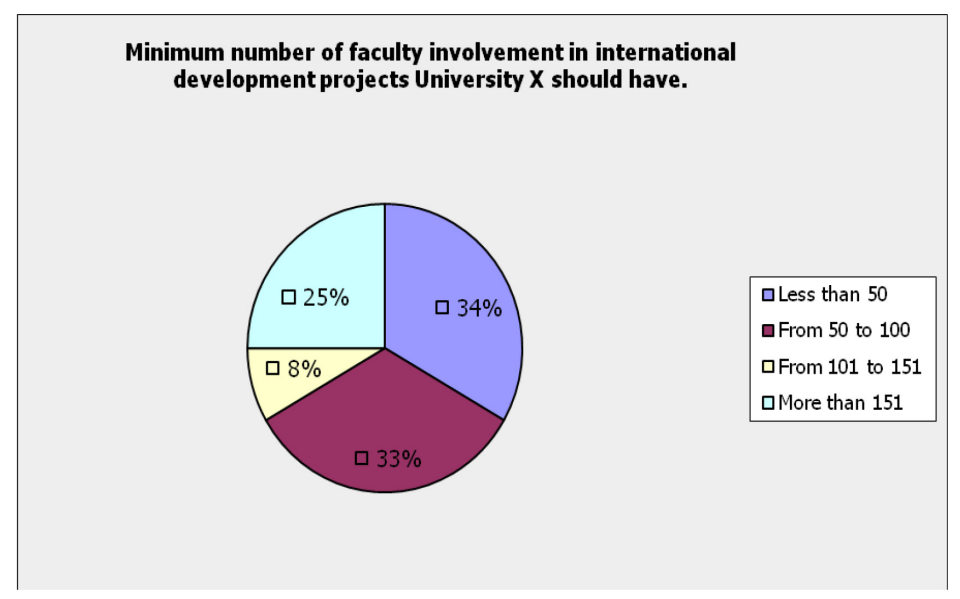

Figure 7. Panel of Experts' Percentage Agreement on Minimum Number of Faculty Involvement in International Development Projects.

\section{Student and Faculty Attitudes Survey on Internationalization}

This section presents the student and faculty attitudes survey results on internationalization to answer Research Question 3 of the study: How do FIU student and faculty attitudes toward internationalization compare on the General Attitudes, Support, and Benefits scales?, and test the hypothesis: There is a relationship between student and faculty attitudes (or vice versa) toward internationalization on the General Attitudes, Support, and Benefits scales at FIU. 


\section{Pilot Study}

A small pilot study $(n=10)$ of five faculty members and students was done. The Students' and Faculty Survey on Internationalization was sent to five students and five FIU faculty members. From the students' responses, a link to the FIU Mission statement was added to the question dealing with FIU Mission statement. Revisions were also made to the wording of some questions for clarity based on the responses to the Faculty Attitude Survey.

\section{Participants}

The Students' Attitudes Survey on Internationalization was distributed to all FIU students via the FIU students email list-serv system during the month of January 2010. Of the 59,985 recipients on the distribution list, $n=552$ responses were received leading to a response rate of $0.92 \%$.

The Faculty Attitude Survey on Internationalization was distributed to a sample of the faculty $(n=442)$ during the spring semester via groups and personalized emails and hand-delivery. The number of completed faculty survey was low ( $n=98)$ leading to a faculty response rate of $22.1 \%$. For both samples, the response rate received was below the minimum $60 \%$ desired as recommended by the Division of Instructional Innovation and Assessment at the University of Texas at Austin (2007). Table 10 below shows a breakdown of the participating student and faculty demographics. 
Table 10

Student and Faculty Demographics

\begin{tabular}{|c|c|c|}
\hline Demographics' Variables & $\begin{array}{c}\text { Students } \\
(n=552) \\
\%\end{array}$ & $\begin{array}{c}\text { Faculty } \\
(n=98) \\
\%\end{array}$ \\
\hline \multicolumn{3}{|l|}{ Gender } \\
\hline Female & 70.3 & 45.9 \\
\hline Male & 29.7 & 54.1 \\
\hline \multicolumn{3}{|l|}{ Race/Ethnicity } \\
\hline Black/African-American & 5.8 & 7.1 \\
\hline Hispanic & 58.5 & 13.3 \\
\hline Asian & 6.9 & 7.1 \\
\hline White Non-Hispanic & 20.5 & 59.2 \\
\hline Other & 8.3 & 13.3 \\
\hline \multicolumn{3}{|l|}{ Ages (students) } \\
\hline $18-22$ years & 40 & - \\
\hline 23-29 years & 35.7 & - \\
\hline $30-45$ years & 20.8 & - \\
\hline $46-50$ years & 1.3 & - \\
\hline 51 and over & 2.2 & - \\
\hline \multicolumn{3}{|l|}{ Class level } \\
\hline Undergraduate & 60.9 & - \\
\hline Graduate & 39.1 & - \\
\hline \multicolumn{3}{|l|}{ Students Status } \\
\hline Full-time & 80.1 & - \\
\hline Part-time & 19.9 & - \\
\hline \multicolumn{3}{|l|}{ Ages (Faculty) } \\
\hline Less than 36 years & - & 5.1 \\
\hline $36-40$ years & - & 8.2 \\
\hline $41-45$ years & - & 9.2 \\
\hline $46-50$ years & - & 19.4 \\
\hline 51 and over & - & 58.2 \\
\hline \multicolumn{3}{|l|}{ Tenure status } \\
\hline Tenured & - & 50 \\
\hline Tenure Earning & - & 15.3 \\
\hline Non-Tenured & - & 34.7 \\
\hline
\end{tabular}


Demographic data collected from the student and faculty surveys were compared to demographic data reported by the FIU Facts Sheet and the Office of Planning and Institutional Effectiveness to establish some faculty and student populations' parameters. A comparison of both demographic data seems to represent FIU students and faculty population (Carley, Cheurprakobkit, Paracka, 2006).

Students and faculty were also surveyed on past experiences regarding study abroad participation, knowledge of travel grants for students, awareness of cocurriculum, offshore programs participation, and international faculty. Table 11 below shows the breakdown of the students and faculty past experiences:

Table 11

Student and Faculty Experiences

\begin{tabular}{lcc}
\hline \multicolumn{1}{c|}{ Experiences' Variables } & $\begin{array}{c}\text { Students } \\
(n=552) \\
\%\end{array}$ & $\begin{array}{c}\text { Faculty } \\
(n=98) \\
\%\end{array}$ \\
\hline Visited Office of Study & & \\
Abroad & 78.6 & 76.5 \\
$\quad$ No & 21.4 & 23.5 \\
$\quad$ Yes & & \\
International Travel Grants & & 50 \\
Awareness & 62.3 & 50 \\
No & 37.7 & \\
$\quad$ Yes & & - \\
Awareness of Co-Curriculum & & - \\
International Activities & & \\
No & 27.9 & - \\
Yes & 72.1 & (table continues) \\
Participated in Study Abroad & & \\
No & & \\
Yes & 84.1 & \\
\hline & 15.9 & \\
\end{tabular}


Table 11 (continued)

\begin{tabular}{|c|c|c|}
\hline Experiences' Variables & $\begin{array}{c}\text { Students } \\
(n=552) \\
\%\end{array}$ & $\begin{array}{c}\text { Faculty } \\
(n=98) \\
\%\end{array}$ \\
\hline Like to Participate in Study & & Like to Participate in Study \\
\hline Abroad & & Abroad \\
\hline No & 22.5 & No \\
\hline Yes & 77.5 & Yes \\
\hline \multirow{2}{*}{\multicolumn{3}{|c|}{$\begin{array}{l}\text { Participated in Study Abroad- } \\
\text { Faculty Role }\end{array}$}} \\
\hline & & \\
\hline No & - & 68.4 \\
\hline Yes & - & 31.6 \\
\hline \multicolumn{3}{|l|}{ Like to Participate in Study } \\
\hline \multicolumn{3}{|l|}{ Abroad - Faculty Role } \\
\hline No & - & 22.4 \\
\hline Yes & - & 77.6 \\
\hline \multicolumn{3}{|l|}{$\begin{array}{l}\text { Have participated in Offshore } \\
\text { programs }\end{array}$} \\
\hline No & - & 57.1 \\
\hline Yes & - & 42.9 \\
\hline \multicolumn{3}{|c|}{$\begin{array}{l}\text { Like to participate in Offshore } \\
\text { programs }\end{array}$} \\
\hline No & - & 20.4 \\
\hline Yes & - & 79.6 \\
\hline \multicolumn{3}{|l|}{ International Faculty (Not } \\
\hline \multicolumn{3}{|l|}{ Born in the U.S.) } \\
\hline No & - & 61.2 \\
\hline Yes & - & 38.8 \\
\hline
\end{tabular}

The Students' and Faculty's Attitude Surveys on Internationalization were analyzed in two parts: (a) A Psychometric analysis was performed through the computation of factor analyses and reliability, and (b) Spearman Rho correlations analysis of the surveys' General Attitudes, Support, and Benefits scales with demographics and experiences variables. 


\section{Psychometric Analysis}

Three steps were followed for factor analysis: (a) computation of correlation matrix, (b) extraction of factors through the Principal Component Method, and (c) varimax rotation of extracted factors.

Student Attitudes Survey on Internationalization. The Students' Attitude

Survey on Internationalization consists of a total of 39 items. Of the 39 items, only the 26 Likert-type- items corresponding to the scales General Attitudes About Internationalization, FIU's Support for Internationalization, and Benefits of Internationalization, were subjected to factor analysis to reduce the data into latent variables.

An examination of the correlation matrix demonstrated the items in the survey have high correlations and do cluster together with a yielded Kaiser-Meyer-Olkin (KMO) value of .902 and a Bartlett's Test of Sphericity value of 6225.35 and an associated level of significance of .000 . The Bartlett's Test of Sphericity value confirms the adequacy of the correlation matrix.

The first run of the factor analysis lead to four factors. However, even though the fourth factor reported an eigenvalue of 1.14 , representing $4.388 \%$ of the variance, a look at the scree plot (see Figure 8 below) showed three factors before the elbow line began. In addition, a look at the rotated component matrix shows that the two items appearing in the fourth factor can be grouped into one of the three factors. As a result, a factor analysis was run a second time with only three factors. 


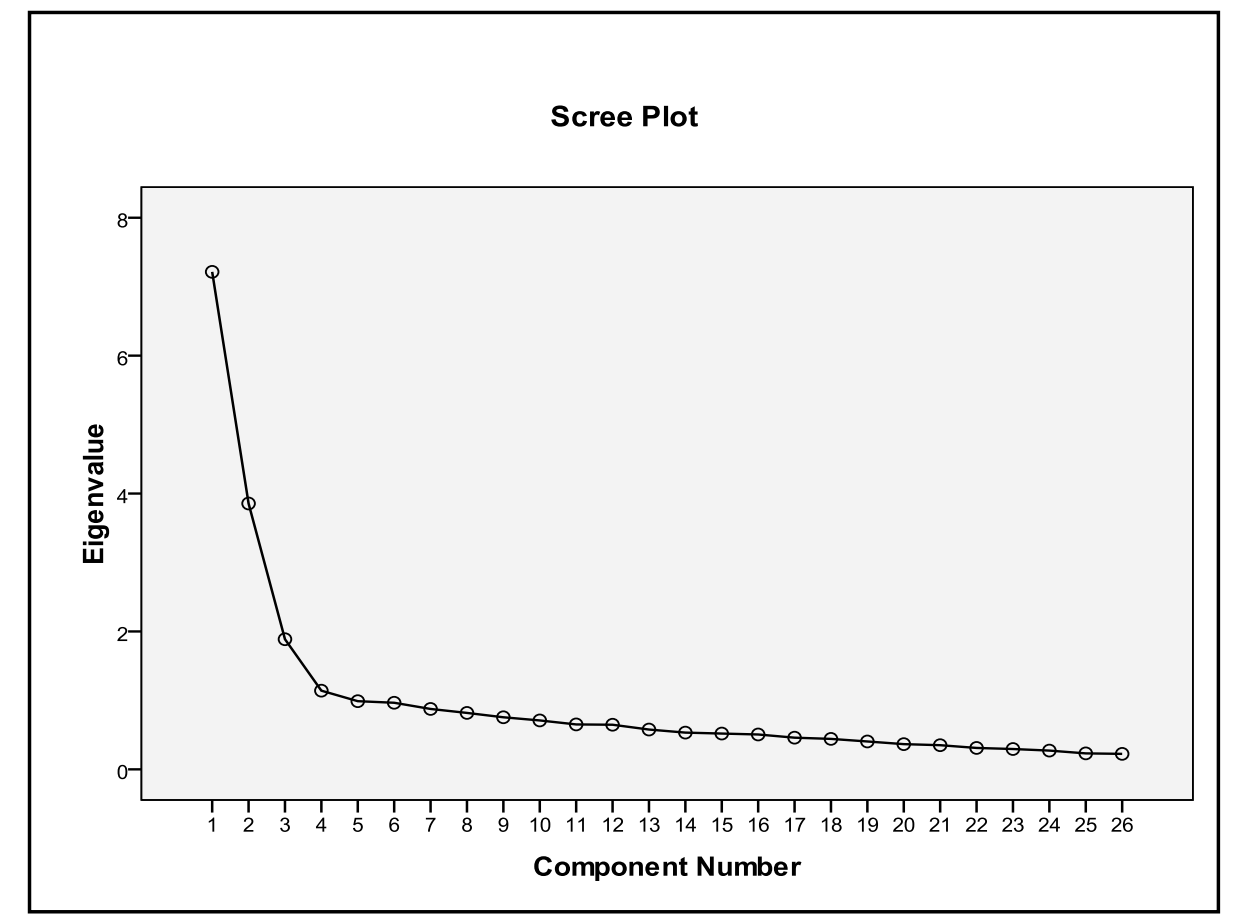

Figure 8. Student Factors Scree Plot.

An examination of the three factors total variance explained matrix showed that the three factors account for $49.83 \%$ of the total variance with eigenvalues of $7.21,3.85$, and 1.88 respectively. No cross-loaded items among the three factors were seen.

A preliminary review of the rotated component variance showed that three items of the survey had a factor loading of less than .4. These items were not included in the analysis.

A further review of the rotated component variance shows that Factor 1 is composed of nine items. A closer look at the items demonstrated that the six items from the Benefits of Internationalization scale loaded into that factor. The remaining three items came from the general attitudes scale. Because all nine items underlie the Benefits of Internationalization, Factor 1 was labeled Benefits. The highest item loading of the factor, International Education helps me recognize and understand the impact of other 
cultures have on American life and vice versa, presented a loading value of .806. The lowest item loading, International education can explain the root causes of basic global problems such as overpopulation, poverty, climate change, and disease, presented a loading value of .587 .

Factor 2 included seven items all from the FIU's Support for Internationalization scale. As a result, factor 2 was labeled Support. The highest item loading on the factor, $I$ have been encouraged in my department to take courses that incorporate international content, reported a factor loading of .792. The statement My courses with international content have provided examples from all regions of the world had the lowest factor loading of .6222.

Finally, Factor 3 was comprised of seven items from the General Attitudes about Internationalization scale. Consequently, Factor 3 was labeled General Attitudes. The item FIU's Global Leaning Quality Enhancement Plan is understood and discussed by all FIU stakeholders (students, administrators, and faculty), had a factor loading of .740 compared to the lowest factor loading of .460, for the item FIU's exchange programs with institutions in other countries foster internationalization of instruction, research, and service learning. The detailed Rotated Component Matrix for the three factors is presented in Appendix P.

The internal consistency reliability for the three factors representing the scales was determined using the Cronbach's Alpha method. Table 12 shows the Cronbach's Alpha coefficients for each factor: 
Table 12

Student Factors Reliability Statistics

\begin{tabular}{lcc}
\hline \multicolumn{1}{c}{ Factors } & Cronbach's Alpha & N of Items \\
\hline Factor 1- Benefits & .888 & 9 \\
Factor 2- Support & .877 & 7 \\
Factor 3- General Attitudes & .808 & 7 \\
\hline
\end{tabular}

All three factors met the minimum desired .70 Cronbach's Alpha coefficient value (Nunnally, 1978) indicating that all the items are reliable and the survey presents a high internal consistency (Ho, 2006). In addition, the analysis of the Item-Total correlations matrix for Factor 2 and 3 confirms that all items in the respective factors should be retained. The deletion of any of the items will not improve the above stated Cronbach's Alpha coefficient value. For factor 1, the last two items indicated that deleting the items would increase the Cronbach's value to .890 . However, given the current Cronbach's coefficient for Factor 1 would only increase by .002 if the items were retained. Furthermore, both items presented a corrected Item-Total correlation of .500 and .519 indicating "the factor loading meets the minimum level of practical significance" (Ho, p. 207).

Faculty Attitudes Survey on Internationalization. The Faculty Attitudes Survey on Internationalization consists of a total of 45 items. Of the 45 items, only the 30 Likert-type- items corresponding to the scales General Attitudes About Internationalization, FIU's Support for Internationalization, and Benefits of Internationalization, were subjected to the process of factor analysis. 
An examination of the correlation matrix also demonstrated the items in the faculty survey have high correlations and do cluster together with a yielded KaiserMeyer-Olkin (KMO) value of .833 and a Bartlett's Test of Sphericity value of 1897.157 and an associated level of significance of .000. The Bartlett's Test of Sphericity value confirms the adequacy of the correlation matrix.

The first run of factor analysis on the 30 Likert-type- items of the faculty survey led to six factors of eigenvalues greater than 1 . However, a closer look at the scree plot diagram (Figure 9 below) showed a three-factor's model.

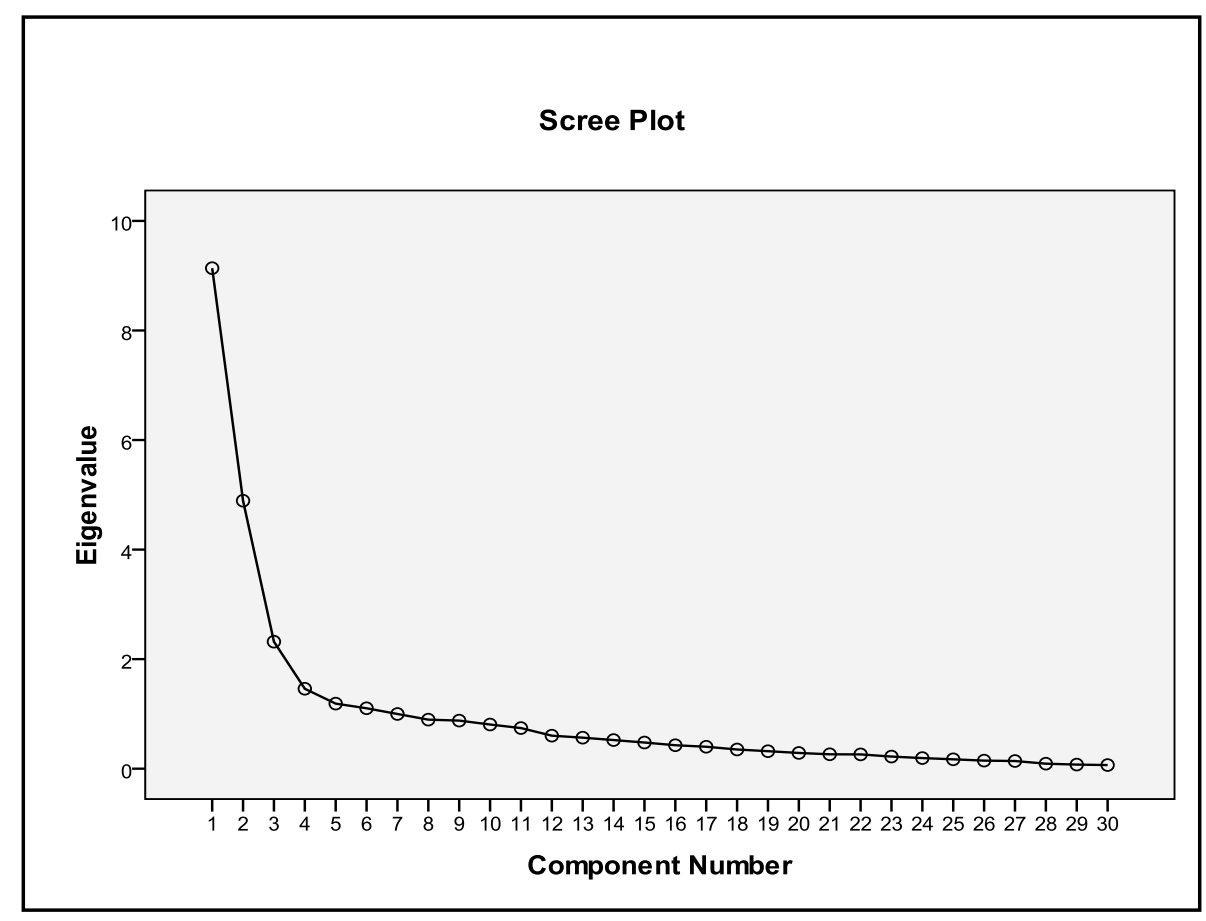

Figure 9. Faculty Factors Scree Plot.

A second run of factor analysis was performed using three factors. An examination of the Total Variance Explained matrix shows that the three factors extracted account for $30.53 \%, 16.58 \%$, and $7.16 \%$ of the variance respectively, representing a 
cumulative $54.28 \%$ of the total variance. The reported eigenvalues were of $9.13,4.89$, and 2.31

The Rotated Component Matrix on Appendix R presents the three factors with their respective loadings, as well as the four items not loading into any factors. One item, FIU's Global Learning Quality Enhancement Plan is understood and discussed by all FIU stakeholders (students, administrators, and faculty), cross-loaded in Factors 1 and 3. Therefore, it was deleted to obtain a clear interpretation.

Factor 1 contains all 10 items from the Support scale. Since Factor 1 underlies Support to Internationalization, it was labeled Support. The highest item loading of the factor, My College/School/Department encourages me to conduct research on international topics, presented a loading value of .850. The lowest item loading, $M y$ College/School/Department provides seminars/training/workshops to faculty on internationalizing the curriculum, presented a loading value of .589.

Factor 2 contains 10 items, all six items from the Benefits of Internationalization scale and four items from the General Attitudes toward Internationalization scale (items from General Attitudes scales are marked by an Asterisk in Appendix Q). Given that all 10 items reflect Benefits of internationalization, Factor 2 was labeled Benefits. The highest loaded item of the factor was, The more we know about other countries, the better we will understand our own, with a factor loading of .912. The lowest item loading was represented by the statement Learning a foreign language is not essential for an undergraduate education, with a factor loading of .440.

Finally, Factor 3 contains five items, all from the General Attitudes Toward Internationalization scale. As a result, Factor 3 was labeled General Attitudes. The 
highest factor item loading in Factor 3 was FIU's current mission statement supports the definition of internationalization presented, with a factor loading of .724. The statement/item International learning is an important element of the educational process at FIU, had the lowest factor loading of .673.

The internal consistency reliability for the three Factors representing the scales was determined using the Cronbach's Alpha method. Table 13 shows the Cronbach's Alpha coefficients for each factor:

Table 13

Faculty Factors Reliability Statistics

\begin{tabular}{lcc}
\hline \multicolumn{1}{c}{ Factors } & Cronbach's Alpha & N of Items \\
\hline Factor 1- Support & .921 & 10 \\
Factor 2- Benefits & .901 & 10 \\
Factor 3- General Attitudes & .836 & 5 \\
\hline
\end{tabular}

All three factors met the minimum desired .70 Cronbach's Alpha coefficient value (Nunnally, 1978). These results indicated that all the items are reliable and the survey has a high internal consistency $(\mathrm{Ho}, 2006)$. In addition, the analysis of the Item-Total correlations matrix for Factor 1 and 3 confirms that all items in the respective factors should be retained. The deletion of any of the items would not have improved the above stated Cronbach's Alpha coefficient value. For Factor 2, the last item indicated that deleting the item would increase the Cronbach's value to .923 . However, given the current Cronbach's coefficient for Factor 2, it would only increase by .022, the item was retained. 
The Student and Faculty Surveys Toward Internationalization presented three scales, General Attitudes, Support and Benefits of Internationalization. Factor Analysis reported a three factors model for both the students and faculty survey representing the three scales: General Attitudes, Support, and Benefits.

\section{Student and Faculty Survey Responses Toward Internationalization}

As a matter of consistency, descriptive statistics and Spearman Rho correlations on items were analyzed by student and faculty factors.

\section{Student and Faculty General Attitudes Toward Internationalization Factor}

Student and Faculty reported overall positive general attitudes toward internationalization. On a 5-point Likert-type-scale, with the highest number indicating strong agreement and positive attitude, students and faculty reported an overall mean score of 3.5 and 3.6 respectively. Table 14 shows Student and Faculty General Attitude's factor descriptive statistics:

Table 14

Student and Faculty General Attitudes Toward Internationalization Descriptive Statistics

\begin{tabular}{|c|c|c|c|c|c|c|c|c|}
\hline \multirow[t]{2}{*}{ Statement } & \multicolumn{2}{|c|}{$\begin{array}{l}\text { Agree (Strongly } \\
\text { agree \& Agree) }\end{array}$} & \multicolumn{2}{|c|}{ Neutral } & \multicolumn{2}{|c|}{$\begin{array}{c}\text { Disagree } \\
\text { (Strongly disagree } \\
\text { \& Disagree) }\end{array}$} & \multicolumn{2}{|c|}{ Mean Score } \\
\hline & $\mathrm{S}$ & $\mathrm{F}$ & $\mathrm{S}$ & $\mathrm{F}$ & $\mathrm{S}$ & $\mathrm{F}$ & $\mathrm{S}$ & $\mathrm{F}$ \\
\hline $\begin{array}{l}\text { FIU's Global } \\
\text { Learning } \\
\text { Quality } \\
\text { Enhancement } \\
\text { Plan is } \\
\text { understood } \\
\text { and discussed } \\
\text { by all } \\
\text { stakeholders } \\
\text { (students, } \\
\text { administrators } \\
\text {, and faculty). }\end{array}$ & $\begin{array}{c}153 \\
(28 \%)\end{array}$ & - & $\begin{array}{c}161 \\
(29 \%)\end{array}$ & - & $\begin{array}{c}238 \\
(43 \%)\end{array}$ & - & 2.80 & - \\
\hline
\end{tabular}


Table 14 (continued)

\begin{tabular}{|c|c|c|c|c|c|c|c|c|}
\hline \multirow[t]{2}{*}{ Statement } & \multicolumn{2}{|c|}{$\begin{array}{l}\text { Agree (Strongly } \\
\text { agree \& Agree) }\end{array}$} & \multicolumn{2}{|c|}{ Neutral } & \multicolumn{2}{|c|}{$\begin{array}{c}\text { Disagree } \\
\text { (Strongly disagree } \\
\text { \& Disagree) }\end{array}$} & \multicolumn{2}{|c|}{ Mean Score } \\
\hline & $\mathrm{S}$ & $\mathrm{F}$ & $\mathrm{S}$ & $\mathrm{F}$ & $\mathrm{S}$ & $\mathrm{F}$ & $\mathrm{S}$ & $\mathrm{F}$ \\
\hline $\begin{array}{l}\text { The process } \\
\text { of } \\
\text { internationali } \\
\text { zation is } \\
\text { understood } \\
\text { and discussed } \\
\text { by all FIU } \\
\text { stakeholders } \\
\text { (students, } \\
\text { administrators } \\
\text {, and faculty). }\end{array}$ & $\begin{array}{c}219 \\
(40 \%)\end{array}$ & $\begin{array}{c}27 \\
(28 \%)\end{array}$ & $\begin{array}{c}141 \\
(25 \%)\end{array}$ & $\begin{array}{c}33 \\
(34 \%)\end{array}$ & $\begin{array}{c}192 \\
(35 \%)\end{array}$ & $\begin{array}{c}38 \\
(39 \%)\end{array}$ & 3.04 & 2.81 \\
\hline $\begin{array}{l}\text { FIU's current } \\
\text { mission } \\
\text { statement } \\
\text { supports the } \\
\text { definition of } \\
\text { internationali } \\
\text { zation } \\
\text { presented } \\
\text { above. }\end{array}$ & $\begin{array}{c}376 \\
(68 \%)\end{array}$ & $\begin{array}{c}70 \\
(71 \%)\end{array}$ & $\begin{array}{c}86 \\
(16 \%)\end{array}$ & $\begin{array}{c}12 \\
(12 \%)\end{array}$ & $\begin{array}{c}90 \\
(16 \%)\end{array}$ & $\begin{array}{c}16 \\
(16 \%)\end{array}$ & 3.70 & 3.84 \\
\hline $\begin{array}{l}\text { There is a } \\
\text { genuine } \\
\text { commitment } \\
\text { to } \\
\text { internationali } \\
\text { zation at FIU }\end{array}$ & $\begin{array}{c}344 \\
(62 \%)\end{array}$ & $\begin{array}{c}58 \\
(59 \%)\end{array}$ & $\begin{array}{c}145 \\
(26 \%)\end{array}$ & $\begin{array}{c}27 \\
(28 \%)\end{array}$ & $\begin{array}{c}63 \\
(11 \%)\end{array}$ & $\begin{array}{c}13 \\
(13 \%)\end{array}$ & 3.62 & 3.64 \\
\hline $\begin{array}{l}\text { International } \\
\text { learning is an } \\
\text { important } \\
\text { element of the } \\
\text { educational } \\
\text { process. }\end{array}$ & $\begin{array}{c}409 \\
(74 \%)\end{array}$ & $\begin{array}{c}58 \\
(59 \%)\end{array}$ & $\begin{array}{c}73 \\
(13 \%)\end{array}$ & $\begin{array}{c}22 \\
(22 \%)\end{array}$ & $\begin{array}{c}70 \\
(13 \%)\end{array}$ & $\begin{array}{c}18 \\
(18 \%)\end{array}$ & 3.88 & 3.58 \\
\hline $\begin{array}{l}\text { Internationali } \\
\text { zation is a } \\
\text { component of } \\
\text { FIU's 3.0: A } \\
\text { new Strategic } \\
\text { Paradigm } \\
\text { Plan. }\end{array}$ & $\begin{array}{c}304 \\
(55 \%)\end{array}$ & $\begin{array}{c}81 \\
(83 \%)\end{array}$ & $\begin{array}{c}216 \\
(39 \%)\end{array}$ & $\begin{array}{c}13 \\
(13 \%)\end{array}$ & $\begin{array}{c}32 \\
(6 \%)\end{array}$ & $\begin{array}{c}4 \\
(4 \%)\end{array}$ & 3.66 & 4.17 \\
\hline
\end{tabular}

(table continues) 
Table 14 (continued)

\begin{tabular}{|c|c|c|c|c|c|c|c|c|}
\hline \multirow[t]{2}{*}{ Statement } & \multicolumn{2}{|c|}{$\begin{array}{l}\text { Agree (Strongly } \\
\text { agree \& Agree) }\end{array}$} & \multicolumn{2}{|c|}{ Neutral } & \multicolumn{2}{|c|}{$\begin{array}{c}\text { Disagree } \\
\text { (Strongly disagree } \\
\text { \& Disagree) }\end{array}$} & \multicolumn{2}{|c|}{ Mean Score } \\
\hline & $\mathrm{S}$ & $F$ & $S$ & $F$ & $\mathrm{~S}$ & $F$ & $S$ & $F$ \\
\hline $\begin{array}{l}\text { FIU exchange } \\
\text { programs } \\
\text { with } \\
\text { institutions in } \\
\text { other } \\
\text { countries } \\
\text { foster } \\
\text { internationali } \\
\text { zation of } \\
\text { instruction, } \\
\text { research, and } \\
\text { service } \\
\text { learning. }\end{array}$ & $\begin{array}{c}449 \\
(81 \%)\end{array}$ & - & $\begin{array}{c}77 \\
(14 \%)\end{array}$ & - & $\begin{array}{c}26 \\
(5 \%)\end{array}$ & - & 4.16 & - \\
\hline
\end{tabular}

Note. $\mathrm{S}=$ Students, $\mathrm{F}=$ Faculty; Scale ranged from 1 to 5 , with a lower number indicating stronger disagreement/attitude.

Students expressed a strong agreement (agree and strongly agree) on the following items: FIU exchange programs with institutions in other countries foster internationalization of instruction, research and service leaning (81\%), and International learning is an important element of the educational process (74\%). Faculty, on the other hand, reported a strong agreement with the statements: Internationalization is a component of FIU's 3.0: A New Strategic Paradigm Plan (83\%) and FIU's Current Mission statement supports the definition of internationalization (71\%).

Both students and faculty reported disagreement with the statement, The process of internationalization is understood and discussed by all FIU stakeholders (students, administrators, and faculty). Only 40\% $(M=3.04)$ of the students agree with the previous statement while faculty reported a $28 \%(M=2.81)$. In addition, only $28 \%(M=2.80)$ of 
the students expressed agreement with the statement FIU's Global Learning Quality

Enhancement Plan is understood and discussed by all stakeholders (students,

administrators, and faculty).

\section{Student and Faculty Perceived Support Toward Internationalization Factor}

Overall, students and faculty reported a less positive attitude regarding perceived support toward internationalization $(M=3.4, M=3.1$, respectively). Table 15 presents the student and faculty descriptive statistics of their perceived support of internationalization:

Table 15

Student and Faculty Support for Internationalization Descriptive Statistics

\begin{tabular}{|c|c|c|c|c|c|c|c|c|}
\hline \multirow[t]{2}{*}{ Statement } & \multicolumn{2}{|c|}{$\begin{array}{l}\text { Agree (Strongly } \\
\text { agree \& Agree) }\end{array}$} & \multicolumn{2}{|c|}{ Neutral } & \multicolumn{2}{|c|}{$\begin{array}{c}\text { Disagree } \\
\text { (Strongly } \\
\text { disagree \& } \\
\text { Disagree) }\end{array}$} & \multicolumn{2}{|c|}{ Mean Score } \\
\hline & $\mathrm{S}$ & $\mathrm{F}$ & $\mathrm{S}$ & $\mathrm{F}$ & $\mathrm{S}$ & $\mathrm{F}$ & $\mathrm{S}$ & $\mathrm{F}$ \\
\hline $\begin{array}{l}\text { I have been } \\
\text { encouraged in my } \\
\text { department to } \\
\text { take/offer courses } \\
\text { that incorporate } \\
\text { international } \\
\text { content. }\end{array}$ & $\begin{array}{c}287 \\
(52 \%)\end{array}$ & $\begin{array}{c}62 \\
(63 \%)\end{array}$ & $\begin{array}{c}83 \\
(15 \%)\end{array}$ & $\begin{array}{c}20 \\
(20 \%)\end{array}$ & $\begin{array}{c}182 \\
(33 \%)\end{array}$ & $\begin{array}{c}16 \\
(16 \%)\end{array}$ & 3.35 & 3.74 \\
\hline $\begin{array}{l}\text { My } \\
\text { College/School/De } \\
\text { partment } \\
\text { encourages me to } \\
\text { conduct research on } \\
\text { international topics. }\end{array}$ & $\begin{array}{c}285 \\
(52 \%)\end{array}$ & $\begin{array}{c}39 \\
(40 \%)\end{array}$ & $\begin{array}{c}126 \\
(23 \%)\end{array}$ & $\begin{array}{c}32 \\
(33 \%)\end{array}$ & $\begin{array}{c}141 \\
(25 \%)\end{array}$ & $\begin{array}{c}27 \\
(28 \%)\end{array}$ & 3.38 & 3.14 \\
\hline $\begin{array}{l}\text { My } \\
\text { College/School/De } \\
\text { partment strongly } \\
\text { promotes students } \\
\text { engagement in } \\
\text { internationalization }\end{array}$ & $\begin{array}{c}333 \\
(60 \%)\end{array}$ & $\begin{array}{c}53 \\
(54 \%)\end{array}$ & $\begin{array}{c}118 \\
(21 \%)\end{array}$ & $\begin{array}{c}22 \\
(22 \%)\end{array}$ & $\begin{array}{c}101 \\
(18 \%)\end{array}$ & $\begin{array}{c}23 \\
(23 \%)\end{array}$ & 3.64 & 3.45 \\
\hline
\end{tabular}

(table continues) 
Table 15 (continued)

\begin{tabular}{|c|c|c|c|c|c|c|c|c|}
\hline \multirow[t]{2}{*}{ Statement } & \multicolumn{2}{|c|}{$\begin{array}{l}\text { Agree (Strongly } \\
\text { agree \& Agree) }\end{array}$} & \multicolumn{2}{|c|}{ Neutral } & \multicolumn{2}{|c|}{$\begin{array}{c}\text { Disagree } \\
\text { (Strongly } \\
\text { disagree \& } \\
\text { Disagree) }\end{array}$} & \multicolumn{2}{|c|}{ Mean Score } \\
\hline & $\mathrm{S}$ & $F$ & $\mathrm{~S}$ & 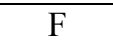 & $\mathrm{S}$ & $\mathrm{F}$ & $\mathrm{S}$ & $F$ \\
\hline $\begin{array}{l}\text { My } \\
\text { College/School/D } \\
\text { epartment } \\
\text { encourages me to } \\
\text { participate in } \\
\text { study abroad } \\
\text { program. }\end{array}$ & $\begin{array}{c}258 \\
(47 \%)\end{array}$ & $\begin{array}{c}30 \\
(31 \%)\end{array}$ & $\begin{array}{c}119 \\
(22 \%)\end{array}$ & $\begin{array}{c}28 \\
(29 \%)\end{array}$ & $\begin{array}{c}175 \\
(32 \%)\end{array}$ & $\begin{array}{c}40 \\
(41 \%)\end{array}$ & 3.24 & 2.79 \\
\hline $\begin{array}{l}\text { My } \\
\text { College/School/D } \\
\text { epartment } \\
\text { encourages me to } \\
\text { attend } \\
\text { international } \\
\text { symposiums/lectur } \\
\text { es on campus }\end{array}$ & $\begin{array}{c}293 \\
(53 \%)\end{array}$ & $\begin{array}{c}41 \\
(42 \%)\end{array}$ & $\begin{array}{c}116 \\
(21 \%)\end{array}$ & $\begin{array}{c}33 \\
(34 \%)\end{array}$ & $\begin{array}{c}143 \\
(26 \%)\end{array}$ & $\begin{array}{c}24 \\
(24 \%)\end{array}$ & 3.39 & 3.27 \\
\hline $\begin{array}{l}\text { My } \\
\text { College/School/D } \\
\text { epartment takes } \\
\text { advantage of } \\
\text { community } \\
\text { resources to } \\
\text { enhance the } \\
\text { international } \\
\text { learning } \\
\text { experience. }\end{array}$ & $\begin{array}{c}252 \\
(46 \%)\end{array}$ & $\begin{array}{c}41 \\
(42 \%)\end{array}$ & $\begin{array}{c}160 \\
(29 \%)\end{array}$ & $\begin{array}{c}30 \\
(31 \%)\end{array}$ & $\begin{array}{c}140 \\
(25 \%)\end{array}$ & $\begin{array}{c}27 \\
(28 \%)\end{array}$ & 3.27 & 3.15 \\
\hline $\begin{array}{l}\text { My courses with } \\
\text { international } \\
\text { content have } \\
\text { provided } \\
\text { examples from all } \\
\text { regions of the } \\
\text { world }\end{array}$ & $\begin{array}{c}310 \\
(56 \%)\end{array}$ & - & $\begin{array}{c}121 \\
(22 \%)\end{array}$ & - & $\begin{array}{c}121 \\
(22 \%)\end{array}$ & - & 3.48 & - \\
\hline $\begin{array}{l}\text { My } \\
\text { College/School/D } \\
\text { epartment takes } \\
\text { provides } \\
\text { seminars/training/ } \\
\text { workshops to } \\
\text { faculty yon } \\
\text { internationalizing } \\
\text { the curriculum. }\end{array}$ & - & $\begin{array}{c}33 \\
(34 \%)\end{array}$ & - & $\begin{array}{c}27 \\
(28 \%)\end{array}$ & - & $\begin{array}{c}38 \\
(39 \%)\end{array}$ & - & 2.97 \\
\hline
\end{tabular}

(table continues) 
Table 15 (continued)

\begin{tabular}{|c|c|c|c|c|c|c|c|c|}
\hline \multirow[t]{2}{*}{ Statement } & \multicolumn{2}{|c|}{$\begin{array}{l}\text { Agree (Strongly } \\
\text { agree \& Agree) }\end{array}$} & \multicolumn{2}{|c|}{ Neutral } & \multicolumn{2}{|c|}{$\begin{array}{c}\text { Disagree } \\
\text { (Strongly } \\
\text { disagree \& } \\
\text { Disagree) }\end{array}$} & \multicolumn{2}{|c|}{ Mean Score } \\
\hline & $\mathrm{S}$ & $\mathrm{F}$ & $\mathrm{S}$ & $\mathrm{F}$ & $\mathrm{S}$ & $\mathrm{F}$ & $\mathrm{S}$ & $\mathrm{F}$ \\
\hline $\begin{array}{l}\text { My } \\
\text { College/School/D } \\
\text { epartment } \\
\text { encourages me to } \\
\text { belong to an } \\
\text { international } \\
\text { professional } \\
\text { organization. }\end{array}$ & - & $\begin{array}{c}36 \\
(37 \%)\end{array}$ & - & $\begin{array}{c}23 \\
(23 \%)\end{array}$ & - & $\begin{array}{c}39 \\
(40 \%)\end{array}$ & - & 2.97 \\
\hline $\begin{array}{l}\text { My } \\
\text { College/School/D } \\
\text { epartment } \\
\text { encourages me to } \\
\text { serve as Faculty } \\
\text { Advisor to } \\
\text { Students } \\
\text { Organizations } \\
\text { involved in } \\
\text { projects with an } \\
\text { international } \\
\text { focus. }\end{array}$ & - & $\begin{array}{c}20 \\
(20 \%)\end{array}$ & - & $\begin{array}{c}34 \\
(35 \%)\end{array}$ & - & $\begin{array}{c}44 \\
(45 \%)\end{array}$ & - & 2.66 \\
\hline $\begin{array}{l}\text { My } \\
\text { College/School/D } \\
\text { epartment } \\
\text { encourages me to } \\
\text { publish on } \\
\text { international or } \\
\text { global issues. }\end{array}$ & - & $\begin{array}{c}36 \\
(37 \%)\end{array}$ & - & $\begin{array}{c}34 \\
(35 \%)\end{array}$ & - & $\begin{array}{c}28 \\
(29 \%)\end{array}$ & - & 3.10 \\
\hline
\end{tabular}

Note. $\mathrm{S}=$ Students, $\mathrm{F}=$ Faculty; Scale ranged from 1 to 5 , with a lower number indicating stronger disagreement/attitude.

Students demonstrated strong agreement with the statements: $M y$

College/School/Department strongly promotes students engagement in

internationalization (60\%), My courses with international content have provided

examples from all regions of the world (56\%), and My College/School/Department 
encourages me to attend international symposiums/lectures on campus (53\%), and I have been encouraged in my department to take courses that incorporate international content $(52 \%)$.

Similar to the students, faculty showed strong agreement with the statements $I$ have been encouraged in my department to offer courses that incorporate international content (63\%), My College/School/Department strongly promotes faculty engagement in internationalization (54\%), and My College/School/Department encourages me to attend international symposiums/lectures on campus (42\%).

Faculty indicated a strong disagreement with the following items: $M y$ College/School/Department encourages me to serve as Faculty Advisor to Student Organizations involved in projects with an international focus (45\%), My College/School/Department provides seminars/training/workshops to faculty on internationalizing the curriculum (39\%), and My College/School/Department encourages me to belong to an international professional organization (40\%). Finally, faculty also indicated disagreement with My College/School/Department encourages me to participate in study a abroad program (41\%), which seems to be aligned with the $31.6 \%$ response of faculty that indicated having participated in study abroad compared to $77.6 \%$ that would like to participate.

\section{Student and Faculty Perceived Benefits of Internationalization Factor}

Both students and faculty reported a strong positive attitude toward the benefits of internationalization with mean scores of 4.3 for the students and 4.2 for faculty respectively. Table 16 presents the Student and Faculty perceived Benefits of Internationalization descriptive statistics: 
Table 16

Student and Faculty Benefits of Internationalization Descriptive Statistics

\begin{tabular}{|c|c|c|c|c|c|c|c|c|}
\hline \multirow[t]{2}{*}{ Statement } & \multicolumn{2}{|c|}{$\begin{array}{l}\text { Agree (Strongly } \\
\text { agree \& Agree) }\end{array}$} & \multicolumn{2}{|c|}{ Neutral } & \multicolumn{2}{|c|}{$\begin{array}{c}\text { Disagree } \\
\text { (Strongly } \\
\text { disagree \& } \\
\text { Disagree) }\end{array}$} & \multicolumn{2}{|c|}{ Mean Score } \\
\hline & $\mathrm{S}$ & $\mathrm{F}$ & $\mathrm{S}$ & $\mathrm{F}$ & $\mathrm{S}$ & $\mathrm{F}$ & $\mathrm{S}$ & $\mathrm{F}$ \\
\hline $\begin{array}{l}\text { International } \\
\text { education helps me } \\
\text { recognize and } \\
\text { understand the impact } \\
\text { other cultures have on } \\
\text { American life and } \\
\text { vice versa. }\end{array}$ & $\begin{array}{c}517 \\
(94 \%)\end{array}$ & $\begin{array}{c}88 \\
(90 \%)\end{array}$ & $\begin{array}{c}22 \\
(4 \%)\end{array}$ & $\begin{array}{c}7 \\
(7 \%)\end{array}$ & $\begin{array}{c}13 \\
(2 \%)\end{array}$ & $\begin{array}{c}3 \\
(3 \%)\end{array}$ & 4.46 & 4.41 \\
\hline $\begin{array}{l}\text { International } \\
\text { learning makes me } \\
\text { appreciate more of } \\
\text { other cultures. }\end{array}$ & $\begin{array}{c}513 \\
(93 \%)\end{array}$ & $\begin{array}{c}87 \\
(89 \%)\end{array}$ & $\begin{array}{c}23 \\
(4 \%)\end{array}$ & $\begin{array}{c}5 \\
(5 \%)\end{array}$ & $\begin{array}{l}16 . \\
(3 \%)\end{array}$ & $\begin{array}{c}6 \\
(6 \%)\end{array}$ & 4.46 & 4.37 \\
\hline $\begin{array}{l}\text { The more we know } \\
\text { about other cultures, } \\
\text { the better we will } \\
\text { understand our own }\end{array}$ & $\begin{array}{c}481 \\
(87 \%)\end{array}$ & $\begin{array}{c}81 \\
(83 \%)\end{array}$ & $\begin{array}{c}43 \\
(8 \%)\end{array}$ & $\begin{array}{c}10 \\
(10 \%)\end{array}$ & $\begin{array}{c}28 \\
(5 \%)\end{array}$ & $\begin{array}{c}7 \\
(7 \%)\end{array}$ & 4.30 & 4.27 \\
\hline $\begin{array}{l}\text { International learning } \\
\text { helps prepare } \\
\text { students to become } \\
\text { responsible global } \\
\text { citizens. }\end{array}$ & $\begin{array}{c}509 \\
(92 \%)\end{array}$ & $\begin{array}{c}89 \\
(91 \%)\end{array}$ & $\begin{array}{c}28 \\
(5 \%)\end{array}$ & $\begin{array}{c}5 \\
(5 \%)\end{array}$ & $\begin{array}{c}15 \\
(3 \%)\end{array}$ & $\begin{array}{c}4 \\
(4 \%)\end{array}$ & 4.40 & 4.36 \\
\hline $\begin{array}{l}\text { Learning other } \\
\text { cultures helps me } \\
\text { better tolerate } \\
\text { ambiguity when } \\
\text { communicating with } \\
\text { a foreign person. }\end{array}$ & $\begin{array}{c}506 \\
(92 \%)\end{array}$ & $\begin{array}{c}83 \\
(85 \%)\end{array}$ & $\begin{array}{c}29 \\
(5 \%)\end{array}$ & $\begin{array}{c}10 \\
(10 \%)\end{array}$ & $\begin{array}{c}17 \\
(3 \%)\end{array}$ & $\begin{array}{c}5 \\
(5 \%)\end{array}$ & 4.39 & 4.30 \\
\hline $\begin{array}{l}\text { Learning about } \\
\text { people from different } \\
\text { cultures is a very } \\
\text { important part of } \\
\text { education. }\end{array}$ & $\begin{array}{c}514 \\
(93 \%)\end{array}$ & $\begin{array}{c}94 \\
(96 \%)\end{array}$ & $\begin{array}{c}25 \\
(4 \%)\end{array}$ & $\begin{array}{c}3 \\
(3 \%)\end{array}$ & $\begin{array}{c}13 \\
(2 \%)\end{array}$ & $\begin{array}{c}1 \\
(1 \%)\end{array}$ & 4.56 & 4.60 \\
\hline $\begin{array}{l}\text { I believe an } \\
\text { understanding of } \\
\text { international issues is } \\
\text { important for success } \\
\text { in the workforce. }\end{array}$ & $\begin{array}{c}479 \\
(87 \%)\end{array}$ & $\begin{array}{c}80 \\
(82 \%)\end{array}$ & $\begin{array}{c}48 \\
(9 \%)\end{array}$ & $\begin{array}{c}9 \\
(9 \%)\end{array}$ & $\begin{array}{c}25 \\
(4 \%)\end{array}$ & $\begin{array}{c}9 \\
(9 \%)\end{array}$ & 4.33 & 4.14 \\
\hline
\end{tabular}

(table continues) 
Table 16 (continued)

\begin{tabular}{|c|c|c|c|c|c|c|c|c|}
\hline \multirow[t]{2}{*}{ Statement } & \multicolumn{2}{|c|}{$\begin{array}{l}\text { Agree (Strongly } \\
\text { agree \& Agree) }\end{array}$} & \multicolumn{2}{|c|}{ Neutral } & \multicolumn{2}{|c|}{$\begin{array}{c}\text { Disagree } \\
\text { (Strongly } \\
\text { disagree \& } \\
\text { Disagree) } \\
\end{array}$} & \multicolumn{2}{|c|}{ Mean Score } \\
\hline & $\mathrm{S}$ & $F$ & $\mathrm{~S}$ & $F$ & $\mathrm{~S}$ & $\mathrm{~F}$ & $\mathrm{~S}$ & $\mathrm{~F}$ \\
\hline $\begin{array}{l}\text { Students can } \\
\text { understand their own } \\
\text { culture more fully if } \\
\text { they have studied } \\
\text { another }\end{array}$ & $\begin{array}{c}470 \\
(85 \%)\end{array}$ & $\begin{array}{c}85 \\
(87 \%)\end{array}$ & $\begin{array}{c}36 \\
(6 \%)\end{array}$ & $\begin{array}{c}9 \\
(9 \%)\end{array}$ & $\begin{array}{c}46 \\
(8 \%)\end{array}$ & $\begin{array}{c}4 \\
(4 \%)\end{array}$ & 4.19 & 4.33 \\
\hline $\begin{array}{l}\text { International } \\
\text { education can explain } \\
\text { the root causes of } \\
\text { basic global problems } \\
\text { such as } \\
\text { overpopulation, } \\
\text { poverty, climate } \\
\text { change, and disease. }\end{array}$ & $\begin{array}{c}430 \\
(78 \%)\end{array}$ & $\begin{array}{c}68 \\
(69 \%)\end{array}$ & $\begin{array}{c}72 \\
(13 \%)\end{array}$ & $\begin{array}{c}18 \\
(18 \%)\end{array}$ & $\begin{array}{c}50 \\
(9 \%)\end{array}$ & $\begin{array}{c}12 \\
(12 \%)\end{array}$ & 4.04 & 3.81 \\
\hline $\begin{array}{l}\text { Learning a foreign } \\
\text { language is not } \\
\text { essential for an } \\
\text { undergraduate } \\
\text { education. }\end{array}$ & - & $\begin{array}{c}18 \\
(18 \%)\end{array}$ & - & $\begin{array}{c}12 \\
(12 \%)\end{array}$ & - & $\begin{array}{c}68 \\
(69 \%)\end{array}$ & - & 3.80 \\
\hline
\end{tabular}

Note. $\mathrm{S}=$ Students, $\mathrm{F}=$ Faculty; Scale ranged from 1 to 5 , with a lower number indicating stronger disagreement/attitude.

Strong agreement was shown by both students and faculty with the statements:

International Education helps me recognize and understand the impact of other cultures

have on American life and vice versa (94\% students and 90\% faculty), International

learning helps prepare students to become global citizens (92\% students and $91 \%$

faculty), and Learning about people from different cultures is a very important part of

education (93\% students and 96\% faculty). Lower mean scores within the Benefits factor

were reported by faculty and students on the statement about international education

being able to explain the root causes of global issues ( $M=4.04$ and 3.81 respectively). 
To further the understanding of the students and faculty attitudes, Spearman's rho correlations were run for the students and faculty factors' means with the various demographic variables as well as the faculty and student experiences (yes/no questions).

\section{Students' Correlations with Demographic Variables}

The factors, General Attitudes toward internationalization, Perceived Benefits of Internationalization, and Support for Internationalization, were correlated with the demographic variables: Age, Gender, Race/Ethnicity, Class Status, Student Status, and Work Status. Table 17 shows the student factors significant correlation results with demographics variables:

Table 17

Student Factors Correlations with Demographics

\begin{tabular}{lccc}
\hline $\begin{array}{c}\text { Students Demographic } \\
\text { Variables }\end{array}$ & $\begin{array}{c}\text { Mean General } \\
\text { Attitude toward } \\
\text { internationalization } \\
\text { (Factor 3) }\end{array}$ & $\begin{array}{c}\text { Mean Perception } \\
\text { of the Benefits of }\end{array}$ & $\begin{array}{c}\text { Mean Support } \\
\text { for }\end{array}$ \\
& -.078 & .004 & -.029 \\
Age & -.008 & $-.130^{* *}$ & .020 \\
Gender & $.091^{*}$ & .041 & .018 \\
Race/Ethnicity & $-.101^{*}$ & .036 & -.013 \\
Class & -.015 & -.021 & -.063 \\
Student Status & .006 & -.005 & .050 \\
Work Status & & &
\end{tabular}

Note. ${ }^{*} \mathrm{p}<.05 ;{ }^{*} \mathrm{p}<.01 ; \quad$ Gender $($ female $=1$, male $=2)$; Race $($ Non Hispanic $=0$, Hispanic $=1) ;$ Age $(18-22$ years $=1$, 23-29 years $=2,30-45$ years $=3,46-50$ years $=4,51$ years and over $=5$ ), Your Class $($ Undergraduate $=1$, Graduate $=2)$, Your Student Status (Full-Time=1, Part-Time=2), Your Work Status (Full-Time Worker=1,Part-Time Worker=2, Not Employed=3).

The General Attitudes Toward Internationalization factor was significantly positively correlated with Race/Ethnicity (Hispanics vs. non Hispanics), $\mathrm{r}_{\mathrm{s}}=.091, \mathrm{p}<.05$. 
Specifically, this finding indicated that Hispanics reported a significantly more favorable general attitude toward internationalization than non-Hispanics.

An analysis of the General Attitudes Toward Internationalization factor items showed statistically significant associations between the underlying distributions of the scores of Hispanic and non-Hispanic students on three out of seven items: FIU's Global Learning Quality Enhancement Plan is understood and discussed by all FIU stakeholders $\left(\mathrm{r}_{\mathrm{s}}=.103, \mathrm{p}<.05\right)$, There is a genuine commitment of internationalization at FIU $\left(\mathrm{r}_{\mathrm{s}}=.098\right.$, $\mathrm{p}<.05)$, and FIU's current mission statement supports the definition of internationalization $\left(\mathrm{r}_{\mathrm{s}}=.093, \mathrm{p}<.05\right)$. For all three items, Hispanics had significantly more favorable general attitudes toward internationalization.

Also, the General Attitudes Toward Internationalization factor was significantly negative correlated with class $\left(\mathrm{r}_{\mathrm{s}}=-.101, \mathrm{p}<.05\right)$. Undergraduate students had significantly more favorable general attitudes toward internationalization than graduate students. A more detailed analysis of the factor's items denote statistically significant associations between the underlying distributions of the scores of undergraduate and graduates students for two items: FIU's current mission statement support the definition of internationalization presented $\left(\mathrm{r}_{\mathrm{s}}=-.132, \mathrm{p}<.01\right)$ and International learning is an important element of the educational process at FIU $\left(\mathrm{r}_{\mathrm{s}}=-.091, \mathrm{p}<.05\right)$. For both items, undergraduates had more favorable general attitudes than graduate students.

The Perceived Benefits of Internationalization was significantly correlated with gender, $\mathrm{r}_{\mathrm{s}}=-.130, \mathrm{p}<.01$. Female students had significantly more favorable perceptions of the benefits of internationalization than male students. An analysis of the Perceived Benefits of Internationalization factor items revealed statistically significant associations 
between the underlying distributions of the scores of male and female students on five of the nine statements: International learning makes me appreciate more other cultures $\left(\mathrm{r}_{\mathrm{s}}=\right.$ $-.149, \mathrm{p}<.01)$, International education can explain the root causes of basic global problems such as overpopulation, poverty, climate change and disease $\left(\mathrm{r}_{\mathrm{s}}=-.133, \mathrm{p}\right.$ $<.01)$, International education helps me recognize and understand the impact other cultures have on American life and vice versa $\left(\mathrm{r}_{\mathrm{s}}=-.123, \mathrm{p}<.01\right)$, Learning other cultures helps me better tolerate ambiguity when communicating with a foreign person $\left(\mathrm{r}_{\mathrm{s}}=-.122\right.$, $\mathrm{p}<.01$ ), International learning helps prepare students to become responsible global citizens $\left(\mathrm{r}_{\mathrm{s}}=-.118, \mathrm{p}<.01\right)$, and I believe an understanding of international issues is important for success in the workforce $\left(\mathrm{r}_{\mathrm{s}}=-.103, \mathrm{p}<.05\right)$. For all statements, female students perceived significantly more benefits of internationalization than male students. Perceived Benefits of Internationalization was not significantly correlated with

the demographic variables Age, Race/Ethnicity, Class Status, Student Status, and Work Status. General Attitudes toward internationalization was not significantly correlated with the demographic variables Age, Student Status, and Work Status. Support for Internationalization was not significantly correlated with any of the demographic variables.

\section{Students' Correlations With Experience Variables}

The three factors were tested for correlation with the experience variables: Visited FIU's Office of Education Abroad, Knowledge on international travel grants for students, Knowledge of co-curricular international activities, Participated in Study Abroad, Like to Participate in Study Abroad. 
Table 18 shows the student factors significant correlation results with experience

variables:

Table 18

Student Factors Correlations with Experiences

\begin{tabular}{|c|c|c|c|}
\hline $\begin{array}{c}\text { Students Experience } \\
\text { Variables }\end{array}$ & $\begin{array}{c}\text { Mean General } \\
\text { Attitude toward } \\
\text { internationalization } \\
\text { (Factor 3) }\end{array}$ & $\begin{array}{l}\text { Mean Perception } \\
\text { of the Benefits of } \\
\text { internationalization } \\
\text { (Factor } 1)\end{array}$ & $\begin{array}{l}\text { Mean Support } \\
\text { for } \\
\text { internationaliza- } \\
\text { tion (Factor 2) } \\
\end{array}$ \\
\hline $\begin{array}{l}\text { Have you visited FIU's Office } \\
\text { of Education Abroad? }\end{array}$ & $.112^{* *}$ & $.138^{* *}$ & $.224^{* *}$ \\
\hline $\begin{array}{l}\text { Do you know if there are } \\
\text { international travel grants } \\
\text { offered to FIU students? }\end{array}$ & $.096^{*}$ & $.120^{* *}$ & $.223^{* *}$ \\
\hline $\begin{array}{l}\text { Do you know if there are co- } \\
\text { curricular international activities } \\
\text { on campus? (i.e. international } \\
\text { festivals or clubs) }\end{array}$ & .063 & -.015 & $.221^{* *}$ \\
\hline $\begin{array}{l}\text { Have you ever participated in a } \\
\text { study abroad program? }\end{array}$ & $.091^{*}$ & $.159^{* *}$ & $.197^{* *}$ \\
\hline $\begin{array}{l}\text { Would you like to participate in } \\
\text { a study abroad program? }\end{array}$ & .072 & $.228^{* *}$ & .048 \\
\hline
\end{tabular}

Note. ${ }^{*} \mathrm{p}<.05 ;{ }^{* *} \mathrm{p}<.01$; Have visited FIU's Office of Education Abroad (no=0, yes=1); Do you know if there are international travel grants for students (no $=0$, yes $=1$ ); Have participated in Study Abroad (no $=0$, yes $=1$ ), Would like to participate in Study Abroad (no $=0$, yes $=1$ )

The General Attitudes Toward Internationalization factor was significantly positively correlated with the following questions: (a) Have you visited FIU's Office of Education Abroad?, (b) Do you know if there are international travel grants offered to FIU students?, and (c) Have you ever participated in a study abroad program?. These findings indicate that students have more favorable general attitudes toward internationalization when students have visited the office of education abroad $\left(\mathrm{r}_{\mathrm{s}}=.112\right.$, 
$\mathrm{p}<.01)$, have knowledge of international travel grants for students $\left(\mathrm{r}_{\mathrm{s}}=.096, \mathrm{p}<.05\right)$, and have participated in study abroad $\left(\mathrm{r}_{\mathrm{s}}=.091, \mathrm{p}<.05\right)$.

Table 19 shows the analysis of the General Attitudes toward Internationalization

Factor items with the significant correlated questions Have you visited FIU's Office of

Education Abroad?, Do you know if there are international travel grants offered to FIU

students?, and Have you ever participated in a study abroad program?.

Table 19

Student General Attitudes Factor Items Correlations Results

\begin{tabular}{|c|c|c|c|}
\hline $\begin{array}{c}\text { General Attitudes Factor Items } \\
\text { (Students) }\end{array}$ & $\begin{array}{c}\text { Have you } \\
\text { visited FIU's } \\
\text { Office of } \\
\text { Education } \\
\text { Abroad? }\end{array}$ & $\begin{array}{l}\text { Do you know if } \\
\text { there are } \\
\text { international } \\
\text { travel grants } \\
\text { offered to FIU } \\
\text { students? }\end{array}$ & $\begin{array}{l}\text { Have you ever } \\
\text { participated in a } \\
\text { study abroad } \\
\text { program? }\end{array}$ \\
\hline \multicolumn{4}{|l|}{ FIU's Global Learning Quality } \\
\hline \multicolumn{4}{|l|}{$\begin{array}{l}\text { Enhancement Plan is } \\
\text { understood and discussed by all }\end{array}$} \\
\hline \multicolumn{4}{|l|}{$\begin{array}{l}\text { FIU stakeholders (students, } \\
\text { administrators, and faculty). }\end{array}$} \\
\hline $\begin{array}{l}\text { The process of } \\
\text { internationalization is } \\
\text { understood and discussed by all }\end{array}$ & & & \\
\hline \multicolumn{4}{|l|}{$\begin{array}{l}\text { FIU stakeholders (students, } \\
\text { administrators, and faculty). }\end{array}$} \\
\hline $\begin{array}{l}\text { FIU's current mission } \\
\text { statement supports the } \\
\text { definition of } \\
\text { internationalization presented }\end{array}$ & $.084^{*}$ & & \\
\hline $\begin{array}{l}\text { There is a genuine commitment } \\
\text { to internationalization at FIU. }\end{array}$ & $.104 *$ & $.109 *$ & \\
\hline
\end{tabular}

(table continues) 
Table 19 (continued)

\begin{tabular}{lccc}
\hline $\begin{array}{c}\text { General Attitudes Factor Items } \\
\text { (Students) }\end{array}$ & $\begin{array}{c}\text { Have you } \\
\text { visited FIU's } \\
\text { Office of } \\
\text { Education } \\
\text { Abroad? }\end{array}$ & $\begin{array}{c}\text { Do you know if } \\
\text { there are } \\
\text { international } \\
\text { travel grants } \\
\text { offered to FIU } \\
\text { students? }\end{array}$ & $\begin{array}{c}\text { Have you ever } \\
\text { participated in a } \\
\text { study abroad } \\
\text { program? }\end{array}$ \\
\hline $\begin{array}{l}\text { International learning is an } \\
\text { important element of the } \\
\text { educational process at FIU }\end{array}$ & $.136^{* *}$ & \\
$\begin{array}{l}\text { Internationalization is a } \\
\text { component of FIU's 3.0: A }\end{array}$ & $.141^{* *}$ \\
$\begin{array}{l}\text { New Strategic Paradigm } \\
\text { FIU's exchange programs with } \\
\text { institutions in other countries } \\
\text { foster internationalization of } \\
\text { instruction, research, and } \\
\text { service learning. }\end{array}$ & $.145^{* *}$ & $.086^{*}$ \\
\hline
\end{tabular}

Note. ${ }^{*} \mathrm{p}<.05 ;{ }^{* *} \mathrm{p}<.01$; Have visited FIU's Office of Education Abroad (no=0, yes $=1$ ); Do you know if there are international travel grants for students no=0, yes=1); Have participated in Study Abroad (no=0, yes=1).

The analysis of the General Attitudes Toward Internationalization factor items indicated that four items out of the seven correlated statistically significantly with the question Have you visited FIU's Office of Education Abroad?: FIU's exchange programs with institutions in other countries foster internationalization of instruction, research, and service learning $\left(\mathrm{r}_{\mathrm{s}}=.145, \mathrm{p}<.01\right)$, International learning is an important element of the educational process at FIU $\left(\mathrm{r}_{\mathrm{s}}=.136, \mathrm{p}<.01\right)$, There is a genuine commitment to internationalization at FIU $\left(\mathrm{r}_{\mathrm{s}}=.104, \mathrm{p}<.05\right)$, and FIU's current mission statement supports the definition of internationalization presented $\left(\mathrm{r}_{\mathrm{s}}=.084, \mathrm{p}<.05\right)$. For all of these items, having visited the office of education abroad had a more favorable perception of the general attitudes' items.

Also, the analysis of the General Attitudes Toward Internationalization factor items indicated that two items out of the seven correlated statistically significantly with 
the question Do you know if there are international travel grants offered to FIU students?: FIU's exchange programs with institutions in other countries foster internationalization of instruction, research, and service learning $\left(\mathrm{r}_{\mathrm{s}}=.167, \mathrm{p}<.01\right)$, and There is a genuine commitment to internationalization at FIU $\left(\mathrm{r}_{\mathrm{s}}=.109, \mathrm{p}<.01\right)$. The knowledge of international travel grants for students indicated a more favorable student general attitude toward FIU's exchange programs with other institutions and FIU's commitment to internationalization.

Last, the analysis of the General Attitudes Toward Internationalization factor items indicated that three items out of the seven correlated statistically significantly with the question Have you ever participated in a study abroad program?: FIU's exchange programs with institutions in other countries foster internationalization of instruction, research, and service learning $\left(\mathrm{r}_{\mathrm{s}=} .149, \mathrm{p}<.01\right)$, International learning is an important element of the educational process at FIU $\left(\mathrm{r}_{\mathrm{s}}=.141, \mathrm{p}<.01\right)$, and Internationalization is a component of FIU's 3.0: A New Strategic Paradigm $\left(\mathrm{r}_{\mathrm{s}}=.086, \mathrm{p}<.05\right)$. Having participated in Study Abroad indicated a more favorable attitude toward these particular general attitudes' items.

The Perceived Benefits of Internationalization factor was significantly positively correlated with the questions: (a) Have you visited FIU's Office of Education Abroad?, (b) Do you know if there are international travel grants offered to FIU students?, (c) Have you ever participated in a study abroad program?, and (d) Would you like to participate in a study abroad program? as shown in Table 18. These results showed students have more favorable perception of the benefits of internationalization when students have visited the office of education abroad $\left(\mathrm{r}_{\mathrm{s}}=.138, \mathrm{p}<.01\right)$, have knowledge of international travel grants 
for students $\left(\mathrm{r}_{\mathrm{s}}=.120, \mathrm{p}<.05\right)$, have participated in study abroad $\left(\mathrm{r}_{\mathrm{s}}=.159, \mathrm{p}<.01\right)$, and would like to participate in study abroad $\left(\mathrm{r}_{\mathrm{s}}=.228, \mathrm{p}<.01\right)$.

Table 20 exhibits the analysis of Perceived Benefits of Internationalization factor items with the four significant correlated questions:

Table 20

\section{Student Perceived Benefits Factor Items Correlation Results}

\begin{tabular}{|c|c|c|c|c|}
\hline $\begin{array}{l}\text { Benefits Factor Items } \\
\text { (Students) }\end{array}$ & $\begin{array}{l}\text { Have you visited } \\
\text { FIU's Office of } \\
\text { Education Abroad? }\end{array}$ & $\begin{array}{l}\text { Do you know if } \\
\text { there are } \\
\text { international } \\
\text { travel grants } \\
\text { offered to FIU } \\
\text { students? }\end{array}$ & $\begin{array}{l}\text { Have you ever } \\
\text { participated in a } \\
\text { study abroad } \\
\text { program? }\end{array}$ & $\begin{array}{l}\text { Would you like } \\
\text { to participate in } \\
\text { a study abroad } \\
\text { program? }\end{array}$ \\
\hline $\begin{array}{l}\text { International education helps me } \\
\text { recognize and understand the } \\
\text { impact other cultures have on } \\
\text { American life and vice versa. }\end{array}$ & $.163^{* *}$ & $.151^{* *}$ & $.162 * *$ & $.163^{* *}$ \\
\hline $\begin{array}{l}\text { International learning makes me } \\
\text { appreciate more of other } \\
\text { cultures. }\end{array}$ & $.158 * *$ & $.091 *$ & $.174 * *$ & $.217 * *$ \\
\hline $\begin{array}{l}\text { The more we know about other } \\
\text { countries, the better we will } \\
\text { understand our own. }\end{array}$ & $.146^{* *}$ & & & $.181 * *$ \\
\hline $\begin{array}{l}\text { International learning helps } \\
\text { prepare students to become } \\
\text { responsible global citizens. }\end{array}$ & & $.109 *$ & $.161^{* *}$ & $.209 * *$ \\
\hline $\begin{array}{l}\text { Learning other cultures helps me } \\
\text { better tolerate ambiguity when } \\
\text { communicating with a foreign } \\
\text { person. }\end{array}$ & $.120 * *$ & $.113 * *$ & $112 * *$ & $.190 * *$ \\
\hline $\begin{array}{l}\text { Learning about people from } \\
\text { different cultures is a very } \\
\text { important part of education }\end{array}$ & $.098^{*}$ & & $.115^{* *}$ & $.173 * *$ \\
\hline
\end{tabular}

(table continues) 
Table 20 (continued)

\begin{tabular}{|c|c|c|c|c|}
\hline $\begin{array}{l}\text { Benefits Factor Items } \\
\quad \text { (Students) }\end{array}$ & $\begin{array}{l}\text { Have you visited } \\
\text { FIU's Office of } \\
\text { Education Abroad? }\end{array}$ & $\begin{array}{c}\text { Do you know if } \\
\text { there are } \\
\text { international } \\
\text { travel grants } \\
\text { offered to FIU } \\
\text { students? }\end{array}$ & $\begin{array}{l}\text { Have you ever } \\
\text { participated in a } \\
\text { study abroad } \\
\text { program? }\end{array}$ & $\begin{array}{c}\text { Would you like } \\
\text { to participate in } \\
\text { a study abroad } \\
\text { program? }\end{array}$ \\
\hline $\begin{array}{l}\text { I believe an understanding of } \\
\text { international issues is important } \\
\text { for success in the workforce. }\end{array}$ & $.093 *$ & $.103 *$ & $.133^{* *}$ & $.085^{*}$ \\
\hline $\begin{array}{l}\text { Students can understand their } \\
\text { own culture more fully if they } \\
\text { have studied another. }\end{array}$ & $.094 *$ & & $.130 * *$ & $.147^{* *}$ \\
\hline $\begin{array}{l}\text { International education can } \\
\text { explain the root causes of basic } \\
\text { global problems such as } \\
\text { overpopulation, poverty, climate } \\
\text { change, and disease. }\end{array}$ & & & & $.165^{* *}$ \\
\hline \multicolumn{5}{|c|}{$\begin{array}{l}\text { Note. } * \mathrm{p}<.05 ; * * \mathrm{p}<.01 \text {; Have visited FIU's Office of Education Abroad (no=0, yes }=1 \text { ); Do you know if there are } \\
\text { international travel grants for students }(\mathrm{no}=0 \text {, yes }=1 \text { ); Have participated in Study Abroad (no }=0 \text {, yes }=1 \text { ); Would like to } \\
\text { participate in Study Abroad (no }=0 \text {, yes }=1 \text { ). }\end{array}$} \\
\hline \multicolumn{5}{|c|}{ The review of the Perceived Benefits of Internationalization factor items indicated } \\
\hline \multirow{2}{*}{\multicolumn{5}{|c|}{$\begin{array}{l}\text { that seven items out of the nine correlated statistically significant with the question Have } \\
\text { you visited FIU's Office of Education Abroad?, five out of nine with the question Do you }\end{array}$}} \\
\hline & & & & \\
\hline \multicolumn{5}{|c|}{ know if there are international travel grants offered to FIU students?, seven out of nine } \\
\hline \multicolumn{5}{|c|}{ with the question Have you ever participated in a study abroad program?, and nine out of } \\
\hline \multicolumn{5}{|c|}{ nine with the question Would you like to participate in a study abroad program?. } \\
\hline \multicolumn{5}{|c|}{ Four items significantly correlated with all four questions: International } \\
\hline \multicolumn{5}{|c|}{ education helps me recognize and understand the impact other cultures have on } \\
\hline \multicolumn{5}{|c|}{ American life and vice versa $\left(\mathrm{r}_{\mathrm{s}}=.163, \mathrm{p}<.01, \mathrm{r}_{\mathrm{s}}=.151, \mathrm{p}<.01, \mathrm{r}_{\mathrm{s}}=.162, \mathrm{p}<.01, \mathrm{r}_{\mathrm{s}}=.163\right.$} \\
\hline
\end{tabular}


$\left(\mathrm{r}_{\mathrm{s}}=.158, \mathrm{p}<.01, \mathrm{r}_{\mathrm{s}}=.091, \mathrm{p}<.05, \mathrm{r}_{\mathrm{s}}=.174, \mathrm{p}<.01, \mathrm{r}_{\mathrm{s}}=.217, \mathrm{p}<.01\right.$, respectively), Learning other cultures helps me better tolerate ambiguity when communicating with a foreign person $\left(\mathrm{r}_{\mathrm{s}}=.120, \mathrm{p}<.01, \mathrm{r}_{\mathrm{s}}=.113, \mathrm{p}<.01, \mathrm{r}_{\mathrm{s}}=.112, \mathrm{p}<.01, \mathrm{r}_{\mathrm{s}}=.190, \mathrm{p}<.01\right.$, respectively), and I believe an understanding of international issues is important for success in the workforce $\left(\mathrm{r}_{\mathrm{s}}=.093, \mathrm{p}<.05, \mathrm{r}_{\mathrm{s}}=.103, \mathrm{p}<.05, \mathrm{r}_{\mathrm{s}}=.133, \mathrm{p}<.01, \mathrm{r}_{\mathrm{s}}=.085, \mathrm{p}<.05\right.$, respectively). For all these items, students showed a more favorable perception of the benefits of internationalization when they have visited the office of education abroad, have knowledge of international travel grants for students, have participated in study abroad, and expressed the desire to participate in study abroad.

Support for Internationalization factor was significant and positively correlated with the questions: (a) Have you visited FIU's Office of Education Abroad?, (b) Do you know if there are international travel grants offered to FIU students?, (c) Do you know if there are co-curricular international activities on campus?, and (d) Have you ever participated in a study abroad program? as seen in Table 18. These results showed that students have more favorable perception of the support for internationalization when students have visited the office of education abroad $\left(\mathrm{r}_{\mathrm{s}}=.224, \mathrm{p}<.01\right)$, have knowledge of international travel grants for students $\left(\mathrm{r}_{\mathrm{s}}=.223, \mathrm{p}<.05\right)$, have knowledge of co-curricular international activities $\left(\mathrm{r}_{\mathrm{s}}=.221, \mathrm{p}<.01\right)$, and have participated on study abroad $\left(\mathrm{r}_{\mathrm{s}}=.197\right.$, $\mathrm{p}<.01)$.

Table 21 shows the analysis of Perceived Support for Internationalization factor items with the four significant correlated questions: 
Table 21

\section{Student Perceived Support Factor Items Correlation Results}

\begin{tabular}{|c|c|c|c|c|}
\hline $\begin{array}{l}\text { Support Factor Items } \\
\text { (Students) }\end{array}$ & $\begin{array}{l}\text { Have you visited } \\
\text { FIU's Office of } \\
\text { Education } \\
\text { Abroad? }\end{array}$ & $\begin{array}{l}\text { Do you know if } \\
\text { there are } \\
\text { international } \\
\text { travel grants } \\
\text { offered to FIU } \\
\text { students? }\end{array}$ & $\begin{array}{l}\text { Do you know if } \\
\text { there are co- } \\
\text { curricular } \\
\text { international } \\
\text { activities on } \\
\text { campus? }\end{array}$ & $\begin{array}{l}\text { Have you ever } \\
\text { participated in a } \\
\text { study abroad } \\
\text { program? }\end{array}$ \\
\hline $\begin{array}{l}\text { I have been encouraged in my } \\
\text { department to take courses } \\
\text { that incorporate international } \\
\text { content. }\end{array}$ & $.155^{* *}$ & $.113^{* *}$ & $.110 * *$ & $.160 * *$ \\
\hline $\begin{array}{l}\text { My college/school/department } \\
\text { encourages me to conduct } \\
\text { research on international } \\
\text { topics. }\end{array}$ & $.145^{* *}$ & $.171^{* *}$ & $.160^{* *}$ & $.143^{* *}$ \\
\hline $\begin{array}{l}\text { My college/school/department } \\
\text { strongly promotes students } \\
\text { engagement in } \\
\text { internationalization. }\end{array}$ & $.179 * *$ & $.154^{* *}$ & $.191^{* *}$ & $.166^{* *}$ \\
\hline $\begin{array}{l}\text { My college/school/department } \\
\text { encourages me to participate } \\
\text { in a study abroad program. }\end{array}$ & $.217 * *$ & $.241 * *$ & $.193 * *$ & $.251 * *$ \\
\hline $\begin{array}{l}\text { My college/school/department } \\
\text { encourages me to attend } \\
\text { international } \\
\text { symposiums/lectures on } \\
\text { campus. }\end{array}$ & $.196^{* *}$ & $.245^{* *}$ & $.310 * *$ & $.143 * *$ \\
\hline $\begin{array}{l}\text { My college/school/department } \\
\text { takes advantage of community } \\
\text { resources to enhance the } \\
\text { international learning } \\
\text { experience. }\end{array}$ & $.143^{* *}$ & $.199 * *$ & $.173 * *$ & $.089 *$ \\
\hline
\end{tabular}

(table continues) 
Table 21 (continued)

\begin{tabular}{lcccc}
\hline \multicolumn{1}{c}{$\begin{array}{c}\text { Support Factor Items } \\
\text { (Students) }\end{array}$} & $\begin{array}{c}\text { Have you visited } \\
\text { FIU's Office of } \\
\text { Education } \\
\text { Abroad? }\end{array}$ & $\begin{array}{c}\text { Do you know if } \\
\text { there are } \\
\text { international } \\
\text { travel grants } \\
\text { offered to FIU } \\
\text { students? }\end{array}$ & $\begin{array}{c}\text { Do you know if } \\
\text { there are co- } \\
\text { curricular } \\
\text { international } \\
\text { activities on } \\
\text { campus? }\end{array}$ & $\begin{array}{c}\text { Have you ever } \\
\text { participated in a } \\
\text { study abroad } \\
\text { program? }\end{array}$ \\
\hline $\begin{array}{l}\text { My courses with international } \\
\text { content have provided } \\
\text { examples from all regions of } \\
\text { the world. }\end{array}$ & $.142^{* *}$ & & $.107^{*}$ \\
\hline
\end{tabular}

Note. ${ }^{*} \mathrm{p}<.05 ; * * \mathrm{p}<.01$; Have visited FIU's Office of Education Abroad (no $=0$, yes $=1$ ); Do you know if there are international travel grants offered to FIU students? (no $=0$, yes $=1$ ); Do you know if there are co-curricular international activities on campus? (no=0, yes $=1)$; Have you ever participated in a study abroad program? (no=0, yes $=1)$.

An analysis of the Support for Internationalization factor items indicated that seven items out of the seven correlated statistically significant with the question Have you visited FIU's Office of Education Abroad?, six out of seven with the questions Do you know if there are international travel grants offered to FIU students? and Do you know if there are co-curricular international activities on campus?, and seven out of seven with the question Have you ever participated in a study abroad program?

Six items significantly correlated with all four questions: I have been encouraged in my department to take courses that incorporate international content $\left(\mathrm{r}_{\mathrm{s}}=.155, \mathrm{p}<.01\right.$, $\left.\mathrm{r}_{\mathrm{s}}=.113, \mathrm{p}<.01, \mathrm{r}_{\mathrm{s}}=.110, \mathrm{p}<.01, \mathrm{r}_{\mathrm{s}}=.160, \mathrm{p}<.01\right)$, My College/School/Department encourages me to conduct research on international topics $\left(\mathrm{r}_{\mathrm{s}}=.145, \mathrm{p}<.01, \mathrm{r}_{\mathrm{s}}=.171\right.$, $\left.\mathrm{p}<.01, \mathrm{r}_{\mathrm{s}}=.160, \mathrm{p}<.01, \mathrm{r}_{\mathrm{s}}=.143, \mathrm{p}<.01\right)$, My College/School/Department strongly promotes students engagement in internationalization $\left(\mathrm{r}_{\mathrm{s}}=.179, \mathrm{p}<.01, \mathrm{r}_{\mathrm{s}}=.154, \mathrm{p}<.01, \mathrm{r}_{\mathrm{s}}\right.$ $\left.=.191, \mathrm{p}<.01, \mathrm{r}_{\mathrm{s}}=.166, \mathrm{p}<.01\right)$, My College/School/Department encourages me to participate in study abroad program $\left(\mathrm{r}_{\mathrm{s}}=.217, \mathrm{p}<.01, \mathrm{r}_{\mathrm{s}}=.241, \mathrm{p}<.01, \mathrm{r}_{\mathrm{s}}=.193, \mathrm{p}<.01, \mathrm{r}_{\mathrm{s}}\right.$ $=.251, \mathrm{p}<.01)$, My College/School/Department encourages me to attend international 
symposiums/lectures on campus $\left(\mathrm{r}_{\mathrm{s}}=.196, \mathrm{p}<.01, \mathrm{r}_{\mathrm{s}}=.245, \mathrm{p}<.01, \mathrm{r}_{\mathrm{s}}=.310, \mathrm{p}<.01, \mathrm{r}_{\mathrm{s}}\right.$ $=.143, \mathrm{p}<.01)$, and My College/School/Department takes advantage of community resources to enhance the international learning experience $\left(\mathrm{r}_{\mathrm{s}}=.143, \mathrm{p}<.01, \mathrm{r}_{\mathrm{s}}=.199\right.$, $\left.\mathrm{p}<.01, \mathrm{r}_{\mathrm{s}}=.173, \mathrm{p}<.01, \mathrm{r}_{\mathrm{s}}=.089, \mathrm{p}<.05\right)$. For all these items, students presented a more favorable perception of the support of internationalization when they have visited the office of education abroad, have knowledge of international travel grants for students and international co-curriculum on campus, and have participated in study abroad.

\section{Faculty Correlations With Demographic Variables}

The factors General Attitudes Toward Internationalization, Perceived Benefits of Internationalization, and Support for Internationalization were correlated with the demographic variables: Age, Gender, Race/Ethnicity, Tenure Status, Period Teaching at FIU, Period Teaching in higher education following terminal degree, and International Faculty. Table 22 shows the Faculty factors significant correlation results with demographics variables:

Table 22

Faculty Factors Correlations with Demographics

\begin{tabular}{|c|c|c|c|}
\hline $\begin{array}{l}\text { Faculty Demographic } \\
\text { Variables }\end{array}$ & $\begin{array}{c}\text { Mean General } \\
\text { Attitude toward } \\
\text { internationalization } \\
\text { (Factor } 3)\end{array}$ & $\begin{array}{l}\text { Mean Perception } \\
\text { of Support for } \\
\text { internationalization } \\
\text { (Factor } 1)\end{array}$ & $\begin{array}{l}\text { Mean perceived } \\
\text { Benefits of } \\
\text { internationalization } \\
\text { (Factor } 2)\end{array}$ \\
\hline Tenure Status & -.034 & .005 & .134 \\
\hline Age & .134 & .061 & $.236^{*}$ \\
\hline Race & -.085 & -.174 & -.137 \\
\hline Period of Teaching at FIU & .139 & .145 & .194 \\
\hline
\end{tabular}


Table 22 (continued)

\begin{tabular}{lccc}
\hline \multicolumn{1}{c}{$\begin{array}{c}\text { Faculty Demographic } \\
\text { Variables }\end{array}$} & $\begin{array}{c}\text { Mean General } \\
\text { Attitude toward } \\
\text { internationalization } \\
\text { (Factor 3) }\end{array}$ & $\begin{array}{c}\text { Mean Perception } \\
\text { of Support for } \\
\text { (Factor 1) }\end{array}$ & $\begin{array}{c}\text { Mean perceived } \\
\text { Benefits of } \\
\text { (Factor 2) }\end{array}$ \\
\hline $\begin{array}{l}\text { Period of Teaching in higher } \\
\text { education following }\end{array}$ & .092 & .125 & .156 \\
terminal degree & & & .091 \\
Gender & .068 & .096 & .087 \\
Are you an international & -.000 & & .084 \\
faculty not born in the U.S? & & & \\
\hline
\end{tabular}

Note. ${ }^{*} \mathrm{p}<.05 ;{ }^{*} \mathrm{p}<.01 \quad$ Tenure status (tenured=1, non-tenured=2); Gender (female=1, male=2); Race (Hispanic=1, Non Hispanic $=2)$; Period of Teaching at FIU $(<5$ years $=1,5-10$ years $=2,11-15$ years $=3,16-20$ years $=4,20+$ years $=5)$; Period of Teaching in higher education following terminal degree $(<5$ years' $=1,5-10$ years $=2,11-15$ years $=3$, $16-20$ years $=4,20+$ years $=5)$; Age $(50$ years and under=1, over $50=2)$; International Faculty (no=0, yes $=1)$.

The Perceived Benefits of Internationalization factor was significantly correlated with the demographic variable age $\left(\mathrm{r}_{\mathrm{s}}=.236, \mathrm{p}<.05\right)$. This result indicated that older faculty have more favorable perceptions of the benefits of internationalization than younger faculty.

An analysis of the Perceived Benefits of Internationalization factor items revealed statistically significant associations between the underlying distributions of the scores of older and younger faculty on 5 of the 10 statements: Learning about people from cultures is a very important part of education $\left(\mathrm{r}_{\mathrm{s}}=.254, \mathrm{p}<.05\right)$, International education can explain roots causes of basic global problems $\left(\mathrm{r}_{\mathrm{s}}=.236, \mathrm{p}<.05\right)$, The more we know about other countries, the better we will understand our own $\left(\mathrm{r}_{\mathrm{s}}=.234, \mathrm{p}<.05\right)$, Learning a foreign language is not essential for an undergraduate education $\left(\mathrm{r}_{\mathrm{s}}=.228, \mathrm{p}<.05\right)$, and I believe an understanding of international issues is important for success in the workforce $\left(\mathrm{r}_{\mathrm{s}}=.209, \mathrm{p}<.05\right)$. 
The Perceived Benefits of Internationalization factor was not significantly correlated with the demographic variables Gender, Race/Ethnicity, Tenure Status, Period of Teaching at FIU, Period of Teaching in Higher Education following Terminal Degree, and International Faculty. The General Attitudes toward Internationalization and Support for Internationalization factors were not significantly correlated with any of the demographic variables.

\section{Faculty Correlations With Experience Variables}

The factors General Attitudes Toward Internationalization, Support for Internationalization, and Perceived Benefits of Internationalization were correlated with the experiences variables: (a) Have you visited the Office of Education Abroad?, (b) Do you know if there are international travel grants for students?, (c) Have you participated in Study Abroad (on a Faculty role)?, (d)Would you like to participate in Study Abroad (on a Faculty role)?, (e) Have you participated in Offshore programs?, and (f) Would you like to participate in Offshore programs?. Table 23 shows the Faculty factors significant correlation results with experience variables:

Table 23

Faculty Factors Correlations with Experiences

\begin{tabular}{lccc}
\hline \multicolumn{1}{c}{$\begin{array}{c}\text { Faculty Experience } \\
\text { Variables }\end{array}$} & $\begin{array}{c}\text { Mean General } \\
\text { Attitude toward } \\
\text { internationalization } \\
\text { (Factor 3) }\end{array}$ & $\begin{array}{c}\text { Mean Perception } \\
\text { of Support for } \\
\text { (Factor 1) }\end{array}$ & $\begin{array}{c}\text { Mean perceived } \\
\text { Benefits of }\end{array}$ \\
\hline $\begin{array}{l}\text { Have you visited FIU's } \\
\text { Office of Education Abroad? }\end{array}$ & -.019 & $.211^{*}$ & $.261^{* *}$ \\
$\begin{array}{l}\text { Do you know if there are } \\
\text { international travel grants } \\
\text { offered to FIU students? }\end{array}$ & .149 & $.340^{* *}$ & .100 \\
\hline
\end{tabular}

(table continues) 
Table 23 (continued)

\begin{tabular}{lccc}
\hline \multicolumn{1}{c}{$\begin{array}{c}\text { Faculty Experience } \\
\text { Variables }\end{array}$} & $\begin{array}{c}\text { Mean General } \\
\text { Attitude toward } \\
\text { internationalization } \\
\text { (Factor 3) }\end{array}$ & $\begin{array}{c}\text { Mean Perception } \\
\text { of Support for } \\
\text { internationalization } \\
\text { (Factor 1) }\end{array}$ & $\begin{array}{c}\text { Mean perceived } \\
\text { Benefits of } \\
\text { (Factor 2) }\end{array}$ \\
\hline $\begin{array}{l}\text { Have you ever participated in } \\
\text { a study abroad program (in a } \\
\text { faculty role)? }\end{array}$ & .014 & .152 & .116 \\
$\begin{array}{l}\text { Would you like to participate } \\
\text { in a study abroad program }\end{array}$ & .173 & & $.311^{* *}$ \\
(in a faculty role)? & & & .167 \\
$\begin{array}{l}\text { Have you participated in } \\
\text { offshore (transnational) } \\
\text { programs? }\end{array}$ & .137 & $.252^{*}$ & \\
$\begin{array}{l}\text { Would you like to participate } \\
\text { in offshore (transnational) } \\
\text { programs? }\end{array}$ & .163 & & $.489^{* *}$ \\
\hline
\end{tabular}

Note. $* \mathrm{p}<.05 ; * *_{\mathrm{p}}<.01 \quad$ Have visited FIU's Office of Education Abroad (no=0, yes=1); Do you know if there are international travel grants for students ( $\mathrm{no}=0$, yes $=1)$; Have participated in Study Abroad (no=0, yes=1); Would like to participate in Study Abroad (no=0, yes=1); Have participated in Offshore Programs (no=0, yes=1); Would like to participate in Offshore Programs (no=0, yes $=1$ ).

The Perceived Support for Internationalization factor was significantly and positively correlated with the questions, Have you visited FIU's Office of Education Abroad?, Do you know if there are international travel grants offered to FIU students?, Have participated in offshore programs?, and Would you like to participate in offshore programs?. These results showed faculty have more favorable perceptions of the support for internationalization when faculty have visited the office of education abroad $\left(r_{s}=.211\right.$, $\mathrm{p}<.05)$, have knowledge of international travel grants for students $\left(\mathrm{r}_{\mathrm{s}}=.340, \mathrm{p}<.01\right)$, have you participated on offshore programs $\left(\mathrm{r}_{\mathrm{s}}=.252, \mathrm{p}<.05\right)$, would like to participate in offshore programs $\left(\mathrm{r}_{\mathrm{s}}=.211, \mathrm{p}<.05\right)$.

Table 24 shows the analysis of faculty Perceived Support for Internationalization factor items with the four significant correlated questions: 
Table 24

Faculty Perceived Support Factor Items Correlation Results

\begin{tabular}{|c|c|c|c|c|}
\hline $\begin{array}{l}\text { Support Factor Items } \\
\text { (Faculty) }\end{array}$ & $\begin{array}{l}\text { Have you } \\
\text { visited } \\
\text { FIU's Office } \\
\text { of Education } \\
\text { Abroad? }\end{array}$ & $\begin{array}{l}\text { Do you know } \\
\text { if there are } \\
\text { international } \\
\text { travel grants } \\
\text { offered to FIU } \\
\text { students? }\end{array}$ & $\begin{array}{l}\text { Have you } \\
\text { participated } \\
\text { in offshore } \\
\text { (transnation }\end{array}$ & $\begin{array}{l}\text { Would you } \\
\text { like to } \\
\text { participate in } \\
\text { offshore } \\
\text { (transnational } \\
\text { ) programs? }\end{array}$ \\
\hline
\end{tabular}

programs?

My college/school/department provides

seminars/training/workshops to

faculty on internationalizing the

curriculum.

My college/school/department encourages me to belong to an international professional organization.

My college/school/department encourages me to publish on international or global topics.

My college/school/department encourages me to conduct research on international topics.

My college/school/department encourages me to attend international symposiums/lectures on campus

My college/school/department strongly promotes faculty engagement in internationalization.

I have been encouraged in my department to offer courses that incorporate international content.

My college/school/department encourages me to participate in a study abroad program.
$.271^{* * *}$

$.252^{*} \quad .222^{*}$

$.216^{*} \quad .353^{* *} \quad .279^{* *}$

$.321^{* *}$ $.251^{*}$

$.259^{* *}$ $.201^{*}$

$.268^{* *}$

$.210^{*}$

$.263^{* *}$

$.255^{*} \quad .229^{*}$

$.215^{*}$

Note. ${ }^{*} \mathrm{p}<.05 ;{ }^{*} \mathrm{p}<.01 ;$ Have visited FIU's Office of Education Abroad (no=0, yes=1); Do you know if there are international travel grants for students $(\mathrm{no}=0$, yes $=1)$; Participated in Offshore Programs (no=0, yes=1); Like to participate in Offshore Programs $(\mathrm{no}=0$, yes $=1)$;

An analysis of the Support for Internationalization factor items indicated that two items out of the nine correlated statistically significant with the question Have you visited 
FIU's Office of Education Abroad?; eight out of nine with the question, Do you know if there are international travel grants offered to FIU students?; four out of nine with the question have you participated in offshore programs?; and two items out nine with the question Would you like to participate in offshore programs?

The question Have you visited FIU's Office of Education Abroad? correlated statistically significant with the items: My College/School/Department encourages me to participate in a study abroad program $\left(\mathrm{r}_{\mathrm{s}}=.255, \mathrm{p}<.05\right)$, and $M y$ college/school/department encourages me to publish on international or global topics $\left(\mathrm{r}_{\mathrm{s}}\right.$ $=.216, \mathrm{p}<.05)$.

The question Do you know if there are international travel grants offered to FIU student? correlated statistically significant with the following items: $M y$ College/School/Department encourages me publish on international or global topics $\left(\mathrm{r}_{\mathrm{s}}\right.$ $=.353, \mathrm{p}<.01)$, My College/School/Department encourages me to conduct research on international topics $\left(\mathrm{r}_{\mathrm{s}}=.321, \mathrm{p}<.01\right)$, My College/School/Department provides seminars/training/workshops to faculty on internationalizing the curriculum $\left(\mathrm{r}_{\mathrm{s}}=.271\right.$, $\mathrm{p}<.01)$, My College/School/Department strongly promotes faculty engagement in internationalization $\left(\mathrm{r}_{\mathrm{s}}=.268, \mathrm{p}<.01\right)$, My College/School/Department encourages me to attend international symposiums/lectures on campus $\left(\mathrm{r}_{\mathrm{s}}=.259, \mathrm{p}<.01\right)$, My College/School/Department encourages me to belong to an international professional organization $\left(\mathrm{r}_{\mathrm{s}}=.252, \mathrm{p}<.05\right)$, My College/School/Department encourages me to participate in a study abroad program $\left(\mathrm{r}_{\mathrm{s}}=.229, \mathrm{p}<.05\right)$, and I have been encouraged in my department to offer courses that incorporate international learning $\left(\mathrm{r}_{\mathrm{s}}=.210, \mathrm{p}<.05\right)$. 
For all these items the perception of support for internationalization is more favorable when faculty have knowledge of international travel grants offered to students.

The question Have you participated in offshore programs? also showed statistically significant correlations with the following items $M y$ College/School/Department encourages me publish on international or global topics $\left(\mathrm{r}_{\mathrm{s}}\right.$ $=.279, \mathrm{p}<.01)$, I have been encouraged in my department to offer courses that incorporate international learning $\left(\mathrm{r}_{\mathrm{s}}=.263, \mathrm{p}<.01\right)$, My College/School/Department encourages me to conduct research on international topics $\left(\mathrm{r}_{\mathrm{s}}=.251, \mathrm{p}<.05\right)$, and My College/School/Department encourages me to belong to an international professional organization $\left(\mathrm{r}_{\mathrm{s}}=.222, \mathrm{p}<.05\right)$. For all these items the perception of support for internationalization is more favorable when faculty has participated in offshore programs.

Finally, the question Would you like to participate in offshore programs? correlated statistically significantly with the items: My College/School/Department encourages me to participate in a study abroad program $\left(\mathrm{r}_{\mathrm{s}}=.215, \mathrm{p}<.05\right)$, and My College/School/Department encourages me to attend international symposiums/lectures on campus $\left(\mathrm{r}_{\mathrm{s}}=.201, \mathrm{p}<.05\right)$. $)$. For all these items the perception of support for internationalization was more favorable when faculty would like to participate in offshore programs.

Perceived Benefits of Internationalization factor was significantly and positively correlated with the questions Have you visited FIU's Office of Education Abroad?, Would you like to participate in Study Abroad?, and Would you like to participate in Offshore programs? as presented on Table 23 . These results showed faculty have more favorable perceptions of the benefits of internationalization when faculty say they would 
like to participate in offshore programs $\left(\mathrm{r}_{\mathrm{s}}=.489, \mathrm{p}<.01\right)$, Would like to participate in

Study Abroad $\left(r_{s}=.311, p<.01\right)$, and Have visited the office of education abroad $\left(r_{s}=.261\right.$, $\mathrm{p}<.05)$.

Table 25 shows the analysis of faculty Perceived Benefits for Internationalization factor items with the three significant correlated questions:

Table 25

Faculty Perceived Benefits Factor Items Correlation Results

\begin{tabular}{|c|c|c|c|}
\hline $\begin{array}{l}\text { Benefits Factor Items } \\
\text { (Faculty) }\end{array}$ & $\begin{array}{l}\text { Have you visited } \\
\text { FIU's Office of } \\
\text { Education } \\
\text { Abroad? }\end{array}$ & $\begin{array}{l}\text { Would you like to } \\
\text { participate in a } \\
\text { study abroad } \\
\text { program (in a } \\
\text { faculty role)? } \\
\end{array}$ & $\begin{array}{l}\text { Would you like } \\
\text { to participate in } \\
\text { offshore } \\
\text { (transnational) } \\
\text { programs? }\end{array}$ \\
\hline $\begin{array}{l}\text { International learning helps } \\
\text { prepare students to become } \\
\text { responsible global citizens. }\end{array}$ & & $.214^{*}$ & $.408 * *$ \\
\hline $\begin{array}{l}\text { International learning makes } \\
\text { me appreciate more other } \\
\text { cultures. }\end{array}$ & & $.273 * *$ & $.457 * *$ \\
\hline $\begin{array}{l}\text { The more we know about } \\
\text { other countries, the better we } \\
\text { will understand our own. }\end{array}$ & & $.253^{*}$ & $.422 * *$ \\
\hline $\begin{array}{l}\text { International education helps } \\
\text { me recognize and understand } \\
\text { the impact other cultures have } \\
\text { on American life and vice } \\
\text { versa. }\end{array}$ & $.242 *$ & $.316^{* *}$ & $.414 * *$ \\
\hline $\begin{array}{l}\text { Learning other cultures helps } \\
\text { me better tolerate ambiguity } \\
\text { when communicating with a } \\
\text { foreign person. }\end{array}$ & $.245^{*}$ & $.307 * *$ & $.434 * *$ \\
\hline $\begin{array}{l}\text { International education can } \\
\text { explain root causes of basic } \\
\text { global problems such as } \\
\text { overpopulation, poverty, } \\
\text { climate change, and disease. }\end{array}$ & & $.306 * *$ & $.436 * *$ \\
\hline $\begin{array}{l}\text { Students can understand their } \\
\text { own culture more fully if they } \\
\text { have studied another. }\end{array}$ & $.201^{*}$ & & $.307 * *$ \\
\hline
\end{tabular}


Table 25 (continued)

\begin{tabular}{lccc}
\hline \multicolumn{1}{c}{$\begin{array}{c}\text { Benefits Factor Items } \\
\text { (Faculty) }\end{array}$} & $\begin{array}{c}\text { Have you visited } \\
\text { FIU's Office of } \\
\text { Education } \\
\text { Abroad? }\end{array}$ & $\begin{array}{c}\text { Would you like to } \\
\text { participate in a } \\
\text { study abroad } \\
\text { program (in a } \\
\text { faculty role) }\end{array}$ & $\begin{array}{c}\text { Would you like } \\
\text { to participate in } \\
\text { offshore } \\
\text { (transnational) } \\
\text { programs? }\end{array}$ \\
\hline $\begin{array}{l}\text { I believe an understanding of } \\
\text { international issues is } \\
\text { important for success in the } \\
\text { workforce. }\end{array}$ & $.302^{* *}$ & $.367^{* *}$ & $.380^{* *}$ \\
$\begin{array}{l}\text { Learning about people from } \\
\text { different cultures is a very } \\
\text { important part of education. }\end{array}$ & $.256^{*}$ & & \\
$\begin{array}{l}\text { Learning a foreign language is } \\
\text { not essential for an } \\
\text { undergraduate. }\end{array}$ & & & $.232^{*}$ \\
\hline
\end{tabular}

Note. ${ }^{*} \mathrm{p}<.05 ; * * \mathrm{p}<.01$ Have visited FIU's Office of Education Abroad (no=0, yes $\left.=1\right)$; Like to participate in Study Abroad (no=0, yes=1); Like to participate in Offshore Programs (no=0, yes $=1)$.

The analysis of the 10 Perceived Benefits of Internationalization factor items, shows that 6 significantly correlated with the question, Have you visited FIU's Office of Education Abroad?; 8 with the question Would you like to participate in a Study Abroad program (in a faculty role)?; and 9 with the question Would you like to participate in Offshore programs?.

Three items significantly correlated with the questions Have you visited FIU's Office of Education Abroad?, Would you like to participate in Study Abroad?, and would you like to participate in offshore programs?. The three items are, International Education helps me recognize and understand the impact other cultures have on American life and vice versa $\left(\mathrm{r}_{\mathrm{s}}=.242, \mathrm{p}<.05, \mathrm{r}_{\mathrm{s}}=.316, \mathrm{p}<.01, \mathrm{r}_{\mathrm{s}}=.414, \mathrm{p}<.01\right)$, Learning other cultures helps me better tolerate ambiguity when communicating with a foreign person $\left(\mathrm{r}_{\mathrm{s}}=.245, \mathrm{p}<.05, \mathrm{r}_{\mathrm{s}}=.307, \mathrm{p}<.01, \mathrm{r}_{\mathrm{s}}=.434, \mathrm{p}<.01\right)$, and I believe an understanding of international issues is important for success in the workforce $\left(\mathrm{r}_{\mathrm{s}}=.302, \mathrm{p}<.01, \mathrm{r}_{\mathrm{s}}=.367\right.$, 
$\left.\mathrm{p}<.01, \mathrm{r}_{\mathrm{s}}=.380, \mathrm{p}<.01\right)$. For all these items, having visited the Office of Education Abroad and having the desire to participate in Study Abroad or Offshore Programs showed a more favorable perception of the Benefits of Internationalization in relation to international education and understanding other cultures.

\section{Summary}

This chapter presented the analyses of data collected through interviews, document analysis, and attitude surveys of students and faculty in order to answer the research questions and test hypotheses.

The findings showed that FIU is placed on position 6 of the Van Dijk and Meijer Internationalization Cube (1997) characterized with a priority Policy, one-sided Support and structured Implementation dimensions. The analysis of FIU's international activities results (collected using the IDI) in relation to the panel of experts' responses showed that FIU presents all the activities considered as strongly indicators of internationalization as identified by Afonso (1990) and Krane (1994), but is not aligned to the panel of experts' responses on the minimum number or percentages in outcomes FIU reports on those international activities.

Finally, the Student and Faculty Attitudes Survey on Internationalization shed some light on what these stakeholders feel about internationalization. Overall, both students and faculty indicated a positive agreement on the Benefits of Internationalization. Also, the analysis of the student and faculty attitudes in relation to the demographic and experiences variables pointed out that differences in views exist, such as the perceptions of benefits of internationalization between Hispanic and NonHispanic students or between older and younger faculty; and must be taken into account 
when planning and engaging in sustaining internationalization efforts. The next chapter will discuss the results and their implications to FIU and offer recommendations for future studies. 


\section{CHAPTER V}

\section{DISCUSSION AND RECOMMENDATIONS}

The internationalization of Higher Education institutions (HEIs) is an endeavor at the heart of HEIs today. An in-depth understanding of what internationalization means and entails is pivotal for its sustainable management within HEIs. This study was designed to address this reality by assessing Florida International University's (FIU) Internationalization process. Using a case study mixed methods approach, the study sought to present a snapshot of FIU's internationalization process by answering three questions. The first question, What is FIU's position on the Van Dijk and Meijer Internationalization Cube? looked at FIU's policy, support and implementation dimensions toward internationalization. Determining where FIU stands in the Internationalization Cube set up the framework for analyzing FIU's internationalization efforts. Specifically, Question One was answered by reviewing institutional documents and data from interviews with the provost, five academic deans, and directors from the Graduate Admissions Office, Study Abroad, Office of Global Learning, and School of International and Public Affairs (SIPA).

The second question, To what extent is FIU's position on the Van Dijk and Meijer's Internationalization Cube aligned to the International Dimension Index (IDI) results on internationalization?, expanded this examination of FIU's internationalization process by looking at its international activities. FIU's international activities results were collected through the International Dimension Index (IDI). The IDI, developed by Afonso (1990) and Krane (1994), represents quantitative indicators that highly correlate to internationalization. The IDI results were analyzed in relation to the Item Relevancy 
Index (IRI) obtained from a panel of expert's. The last question, How do FIU student and faculty attitudes toward internationalization compare on the General Attitudes, Support, and Benefits scales?, was designed to understand FIU's faculty and students' attitudes toward internationalization given their stakeholders status. Student and faculty attitudes were collected using the adapted versions of the Student and Faculty Attitude Survey on Internationalization developed by Kennesaw State University.

By answering the three research questions, the study sought to present a holistic organizational assessment and enhance the understanding of the Internationalization process within a Higher Education Institution.

\section{Summary of Findings}

\section{FIU's Position on the Van Dijk and Mejier International Cube}

The analysis of FIU's policy, support and implementation dimensions places FIU in cell six of the Internationalization Cube. An analysis of FIU's policy documents and interview data on internationalization demonstrates FIU's commitment toward internationalization has been present since its establishment. Yet, for FIU, a fast-growing urban university facing economic challenges, internationalization has not always been at the top of the agenda.

Today, FIU's internationalization process has been reinvigorated with the Quality Enhancement Plan (QEP) initiative. The QEP aligns FIU's strategic goals and institutional priority to educating global citizens expressed in the theme Global Learning for Global Citizenship. As a result, the QEP has led to changes in the undergraduate curriculum and the development of new co-curriculum. At the same time, the interactive support and systematic implementation nature of the QEP demonstrate that it is a top- 
down project. However, it should be noted that the QEP initiative focuses on one aspect of internationalization, that is, student learning as manifested in the curriculum and cocurriculum. Therefore, FIU's rationale for internationalization can be described as following a "Competency Approach" (Knight, 2004). Priority of internationalization as well as its assessment is tied to students' outcomes, defined as a set of knowledge, skills and attitudes students graduating from FIU must have.

Overall, FIU's development and support of international activities remain a onesided effort, with faculty and Colleges/Schools engaging in international activities - from study abroad programs, offshore programs, to faculty research abroad - as funding permits. The study done by Van Dijk and Meijer (1997) on the internationalization process of Dutch universities, reported that a priority policy on internationalization correlates to the support for internationalization available within higher education institutions. At FIU, this seems to be true for the international activities or efforts that are university-wide directives like the QEP, creating a gap in the support available to other international activities despite FIU's priority policy on internationalization. This onesided, decentralized support can be considered a hindering factor of internationalization (Childress, 2009).

The implementation of international activities follows a highly systematic approach for internationalization. Though international activities originally surfaced with few or no processes in place, the on-the-go learning process has led to carefully drafted processes and offices that monitor the activities (specially study abroad and offshore programs) and make sure they maintain FIU's quality assurance. Despite the systematic approach, though, FIU shows a blurry organizational structure when it comes to 
internationalization. The lack of a Chief International Educator Administrator (CIEA) contradicts FIU's priority policy toward internationalization, and creates a void for the university-wide internationalization process in terms of communication and coordination. According to Green and Olson (2003), the CIEAs are the "champions for internationalization", providing a clear policy of where the institution is going as well as gathering support and implementations processes. It is relevant to mention that up until 2 years ago FIU had an Office of International Programs headed by a Vice Provost for International Studies. Interestingly enough, the Office of International Programs and the position of Vice Provost for International Studies were abolished and their functions were distributed among SIPA, the Office of Global Learning Initiative, and other units of the university.

Finally, the study has identified some challenges facing FIU's internationalization process. The most cited challenges were the lack of funding to engage in more international activities or provide financial support, as well as faculty feelings of overwhelming in terms of administrative reporting pertaining to quality assurance.

\section{FIU's Results on International Activities}

Question Two of the study, To what extent is FIU's position on the Van Dijk and Meijer's Internationalization Cube aligned to the IDI results? explored FIU's international activities results in relation to panel of experts' responses. The findings show that the panel of experts considered the eight items on the IDI (Foreign Language, International Curriculum, International Students, Faculty Exchange, Co-curriculum, 
study Abroad, Faculty International Development Projects, and Offshore Programs) relevant for a university placed on position 7 of the Van Dijk and Meijer's Internationalization Cube.

A comparison of FIU's results on international activities to the panel of experts' responses shows that: (a) an alignment exists between FIU' international activities and the panel of experts' items relevancy index, and (b) a difference exists in the numbers or percentages FIU reported on five out of eight items' subcategories of its international activities results based on the minimum requirement estimated by the panel of experts. It should be noted that the panel of experts presented an estimation of the minimum requirement on the activities for an institution placed on position 7 of the Internationalization Cube. Therefore, given FIU's placement on cell 6 of the Internationalization Cube this difference in output can: (a) be explained by the lack of strategic planning on these items, and (b) reinforce FIU's position on the Internationalization Cube. FIU's results on international activities could correspond with an institution on position 6 of the Internationalization Cube as indicated by the panel responses.

The presence of the highly correlated quantitative indicators on internationalization as described by Afonso (1990) and Krane (1994) shows that FIU's advancement of internationalization has been slow-moving. Given FIU's student and faculty size population, an assessment of the student and faculty participation and/or involvement in different international activities depicts a history of an overlooked policy 
in the areas of foreign language enrollment, study abroad participation, percentage of international students on campus, international movement of faculty, and involvement in international development projects.

Burriss (2006) study indicated that a relationship exists between an institution's position on the Internationalization Cube and the results of internationalization. This interaction fosters an environment that enhances organizational change and a sustainable internationalization process. Following Burriss (2006) comparison model, given FIU's position on the Cube and its results on international activities, FIU can be described as an institution with a Far-Reaching typology of change characterized with low depth and high pervasiveness (Eckel, Green, Hill, 1998). Changes in internationalization are taking place within FIU, especially with the QEP, but they do not seem to affect all areas in a profound and or equal manner such as foreign language or study abroad among others.

\section{Student and Faculty Survey on Internationalization}

A psychometric analysis of the student and faculty survey on internationalization was done to estimate validity of the three scales in the survey: General Attitudes, Support for Internationalization and Benefits of Internationalization. Principal Component Analysis (PCA) was used to extract factors that were then subjected to a Varimax rotation.

Overall, the factor analysis demonstrated that for both the student and faculty surveys, the three scales or three factor models were present. Students' PCA showed Benefits of Internationalization as first factor (with the highest loading items), Support for Internationalization as second, and General Attitudes as third. For Faculty, Support 
for Internationalization was the first factor, followed by Beliefs on Internationalization, and General Attitudes toward Internationalization as the third factor.

The internal reliability estimates of the three scales determined through the coefficient Alpha was calculated. Following Nunnally's (1978) minimum requirement of .70 or higher as an acceptable alpha coefficient value, the study demonstrated that the survey scales (for student and faculty) were internally consistent with alpha values ranging from .877 to .921 . These findings corroborated that the survey items focused indeed on the notion of attitudes toward internationalization.

General Attitudes Toward Internationalization. The student and faculty surveys showed that overall, FIU's students and faculty have positive attitudes toward internationalization. International learning, for both students and faculty, is relevant as an element of the educational process. The need for educating students capable of working locally or abroad while understanding cultural differences was highlighted by the students, representing their awareness of these skills. These findings demonstrate an alignment between students' and faculty attitudes toward internationalization. Most importantly, perhaps, is the fact that it contradicts the findings presented by ACE (Green, Luu, Burriss, 2008) that claim that a contradiction exists between student and faculty attitudes toward internationalization.

It is interesting to point out that both FIU students and faculty reported that there is a genuine commitment to internationalization at FIU, and that FIU's current mission statement supports Knight's (2003) definition of internationalization used in the study. Yet, it is worth noting that during the interviews, interviewees tended to interpret FIU's 
mission statement according to their definitions. This demonstrated a pragmatic posture toward the definition of internationalization.

FIU's Quality Enhancement Plan (QEP) was designed on the notion of preparing Global Citizens. Yet, only small percentages of students and faculty reported that the QEP is discussed and understood by stakeholders. The student and faculty attitudes toward this particular item may indicate that despite FIU's efforts in promoting the QEP, more discussions and conversations are still needed. The QEP, being the central force driving the internationalization efforts at FIU, call for all stakeholders (students, faculty, and administrators) to have a solid understanding of the QEP process.

Perceived Support for Internationalization. As identified in question one, FIU's support for internationalization can be categorized as one-sided; Schools/Colleges/Departments have the main responsibility for supporting internationalization efforts. This approach has been certainly felt by students and faculty who reported a less positive attitude toward the support for internationalization available at FIU. Specifically, faculty reported a perceived lack of support for activities such as serving as an advisor for students' organizations with international focus, and providing seminars/training/workshops in internationalizing the curriculum; all key components for fostering faculty global competency, enhancing an internationalized curriculum, and promoting a campus ethos (Green \& Olson, 2003).

Faculty and students also indicated a low perception of support from their Colleges/Schools/departments toward study abroad. This finding is significant as literature on internationalization defines study abroad as an element of undergraduate education that promotes cultural understanding and awareness (Green and Olson, 2003). 
The data collected demonstrated that the percentage of students and faculty who have actually participated in study abroad was low despite the high percentage of students and faculty expressed interest in doing so. These results seem to be aligned with the need to incorporate international activities efforts into the Faculty Handbook delineating faculty benefits or incentives for doing international work either through research or service. In terms of students, this finding reflects the need to explore the possibility of incorporating study abroad into the undergraduate curriculum.

On the other hand, students and faculty both showed a positive perception of the support from their Colleges/Schools/Department to take or offer courses with an international content. These findings are relevant as they align with the QEP goal of forming globally competent students, and reinforced FIU's stand on an internationalized curriculum.

Perceived Benefits of Internationalization. Results from the student and faculty survey indicated that students and faculty have a strong positive perception of the benefits of internationalization as supported by the survey statistics analysis. Faculty and students demonstrated a positive view of international learning as a means to educating global citizens. The students and faculty perceptions are encouraging news for FIU for several reasons: (a) students indicated an explicit interest in understanding and learning about other cultures, and (b) faculty's awareness of the students' needs and interest would increase the likelihood of faculty incorporating an international dimension in their course work (Carley, Cheurprakobkit, \& Paracka, 2006). 


\section{Demographic Variables and Past Experiences on Students and Faculty Views}

The study's findings demonstrated that students' race/ethnicity, class status and gender have some relationship to their attitudes toward internationalization. For faculty, surprisingly, the age variable is related to the appreciation of the Benefits of Internationalization. Though these findings do not certainly show causation, they do point to differences in perceptions among students and faculty (Carley, Cheurprakobkit, \& Paracka, 2006). Recognizing these differences can be useful when promoting dialogue about internationalization among the different stakeholders.

In terms of students' experiences, the variables of Education Abroad (have visited the office of Education Abroad and having participated in Study Abroad) and awareness of international grants available for students are the ones that most consistently and significantly correlated with attitudes toward internationalization. For faculty, similar findings were seen on the variables of Study Abroad and Offshore programs. These findings are encouraging for FIU for two reasons: (a) they corroborate the notion that experiences abroad contribute to developing positive attitudes/perceived benefits of international education. Green (2005) reported on her study on students' perspectives toward internationalization that "the experience [of participating in study abroad] made them [the students] more knowledgeable and understanding of other people and cultures" (p. 11), and (b) encouraging students to participate in study abroad as well as faculty on study abroad and/or offshore programs can certainly be one of the most significant instruments for developing a more internationalized faculty and students as well as promoting an internationalized campus ethos (Carley, Cheurprakobkit, Paracka, 2006). 


\section{Implications of the Study}

In this study, internationalization is defined as the "process of integrating an international/intercultural dimension into the teaching, research and service functions of the institution (Knight, 1997). A deconstruction of the definition of internationalization means embedding an international and/or global perspective in all university processes, from what faculty teaches what students learn though formal activities or co-curriculum, to faculty research and involvement in international/global issues. All these components provide the starting point for setting goals and rationales for the internationalization of HEIs. In addition, it reinforces a holistic organizational assessment of internationalization rather than a fragmented one.

FIU's current approach that focuses on the development of students' global competencies certainly sets the ground for an internationalization effort. Yet, in order to advance internationalization and FIU's position on the internationalization cube, this approach should be expanded to manifest a coherent policy on internationalization in the following areas:

FIU's current mission statement emphasizes FIU's research aspect but overlooks FIU's international goal. The mission statement of a HEI is a written declaration of what the university stands for setting the path for processes and support to follow. Therefore, a clear and articulated FIU mission statement including the importance of international education will "create a stronger foundation for operationalizing this commitment and intent" (Childress, p. 304). An instructive mission statement will endorse an 
organizational ethos that champions internationalization at all university levels, from admission recruitment pamphlets to human resources practices while reinforcing its sustainability.

Second, focusing internationalization on just the QEP or student outcomes can be a constraint. FIU's institutional policy of internationalization is the QEP, which is tied to FIU's Southern Association for Colleges and Schools' (SACS) reaffirmation of accreditation process. Defining internationalization as a QEP effort underlines internationalization as a priority while the QEP efforts are in place. Moving from an "Outcome Approach" to a "Process Approach" can be instrumental in the sustainability of FIU's internationalization efforts. Though the Outcome and Process Approach are not mutually exclusive, the process approach will compel FIU to revisit its current policies, procedures, hiring practices, and resources in all aspects of the organizational process, and develop additional performance indicators aside from the QEP. The Process Approach will present a framework for FIU's internationalization efforts focusing on the input (FIU's organizational elements) and output (students' competencies) at the same time (McNeil, Newman, \& Steinhauser, 2005). In addition, it will remove the perception of a top-down project and convey the intrinsic nature of an internationalization process.

Third, the analysis of FIU's position on the Internationalization Cube in relation to its results in international activities identified five areas of weakness. To continue enhancing its internationalization efforts, FIU will need to re-examine its commitment, policies, and support to (a) foreign language study, (b) study abroad, (c) international students, (d) international movement of faculty, and (e) international development projects. The student and faculty survey responses indicated that those areas, in particular 
study abroad and foreign language study, are important to the stakeholders. Therefore, by addressing these shortcomings, FIU could move from a Far-Reaching typology change to an institution nurturing Transformational Change, high depth and high pervasiveness (Eckel, Green, Hill, 1998).

Fourth, literature on internationalization describes leadership from the top as an essential factor in making internationalization sustainable (Green and Olson, 2003; Knight, 2004). Consequently, FIU's current leadership's (President and Provost) explicit commitment to internationalization is crucial to advancing organizational change. The top leadership should continue to encourage discussions on internationalization among faculty, students and administrators by addressing areas of weaknesses within the FIU internationalization process. This on-going dialogue, having in mind students' age, ethnicity/race, and class, as well as faculty's age and students and faculty past experiences, will keep the internationalization efforts current and allow for incremental modifications in terms of values, beliefs, practices, and secure financial assistance where needed.

Fifth, results from the faculty survey also point to another area of improvement in FIU's internationalization process related to faculty and personnel development. Knight (2004) indicated that consideration should be given to the reward and promotion policies that boost faculty and staff contributions, faculty and staff professional development activities, as well as support for international assignments and sabbaticals. Human resource written policies included in the faculty handbook that explicitly address tenure, promotion, sabbaticals, etc. will strengthen FIU's true commitment to internationalization. Internationally engaged faculty can then have more influence on the 
teaching and learning activities of the institution in much more profound ways. In addition, university leadership is a key element in this matter as university leadership should serve as agents of "Promotion and Publicity" (Paige, 2005) of faculty international activities while encouraging Deans and department chairs to "internationalize by incorporating international expertise standards into faculty and staff job descriptions" (NASULGC, 2007, p. 6).

Finally, FIU will benefit by defining its organizational structure when it comes to the internationalization process. Given the Office of Global Learning Initiatives (OGLI) has taken on the task of FIU's QEP efforts, it seems effective and efficient to expand its role. The OGLI has the potential to become the core office for internationalization while supporting and maintaining high priority on internationalization. The study done by Childress (2009) suggests that with support and infrastructure "internationalization may become more fully integrated into an institution's activities and ethos" (p. 302).

Furthermore, a dedicated office responsible for the monitoring of the internationalization process is a key component in making sure the internationalization efforts are sustained.

\section{Conclusion}

The study attempted to present a conceptual framework for examining FIU's Internationalization Process. The Van Dijk and Meijer (1997) Model was used in assessing the internationalization process in terms of FIU's Policies, Support, and Implementation dimensions. The results in these three areas placed FIU on position six of the Internationalization Cube - Priority Policy, One-Sided Support, and Structured Implementation. This explorative model for understanding FIU's internationalization process suggests to decision-makers that to move on to the next level on the 
Internationalization Cube (if desired), they should address appropriate adjustments in the policy, support or implementation dimensions.

The study also identified, through the use of the IDI, the international activities in need of improvement. It is desired that these findings will serve as a starting-point for conversations among the different stakeholders within the university. Certainly, attending to these shortcomings will have a positive impact on FIU's policy, support and implementation dimensions. In particular, by addressing these challenges, FIU will need to revisit its current policies toward foreign language study, international students, study abroad, faculty movement and involvement in international projects by connecting these activities to the university's overall internationalization efforts. The provision of financial and personnel resources for these activities should also be enhanced. Changes in any of these areas will certainly further FIU's internationalization efforts and position in the Internationalization Cube.

Finally, the study looked at FIU's student and faculty attitudes toward internationalization. It can be concluded that FIU's stakeholders have overall positive attitudes/predisposition toward internationalization. The benefits of an international education are well understood and desired by both stakeholders. Support for internationalization at FIU is an area that students and faculty considered can be enhanced. Once again, the implementation of these findings will have a positive effect on FIU's policy, support and implementation by developing support policies and mechanisms - such as increasing scholarships funding for students going abroad or including faculty international activities as part of their tenure and promotion - that will promote faculty and students participation on international activities. 


\section{Limitations}

This study has several limitations worth mentioning. First, the positioning of Florida International University's on the Van Dijk and Meijer Internationalization Cube (1997) was based on interviews and document reviews. As a result, interviewees' responses may have some biases influencing the final analysis. Second, as stated in Chapter 1, the Van Dijk and Meijer Internationalization Cube takes for granted that external factors have already influenced a HEI's policy, support, and implementation dimensions. Though this study sought to present a holistic view of FIU's internationalization process, the main emphasis was on assessing FIU's policy, support and implementation dimensions without indicating the effects of external factors on the three dimensions.

FIU's results on international activities were assessed in relation to the 12 panel of experts' responses Item Relevancy Index (IRI). Given that all the experts were administrators with international experience, the IRI results may be biased. As a result, the panel's preconceptions of the items presented may influence the final results. Also, though HEIs try their best to collect and record accurate data on internationalization, it must be acknowledged that the IDI quantitative data may present some imprecision. Hence, the inherent limitation of the available quantitative data certainly influenced the results of the study.

In terms of the Student and Faculty Attitudes Survey toward Internationalization, low response rates to the student and faculty surveys may hinder any type of 
generalization. In addition, a self- selection bias should be noted. Faculty and students who decided to participate in the study may have some interest in the international education field.

Last, though an attempt was made to make the survey clear, some faculty and students selected Neutral on the survey when not sure how to answer or if the question did not apply to them. This response practice can lead to skewed results.

\section{Recommendations for Future Research}

The current research was designed to advance the understanding of the internationalization process within HEIs. Looking at the process in relation to a HEI's policy, support, and implementation dimension, its relationships to its international activities, the student and faculty attitudes, the study sought to present a comprehensive method for assessing HEIs' internationalization efforts. The following are recommended for future research:

1. The use of the Van Dijk and Meijer Internationalization Cube prescriptive Model. The researcher understands that the application of this model by future researchers will lead to a constant improvement of the theoretical model for internationalization.

2. The application and expansion of the Item Relevancy Index as a tool to assess Higher Education Institutions' international activities in relation to their position on the Internationalization Cube.

3. Repeat the student and faculty attitudes survey on internationalization with a larger sample allowing for generalizations and better insight.

4. Perform a 5-year study assessment of FIU's internationalization efforts. 
5. Review the impact of FIU's Quality Enhancement Plan on international activities, in particular foreign language study, international students, study abroad and faculty movement, and international projects involvement.

6. Perform a comparative analysis of FIU's QEP Internationalized curriculum and Study Abroad experiences in developing students' global perspectives.

7. Perform a comparative analysis of Study Abroad and Offshore programs' impact on faculty attitudes toward internationalization. 


\section{REFERENCES}

Afonso, J. (1990). The international dimension in American higher education. Ph.D. dissertation, The University of Arizona, Arizona. Retrieved from Dissertations \& Theses: A\&I. (Publication No. AAT 9108411)

Aigner, J., et. al. (1992). Internationalizing the university: Making it work (Report No. 025 287). International Education Forum, 12, 49-60. (ERIC Document Reproduction Service No. ED 342 316)

Altbach, P. (2004). Higher education crosses borders. Change Magazine, 36, 18-25.

Altbach, P. (2005). Academic challenges: The American professoriate in comparative perspective. In A. Welch (Ed.), Higher education dynamics: The professoriate, profile of profession, (pp. 147-165). Netherlands: Springer.

American Association of State Colleges and Universities (1985). Guidelines: Incorporating an international dimension in colleges and universities. Washington, DC: American Association of State Colleges and Universities

American Council on Education. (2003). Internationalization strategies. Washington, DC: Author.

Arum, S., \& van de Water, J. (1992). The need for a definition of international education in U.S. universities. In C. Klasek (Ed.), Bridges to the futures: Strategies for internationalizing higher education (pp. 191-203). Carbondale, IL: Association of International Education Administrators.

Association of International Education Administrators. (2003). Securing America's future: Global education for a global age. Report of the strategic taskforce on study abroad. Retrieved from:

http://www.nafsa.org/_Document/_/securing_america_s_future.pdf

Association of International Educators [NAFSA]. (2009). The Economic Benefits of International Education to the United States for the 2008-2009 Academic Year: A Statistical Analysis. Retrieved from: http://www.nafsa.org/_File/_eis09/Utah.pdf

Audas, M. (1991). Comparing policy statements and practices in the international dimension of selected institutions of higher education, Part II. International Education Forum, 11(2), 86-108.

Bann, C., Terrell, S., McCormack, L., \& Berkman, N. (2003) Measuring beneficiary knowledge of the Medicare program: A psychometric analysis. Health Care Financing Review, 24(4), 111-125. 
Becker, H. (1968). Social observation and social case studies. In International Encyclopedia of the Social Sciences (1st ed.). New York, NY: Macmillan.

Bentler, P., \& Bonett, D. (1980). Significance tests and goodness of fit in the analysis of covariance structures. Psychological Bulletin, 88(3), 588 -606.

Bogdan, R, \& Biklen, S. (1982). Qualitative research for education: An introduction to theory and methods. New York, NY: Allyn and Bacon.

Bremer, L., \& van der Wende, M. (eds.) (1995). Internationalizing the curriculum in higher education: Experiences in the Netherlands. The Hague, The Netherlands: Organization for International Co-operation in Higher Education.

Briggs, A., \& Coleman, M. (2007). Research methods in educational leadership and management (2nd ed.). Los Angeles, CA: Sage.

Brustein, W. (2005). Paths to global competence: Preparing American college students to meet the world. Retrieved from: http://www.iienetwork.org/page/84657/

Burke, W. (2002). Organization change: Theory and practice. Los Angeles, CA: Sage.

Burriss, A. (2006). Institutional effectiveness in internationalization: A case study of internationalization at three higher education institutions. Ed.D. dissertation, The George Washington University, District of Columbia. Retrieved from Dissertations \& Theses: A\&I. (Publication No. AAT 3199633)

Callan, H. (2000). International vision in practice: A decade of evolution. Higher Education in Europe, 25(1), 16-23.

Caracelli, V., \& Greene, J. (1993). Data analysis strategies for mixed-method evaluation designs. Educational Evaluation and Policy Analysis, 15(2), 195-207.

Carley, S., Cheurprakobkit, S., \& Paracka, D. (2006). Faculty attitudes toward international education: A campus experience. Journal of Global Initiatives:

Policy, Pedagogy, Perspective, 1(1), 1-30.

Carter, H. (1992). Implementation of international competence strategies: Faculty. In C. Klasek (Ed.), Bridges to the futures: Strategies for internationalizing higher education (pp. 39-51). Carbondale, IL: Association of International Education Administrators.

Center for International Business Education and Research. (2010). 14th Annual Mercosur FDIB Program. Retrieved from: http://www.fiu.edu/ ciber/pdibmercosur.htm. 
Childress, L. (2009). Internationalization plans for higher education institutions. Journal of Studies in International Education, 13, 289 - 309.

Christensen, G., \& Thielen, T. (1983).Cross cultural activities: Maximizing the benefits of educational interchange. In H. M. Jenkins (Ed.), Educating students from other nations (pp. 210-236). San Francisco, CA: Jossey-Bass.

Clinton, W. (2000). Memorandum for the heads of executive departments and agencies, The White House. Retrieved from: http://www.nafsa.org/_Document/_/president_clinton_issues_1.pdf

Cochran, K. (April, 2009). Mark Rosenberg appointed president of FIU. Retrieved from: http://news.fiu.edu/2009/04/mark-rosenberg-appointed-president-offiu/\#printpreview

Commission on Colleges of the Southern Association of Colleges and Schools (2004). Handbook for Reaffirmation of Accreditation. Retrieved from: http://www.sacscoc.org/pdf/handbooks/Exhibit\%2027.ReaffirmationOfAccreditat ion.pdf

Conrad, C., \& Serlin, R. (2006). The Sage handbook for research in education: Engaging ideas and enriching inquiry. Thousand Oaks, CA: Sage.

Cummings, W. (2001). Current challenges of international Education. Washington, DC: ERIC Clearinghouse on Higher Education. (ERIC Document Reproduction Service No. ED 464 523)

Daniel, L. G. (1989, November). Comparisons of exploratory and confirmatory factor analysis. Paper presented at the annual meeting of the Southwest Educational Research Association, Little Rock, AR. (ERIC Document Reproduction Service No. ED 314 447)

Davies, J. (1992). Developing a strategy for internationalization in universities: Towards a conceptual framework. In C. Klasek (Ed.), Bridges to the futures: Strategies for internationalizing higher education (pp. 177-190). Carbondale, IL: Association of International Education Administrators.

DeVon, H., Block, M., Moyle-Wright, P., Ernst, D., Hayden, S. Lazzara, D. et al. (2007). A psychometric toolbox for testing validity and reliability. Journal of Nursing Scholarship, 39(2), 155-164

De Wit, H. (1995). Strategies for internationalization of higher education: a comparative study of Australia, Canada, Europe, and the United States. Amsterdam: European Association for International Education. 
De Wit, H. (2000). Changing rationales for the internationalization of higher education. In L. Barrows (Ed.), Internationalization of higher education: An institutional perspective (pp. 9-22). Bucharest, Romania: CEPES/UNESCO (ERIC Document Reproduction Service No.ED 450 662)

De Wit, H. (2002). Internationalization of higher education on the United States of America and Europe. Westport, CT: Greenwood Publishing Group.

Division of Instructional Innovation and Assessment, The University of Texas at Austin. (2007). Response rates. Instructional assessment resources. Retrieved from http//www.utexas.edu/academic/diia/assessment/iar/teaching/gather/method/surve y-Response.php?task=research

Eckel, P., Green, M., \& Hill, B. (2001). On change V-Riding the waves of change: Insights from transforming institutions. Washington, DC: American Council of Education.

Ellingboe, B. (1998). Divisional strategies to internationalize a campus portrait: Results, resistance, and recommendations from a case study at a US university. In J. A. Mestenhauser \& B. J. Ellingboe (Eds.), Reforming the higher education curriculum: Internationalizing the campus (pp. 198-228). Phoenix, AZ: Oryx

Ellingboe, B. J. (2003). Finding your path: Working effectively with an internationalization consultant. International Educator, 12(3), 22-29.

Engberg, D., \& Green, M. (2002). Promising practices: Spotlighting excellence in comprehensive internationalization. Washington, DC: American Council on Education.

Erickson, F. (1986). Qualitative methods in research on teaching. In M. C. Wittrock (Ed.), Handbook of research on teaching (3rd ed.). New York, NY: Macmillan.

Florida Department of State. (1976). Florida International University: 6C8-1: Organization, powers, duties and function. Retrieved from: https://www.flrules.org/gateway/ChapterHome.asp?Chapter=6C8-1

FIU to break ground on forum for global exchange: New building to house School of International and Public Affairs. (2008, December). Retrieved from: http://news.fiu.edu/2008/12/fiu-to-break-ground-on-forum-for-global-exchangenew-building-to-house-school-of-international-and-public-affairs/

Florida International University. (2010). Florida International University's Quality enhancement Plan: Global learning for global citizenship. Miami, Fl: Author 
Florida International University, International Student and Scholar Services (ISSS).

(n.d.). Enrolled International Students 2006-2007. Retrieved from:

http://isss.fiu.edu/downloads/statistics.pdf

Florida International University. (n.d). Millennium Strategic Plan 2001-2010. Retrieved from: http://www.fiu.edu/oir/docs/msp.pdf

Florida International University. (2009, Fall). About FIU. Retrieved from: http://www.fiu.edu/docs/about_fiu.htm

Francis, E. (1993, summer). Facing the future: The internationalization of postsecondary institutions in British Columbia. Vancouver, Canada: British Columbia Centre for International Education.

Friedman, T. (2005). The world is flat 3.0: A brief history of the Twenty-First century. New York, NY: Picador.

Fung, S., \& Filippo, J. (2002, Spring). What Kinds of Professional International Opportunities May be Secured for Faculty? New Directions for Higher Education, 117, 57-62.

Gall, M., Gall, J. \& Borg, W. (2003). Educational research: An introduction ( $7^{\text {th }}$ ed.). New York: Allyn \& Bacon.

Ghosh, R. (2004). Globalization in the North American region: Toward renegotiation of cultural space. McGill Journal of Education, 39(1), 87-101.

Green, M. (2002). Internationalizing undergraduate education: Challenges and lessons of successes. In D. Engberg \& M. F. Green (Eds.), Promising practices: Spotlighting excellence in comprehensive internationalization (pp. 7-20). Washington, DC: American Council on Education.

Green, M. (2005). Internationalization in U.S. higher education: The student perspective. Washington, DC: American Council on Education.

Green, M. (n.d). The challenge of internationalizing undergraduate education: global learning for all. Retrieved from:

http://www.jhfc.duke.edu/ducis/globalchallenges/pdf/green.pdf

Green, M., Siaya, L., \& Porcelli, M. (2002, September). One year later: Attitudes about international education since September 11. Retrieved from: http://www.acenet.edu/bookstore/pdf/2002_one-year-later.pdf

Green, M., \& Olson, C. (2003). Internationalizing the Campus: A user's guide. Washington, DC: American Council on Education. 
Green, M, Luu, D., and Burris, B. (2008). Mapping Internationalization on U.S. Campuses: 2008 Edition. Washington, DC: American Council on Education.

Gross, K., \& Godwin, P. (2005). Education's many stakeholders. Educational administrators are increasingly recognizing what businesses have long understood: customer satisfactin matters. Retrieve from http://www.universitybusiness.com/viewarticle.aspx?articleid=174\&p=3\#0

Guba, E., \& Lincoln, Y. (1981). Effective Evaluation. San Francisco: Jossey-Bass.

Hamilton, M. (2003). Online survey response rates and times: background and guidance for industry. Retrieved from:

http://www.supersurvey.com/papers/supersurvey_white_paper_response_rates.ht $\mathrm{m}$

Hanson, M. (1979). Educational Administration and Organizational Behavior. Boston, Massachusetts: Allyn and Bacon.

Harari, M. (1972). Global Dimensions in U.S. education: the university. New York: Center for War/peace Studies.

Harari, M. (1977). Internationalization of higher education. In the International Encyclopedia of Higher Education, edited by Asa S. Knowles. San Francisco, CA: Jossey-Bass.

Harari, M. (1981). Internationalizing the curriculum and the campus: Guidelines for AASCU Institutions. Washington, DC: American Association of State Colleges and University.

Harari, M. (1989). Internationalization of Higher Education: Effecting Institutional Change in the Curriculum and Campus. Long Beach, CA: Center for International Education, California State University.

Harari, M. (1992). The internationalization of the curriculum. In C. Klasek (Ed.), Bridges to the futures: Strategies for internationalizing higher education (pp. 52-79). Carbondale, IL: Association of International Education Administrators.

Heyl, J. (2007). The Senior International Officer (SIO) as Change Agent. Washington, DC: Association of International Education Administrators (AIEA)

Hirsch, W. \& Weber, Luc, (2001). Governance in higher education: the university in a state of flux. Geneve: Economica. 
Ho, R. (2006). Handbook of Univariate and Multivariate Data Analysis and Interpretation with SPSS. Boca Raton, FL: Chapman \& Hall/CRC, Taylor and Francis Group.

Hoemeke, T., Krane, M., Young, J., Slavin, G. (2000). A survey on chief international education administrators, their institutions and offices. Washington, DC: Association of International Education Administrators

Hoffa, W. (2007, September). Ethics and Study Abroad. The chronicle review, Section B: the chronicle of higher education, $\operatorname{LIV}(2), \mathrm{B} 16$.

Hovland, K. (2006). Shared futures: Global learning and liberal education. Washington, DC: Association of American Colleges and Universities.

Hunter, B., White, G., \& Godbey, G. (2006). What does it mean to be globally competent?. Journal of Studies in International Education, 10(3), 267-285.

Institute of International Education. (n.d). A brief history of IIE. Retrieved from http://www.iie.org/Content/NavigationMenu/About_IIE1/Mission_and_Profile/Hi story/History.htm

Institute of International Education. (2009). Open Doors 2009: Report on International Educational Exchange. Retrieved from: http://opendoors.iienetwork.org/page/150807/

Johnson, R., \& Onwuengbuzie, A. (2004). Mixed methods research: a research paradigm whose time has come. Educational Researcher, 33(7), 14-26.

Johnson, B., \& Christensen, L. (2004). Educational research: Quantitative, qualitative, and mixed methods ( $2^{\text {nd }}$ ed.). Boston, MA: Pearson Education.

Johnston, I., \& Edelstein, R. (1993). Beyond borders: Profiles in international education. Washington, DC: Association of American Colleges and American Assembly of Collegiate Schools of Business.

Katz, D., \& Kahn, R. (1978). The Social Psychology of Organizations. New York, NY: Wiley \& Sons.

Katz, D., \& Stotland, E. (1959). A preliminary statement to a theory of attitude structure and change. In S. Koch (Ed.), Psychology: A study of a science. New York: McGraw-Hill, 3, 423-475.

Keller, G. (1983). Academic strategy: The management revolution in American higher education. Baltimore, MD: Johns Hopkins University Press. 
Kennesaw State University, (2007). Quality Enhancement Plan on Global Learning for Engaged Citizenship. Retrieved from:

http://accreditation.fiu.edu/index.php?name=qep_references

Kerlinger, F. (1986). Foundations of behavioral research (3rd ed.). New York, NY: Holt, Rinehart, and Winston.

Kirkwood, T. (2001). Our global age requires global education: Clarifying definitional ambiguities. Social Studies, 92, 1-16.

Knight, J. (1994). Internationalization: Elements and Checkpoints. CBIE Research, 7. Ottawa, Canada: Bureau Canadien de L'education Internationale, 1-15.

Knight, J, \& de Wit, H. (eds.). (1997). Internationalization of higher education in Asia Pacific countries. Amsterdam: European Association for International Education.

Knight, J. (1999). Internationalisation of higher education. Quality and internationalisation in higher education. Paris: Organization for Economic Cooperation \& Development, 13-23

Knight, J. (2003a). Updated internationalization definition. International Higher Education, 33, 2-3.

Knight, J. (2003b). Internationalization of higher education practices and priorities: 2003 IAU Survey Report. International Association of Universities. Retrieved from: http://www.unesco.org/iau/internationalization/pdf/Internationalisationen.pdf

Knight, J. (2004). Internationalization remodeled: Definition, approaches, and rationales. Journal of Studies in International Education, 8(1), 5-31.

Koehn, P., \& Rosenau, J. (2002). Transnational competence in an emergent epoch. International Studies perspective, 3, 105-127.

Krane, M. (1994). Development of an internationalization index for U.S. liberal arts colleges. Ed.D. dissertation, Mississippi State University, Mississippi. Retrieved from Dissertations \& Theses:

A\&I.(Publication No. AAT 9428847).

MacDonald, B., \& Walker, R. (1977). Case Study and the Social Philosophy of Educational Research. In D. Hamilton and others (Eds.), Beyond the Numbers Game. London: Macmillan Education. 
Maidique, M. (2009). President's message - Monday June 8, 2009. News at FIU. Retrieved from: http://news.fiu.edu/2009/06/presidents-message-monday-june-82009/

McCarthy, J. (2007). A roadmap for creating the global campus. The Chronicle of Higher Education. Retrieved from: http://chronicle.com/article/A-Roadmap-for-Creatingthe/10279/

McNeil, K.; Newman, I.; \& Steinhauser, J. (2005). How to be involved in program evaluation What every administrator needs to know. Lanham, MD: ScarecrowEducation.

Maxwell. J. (2005). Qualitative research design: An interactive approach ( $2^{\text {nd }}$ ed.). Applied social research methods series, 41. Thousand Oaks, CA: Sage Publications, Inc.

Mestenhauser, J. (2002). In search of a comprehensive approach to international education: a systems perspective. In W. Grunzweig and N. Rinehart (Eds.). Rockin'in Red Square: Critical approaches to international education in the age of cyberculture (pp. 165-202). London: Vit Verlag

Merkx, G. (2003, winter). The two waves of internationalization in the U.S. higher education. International Educator, 12(1), 6-12.

Merriam, S. (1988). Case study research in education: A qualitative approach. San Francisco, CA: Jossey -Bass.

Merriam, S. (1998). Qualitative research and case study application in education. San Francisco, CA: Jossey-Bass.

Miles, M., \& Huberman, M. (1984). Qualitative data analysis: A source book for new methods. Thousand Oaks, CA: Sage.

Miles, M., \& Huberman, M. (1994). Qualitative data analysis: An expanded sourcebook. (2nd ed.). Thousand Oaks, CA: Sage.

Modern Language Association. (2006, Fall). Enrollments in Languages Other Than English in United States Institutions of Higher Education. Retrieved from: http://www.mla.org/pdf/enrollment/inst_fl_2006.pdf

Mooney, P. (2006, October). University leaders see rewards and risks in internationalization, survey results. The Chronicle of Higher Education. Retrieved from: http://chronicle.com/daily/2006/10/2006101605n.htm 
Morris, E. (1996). Internationalize the curriculum by internationalizing the faculty (Working papers on semester conversion \& internationalization of the curriculum). Minneapolis, MN: University of Minnesota, Institute of International Studies and Programs

NASULGC. (2007). A national action agenda for internationalizing higher education. Retrieved from: https://www.aplu.org/NetCommunity/Document.Doc?id=471

Neave, G. (1992). Managing higher education international cooperation: Strategies and solutions. Unpublished reference document. Paris, France: UNESCO.

Nunnally, J. (1978). Psychometric theory. New York, NY: McGraw-Hill.

Obst, D., Bhandari, R., \& Whitherell, S. (2007, May). Meeting America's global education challenge: current trends in U.S. Study abroad and the impact of strategic diversity. Study abroad white paper series (1). Washington, DC: Institute of International Education.

Odgers, T., \& Giroux, I. (2006). Internationalizing faculty: A phased approach to transforming curriculum design and instruction. Paper presented at the Internationalizing Canada's Universities, York University, Toronto, Canada

Office of Accreditation, (2009). QEP Development Team. Retrieved from: http://accreditation.fiu.edu/index.php?name=qep_development_team

Office of Education Abroad. (n.d.). About US. Florida International University. Retrieved from: http://educationabroad.fiu.edu/page.php?c=about us

Osborne, J., \& Costello, A. B. (2005). Best practices in exploratory factor analysis: Four recommendations for getting the most from analysis. Practical Assessment, Research \& Evaluation, 10(7). Retrieved from: http://pareonline.net/pdf/v10n7.pdf

Otten, M. (2000). Impact of cultural diversity at home. In P. Crowther, M. Joris, M., Otten, B. Nilsson, S. Teekens, \& B.Wächter (Eds.), Internationalisation at home: A position paper (pp. 15-20). Amsterdam: European Association for International Education, Drukkerij Raddraaier.

Oudhof, K. \& Keuzenkamp, S. (2002). Engendering attitudes. Working paper (17). Netherlands: Statistical Commission and Economic Commission for Europe. 
Paige, M. (2005). Internationalization of higher education: Performance assessment and indicators. Retrieved from:

http://72.14.205.104/search?q=cache:rI9bpQfwX9YJ:www.cshe.nagoya-

u.ac.jp/publications/journal/no5/08.pdf+Internationalization + of + higher+education :+performance + assessment + and + indicators $\& \mathrm{hl}=\mathrm{en} \& \mathrm{ct}=\mathrm{clnk} \& \mathrm{~cd}=1 \& \mathrm{gl}=\mathrm{us} \& \mathrm{clien}$ $\mathrm{t}=$ firefox $-\mathrm{a}$

Paige, M. \& Mestenhauser, J. (1999, October). Internationalizing educational administration. Educational Administration Quarterly, 35(4), 500-517.

Pappano, L. (2007, November). The foreign legions. New York Times. Retrieved from:

http://www.nytimes.com/2007/11/04/education/edlife/studyabroad.html?em\&ex= $1194411600 \&$ en $=0 \mathrm{c} 843 \mathrm{~d} 2 \mathrm{bfa} 2 \mathrm{a} 5 \mathrm{~cd} 5 \& \mathrm{ei}=5087 \% 0 \mathrm{~A}$

Patton, M. (2002). Qualitative research \& evaluation methods ( $3^{\text {rd }}$ ed.). Thousand Oaks, CA: Sage.

Petronis, J. (2000) Internationalization of member institutions of the Association of Collegiate Business Schools and Programs. Publish dissertation: Texas A\&M University-Commerce Library.

Pickert, S. (1992). Preparing for a global community: Achieving an international perspective in higher education. SHE-ERIC Higher Education Report 2. Washington, DC: George Washington University, School of Education and Human Development.

Redwood, S., Goldwasser, C., Street, S. (1999). Action management. Price Waterhouse New York: Coopers: John Wiley \& Sons.

Rubin, H. \& Rubin, I. (1995). Qualitative interviewing: The art of hearing data. Thousand Oaks, CA: Sage.

Rudzki, R. (1998). The strategic management of internationalisation: Towards a model of theory and practice. Ph.D. dissertation, University of Newcastle, Tyne. Retrieved from: http://hdl.handle.net/10443/149

Rudzki, R. (2000, fall). Implementing internationalisation: The practical application of the fractal process. Journal of Studies in International Education, 77-90.

Santos, J. (1999, April). Cronbach's Alpha: A Tool for Assessing the Reliability of Scales. Journal of Extension. Retrieved from: http://www.joe.org/joe/1999april/tt3.php 
Schonlau, M., Fricker, R., \& Elliott, M. (2002). Conducting research surveys via E-mail and the Web. Santa Monica, CA: Rand

Schoorman, D. (1999). The pedagogical implications of diverse conceptualizations of internationalization: A U.S. Based Case Study. Journal of Studies in International Education, 3(3), 3-14.

Scott, R. (1992, September). Campus developments in response to the challenges on internationalization: The case of Ramapo College of New Jersey (USA) (Report No. 025 591). Paper presented at the general conference, Programme on Institutional Management in Higher Education of the Organization for Economic Cooperation and Development, Paris, France (ERIC Document Reproduction Service No. ED 345 678)

Sewell, M. (n.d.). The use of qualitative interviews in evaluation. Retrieved from: http://ag.arizona.edu/fcs/cyfernet/cyfar/Intervu5.htm

Sheehan, K. (2001). E-mail survey response rates: a review. Journal of ComputerMediated Communication, 6(2). Retrieve from:

http://onlinelibrary.wiley.com/doi/10.1111/j.1083-6101.2001.tb00117.x/full

Siaya, L., \& Hayward, F. M. (2003). Mapping Internationalization on U.S. Campuses. Washington, DC: American Council on Education

Soderqvist, M. (2002). Internationalization and its management at higher education institutions: Applying conceptual, content and discourse analysis. Helsinki, Finland: Helsinki School of Economics.

Taylor, John (2004). Toward a strategy for internationalization: Lessons and practices form four universities. Journal of Studies in International Education, 8, 149-166.

Taylor, S., \& Bodgan, R. (1984). Introduction to qualitative research methods (2 ${ }^{\text {nd }}$ ed.). New York, NY: Wiley.

U.S. Department of Education. (n.d.). Centers for International Business Education. Retrieved from: http:/www2.ed.gov/programs/iegpscibe/index.html

U.S. Department of Education. (2007). National Security Language Initiative (NSLI). Retrieved from:

http://www2.ed.gov/about/inits/ed/competitiveness/nsli/nslibrochure.html

U.S. Department of State. (n.d). Office of Private Sector Exchange. Retrieved from: http://exchanges.state.gov/jexchanges/index.html 
U.S. Department of State, Bureau of Educational and Cultural Affairs. (n.d). 2005-2006 annual Fulbright report. Retrieved from:

http://exchanges.state.gov/education/fulbright/ffsb/annualreport/2006/full_report. pdf

van der Wende, M. (1997). Missing links: the relationship between national policies for internationalization and those for higher education in general. In T. Kalvemark \& van der Wende (Eds.), National policies for the internationalization of higher education in Europe (pp. 10-38). Stockholm: National Agency for Higher Education.

van der Wende, M. (1998). Internationalizing the curriculum in Dutch higher education: An international comparative perspective. Ph.D. dissertation, Utrecht University.

van der Wende, M. (1999). An innovation perspective on internationalization of higher education institutionalization: The critical phase. Journal of Studies in International Education, 3(1), 3-22.

Van Dijk, H. and Meijer, K. (1997, March). The internationalization cube: A tentative model for the study of organizational designs and the results of internationalization in higher education. Higher Education Management, 9(1), $157-167$.

Vestal, T. (1994). International Education: Its history and promise for today. Westport, Conn: Praeger.

Walker, H., Armenakis, A., \& Bernerth, J. (2007). Factors influencing organizational change efforts: An integrative investigation of change content, context, process and individual differences. Journal of organizational change Management, 20(6), $761-773$

Warner, G. (1992). International models and the role of the university. International Education Magazine, 21, 21.

Yao, C. \& Hartnett, R. (2009). Assessing Study Abroad Programs at U.S. Research Universities: A Social Systems Study. International Journal of Scholarly Academic International Diversity. Retrieved from:

http://www.nationalforum.com/Electronic\%20Journal\%20Volumes/Yao,\%20Chu nmei\%20Assessing\%20Abroad\%20Programs\%20at\%20U.\%20S.\%20Research\% 20Universities-IJSAID-V11-N1.pdf

Yin, R. (1994). Case study research: Design and methods (2nd ed.). Applied social research methods series. Thousand Oaks, CA: Sage. 
Zammuto, R. (1982). Assessing organizational effectiveness. Albany, NY: State University of New York Press. 


\section{APPENDICES}




\section{Appendix A}

Keller's Elements in the Development of International Strategy in Universities

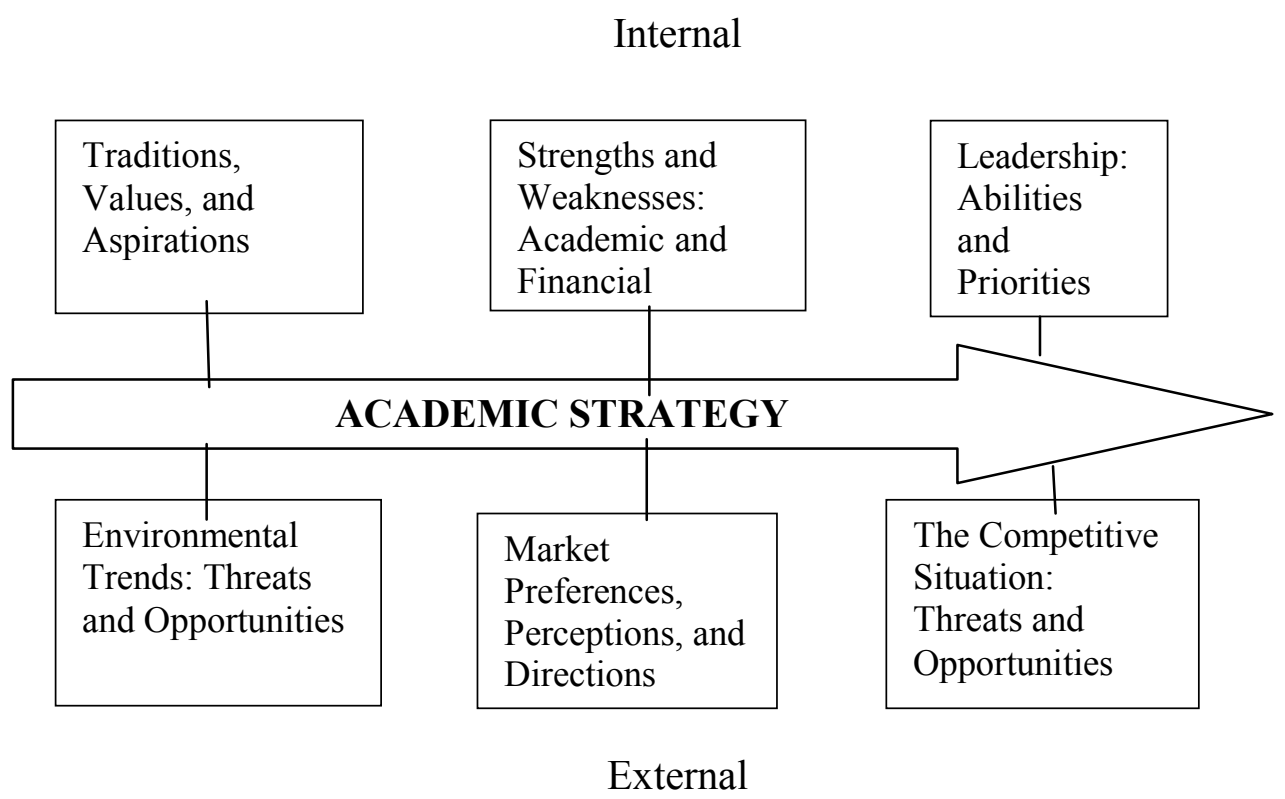




\section{Appendix B}

J. M. Davis Matrix Model, Institutionalization of Approaches to Internationalization in Universities

\begin{tabular}{l|l|}
\hline Ad hoc & systematic \\
\hline & \\
\hline $\boldsymbol{A}$ & $\mathrm{B}$ \\
\hline & \\
\hline & D \\
\hline
\end{tabular}

Marginal

Central 


\section{Appendix C}

Van Dijk and Meijer Internationalization Cube

\begin{tabular}{|llll|}
\hline & \multicolumn{1}{c|}{ A } & \multicolumn{1}{c|}{ B } & \multicolumn{1}{c|}{ C } \\
Cell & (Policy) & (Support) & (Implementation) \\
\hline 1 & Marginal & One-sided & ad hoc \\
2 & Marginal & One-sided & systematic \\
3 & Marginal & Interactive & ad hoc \\
4 & Marginal & Interactive & systematic \\
5 & Priority & One-sided & ad hoc \\
6 & Priority & One-sided & systematic \\
7 & Priority & Interactive & ad hoc \\
8 & Priority & Interactive & systematic \\
\hline
\end{tabular}




\title{
Appendix D
}

\author{
Interview Questions
}

Policy:

1. How do you define internationalization?

2. In your opinion, how does FIU's current mission statement

support your definition of internationalization?

(Florida International University is an urban, multi-campus research university serving South Florida, the state, the nation, and the international community. Our mission is to impart knowledge through excellent teaching, promote public service, discover new knowledge, solve problems through research, and foster creativity)

3. In relation to Fall 2007, Fall 2008 shows an increase in international students. Would you attribute the increase in the number of international students due to a strategic priority?

Implementation:

1. In your opinion, to what extent do you consider personnel policies consistent with FIU's internationalization process? (personnel policy refers to hiring, annual evaluation, tenure and promotion, facilitating research abroad, etc).

2. How would you assess the process for developing the policies and procedures for international activities and programs at FIU? (dealing with the planning, evaluation and assessment of the internalization process - seen in outcomes of international projects, programs and activities?).

3. Can you describe any special steps implemented to increase the number of international students? (i.e international enrollment management plan)

Support:

1. In your opinion, how do you view the support given to the management of the internationalization process?

2. In which ways, do FIU financial systems, policies, and practices support FIU's internationalization goals?

3. How are faculty rewarded for their international efforts? (Such as international grantsmanship, study abroad participation, research, etc.)

Final Question:

In your opinion, what are the challenges or opportunities to internationalization at FIU? 


\section{Appendix E}

\section{Interview Questions by Personnel}

Vice President for Academic Affairs/Interim Provost

1. How do you define internationalization?

2. In your opinion how does FIU's current mission statement support your definition of internationalization?

(Florida International University is an urban, multi-campus research university serving South Florida, the state, the nation, and the international community. Our mission is to impart knowledge through excellent teaching, promote public service, discover new knowledge, solve problems through research, and foster creativity)

3. How would you assess the process for developing the policies and procedures for international activities and programs at FIU? (dealing with the planning, evaluation and assessment of the internalization process - seen in outcomes of international projects, programs and activities?)

4. In your opinion, to what extent do you consider personnel policies consistent with FIU's internationalization process? (personnel policy referring to hiring, annual evaluation, tenure and promotion, facilitating research abroad, etc).

5. In your opinion, how do view the support given to the management of the internationalization process?

6. In which ways, do FIU financial systems, policies, and practices support FIU's internationalization goals?

7. How are faculty rewarded for their international efforts? (Such as international grantsmanship, study abroad participation, research, etc.)

8. In your opinion, what are the challenges or opportunities to internationalization at FIU?

Director of Global Learning Office

1. How do you define internationalization?

2. In your opinion, how does FIU's current mission statement support your definition of internationalization?

(Florida International University is an urban, multi-campus research university serving South Florida, the state, the nation, and the international community. Our mission is to impart knowledge through excellent teaching, promote public service, discover new knowledge, solve problems through research, and foster creativity)

3. How would you assess the process for developing the policies and procedures for international activities and programs at FIU? (dealing with the planning, evaluation and assessment of the internalization process - seen in outcomes of international projects, programs and activities?).

4. In your opinion, to what extent do you consider personnel policies consistent with FIU's internationalization process? (personnel policy refers to hiring, annual evaluation, tenure and promotion, facilitating research abroad, etc). 
5. How are faculty rewarded for their international efforts? (Such as international grantsmanship, study abroad participation, research, etc.)

6. In your opinion, how do you view the support given to the management of the internationalization process?

7. In which ways, do FIU financial systems, policies, and practices support FIU's internationalization goals?

8. In your opinion, what are the challenges or opportunities of internationalization at FIU?

Director of Graduate Admission

1. How do you define internationalization?

2. In your opinion, how does FIU's current mission statement support your definition of internationalization?

(Florida International University is an urban, multi-campus research university serving South Florida, the state, the nation, and the international community. Our mission is to impart knowledge through excellent teaching, promote public service, discover new knowledge, solve problems through research, and foster creativity)

3. In relation to Fall 2007 (6.25\%), Fall 2008 (6.45\%) shows an increase in international students. Would you attribute the increase in the number of international students due to a strategic priority?

4. Can you describe any special steps implemented to increase the number of international students? (i.e. international enrollment management plan)

5. In your opinion, what are the challenges or opportunities to internationalization at FIU? 


\section{Appendix F}

Consent to Participate in Research

\section{Email Presentation}




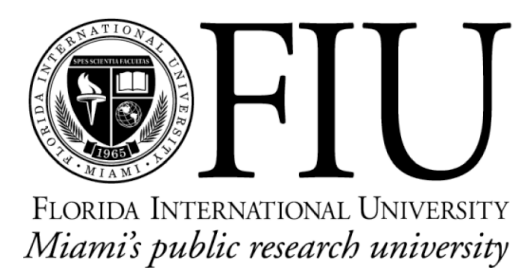

Consent to Participate in Research - Email Presentation

Title: Assessing the Effectiveness of the Internationalization Process in Higher Education Institutions: A Case Study of Florida International University.

Dear [Name of FIU administrator],

My name is Flavia Iuspa, a doctoral student at the College of Education, Department of Curriculum and Instruction. You are invited to take part in a doctoral study about FIU's internationalization process. The purpose of this study is to examine FIU's internationalization process by evaluating FIU's policy, support and implementation dimensions toward internationalization.

The research will be conducted at FIU. If you choose to be in the study, you will be interviewed at a location of your choice. The interview will take about $30-60$ minutes of your time and will be recorded and transcribed for data accuracy.

There are no foreseeable risks or benefits to you for participating in this study. There is no cost or payment to you. If you have questions while taking part, please stop me and ask. You will remain anonymous. Your name other personal identifiers will not be requested.

Your participation in this research is voluntary, and you will not be penalized or lose benefits if you refuse to participate or decide to stop

If you have questions after we have finished you may call me at 305-342-7103 and I will answer your questions. If you have questions about being in a study or you feel as if you were not treated well during this study, call Dr. Patricia Price at 305-348-2618 or 305348-2494. She is the Chair of the Institutional Review Board at FIU.

I look forward to your response to schedule an interview. Should you have any questions, please feel free to contact me at 305-XXX-XXXX or via email at fiusp001@fiu.edu.

Sincerely,

Flavia Iuspa 
Appendix G

Consent to Participate in Research Study 


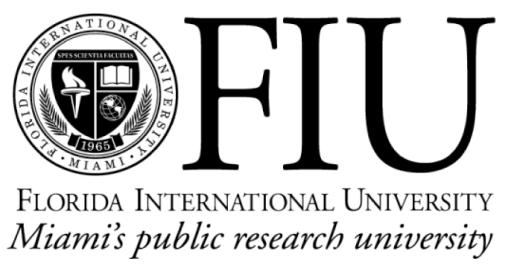

\section{Title: Assessing the Effectiveness of the Internationalization Process in Higher Education Institutions: A Case Study of Florida International University.}

You are invited to take part in doctoral study about FIU's internationalization process. The investigator is Flavia Iuspa, and she is a doctoral student at the College of Education, Department of Curriculum and Instruction. This letter is part of the process known as informed consent. This consent form provides information about the research study, risks and benefits. If you agree to take part in the doctoral study, you will be asked to sign this consent form. Your decision to take part in the study is voluntary. You are free to choose whether or not you will take part in the study.

The purpose of this study is to evaluate FIU's internationalization process. Specially, the study seeks to examine FIU's internationalization process by evaluating FIU's policy, support and implementation dimensions toward internationalization.

The research will be conducted at FIU. If you choose to be in the study, you will be interviewed at a location of your choice. The interview will take about $30-60$ minutes of your time and will be recorded and transcribed for data accuracy. You will remain anonymous. Your name other personal identifiers will not be requested.

There are no foreseeable risks or benefits to you for participating in this study. There is no cost or payment to you. If you have questions while taking part, please stop me and ask.

If you would like more information about this research after you are done, you can contact Dr. Farouk at 305-348-3199 or me at 305-XXX-XXXX. If you have questions about being in a study or you feel as if you were not treated well during this study, call Dr. Patricia Price at 305-348-2618 or 305-348-2494. She is the Chair of the Institutional Review Board at FIU.

Your participation in this research is voluntary, and you will not be penalized or lose benefits if you refuse to participate or decide to stop. Your signature below indicates that 
all questions have been answered to your liking. You are aware of your rights and you would like to be in the study.

Signature of Participant

I have explained the research procedure, subject rights and answered questions asked by the participant. I have offered him/her a copy of this informed consent form. 
Appendix $\mathrm{H}$

List of FIU Interviewees

Executive Vice President \& Provost/Chief Operating Officer

Director of the Office of Global Learning Initiatives

Director of Graduate Admissions 


\section{Appendix I}

List of FIU Deans and Directors Interviewees

College of Education

College of Arts \& Sciences and Director of School of International and Public Affairs

College of Business Administration

School of Hospitality \& Tourism Management 
Appendix J

Interview Questions for Deans and Director School of

International and Public Affairs

Deans and Director School of International and Public Affairs

1. How do you define internationalization?

2. In your opinion, how does FIU's current mission statement support your definition of internationalization?

(Florida International University is an urban, multi-campus research university serving South Florida, the state, the nation, and the international community. Our mission is to impart knowledge through excellent teaching, promote public service, discover new knowledge, solve problems through research, and foster creativity)

3. How are faculty rewarded for their international efforts? (Such as international grantsmanship, study abroad participation, research, etc.)

4. How would you assess the process for developing the policies and procedures for international activities and programs at FIU? (dealing with the planning, evaluation and assessment of the internalization process - seen in outcomes of international projects, programs and activities?).

5. In your opinion, how do view the support given to the management of the internationalization process?

6. In your opinion, to what extent do you consider personnel policies consistent with FIU's internationalization process? (Personnel policy refers to hiring, annual evaluation, tenure and promotion, facilitating research abroad, etc).

7. In which ways, do FIU financial systems, policies and practices support FIU's internationalization goals?

8. In your opinion, what are the challenges or opportunities to internationalization at FIU? 


\section{Appendix K}

Sample Analysis Models

Policy Model Analysis

\begin{tabular}{|c|c|c|}
\hline Document & $\begin{array}{l}\text { Priority }=\mathrm{P} \\
\text { Marginal }=\mathrm{M}\end{array}$ & Criteria \\
\hline \multirow[t]{2}{*}{ Mission Statement } & & $\begin{array}{l}\text { Mention of Global, international, } \\
\text { multicultural mission/goals, } \\
\text { commitment to diversity=P }\end{array}$ \\
\hline & & $\begin{array}{l}\text { No indication of global, international } \\
\text { or multicultural commitment }=\mathrm{M}\end{array}$ \\
\hline \multirow{2}{*}{$\begin{array}{l}\text { Faculty Bios } \\
\text { Experience }\end{array}$} & & Strong Emphasis on global $=\mathrm{P}$ \\
\hline & & No mention of global dimension $=\mathrm{M}$ \\
\hline $\begin{array}{l}\text { Admissions Catalogs } \\
\text { FIU Magazine }\end{array}$ & & $\begin{array}{l}\text { Wide distribution }=\mathrm{P} \\
\text { Prominence of Statement } \\
\text { Frequency }=\mathrm{P} \\
\text { Strong International Component }=\mathrm{P} \\
\text { Little/no global content }=\mathrm{M}\end{array}$ \\
\hline
\end{tabular}


Implementation Analysis Model

Criteria:

Clear Indication or Presence of organizational structure/

guidelines/procedures toward

internationalization $=$ Structured/

Systematic

No clear Indication or Presence of

organizational structure/

guidelines/procedures toward

internationalization $=\mathrm{Ad}$ hoc

ORGANIZATIONAL STRUCTURE

for internationalization

CIEA TITLE

Level of Reporting line

PRIMARY LEVEL OF

RESPONSIBILITY

SECONDARY LEVEL OF

RESPONSIBILITY

EXISTENCE OF CAMPUS-WIDE

INTERNATIONAL ADVISORY

BOARD/COMMITTEE

Appointed

Elected

Number of Meetings/Year

Student Representation

External/Internal/Combined

PERSONNEL policies

International Faculty

Faculty Interests

Faculty backgrounds

Inclusion of International

efforts/expertise for tenure,

hiring, and rewarding decisions

(table continues) 
Implementation Analysis Model (continued)

Criteria:

Clear Indication or Presence of organizational structure/guidelines/procedures=Structured/ Systematic

No clear Indication or Presence of organizational structure/ guidelines/procedures $=\mathrm{Ad}$ hoc

Explicit Procedures developed in an orderly or systematic fashion

International Students recruitment plan

Study Abroad, Offshore

programs, internationalization of

the curriculum, faculty travel to

teach abroad 
Criteria:

Support provided with interaction among central, faculty, and departmental level

$=$ Interactive

Support provided at the central or peripheral level $=$ Unilateral/One-sided

Foreign Languages

FL Department

FL Requirement

Entry Requirements

International Studies

IS Majors/Minors

Internationalization of the

Curriculum

Study Abroad

Internal Programs

Non-academic Support

International Students

Administrative and Staff

Services (i.e. Financial Aid)

International Faculty

Recognition

Integrated into Campus

Faculty Expertise

External Grants

Institutional Support (research)

Other Resources

Funding Sources (external

and internal sources)

Library Resources (international newspapers, foreign films, language aids, etc).

Organization of International

Conferences 


\section{Appendix L}

\section{Interview Content Analysis Summary Matrix}

\section{Policy Dimension: Marginal or Priority}

Legend:

Level of Consistency: High= Priority; Low=Marginal

\section{Frequency counts of \\ Level of Consistency}

Agreement occurrence

How do you define

internationalization?

Key Words:

Incorporation of International

dimension into learning, research and services.

(Explicit agreement on definition of internationalization)

In your opinion, how would you say that FIU's current mission statement supports your definition of internationalization? (Explicit alignment between mission statement and definition of internationalization) 
Implementation Dimension - Ad hoc or Structural

Legend:

Level of Consistency: High= Structured; Low=Ad hoc

Frequency counts on

Items respondents
Level of Consistency on mentioned Items

How is the international process

managed at FIU or in your

College/School?

In your opinion, to what extent do

you consider personnel policies

consistent with FIU's

internationalization process?

(personnel policy referring to

hiring, tenure, facilitating research

abroad, etc).

How would you assess the process for developing the policies and procedures for international activities and programs at FIU? (dealing with the planning, evaluation and assessment of the internalization process - seen in outcomes of international projects, programs and activities?). Can you describe them?

Can you describe any special steps implemented to increase the number of international students? (i.e. International enrollment management plan) 
Support Dimension - Interactive or Unilateral (central or peripheral)

Legend:

Level of Consistency: High= Interactive; Low=One-sided/Unilateral (central or peripheral)

$\begin{array}{ll}\text { Frequency counts on } & \text { Level of Consistency on } \\ \text { Items respondents } & \text { types of support }\end{array}$

In your opinion, how do you view

the support given to the

management of the

internationalization process?

How are faculty rewarded for

their international efforts? (such

as international grantsmanship,

study abroad participation,

research, etc.)

In which ways FIU's financial

systems, policies, and practices

support FIU's internationalization

goals?

\section{Final Question}

\# of respondents mentioning Level of consistency
specific perceptions
(Frequently cited)

In your opinion, what are

the challenges or

opportunities to

internationalization at

FIU? 
Appendix M

Panel Instructions and Survey

\section{Dear Panel Member:}

You are invited to participate in a dissertation study on Assessing the Effectiveness of the Internationalization Process in Higher Education Institutions.

The purpose of this study is to evaluate Higher Education Institutions' (HEIs) internationalization process through the application of the Van Dijk and Mejier (1997) Internationalization Cube theoretical model. In particular, this survey is intended to establish to what extent an HEI's position on the Van Dijk and Meijer's Internationalization Cube is aligned to its international activities. Click here to see Van Dijk \& Meijer Internationalization Cube and Definition of Terms.

As a panel member, your role is to provide your expertise and knowledge in the international education by responding to the following survey on international activities. The panel members' tabulated responses will serve as criteria for analysis. To this end:

1. You are requested to determine if the international activities in the survey are relevant or not to the hypothetical university presented on the next page, and

2. If you choose an international activity as relevant, you will be directed to select the minimum number or percentage the hypothetical university should have/offer of that particular international activity.

The survey consists of a total of 27 questions. However, this number may decrease depending on your responses.

The survey will take about $20-25$ minutes of your time. You will remain anonymous. Your name and other personal identifiers will not be requested.

There are no foreseeable risks or benefits to you for participating in this study. There is no cost or payment to you. If you have questions while taking the survey, please stop and email me at fiusp001@fiu.edu.

If you would like more information about this research after you are done, you can contact Dr. Farouk at 305-348-3199 or me at 305-XXX-XXXX. If you have questions about being in the study or you feel as if you were not treated well during this study, call Dr. Patricia Price at 305-348-2618 or 305-348-2494. She is the Chair of the Institutional Review Board at FIU. 
Your participation in this research is voluntary, and you will not be penalized or lose benefits if you refuse to participate or decide to stop. By clicking the "Next" button below you indicate that all questions have been answered to your liking. You are aware of your rights and you would like to participate in the study.

\section{University hypothetical scenario}

University " $X$ " with an approximately 30,000 student population and 1,000 faculty members is assessing its internationalization process using the Van Dijk and Miejer' Internationalization Cube. Click here to see Van Dijk \& Meijer Internationalization Cube and Definition of Terms.

After a careful analysis, University $\mathrm{X}$ determined that it is placed on position 7 of the Van Dijk and Miejer' Internationalization Cube (1997). According to University X's placement, University X presents the following characteristics towards internationalization: A Priority Policy, an Interactive Support, and an Ad hoc Implementation.

Given the hypothetical scenario above, please answer the following questions:

Click the "Next" button below to continue.

\section{Foreign Language}

Based on University X characteristics toward internationalization, select from the list below all items you deem relevant to University X.

$\square$ Foreign Language (FL) (defined as any other language taught in University X other than English)

$\square$ Foreign Language entrance requirement for all incoming undergraduate University $\mathrm{X}$ $\square$ Foreign Language graduation requirement for undergraduate students

Based on University $\mathrm{X}$ characteristics, what would you consider the minimum number of Majors/Minors in Foreign Languages University X should offer?

\section{Less than 50 \\ From 50 to 100 \\ From 101 to 151 \\ More than 151}

Based on University X student population, what would you say is the minimum number of undergraduate enrollment in Foreign Language University X should have in an academic year?

Less than 500 


\section{From 500 to 1,000}

From 1,001 to 1,501

More than 1,501

Based on University X student population, what would you say is the minimum number of graduate enrollment in Foreign Language University $\mathrm{X}$ should have in an academic year?

Less than 500

From 500 to 1,000

From 1,001 to 1,501

$\square$ More than 1,501

Based on University X characteristics, what is the minimum number of undergraduate degrees in Foreign Languages University X should confer in an academic year?

Less than 50

$\square$ From 50 to 100

$\square$ From 101 to 151

More than 151

Based on University $\mathrm{X}$ characteristics, what is the minimum number of graduate degrees in Foreign Languages University X should confer in an academic year?

Less than 50

$\square$ From 50 to 100

From 101 to 151

More than 151

\section{International Curriculum}

Based on University X characteristics toward internationalization, international degree program areas (International Curriculum) is relevant to University X.

$\square$ Yes

Based on University X characteristics, what is the minimum number of undergraduate international degree program areas University X should confer in an academic year?

Less than 50

From 50 to 100

From 101 to 151

More than 151 
Based on University $\mathrm{X}$ characteristics, what is the minimum number of graduate international degree program areas University X should confer in an academic year?

Less than 50

From 50 to 100

From 101 to 151

More than 151

Based on University X characteristics, what would you consider the minimum number of undergraduate enrollment in international program areas University $\mathrm{X}$ should have in an academic year?

Less than 500

From 500 to 1,000

From 1,001 to 1,501

$\square$ More than 1,501

Based on University X characteristics, what would you consider the minimum number of graduate enrollment in international program areas University $X$ should have in an academic year?

Less than 50

From 50 to 100

From 101 to 151

More than 151

International Students

Based on University X characteristics toward internationalization, international students are relevant to University $\mathrm{X}$.

For the purpose of this survey, international students are defined as holders of $\mathrm{F}$ (students) Visas, H (temporary worker/trainee) Visas, J (temporary educational exchange-visitor) Visas, and M (vocational training) Visas. (ACE, 2008)

$\square$ Yes

Based on University $\mathrm{X}$ student population, what is the minimum percentage of international students University X should have in an academic year?

\footnotetext{
Less than 5 percent

5 percent to 9 percent

10 percent to 25 percent

More than 25 percent
} 
Based on University X student population, what is the minimum number of international undergraduate and graduate enrollment University X should have in an academic year?

$\square$ Less than 5 percent

5 percent to 9 percent 10 percent to 25 percent

More than 25 percent

Faculty Exchange

Based on University $\mathrm{X}$ characteristics toward internationalization, faculty exchange is relevant to University $\mathrm{X}$.

For the purpose of this survey, faculty exchange is defined as the movement of faculty among institutions to conduct research, lecture, and/or consult with other scholars abroad (CIES, 2009).

$\square$ Yes

Based on University X characteristics, what would you recommend as the minimum number of faculty with Fulbright awards to work outside the U.S. University X should have in an academic year?
Less than 50
From 50 to 100
From 101 to 151
More than 151

Based on University X characteristics, what would you recommend as the minimum number of faculty Fulbright awardees hosted by University $\mathrm{X}$ in an academic year?
Less than 50
From 50 to 100
From 101 to 151
More than 151

\section{Co-Curricular activities}

Based on University X characteristics toward internationalization, Co-Curricular Activities are relevant to University X.

For the purpose of this survey, co-curricular activities are defined as international events outside the Classroom.

$\square$ Yes 
Based on University $\mathrm{X}$ characteristics, what would you recommend as the minimum number of co-curricular international events University X should have?
Less than 50
From 50 to 100
From 101 to 151
More than 151

\section{Study Abroad}

Based on University X characteristics toward internationalization, Study Abroad is relevant to University $\mathrm{X}$.

$\square$ Yes

According to University X student population, what would you consider the minimum percentage of students participating in study abroad University X should have in an academic year?
Less than 5 percent
5 percent to 10 percent
11 percent to 20 percent
21 percent to 30 percent
31 percent to 50 percent
$\square$ More than 50 percent

According to University X student population, what would you consider the minimum percentage of external exchange students coming to University $\mathrm{X}$ in an academic year should be?
Less than 5 percent
5 percent to 10 percent
11 percent to 20 percent
Q 21 percent to 30 percent
31 percent to 50 percent
More than 50 percent

\section{Faculty International Development Projects}

Based on University X characteristics toward internationalization, Faculty International Development Projects are relevant to University X.
$\square$ Yes 
Based on University X characteristics, what would you consider the minimum number of faculty involvement in international development projects University X should have?

$\square$ Less than 50

From 50 to 100

From 101 to 151

More than 151

\section{Offshore Degree Programs}

For the purpose of this survey, offshore degree programs are undergraduate and/or graduate degree programs University X offers outside the United States for non-U.S. students (Green, Luu, Burris, 2008)

Based on University X characteristics toward internationalization, offshore degree programs are relevant to University X.

$\square$ Yes

No

Based on University X characteristics, what would you consider the minimum number of offshore undergraduate degree programs University X should have?
Less than 50
$\square$ From 50 to 100
From 101 to 151
More than 151

Based on University X characteristics, what would you consider the minimum number of offshore graduate degree programs University X should have?
Less than 50
From 50 to 100
From 101 to 151
More than 151

Thank you for Completing the Survey. 
Appendix N

Cover Email Invitation and Faculty Survey on Internationalization

Dear FIU Faculty:

You are invited to participate in a dissertation study on Assessing the Effectiveness of the Internationalization Process in Higher Education Institutions: A Case Study of Florida International University. Please read this consent email and ask any questions you may have before agreeing to take part in the study.

Internationalization is defined as "the process of integrating an international, intercultural and/or global dimension into the goals, functions (teaching/learning, research, service) and delivery of higher education" (Knight, 2003, p. 11).

By participating in the study, you will (a) provide invaluable information about the internationalization process at FIU, and (B) contribute to the institutional planning and enhancement of the internationalization process within Higher Education Institutions.

The survey consists of a total of $\underline{45 \text { questions, }}$, and it will take 10 minutes to complete.

There are no risks or benefits involved in the study. Your answers are treated confidentially and cannot be tracked back to you. Your name is not required to participate in this study. Your participation is voluntarily. If you decide to participate, please complete the online survey by no later than Friday April 20, 2010. You are free to withdraw at any time. Please click on the link below and you will be directed to the survey:

http://www.surveymonkey.com/s.aspx?sm=E5mW28OQAU4_2f7TLkCpErfA_3d_3d

The study is carried out by Flavia Iuspa, doctoral candidate at the College of Education under the supervision of Dr. Mohammed K. Farouk. If you have questions, you may contact me at 305-XXX-XXXX or at fiusp001@fiu.edu, or Dr. Farouk at 305-348-3199 or at faroukm@fiu.edu.

The purpose of this research has been explained to me and my participation is entirely voluntary. I understand that the research entails no risks and that my responses are not being recorded in any individually identifiable form. By completing the survey I am consenting to participate in the study and have my data used by the researchers. Thank you in advance.

\section{THIS PAGE MAY BE PRINTED AND KEPT BY EACH PARTICIPANT}

Research at Florida International University that involves human participants is carried 
out under the oversight of an Institutional Review Board. Questions or problems regarding these activities should be addressed to Dr. Patricia Price, Chairperson of the Institutional Review Board, Florida International University, at 305-348-2618 or 305348-2494. 


\section{Faculty Survey on Internationalization}

Internationalization is defined as "the process of integrating an international, intercultural and/or global dimension into the goals, functions (teaching/learning, research, service) and delivery of higher education" (Knight, 2003, p. 11).

Please indicate whether you agree or disagree with the following statements. Please record your answer by selecting the number that best represents the extent of your agreement with each statement.
$\mathrm{SA}=$ Strongly Agree (5)
$\mathrm{D}=$ Disagree (2)
$\mathrm{A}=$ Agree (4)
$\mathrm{SD}=$ Strongly Disagree (1)
$\mathrm{N}=\operatorname{Neutral}(3)$

\section{General attitudes about Internationalization}

1 Internationalization is a component of FIU's 3.0: A New Strategic Paradigm plan.

$\begin{array}{ccccc}\text { SA } & \text { A } & \text { N } & \text { D } & \text { SD } \\ 5 & 4 & 3 & 2 & 1\end{array}$

2 FIU's current mission statement supports the definition of internationalization presented above.

$\begin{array}{ccccc}\text { SA } & \text { A } & \text { N } & \text { D } & \text { SD } \\ 5 & 4 & 3 & 2 & 1\end{array}$

3 The process of internationalization is understood and discussed

SA $\quad$ A $\quad$ N $\quad$ D $\quad$ SD
by all FIU stakeholders (students, administrators, and faculty).

$\begin{array}{ccccc}5 & 4 & 3 & 2 & 1\end{array}$

4 FIU's Global Learning Quality Enhancement Plan is understood SA $\quad$ A $\quad \mathrm{N} \quad \mathrm{D} \quad \mathrm{SD}$ and discussed by all FIU stakeholders (students, administrators, $\begin{array}{llllll}5 & 4 & 3 & 2 & 1\end{array}$ and faculty).

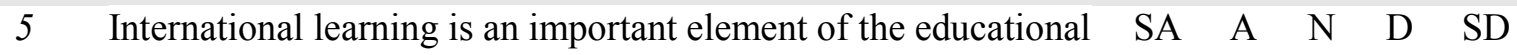
process at FIU.

$\begin{array}{lllll}5 & 4 & 3 & 2 & 1\end{array}$

$6 \quad$ FIU's exchange programs with institutions in other countries foster internationalization of instruction, research, and service learning.

$\begin{array}{ccccc}\text { SA } & \text { A } & \text { N } & \text { D } & \text { SD } \\ 5 & 4 & 3 & 2 & 1\end{array}$

7 Learning a foreign language is not essential for an undergraduate education.

$\begin{array}{ccccc}\text { SA } & \text { A } & \text { N } & \text { D } & \text { SD } \\ 5 & 4 & 3 & 2 & 1\end{array}$

8 Students can understand their own culture more fully if they have studied another.

$\begin{array}{ccccc}\text { SA } & \text { A } & \text { N } & \text { D } & \text { SD } \\ 5 & 4 & 3 & 2 & 1 \\ & & & & \\ \text { SA } & \text { A } & \text { N } & \text { D } & \text { SD } \\ 5 & 4 & 3 & 2 & 1\end{array}$

10 I believe an understanding of international issues is important

$\begin{array}{ccccc}\text { SA } & \text { A } & \text { N } & \text { D } & \text { SD } \\ 5 & 4 & 3 & 2 & 1\end{array}$


11 Learning about people from different cultures is a very

important part of education.

$\begin{array}{ccccc}\text { SA } & \text { A } & \text { N } & \text { D } & \text { SD } \\ 5 & 4 & 3 & 2 & 1\end{array}$

12 Contact with individuals whose background differs from my $\quad$ SA A $\quad$ N $\quad$ D $\quad$ SD own is not an essential part of education.

$\begin{array}{lllll}5 & 4 & 3 & 2 & 1\end{array}$

13 There is a genuine commitment to internationalization at FIU. $\quad$ SA A $\quad$ N D SD

FIU's Support for Internationalization

14 My college/school/department strongly promotes faculty $\quad$ SA A $\quad$ N $\quad$ D $\quad$ SD

engagement in internationalization.

$\begin{array}{ccccc}\text { SA } & \text { A } & \text { N } & \text { D } & \text { SD } \\ 5 & 4 & 3 & 2 & 1\end{array}$

15 I have been encouraged in my department to offer courses that $\begin{array}{lllll}\text { SA } & \text { A } & \text { N } & \text { D } & \text { SD }\end{array}$ incorporate international content.

$\begin{array}{lllll}5 & 4 & 3 & 2 & 1\end{array}$

16 My courses with international content have provided examples from all regions of the world.

SA A $\quad$ N D $\quad$ SD

$\begin{array}{lllll}5 & 4 & 3 & 2 & 1\end{array}$

17 My college/school/department encourages me to participate in a study abroad program.

$\begin{array}{ccccc}\text { SA } & \text { A } & \text { N } & \text { D } & \text { SD } \\ 5 & 4 & 3 & 2 & 1\end{array}$

18 My college/school/department takes advantage of community resources to enhance the international learning experience.

$\begin{array}{ccccc}\mathrm{SA} & \mathrm{A} & \mathrm{N} & \mathrm{D} & \mathrm{SD} \\ 5 & 4 & 3 & 2 & 1\end{array}$

19 My college/school/department provides SA $\quad$ A $\quad \mathrm{N} \quad \mathrm{D} \quad \mathrm{SD}$ seminars/training/workshops to faculty on internationalizing the $\begin{array}{lllllll}5 & 4 & 3 & 2 & 1\end{array}$ curriculum.

20 My college/school/department encourages me to belong to an international professional organization.

SA A $\quad$ N $\quad$ D $\quad$ SD

21 My college/school/department encourages me to serve as $\begin{array}{lllll}5 & 4 & 3 & 2 & 1\end{array}$ Faculty Advisor to Students Organizations involved in projects with an international focus.

22 My college/school/department encourages me to publish on international or global topics.

SA $\quad$ A $\quad$ N $\quad$ D $\quad$ SD

$\begin{array}{lllll}5 & 4 & 3 & 2 & 1\end{array}$

23 My college/school/department encourages me to conduct
research on international topics.

23 My college/school/department encourages me to conduct
research on international topics.

SA $\quad$ A $\quad$ N $\quad$ D $\quad$ SD

$\begin{array}{lllll}5 & 4 & 3 & 2 & 1\end{array}$

SA $\quad$ A $\quad$ N $\quad$ D $\quad$ SD

$\begin{array}{lllll}5 & 4 & 3 & 2 & 1\end{array}$

24 My college/school/department encourages me to attend international symposiums/lectures on campus.

$\begin{array}{ccccc}\text { SA } & \text { A } & \text { N } & \text { D } & \text { SD } \\ 5 & 4 & 3 & 2 & 1\end{array}$

\section{Benefits of Internationalization}

25 International learning helps prepare students to become $\quad$ SA A $\quad$ N $\quad$ D $\quad$ SD responsible global citizens.

$\begin{array}{lllll}5 & 4 & 3 & 2 & 1\end{array}$


26 International learning makes me appreciate more of other cultures.

\section{SA $\quad$ A $\quad$ N $\quad$ D $\quad$ SD}

$\begin{array}{lllll}5 & 4 & 3 & 2 & 1\end{array}$

27 The more we know about other countries, the better we will understand our own.

$\begin{array}{ccccc}\text { SA } & \text { A } & \text { N } & \text { D } & \text { SD } \\ 5 & 4 & 3 & 2 & 1\end{array}$

28 International education helps me recognize and understand the SA $\quad$ A $\quad \mathrm{N} \quad \mathrm{D} \quad \mathrm{SD}$ impact other cultures have on American life and vice versa.

$\begin{array}{lllll}5 & 4 & 3 & 2 & 1\end{array}$

29 Learning other cultures helps me better tolerate ambiguity when communicating with a foreign person.

SA $\quad$ A $\quad$ N $\quad$ D $\quad$ SD

$\begin{array}{lllll}5 & 4 & 3 & 2 & 1\end{array}$

30 International education can explain the root causes of basic global problems such as overpopulation, poverty, climate

SA $\quad$ A $\quad$ N $\quad$ D $\quad$ SD
change, and disease.

\section{Please select one response to the following questions (Yes, No):}

31 Have you visited FIU's Office of Education Abroad? Yes No

32 Do you know if there are international travel grants offered to FIU Yes No students?

33 Have you ever participated in a study abroad program (in a faculty $\quad$ Yes $\quad$ No role)?

34 Would you like to participate in a study abroad program (in a faculty $\quad$ Yes No role)?

35 Have you participated in offshore (transnational) programs? $\quad$ Yes $\quad$ No

36 Would you like to participate in offshore (transnational) programs? $\quad$ Yes $\quad$ No

\section{Please select the demographic category that fits.}

37 Your age:
A. $<36$ years
B. $36-40$ years
C. 41-45 years
D. 46-50 years
E. $51+$ years

38 Your gender: A. Male $\quad$ B. Female

39 Your Race/Ethnicity:
A. Black/African-American
B. Hispanic
C. Asian
D. White Non-Hispanic
E. Other 
40 Period of teaching in higher education following terminal degree:
A. $<5$ years
B. 5-10 years C. 11-15 years
D. $16-20$ years
E. $20+$ years

41 Period of teaching at FIU:
A. $<5$ years
B. 5-10 years C. 11-15 years
D. 16-20 years
E. $20+$ years

42 Your tenure status:
A. Tenured
B. Non-tenured/tenure-track
C. Non-tenure track

43 Are you an international faculty (not born in the U.S.):

A. Yes B. No

44 Your discipline and department:

45 Comments:

Thank you so much for your participation in this survey. This survey is being conducted by Flavia Iuspa, Doctoral Candidate, College of Education, Florida International University 
Appendix O

Cover Email Invitation and Student Survey on Internationalization

Dear FIU Student:

You are invited to participate in a dissertation study on Assessing the effectiveness of the internationalization process in Higher Education Institutions: A case study of Florida International University. Please read this consent email and ask any questions you may have before agreeing to take part in the study.

Internationalization is defined as "the process of integrating an international, intercultural and/or global dimension into the goals, functions (teaching/learning, research, service) and delivery of higher education" (Knight, 2003, p. 11).

By participating in the study, you will (a) provide invaluable information about the internationalization process at FIU, and (B) contribute to the institutional planning and enhancement of the internationalization process within Higher Education Institutions.

The survey consists of a total of $\underline{\mathbf{3 9} \text { questions, }}$, and it will take $\underline{\mathbf{1 0} \text { minutes }}$ to complete.

There are no risks or benefits involved in the study. Your answers are treated confidentially and cannot be tracked back to you. Your name is not required to participate in this study. Your participation is voluntarily. If you decide to participate, please complete the online survey by no later than Friday January 29, 2010 .You are free to withdraw at any time. Please click on the link below and you will be directed to the survey:

http://www.surveymonkey.com/s.aspx?sm=hjEyk20ywQjN0BEvoFrwpg_3d_3d

The study is carried out by Flavia Iuspa, doctoral candidate at the College of Education under the supervision of Dr. Mohammed K. Farouk. If you have questions, you may contact me at 305-XXX-XXXX or at fiusp001@fiu.edu, or Dr. Farouk at 305-348-3199 or at faroukm@fiu.edu

The purpose of this research has been explained to me and my participation is entirely voluntary. I understand that the research entails no risks and that my responses are not being recorded in any individually identifiable form. By completing the survey I am consenting to participate in the study and have my data used by the researchers.

Thank you in advance.

THIS PAGE MAY BE PRINTED AND KEPT BY EACH PARTICIPANT

Research at Florida International University that involves human participants is carried 
out under the oversight of an Institutional Review Board. Questions or problems regarding these activities should be addressed to Dr. Patricia Price, Chairperson of the Institutional Review Board, Florida International University, at 305-348-2618 or 305348-2494. 


\section{Student Survey on Internationalization}

Internationalization is defined as "the process of integrating an international, intercultural and/or global dimension into the goals, functions (teaching/learning, research, service) and delivery of higher education" (Knight, 2003, p. 11).

Please indicate whether you agree or disagree with the following statements. Please record your answer by selecting the number that best represents the extent of your agreement with each statement.
$\mathrm{SA}=$ Strongly Agree (5)
$\mathrm{D}=$ Disagree (2)
$\mathrm{A}=$ Agree (4)
$\mathrm{SD}=$ Strongly Disagree (1)
$\mathrm{N}=\operatorname{Neutral}(3)$

\section{General attitudes about Internationalization}

1 Internationalization is a component of FIU's 3.0: A New Strategic Paradigm plan.

$\begin{array}{ccccc}\text { S5 } & \text { A } & \text { N } & \text { D } & \text { SD } \\ & 4 & 3 & 2 & 1\end{array}$

2 FIU's current mission statement supports the definition of internationalization presented above.

$\begin{array}{ccccc}\text { SA } & \text { A } & \text { N } & \text { D } & \text { SD } \\ 5 & 4 & 3 & 2 & 1\end{array}$

3 The process of internationalization is understood and

$\begin{array}{lllll}\text { SA } & \text { A } & \text { N } & \text { D } & \text { SD }\end{array}$
$\begin{array}{lllllll}\text { discussed by all FIU stakeholders (students, administrators, } & 5 & 4 & 3 & 2 & 1\end{array}$ and faculty).
4 International learning is an important element of the educational process at FIU.

$\begin{array}{ccccc}\mathrm{SA} & \mathrm{A} & \mathrm{N} & \mathrm{D} & \mathrm{SD} \\ 5 & 4 & 3 & 2 & 1\end{array}$
$5 \quad$ FIU's Global Learning Quality Enhancement Plan is SA $\quad$ A $\quad$ N $\quad$ D $\quad$ SD $\begin{array}{lllllll}\text { understood and discussed by all FIU stakeholders (students, } & 5 & 4 & 3 & 2 & 1\end{array}$ administrators, and faculty).

\begin{tabular}{|c|c|c|c|c|c|}
\hline $\begin{array}{l}\text { FIU's exchange programs with institutions in other countries } \\
\text { foster internationalization of instruction, research, and service } \\
\text { learning. }\end{array}$ & $\begin{array}{c}\text { SA } \\
5\end{array}$ & $\begin{array}{l}\mathrm{A} \\
4\end{array}$ & $\begin{array}{l}N \\
3\end{array}$ & $\begin{array}{l}\mathrm{D} \\
2\end{array}$ & $\begin{array}{c}\text { SD } \\
1\end{array}$ \\
\hline $\begin{array}{l}\text { Learning a foreign language is not essential for an } \\
\text { undergraduate education. }\end{array}$ & $\begin{array}{l}\text { SA } \\
5\end{array}$ & $\begin{array}{l}\mathrm{A} \\
4\end{array}$ & $\begin{array}{l}\mathrm{N} \\
3\end{array}$ & $\begin{array}{l}\mathrm{D} \\
2\end{array}$ & $\begin{array}{c}\text { SD } \\
1\end{array}$ \\
\hline $\begin{array}{l}\text { Students can understand their own culture more fully if they } \\
\text { have studied another. }\end{array}$ & $\begin{array}{c}\text { SA } \\
5\end{array}$ & $\begin{array}{l}\mathrm{A} \\
4\end{array}$ & $\begin{array}{l}\mathrm{N} \\
3\end{array}$ & $\begin{array}{l}\mathrm{D} \\
2\end{array}$ & $\begin{array}{c}\text { SD } \\
1\end{array}$ \\
\hline $\begin{array}{l}\text { Study abroad programs are the best way for students to } \\
\text { encounter another culture. }\end{array}$ & $\begin{array}{c}\text { SA } \\
5\end{array}$ & $\begin{array}{l}\text { A } \\
4\end{array}$ & $\begin{array}{l}\mathrm{N} \\
3\end{array}$ & $\begin{array}{l}\mathrm{D} \\
2\end{array}$ & $\begin{array}{c}\text { SD } \\
1\end{array}$ \\
\hline $\begin{array}{l}\text { I believe an understanding of international issues is important } \\
\text { for success in the workforce. }\end{array}$ & $\begin{array}{l}\text { SA } \\
5\end{array}$ & $\begin{array}{l}\text { A } \\
4\end{array}$ & $\begin{array}{l}\mathrm{N} \\
3\end{array}$ & $\begin{array}{l}\mathrm{D} \\
2\end{array}$ & $\begin{array}{l}D \\
1\end{array}$ \\
\hline
\end{tabular}


11 Learning about people from different cultures is a very

important part of education.

$\begin{array}{ccccc}\text { SA } & \text { A } & \text { N } & \text { D } & \text { SD } \\ 5 & 4 & 3 & 2 & 1\end{array}$
$\begin{array}{llcccc}\text { Contact with individuals whose background differs from my } & \text { SA } & \text { A } & \text { N } & \text { D } & \text { SD } \\ \text { own is not an essential part of education. } & 5 & 4 & 3 & 2 & 1\end{array}$

$\begin{array}{lllll}5 & 4 & 3 & 2 & 1\end{array}$

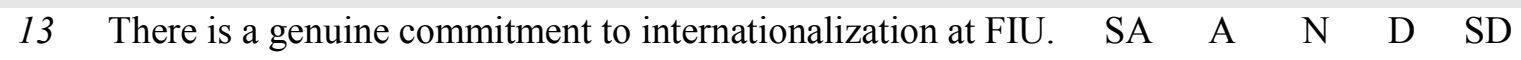

\section{FIU's Support for Internationalization}

14 My college/school/department strongly promotes students $\quad$ SA $\quad$ A $\quad$ N $\quad$ D $\quad$ SD $\begin{array}{lllllll}\text { engagement in internationalization. } & 5 & 4 & 3 & 2 & 1\end{array}$

15 I have been encouraged in my department to take courses that $\begin{array}{lllll}\text { SA } & \text { A } & \text { D } & \text { SD }\end{array}$ incorporate international content.

$\begin{array}{lllll}5 & 4 & 3 & 2 & 1\end{array}$

16 My courses with international content have provided $\quad \begin{array}{ccccc}\text { SA } & \text { A } & \text { N } & \text { D } & \text { SD } \\ 4 & 3 & 2 & 1\end{array}$

17 My college/school/department encourages me to participate in $\begin{array}{ccccc}\text { SA } & \text { A } & \text { N } & \text { D } & \text { SD }\end{array}$ $\begin{array}{lllllll}\text { a study abroad program. } & 5 & 4 & 3 & 2 & 1\end{array}$

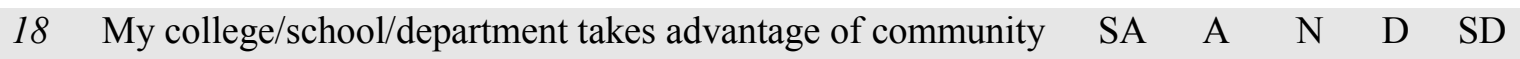
$\begin{array}{llllllll}\text { resources to enhance the international learning experience. } & 5 & 4 & 3 & 2 & 1\end{array}$

19 My college/school/department encourages me to conduct $\quad$ SA A $\quad$ N $\quad$ D $\quad$ SD research on international topics.

$\begin{array}{lllll}5 & 4 & 3 & 2 & 1\end{array}$

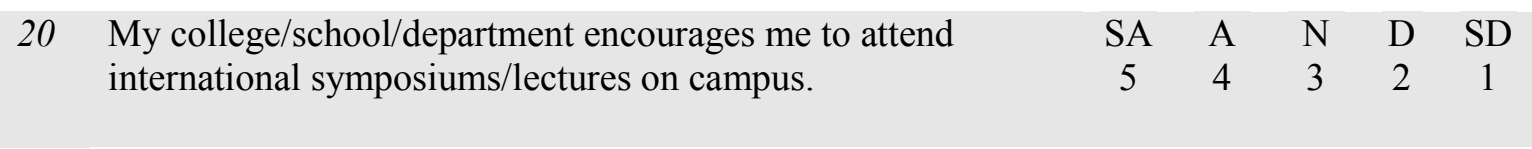

\section{Benefits of Internationalization}

21 International learning helps prepare students to become $\quad$ SA $\quad$ A $\quad$ N $\quad$ D $\quad$ SD $\begin{array}{lllllll}\text { responsible global citizens. } & 5 & 4 & 3 & 2 & 1\end{array}$

22 International learning makes me appreciate more of other $\quad$ SA $\quad$ A $\quad$ N $\quad$ D $\quad$ SD cultures.

$\begin{array}{lllll}5 & 4 & 3 & 2 & 1\end{array}$

23 The more we know about other countries, the better we will $\quad$ SA $\quad$ A $\quad$ N $\quad$ D $\quad$ SD $\begin{array}{llllll}\text { understand our own. } & 5 & 4 & 3 & 2 & 1\end{array}$

24 International education helps me recognize and understand $\quad$ SA A $\quad$ N $\quad$ D $\quad$ SD the impact other cultures have on American life and vice $\quad \begin{array}{lllllll}5 & 4 & 3 & 2 & 1\end{array}$ versa.

25 Learning other cultures helps me better tolerate ambiguity $\quad$ SA A $\quad \begin{array}{lll}\text { N } & \text { D } & \text { SD }\end{array}$ when communicating with a foreign person.

$\begin{array}{lllll}5 & 4 & 3 & 2 & 1\end{array}$


International education can explain the root causes of basic $\quad$ SA $\quad$ A $\quad$ N $\quad$ D $\quad$ SD $\begin{array}{lllllll}\text { global problems such as overpopulation, poverty, climate } & & 5 & 4 & 3 & 2 & 1\end{array}$ change, and disease.

Please select one response to the following questions (Yes, No):

27 Have you visited FIU's Office of Education Abroad? $\quad$ Yes No

28 Do you know if there are international travel grants offered to FIU Yes No students?

29 Do you know if there are co-curricular international activities on campus? Yes No (i.e. international festivals or clubs)

30 Have you ever participated in a study abroad program? $\quad$ Yes No

31 Would you like to participate in a study abroad program? $\quad$ Yes No

Please select the demographic category that fits.
32 Your Age:
A. $18-22$ years
B. 23-29 years C. 30-45 years
D. $46-50$ years
E. $51+$ years
33 Your Gender:
A. Male
B. Female
34 Your Race/Ethnicity:
A. Black/African-American
B. Hispanic
C. Asia D. White Non-Hispanic
E. Other
35 Your Class:
A. Undergraduate
B. Graduate

$36 \quad$ Your Student Status:
A. Full-Time Student
B. Part-Time Student

37 Your Work Status:
A. Full-Time Worker
B. Part-Time Worker
C. Not Employed

38 Your Major: Undecided (interest):

39 Comments:

Thank you so much for your participation in this survey. This survey is being conducted by Flavia Iuspa, Doctoral Candidate, College of Education, Florida International University 


\section{Appendix $\mathrm{P}$}

\section{Students Attitudes Survey on Internationalization Factor Analysis \\ Rotated Component Matrix}

\begin{tabular}{|c|c|c|c|}
\hline & \multicolumn{3}{|c|}{ Component } \\
\hline & 1 & 2 & 3 \\
\hline $\begin{array}{l}\text { International education helps me recognize and understand the impact } \\
\text { other cultures have on American life and vice versa. }\end{array}$ & .806 & & \\
\hline International learning makes me appreciate more of other cultures. & .801 & & \\
\hline $\begin{array}{l}\text { The more we know about other countries, the better we will understand } \\
\text { our own. }\end{array}$ & .777 & & \\
\hline $\begin{array}{l}\text { International learning helps prepare students to become responsible } \\
\text { global citizens. }\end{array}$ & .768 & & \\
\hline $\begin{array}{l}\text { Learning other cultures helps me better tolerate ambiguity when } \\
\text { communicating with a foreign person. }\end{array}$ & .760 & & \\
\hline $\begin{array}{l}\text { Learning about people from different cultures is a very important part of } \\
\text { education. }\end{array}$ & .725 & & \\
\hline $\begin{array}{l}\text { I believe an understanding of international issues is important for success } \\
\text { in the workforce. }\end{array}$ & .638 & & \\
\hline $\begin{array}{l}\text { Students can understand their own culture more fully if they have studied } \\
\text { another. }\end{array}$ & .615 & & \\
\hline $\begin{array}{l}\text { International education can explain the root causes of basic global } \\
\text { problems such as overpopulation, poverty, climate change, and disease. }\end{array}$ & .587 & & \\
\hline $\begin{array}{l}\text { Study abroad programs are the best way for students to encounter } \\
\text { another culture. }\end{array}$ & & & \\
\hline $\begin{array}{l}\text { Learning a foreign language is not essential for an undergraduate } \\
\text { education. }\end{array}$ & & & \\
\hline $\begin{array}{l}\text { Contact with individuals whose background differs from my own is not } \\
\text { an essential part of education. }\end{array}$ & & & \\
\hline $\begin{array}{l}\text { I have been encouraged in my department to take courses that } \\
\text { incorporate international content. }\end{array}$ & & .792 & \\
\hline $\begin{array}{l}\text { My college/school/department encourages me to conduct research on } \\
\text { international topics. }\end{array}$ & & .763 & \\
\hline
\end{tabular}


My college/school/department strongly promotes students engagement in

internationalization.

My college/school/department encourages me to participate in a study

abroad program.

My college/school/department encourages me to attend international

symposiums/lectures on campus.

My college/school/department takes advantage of community resources

to enhance the international learning experience.

My courses with international content have provided examples from all

regions of the world.

FIU's Global Learning Quality Enhancement Plan is understood and

discussed by all FIU stakeholders (students, administrators, and faculty).

The process of internationalization is understood and discussed by all

FIU stakeholders (students, administrators, and faculty).

FIU's current mission statement supports the definition of

internationalization presented above?

There is a genuine commitment to internationalization at FIU.

International learning is an important element of the educational process

at FIU.

Internationalization is a component of FIU's 3.0: A New Strategic

Paradigm.

FIU's exchange programs with institutions in other countries foster internationalization of instruction, research, and service learning.

Extraction Method: Principal Component Analysis.

Rotation Method: Varimax with Kaiser Normalization.

a. Rotation converged in 5 iterations. 


\section{Appendix Q}

\section{Faculty Attitudes Survey on Internationalization Factor Analysis Rotated Component}

\section{Matrix}

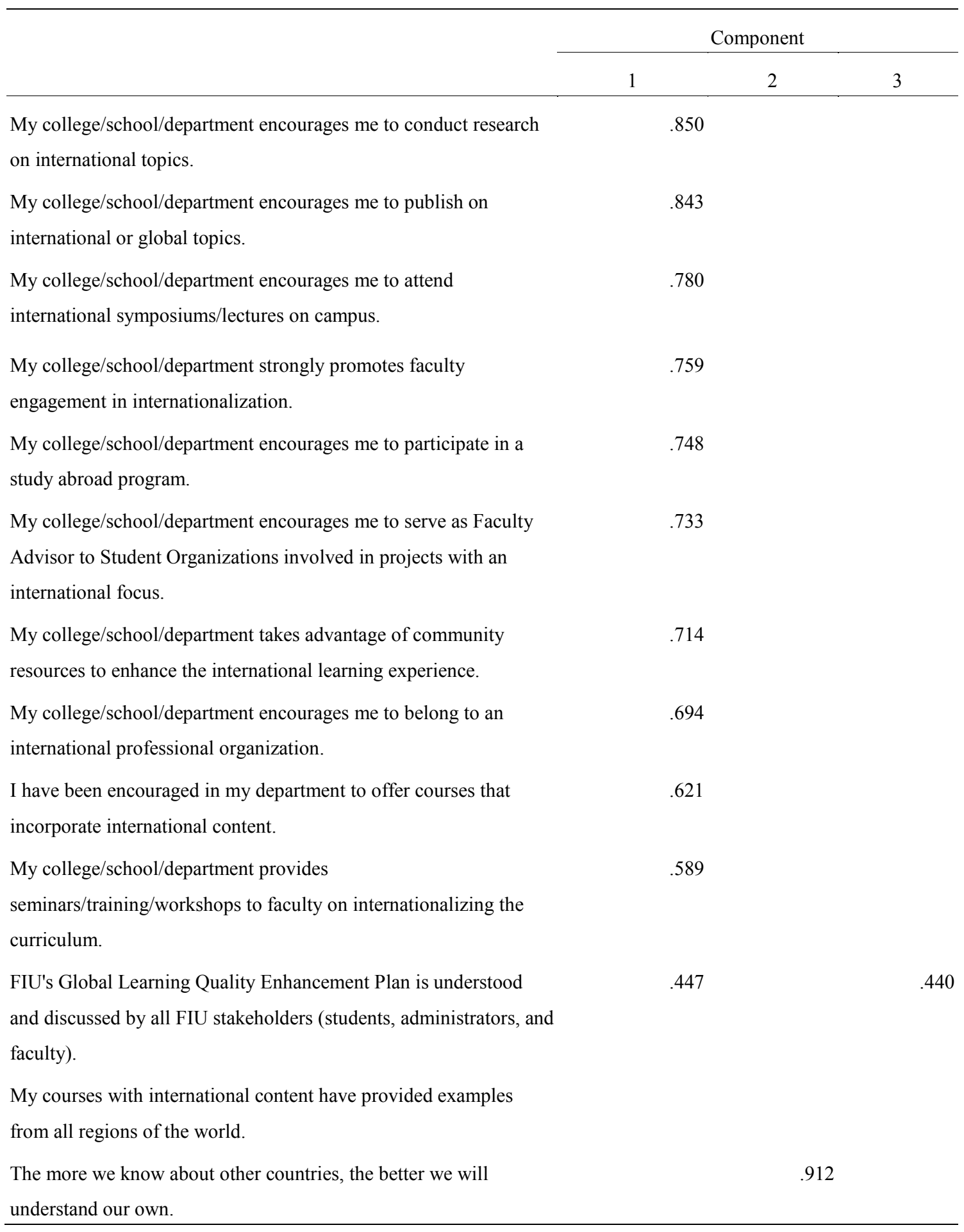


communicating with a foreign person.

International learning makes me appreciate more other cultures.

International education helps me recognize and understand the

impact other cultures have on American life and vice versa.

International learning helps prepare students to become responsible

global citizens.

Students can understand their own culture more fully if they have

studied another.*

I believe an understanding of international issues is important for

success in the workforce.*

International education can explain root causes of basic global

problems such as overpopulation, poverty, climate change, and

disease.

Learning about people from different cultures is a very important

part of education.*

Learning a foreign language is not essential for an undergraduate

education.*

Study abroad programs are the best way for students to encounter another culture.

FIU's exchange programs with institutions in other countries foster internationalization of instruction, research, and service learning.

Contact with individuals whose background differs from my own is not an essential part of education (reverse).

FIU's current mission statement supports the definition of

internationalization presented above

Internationalization is a component of FIU's 3.0: A New Strategic

Paradigm.

There is a genuine commitment to internationalization at FIU.

The process of internationalization is understood and discussed by

all FIU stakeholders (students, administrators, and faculty).

International learning is an important element of the educational

process at FIU.

Extraction Method: Principal Component Analysis. Rotation Method: Varimax with Kaiser Normalization.

a. Rotation converged in 6 iterations. 
VITA

\section{FLAVIA ELEONORA IUSPA}

EDUCATION

$1999-2000$

International Masters of Business Administration

Florida International University

Miami, Florida

1992-1997

Bachelor of Arts

Florida International University

Miami, Florida

International Relations, Minor: French

PROFESSIONAL EXPERIENCE

$2009-2010 \quad$ Graduate Assistant

College of Education

Florida International University, Miami, Florida

2002 - $2007 \quad$ Program Manager

Global Programs Office, Chapman Graduate School of

Business

Florida International University, Miami, Florida

$2000-2002 \quad$ Assistant Director

Global Programs Office \& Office of Professional Education

College of Business Administration

Florida International University, Miami, Florida

\section{PUBLICATION AND PRESENTATION}

Iuspa, F. (April, 2005). Japan's Educational System. Proceeding of The Fourth Annual College of Education Research Conference (pp 54-58). Miami, Fl: Florida International University.

Iuspa, F. (2004). Served on "E-learning in Universities" panel at Effective Internet Strategies Conference organized by ElSalvaldor.com. El Salvador, El Salvador. 